\title{
DISEÑO E IMPLEMENTACIÓN DE UN SISTEMA DE ESTERILIZACIÓN Y SECADO DE SANDACH CON TECNOLOGÍA MULTIMODO DE MICROONDAS Y SU TRANSFERENCIA A LA INDUSTRIA PECUARIA
}

Tecnologías de la Información y las Comunicaciones

Autor: Juan David Reverte Ors

Director: Prof. José Fayos Fernández Codirector: Prof. Juan Luis Pedreño Molina

Cartagena (2020) 


\section{CONFORMIDAD DE SOLICITUD DE AUTORIZACIÓN DE DEPÓSITO DE}

\section{TESIS DOCTORAL POR EL DIRECTOR DE LA TESIS}

D. José Fayos Fernández, director de la Tesis doctoral "DISEÑO E IMPLEMENTACIÓN DE UN SISTEMA DE ESTERILIZACIÓN Y SECADO DE SANDACH CON TECNOLOGÍA MULTIMODO DE MICROONDAS Y SU TRANSFERENCIA A LA INDUSTRIA PECUARIA",

\section{INFORMA:}

Que la referida Tesis Doctoral, ha sido realizada por D. Juan David Reverte Ors, dentro del Programa de Doctorado "3410 - DOCTORADO: TECNOLOGÍAS DE LA INFORMACIÓN Y LAS COMUNICACIONES", dando mi conformidad para que sea presentada ante el Comité de Dirección de la Escuela Internacional de Doctorado para ser autorizado su depósito.

$\square$ Informe positivo sobre el plan de investigación y documento de actividades del doctorando emitido por el Director/Tutor (RAPI).

La rama de conocimiento en la que esta tesis ha sido desarrollada es:

\section{Ciencias}

Ciencias Sociales y Jurídicas

$\checkmark$ Ingeniería y Arquitectura

En Cartagena, a 03 de septiembre de 2020

\section{EL DIRECTOR DE LA TESIS}

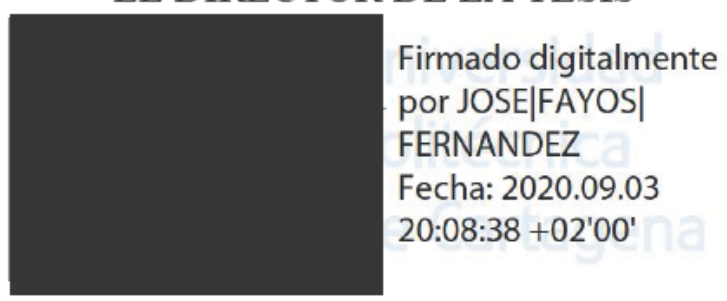

Fdo.: José Fayos Fernández 


\section{CONFORMIDAD DE DEPÓSITO DE TESIS DOCTORAL POR LA COMISIÓN ACADÉMICA DEL PROGRAMA}

D. JORGE LARREY RUÍZ, Presidente/a de la Comisión Académica del Programa DOCTORADO EN TECNOLOGÍAS DE LA INFORMACIÓN Y LAS COMUNICACIONES (3410)

\section{INFORMA:}

Que la Tesis Doctoral titulada, "DISEÑO E IMPLEMENTACIÓN DE UN SISTEMA DE ESTERILIZACIÓN Y SECADO DE SANDACH CON TECNOLOGÍA MULTIMODO DE MICROONDAS Y SU TRANSFERENCIA A LA INDUSTRIA PECUARIA", ha sido realizada, dentro del mencionado Programa de Doctorado, por D. JUAN DAVID REVERTE ORS, bajo la dirección y supervisión del Dr. JOSÉ FAYOS FERNÁNDEZ. En reunión de la Comisión Académica, visto que en la misma se acreditan los indicios de calidad correspondientes y la autorización del Director/a de la misma, se acordó dar la conformidad, con la finalidad de que sea autorizado su depósito por el Comité de Dirección de la Escuela Internacional de Doctorado.

¿ Evaluación positiva del plan de investigación y documento de actividades por el Presidente de la Comisión Académica del programa (RAPI).

La Rama de conocimiento por la que esta tesis ha sido desarrollada es:

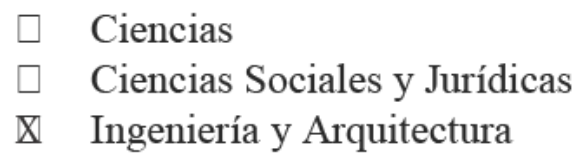

En Cartagena, a 8 de septiembre de 2020

\section{EL PRESIDENTE DE LA COMISIÓN ACADÉMICA}

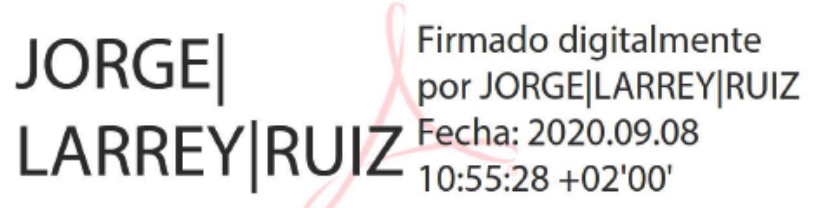

Fdo: Jorge Larrey Ruiz 


\section{AGRADECIMIENTOS}

"El Amor es el significado último de todo lo que nos rodea. No es un simple sentimiento, es la verdad, es la alegría que está en el origen de toda creación"

Rabindranath Tagore (1861-1941)

A mis padres, por su amor, su incansable trabajo y sacrificio en todos estos años, gracias a vosotros he logrado llegar hasta aquí y convertirme en lo que soy.

A mis hermanos por estar siempre presentes en mi vida. A mis primas y padrinos, por ser un apoyo moral y hacerme sentir siempre un hermano y un hijo más.

A ti Juanlu. Sin ti, esto nunca habría pasado. Sumaremos, seguiremos sumando juntos. Simplemente: Vamooooos.

Especialmente a mi mujer, mi compañera de viaje, mi amiga y mi equilibrio vital y a mis hijos. Dais color a mi vida cada día y sois mi principal motivación para superarme y ser mejor persona.

Y quiero dedicar este trabajo de investigación a la memoria de mi madre. Mi ángel de la guarda, la luz que me guía en momentos de penumbra y que me fortalece cada día. 


\section{RESUMEN}

Este trabajo aborda el desarrollo y prueba de concepto de nuevos métodos de secado por microondas, que garanticen una uniformidad de calentamiento viable en todo el volumen del producto para cumplir con las condiciones de esterilización de SANDACH.

Se han analizado los modelos válidos de diseño de aplicadores para dar solución al secado por microondas de los desechos procedentes de piscifactorías. En este trabajo se describen técnicas de diseño de aplicadores (monomodo y multimodo), con el objetivo de obtener un campo eléctrico lo más uniforme posible sobre la muestra.

Para poder medir la esterilización, se han diseño una nueva generación de biosensores que puedan garantizar la seguridad alimentaria. Este modelo se ha basado en microorganismos que permiten conocer de forma precisa la variabilidad de calentamiento en todo el producto y cuantificar los niveles de seguridad.

Se ha diseñado una cavidad monomodo resonante, para realizar pruebas de calentamiento en atmósfera de presión de pequeñas muestras (tubo de ensayo), de tal modo que se garantice la uniformidad de calentamiento en la muestra, y con sensores de temperatura que monitoricen el tratamiento, permitiendo validar la eficacia de los biosensores.

Se han desarrollado los cálculos conducentes a la configuración óptima del horno túnel de microondas para diferentes objetivos de temperatura en muestras de SANDACH, con la inclusión de los biosensores, implementando, así un equipo semi-industrial, diseñado por el Grupo I+D Electromagnetismo y Materia.

Y se recogen los resultados experimentales, medidos en los diseños de los aplicadores desarrollados, fundamentalmente de uniformidad en la cavidad monomodo y análisis bacteriológico y uniformidad en el calentamiento en el proceso de esterilización para el diseño del horno industrial. 


\section{ABSTRACT}

This work addresses the development and proof of concept of new microwave drying methods, which ensure viable heating uniformity throughout the product volume to meet SANDACH sterilization conditions. Valid applicator design models have been analyzed to provide a solution for microwave drying of waste from fish farms. In this work, applicator design techniques (single and multimode) are described, with the aim of obtaining the most uniform electric field possible on the sample.

To be able to measure sterilization, a new generation of biosensors have been designed that can guarantee food safety. This model has been based on microorganisms that make it possible to know precisely the heating variability throughout the product and to quantify the safety levels.

A single-mode resonant cavity has been designed to carry out heating tests in pressure atmosphere of small samples (test tube), in such a way that the heating uniformity in the sample is guaranteed, and with temperature sensors that monitor the treatment, allowing to validate the effectiveness of biosensors.

The calculations leading to the optimal configuration of the microwave tunnel oven have been developed for different temperature objectives in SANDACH samples, with the inclusion of biosensors, thus implementing a semi-industrial equipment, designed by the Electromagnetism and Matter I+ D Group of the UPCT.

And the experimental results are collected, measured in the designs of the developed applicators, fundamentally of uniformity in the single-mode cavity and bacteriological analysis and uniformity in heating in the sterilization process for the design of the industrial oven. 


\section{ÍNDICE}

Capítulo 1. Introducción y objetivos....................................................................

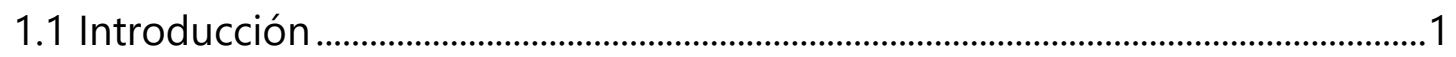

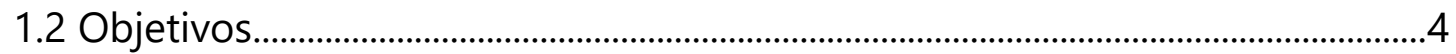

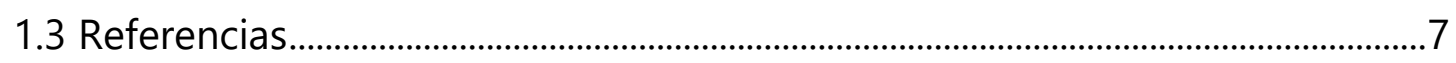

Capítulo 2. Antecedentes y estado del arte .................................................................... 9

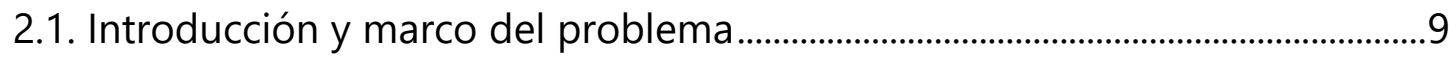

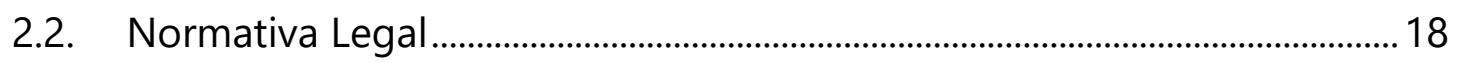

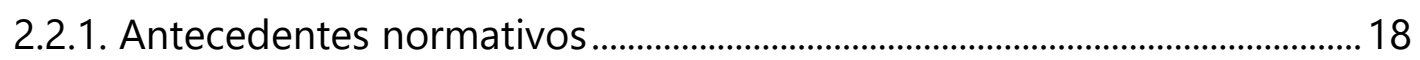

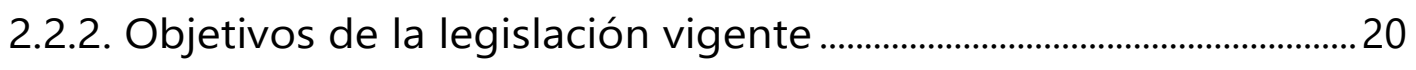

2.2.3. Control de la cadena alimentaria y Consideraciones finales ...... 22

2.3. Esterilización de SANDACH. Metodología del trabajo de

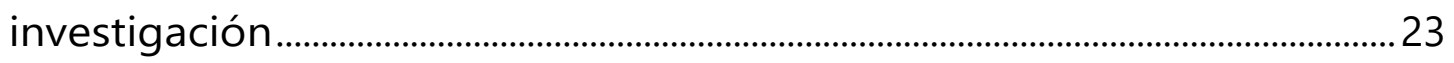

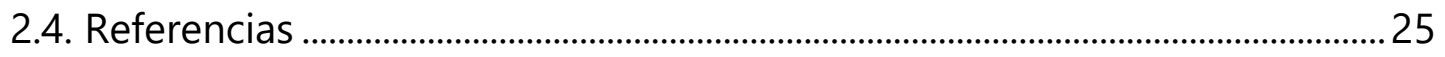

Capítulo 3. Modelado del calentamiento por microondas en cavidades monomodo

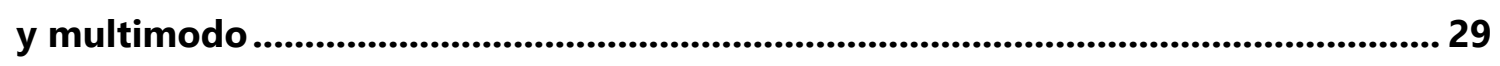

3.1. Características de la tecnología de microondas de calentamiento y secado

3.2 Limitaciones en la aplicación de la tecnología microondas 33

3.3. Procedimiento de diseño de aplicadores microondas. Aplicadores monomodo vs multimodo. 34

3.4. Conceptos básicos de diseño de cavidades microondas multimodo .......... 38

3.4.1. Generación de calor por microondas ................................................................. 40

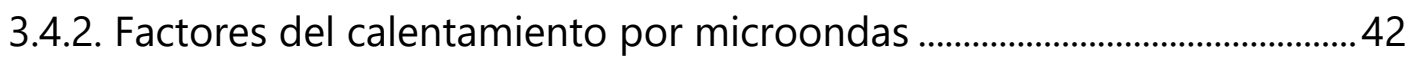

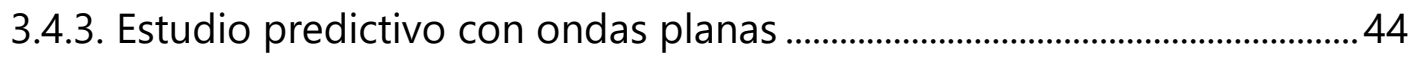


3.4.4. Permitividad relativa compleja: constante dieléctrica y factor de pérdidas.

3.4.4.1. Comportamiento en frecuencia de la permitividad: la ecuación de Debye 48

3.4.4.2. Conducta de la permitividad ante materiales húmedos 50

3.4.4.3. Conducta de la permitividad con la temperatura. 51

3.4.5 Mecanismos de transferencia de calor ...................................................................... 51

3.4.5.1 Conducción de calor..................................................................................

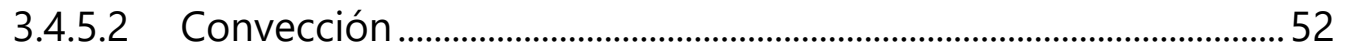

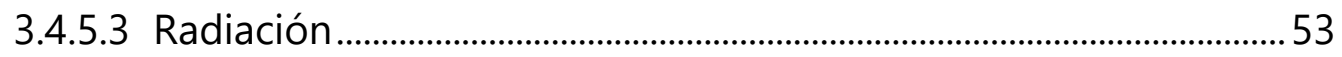

3.4.6. Patrones para el secado por microondas............................................................ 54

3.5. Conclusiones ……………………………………………………………………………... 57

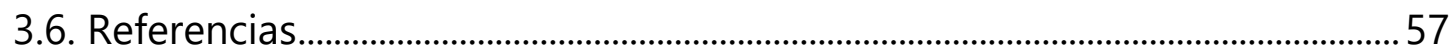

Capítulo 4. Desarrollo de una nueva generación de biosensores microbiológicos específicos para validar procesos de esterilización por microondas...................................60

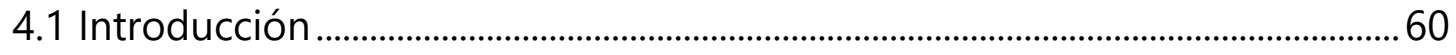

4.2. Materiales y métodos …………………………………………………………………........

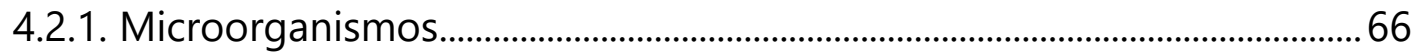

4.2.2. Preparación de la muestra para tratamiento por microondas .................68

4.2.3. Preparación de indicadores de inactivación biológica. (IIBs) .....................68

4.2.4. Enumeración de microorganismos .........................................................................68

4.2.5. Tratamiento térmico en el termorresistómetro Mastia .................................69

4.2.6. Tratamiento con tecnología de microondas .................................................. 70

4.2.7. Modelización matemática y análisis estadístico de la cinética de inactivación bacteriana ........................................................................................................

4.3. Resultados y discusión ................................................................................................... 
4.3.1. Cuantificación de la incertidumbre asociada al procedimiento de enumeración basado en los IIBs

4.3.2. Procesamiento térmico mediante un sistema de microondas de túnel de planta piloto 79

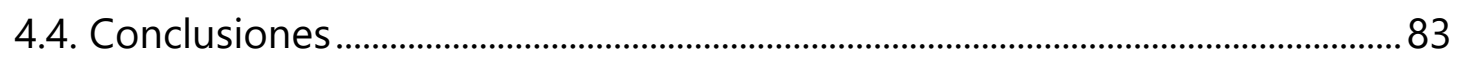

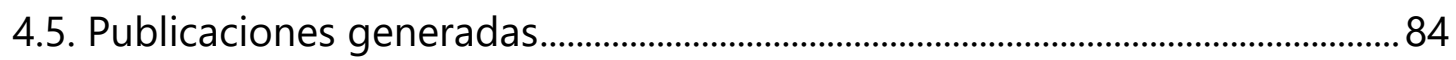

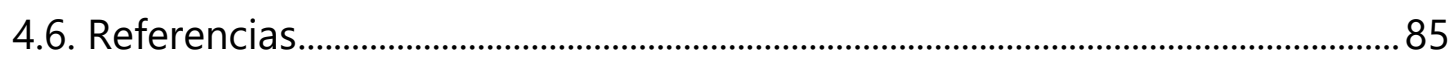

Capítulo 5. Diseño de una solución de esterilización con microondas en cavidad

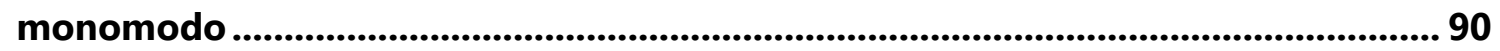

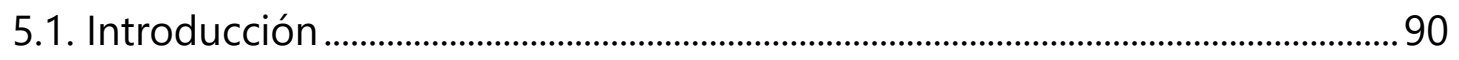

5.2. Materiales, métodos y configuración experimental ..........................................93

5.2.1. Diseño del sistema monomodo de microondas ..........................................93

5.2.1.1. Medida de las Propiedades Dieléctricas de los Materiales Tratados

5.2.1.2. Diseño de la cavidad monomodo .93

5.2.2 Diseño e implementación de software de control de perfiles de calentamiento .98

5.2.3. Determinaciones microbianas y sustratos alimentarios .............................105

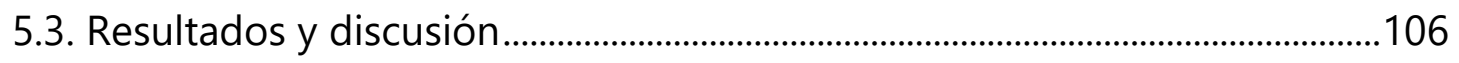

5.3.1. Caracterización dieléctrica de la permitividad de las muestras.............106

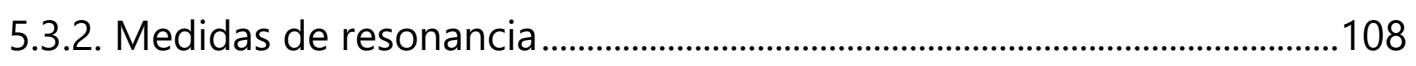

5.3.3. Perfiles de Temperatura en el tratamiento por microondas ...................109

5.3.4. Medidas de Inactivación por calor de Bacillus cereus...............................110

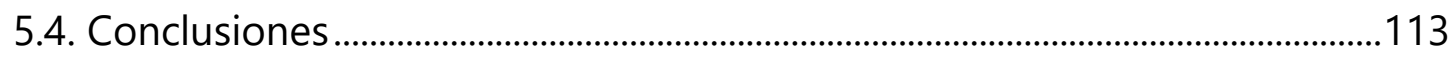

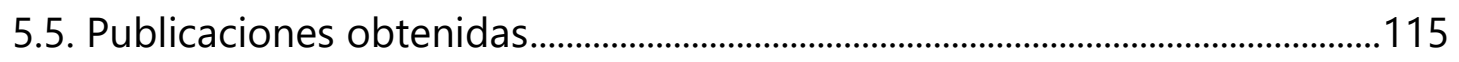

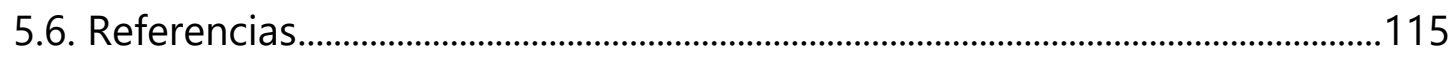


Capítulo 6. Diseño de un horno de túnel de microondas para la esterilización y

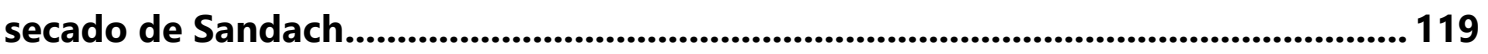

6.1. Introducción y Objetivos.............................................................................................119

6.2. Componentes de horno industrial para secado por microondas ................121

6.3. Herramienta software para el desarrollo del horno industrial ......................131

6.4. Configuración del Horno Industrial de Microondas para secado de Sandach

6.5. Normativa que regula el tratamiento industrial por microondas 138

6.6. Conclusiones 139

6.7. Referencias. .140

Capítulo 7. Resultados para la validación del procesado de sandach en equipo industrial de microondas

7.1. Introducción y Objetivo. .142

7.2. Metodología de experimentación con Sandach .142

7.2.1. Pruebas de deshidratación ..............................................................................142

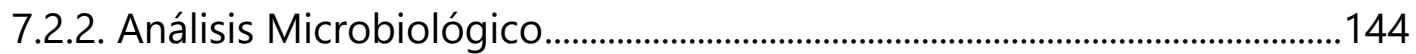

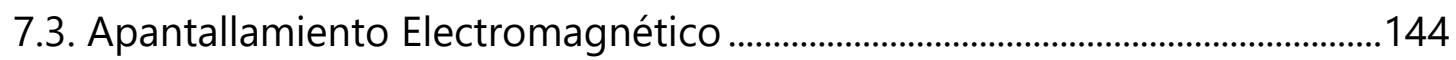

7.4. Caracterización de los materiales ........................................................................146

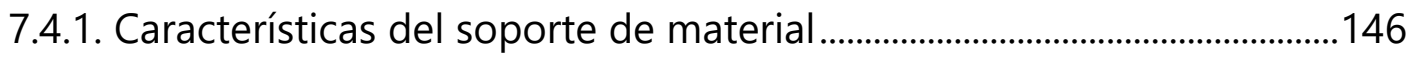

7.4.2. Puré de patata y nuez moscada .........................................................................147

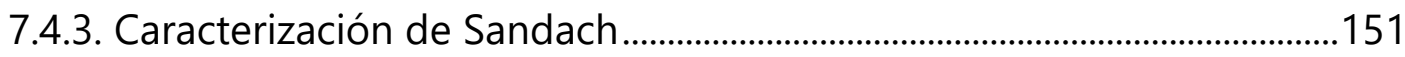

7.5. Cálculo de la curva de temperatura durante el proceso de secado............153

7.6. Disposición y configuración de los Biosensores ................................................156

7.7. Pruebas experimentales del proceso en el horno industrial de microondas de túnel. 


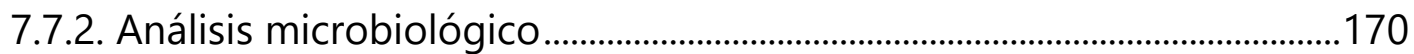

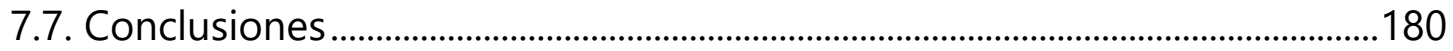

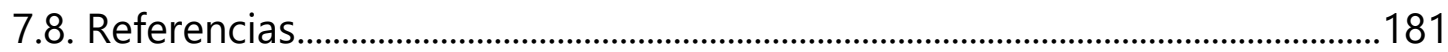

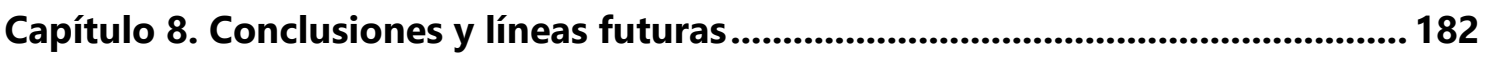

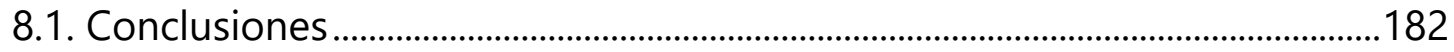

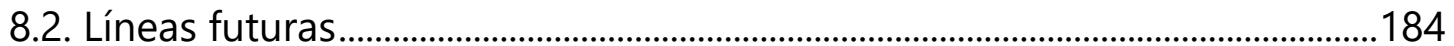




\section{CAPÍTULO 1 \\ INTRODUCCIÓN Y OBJETIVOS}

\subsection{Introducción}

Los procedimientos convencionales de esterilización de alimentos envasados se fundamentan en tratamientos de autoclave, donde éstos productos son sometidos a altas presiones, así como a temperaturas superiores a $100^{\circ} \mathrm{C}$ para garantizar su seguridad para el consumo. Es necesario establecer la seguridad alimentaria del producto final en su totalidad, garantizando la ausencia de microorganismos patógenos y de sustancias tóxicas para el consumidor. En concreto, una cantidad de 0,1g de alimento con toxina botulínica puede causar la muerte del consumidor, por lo que la exigencia de uniformidad en el calentamiento debe ser máxima [1]. Existen ejemplos, en Europa, de productos alimenticios esterilizados por microondas, pero no se comercializan en Estados Unidos, por ejemplo, con una legislación más restrictiva. Además, estos productos presentan una pérdida importante de nutrientes respecto a los procesados con métodos convencionales, pues para garantizar su esterilización es necesario incrementar la temperatura y tiempo de exposición en algunas zonas del mismo [2].

Siendo una tecnología mucho más eficaz, el problema que subyace aquí es la dificultad de obtener un calentamiento uniforme en todo el producto mediante aplicadores de microondas $[3,4]$, siendo esto, extrapolable a cualquier otro proceso industrial de calentamiento con esta tecnología. En la esterilización, esta uniformidad es clave para la obtención de un producto seguro manteniendo su calidad nutricional, siendo éste el principal obstáculo en el uso de las microondas. La posibilidad de utilizar tecnologías de calentamiento/secado por microondas, en procesos de pasteurización y/o esterilización en procesos industriales, es de enorme importancia para reducir el impacto medioambiental sobre el entorno [5-7].

El tratamiento de eliminación o valorización de los Subproductos de origen Animal No

Destinados A Consumo Humano (SANDACH) [8] se encuentra en la misma situación 
y está enmarcado en una normativa de ámbito nacional, que, para este tipo de productos, distingue entre tres categorías de materiales. El ámbito de este trabajo de investigación, se centra en los desechos de piscifactoría o descartes de pesca, es decir, cadáveres de peces retirados diariamente de la producción, pertenecientes a la categoría 3, dentro de los epígrafes "animales acuáticos y parte de los mismos, salvo mamíferos marinos, que no presenten signos de enfermedad transmisible" y "subproductos animales de animales acuáticos procedentes de establecimientos o plantas que fabriquen productos para el consumo humano".

Esta normativa contempla siete métodos estándar de transformación de estos desechos. En concreto, el método 7 hace referencia a cualquier método autorizado por la autoridad competente en base al cumplimiento de dos requisitos: a) la identificación de peligros y riesgos y la capacidad del método para reducirlos, y b) el muestreo diario durante 30 días para el cumplimiento de criterios microbiológicos relativos a Clostridium perfringens, Salmonella y Enterobacteriaceae.

Con la tecnología de microondas, el calentamiento no uniforme del producto viene determinado por dos motivos independientes. En primer lugar, la energía decae exponencialmente conforme la onda penetra en el material y su potencia se disipa en forma de calor. De esta manera, ante productos con elevadas pérdidas, como los biológicos, la onda se atenúa rápidamente y por ello se deben conformar productos laminares, si se quiere tener una buena uniformidad de calentamiento. Por otra parte, el campo eléctrico presenta una alta variabilidad en el interior de una cavidad resonante, resultado de la combinación lineal de los diferentes modos resonantes que son excitados por la fuente de microondas, lo que repercute en un calentamiento no homogéneo.

Con estas dos soluciones se pretende que la energía disipada, en media temporal, sea similar en todos los puntos de la muestra, pero no garantiza una uniformidad de temperatura como la requerida en los procesos de esterilización.

Aunque la utilización de frecuencias más bajas mejora indudablemente la uniformidad del campo eléctrico dentro del aplicador y también permite una mayor penetración de 
la onda en el material, esta tecnología es mucho más cara, sobre todo en las fuentes alimentación de los magnetrones de microondas.

Otra limitación para garantizar la uniformidad es la ausencia de métodos biológicos adaptados a microondas que permitan determinar el grado de variabilidad en el calentamiento alcanzado, en base a la inactivación microbiana en cada punto del alimento. Ésta es la exigencia legislativa en la actualidad por parte de la EFSA (Agencia Europea de Seguridad Alimentaria) para su implantación a nivel industrial y de explotaciones acuícolas.

Este trabajo aborda el desarrollo y prueba de concepto de nuevos métodos de calentamiento por microondas y que garanticen una uniformidad de la temperatura final viable en todo el volumen del producto para cumplir con las condiciones de esterilización de SANDACH. Este objetivo requiere el desarrollo de nuevos aplicadores de calentamiento por microondas, con un enfoque industrial, entendiendo por aplicador la forma y dimensiones de las paredes metálicas que delimitan el espacio de confinamiento de propagación de campo electromagnético a $2,45 \mathrm{GHz}$, junto con cualquier elemento metálico que pueda ser necesario en su interior para mejorar la distribución de campo.

Las condiciones de contorno impuestas por este entorno electromagnéticamente cerrado producen unos modos naturales de resonancia, que dificultan la conformación de otros patrones de campo distintos a los de estos modos. Por último, la excitación de la cavidad en diferentes puntos permite excitar unos modos resonantes en mayor medida que otros (dentro de los posibles modos resonantes determinados por el espectro del magnetrón), lo que proporciona una capacidad, aunque limitada, de conformación del patrón de campo eléctrico en el aplicador.

Por otra parte, es necesario el desarrollo de biosensores que permitan establecer la seguridad alimentaria del producto final en su totalidad, con una información precisa de cada punto del alimento o producto (y no sólo un dato global o promediado), lo que supone garantizar la ausencia de microorganismos patógenos y de sustancias tóxicas para el consumidor. Los biosensores microbiológicos se han utilizado para validar 
procesos de esterilización por calor convencionales, en los que se conoce, al menos aproximadamente, los puntos más fríos.

En el caso del calentamiento por microondas la incertidumbre sobre los puntos fríos es el principal reto para garantizar la seguridad de los alimentos o productos tratados, por lo que se desarrollará, en el ámbito de la colaboración con grupos de investigación en esta área, de una nueva generación de biosensores. Se diseñarán sensores de pequeño tamaño para poder realizar una amplia distribución de los mismos en el producto, con una disposición espacial que permita obtener y modelar la temperatura en base a datos biológicos en cada punto, a partir del conocimiento preciso de los microorganismos inactivados en esos puntos, en vez del promedio en el producto, utilizando dos elementos sensores (microorganismos de diferentes especies) para controlar la variabilidad biológica y garantizar la esterilización real y controlada.

\subsection{Objetivos}

Para conseguir los objetivos planteados en este trabajo de Tesis Doctoral, se ha redactado la memoria, estructurada por los siguientes capítulos, según la cronología de los avances de la misma:

- En el capítulo 2 de este trabajo, se abordará el marco del problema, así como la introducción a la solución planteada. Se abordará el Marco Legal que rige en la actualidad en España la esterilización de SANDACH y se plantearán conclusiones en este sentido que puedan paliar las limitaciones existentes. Actualmente no existen tecnologías de calentamiento por microondas que garanticen, a nivel industrial, la uniformidad de temperatura necesaria para los procesos de esterilización, y la comunidad científica lo considera prácticamente inviable. Éste será el objetivo de la investigación tecnológica propuesta, sin perder las demás características diferenciadoras de las microondas: bajos tiempos de procesamiento, eficiencia energética o mayor control del proceso (menores inercias térmicas). La conformación de campo eléctrico sobre la muestra se realizará mediante un diseño adecuado de la geometría del aplicador microondas 
multimodo y de la disposición de los diferentes sistemas de alimentación y utilización de elementos dieléctricos en su interior.

- En el capítulo 3, se han analizado los modelos válidos de diseño de aplicadores para dar solución al secado por microondas de los desechos procedentes de piscifactorías. Los procesos de secado deben ser lo más eficiente en términos energéticos y temporales, a la vez que deben ofrecer una calidad óptima, sin degradar la estructura y la apariencia del material tratado. En este trabajo se describen técnicas de diseño de aplicadores (monomodo y multimodo), con el objetivo de obtener un campo eléctrico lo más uniforme posible sobre la muestra. Las técnicas de modelado para los aplicadores de calentamiento por microondas tienen como objetivo principal asegurar la uniformidad de temperatura en el material. Sin embargo, debido a las características intrínsecas de las cavidades multimodo (las más utilizadas a nivel industrial), la distribución del campo eléctrico muestra valores máximos y mínimos tanto dentro de los aplicadores como sobre la muestra lo que, como ya se ha descrito, puede producir patrones de temperatura desiguales sobre esta última.

- El capítulo 4 se ha dedicado al diseño de biosensores que puedan garantizar la seguridad alimentaria. Este modelo se ha basado en microorganismos que permiten conocer de forma precisa la variabilidad de calentamiento en todo el producto y cuantificar los niveles de seguridad. Estos desarrollos tienen también aplicación en otros procesos industriales, no sólo en esterilización. La conformación de un patrón de campo eléctrico arbitrario en una cavidad resonante es un problema no resuelto, al contrario de lo que ocurre con los patrones de radiación en espacio libre. El desarrollo de un biosensor es totalmente novedoso en el ámbito de microondas, dado que no se ha estudiado la interacción de los materiales con dicha tecnología. Para validar esta nueva metodología ha sido necesario desarrollar un biosensor específico basado en microorganismos como elemento sensor, que permita establecer de forma cuantitativa la variabilidad de la temperatura en un muestreo óptimo en toda la superficie del producto. 
- El capítulo 5 está dedicado a la descripción del equipo experimental desarrollado como solución de cavidad monomodo. Se ha diseñado una cavidad resonante de este tipo para realizar pruebas de calentamiento en atmósfera de presión de pequeñas muestras (tubo de ensayo), de tal modo que se garantice la uniformidad de calentamiento en la muestra, y con sensores de temperatura que monitoricen el tratamiento, permitiendo validar la eficacia de los biosensores. Para el control de todo el sistema de microondas, ha sido preciso programar una plataforma de captación de los sensores, de actuación y de monitorización del proceso mediante un software de control que permite ajustar la potencia suministrada, de tal forma que la muestra mantenga la temperatura deseada durante el tiempo que se precise. Este sistema permite, además, guardar los resultados del experimento para visualizarlos y analizarlos posteriormente.

- En el capítulo 6, se han desarrollado los cálculos conducentes a la configuración óptima del horno túnel de microondas para diferentes objetivos de temperatura en muestras de SANDACH, con la inclusión de los biosensores, implementando así, un equipo semi-industrial diseñado por el Grupo I+D Electromagnetismo y Materia. Además de la descripción de la plataforma y el diseño propiamente dicho, lo importante de esta fase es que ya se dispone de la caracterización de los biosensores, pudiendo ser utilizados para una correlación de inactivación microbiológica de bastante precisión, en el proceso de deshidratación del SANDACH.

- En el capítulo 7, se recogen los resultados experimentales de uniformidad de calentamiento en la cavidad monomodo y del análisis bacteriológico y uniformidad en el calentamiento por microondas en el proceso de esterilización para el horno semi-industrial, resultados que fueron estimados en los diseños de los aplicadores desarrollados y mostrados en los capítulos 5 y 6 . Finalmente, los objetivos de esta fase han sido divididos en dos partes: Deshidratación y Análisis Microbiológico. Los resultados destallados en este capítulo muestran la verdadera aportación de este trabajo de investigación al sector productivo. 
- Finalmente, en el capítulo 8 se exponen las conclusiones del trabajo realizado en esta Tesis Doctoral, así como las líneas futuras que se proponen para continuar con los resultados obtenidos.

\subsection{Referencias}

[1] Martínez A, Rodrigo D., Fernández P.S., Sampedro F., Pina M.C., Time-temperature integrators for thermal process evaluation. Thermal Food Processing: New Technologies and Quality Issues, $2^{\text {nd }}$ Ed. CRC Press, 2012.

[2] Stanley, R.A.; Petersen, K. Microwave-assisted pasteurization and sterilizationcommercial perspective. In The Microwave Processing of Foods, $2^{\text {nd }}$ ed.; Regier, M., Knoerzer, K., Schubert, H., Eds.;Woodhead Publishing: Sawston, UK, pp. 200-219, 2017.

[3] R. Vadivambal, D. S. Jayas, Non-uniform Temperature Distribution During Microwave Heating of Food Materials-A Review" Food and Bioprocess Technology, 3, 161-171, 2010.

[4] Loc T. Nguyen, Won Choi, Seung Hyun Lee, Soojin Jun, Exploring the heating patterns of multiphase foods in a continuous flow, simultaneous microwave and ohmic combination heater, Journal of Food Engineering 116, 65-71, 2013.

[5] Datta, A.K.; Anatheswaran, R.C. Handbook of Microwave Technology for Food Applications; Marcel Dekker, Ed.; Marcel Dekker: New York, NY, USA, 2000.

[6] Vadivambal, R.; Jayas, D.S. Non-uniform temperature distribution during microwave heating of food materials. A review. Food Bioproc. Technology 3, 161-171, 2010.

[7] Nguyen, L.T.; Choi, W.; Hyun Lee, S.; Jun, S. Exploring the heating patterns of multiphase foods in a continuous flow, simultaneous microwave and ohmic combination heater. Journal of Food Engineering. 2013, 116, 65-71. 
CAPÍTULO 1. INTRODUCCIÓN Y OBJETIVOS

[8] REGLAMENTO (CE) No 1069/2009 DEL PARLAMENTO EUROPEO Y DEL CONSEJO de 21 de octubre de 2009. 


\section{CAPÍTULO 2}

\section{ANTECEDENTES Y ESTADO DEL ARTE}

\subsection{Introducción y marco del problema}

La esterilización es un proceso de calentamiento controlado, que inactiva todos los microorganismos vivos que incluyen bacterias, hongos, virus y esporas bacterianas, excepto priones de una superficie, equipo, medicación o cultivo medio [1]. La esterilización puede utilizar métodos térmicos y no térmicos [2]; mientras que la esterilización térmica sigue siendo la tecnología convencional y ampliamente investigada, los métodos no térmicos [3] han ganado mucha atención, basada en la investigación de los últimos años. El principio detrás de la esterilización térmica se puede explicar, como un aumento de la temperatura en un grado o más allá de modo que las actividades del metabolismo biológico y el metabolismo celular comienzan a disminuir, lo que lleva a la inactivación [4]. La esterilización térmica ha sido utilizada por las industrias alimentarias, para inactivar patógenos transmitidos por los alimentos, incluidas las esporas, para prolongar la vida útil de los alimentos [5].

La esterilización térmica por microondas ha sido validada [6] y aceptada como método por la Administración de Alimentos y Medicamentos (FDA), para la esterilización de alimentos homogéneos y no homogéneos a escala comercial [7]. Más específicamente, fue aceptado por la FDA para la esterilización de puré de patatas, productos cárnicos y filete de salmón en los años 2009, 2010 y 2012 respectivamente [8]. El sistema ha sido patentado por el estado de Washington y descrito por [7]. El sistema como se describe por [7] consta de dos generadores (5 kW y $915 \mathrm{MHz}$ ), dos cavidades de calentamiento por microondas, cavidades de carga y descarga, un sistema de transporte de bandejas de muestras, un sistema de circulación de agua, control y sistema de adquisición de datos. Hay una sección de precalentamiento a la que, bandejas que contienen muestras 
de alimentos se cargan como parte de la entrada, mientras que la región de salida se compone de una cavidad de descarga que también es el sistema de refrigeración. El sistema de circulación de agua, que consta de dos placas intercambiadoras de calor, un tanque de almacenamiento y un accesorio generador de aire comprimido, para presurizar el agua. El sistema de control y registro de datos, está comprendido por tableros de control, registradores de datos, una computadora, sensores del sistema y de fibra óptica, junto con un acondicionador de datos, que monitorea continuamente la temperatura de los alimentos durante el proceso. La segunda generación de sistemas de esterilización por microondas, desarrollada por WSU también consta de circulación de agua y control de temperatura externa. Este sistema puede utilizar sensores metálicos móviles incrustados en la muestra de comida [6]. Se encontró que los sensores de temperatura metálicos móviles eran exactos en la precisión de medición, especialmente con el diámetro esférico y la punta de la sonda más delgada ( $1 \mathrm{~mm}$ ) en comparación a una punta plana o truncada [9]. La tecnología patentada [7] utiliza un modo único de $915 \mathrm{MHz}$, que produce patrones de calentamiento precisos y predecibles y una penetración de microondas más profunda en el producto alimenticio, aplicando energía de microondas mientras los alimentos envasados están presurizados. El baño de agua caliente elimina los problemas de calentamiento de los bordes y maximiza calidad en los alimentos.

El objetivo de la esterilización por microondas es reducir la exposición de tiempo de los alimentos y prevenir el efecto sobre los componentes sensibles al calor mientras se mantiene la exposición suficiente para la inactivación microbiana. Los intentos de calentamiento rápido pretenden eliminar el daño causado a los componentes sensibles al calor, debido a una exposición más prolongada en los métodos de esterilización. 
Siempre ha sido un desafío para los científicos de alimentos, eliminar los patógenos y las esporas en los alimentos sin producir ningún cambio indeseable. Un tratamiento térmico moderado con el objetivo de pasteurizar para inactivar las células vegetativas patógenas, no las esporas bacterianas (si están presentes) y los procesos de esterilización como la retorta que están diseñados para inactivar las esporas; a menudo dan lugar a efectos indeseables importantes en los alimentos que se tratan. Mientras se buscaba la solución completa, que eliminaría los microbios presentes, proporcionando una vida útil prolongada sin o con mínimos cambios que afectan la aceptabilidad de los alimentos, es necesario considerar también el coste. La vida útil prolongada es un requisito, especialmente cuando se trata de comidas listas para comer. De ahí que la búsqueda de una tecnología que puede aumentar la seguridad alimentaria manteniendo la calidad, señala hacia la esterilización térmica asistida por microondas.

Los subproductos animales se definen como "los cuerpos enteros o partes de animales, productos de origen animal u otros productos obtenidos a partir de animales, que no están destinados para el consumo humano, incluidos los ovocitos, los embriones y el esperma".

Los subproductos animales se generan principalmente durante el sacrificio de animales para el consumo humano, en la elaboración de productos de origen animal como los productos lácteos, y en la eliminación de animales muertos o por la aplicación de medidas de control de enfermedades. Independientemente de su procedencia, constituyen un riesgo potencial para la salud pública, la salud animal y el medio ambiente. Este riesgo debe controlarse adecuadamente, bien canalizando esos productos hacia medios de eliminación seguros o utilizándolos para diversos fines, a condición de que se apliquen condiciones estrictas que reduzcan al mínimo los riesgos sanitarios.

Las normas sobre subproductos animales establecidas en los nuevos reglamentos deben aplicarse a los productos que no pueden destinarse al consumo humano de acuerdo con la legislación comunitaria [10], especialmente si no cumplen la legislación sobre higiene alimentaria o cuando no se pueden introducir en el mercado como alimentos porque no 
son seguros. Por otra parte, esas normas deben aplicarse también a los productos que cumplen con las normativas para el consumo, o que son materias primas para productos destinados al consumo humano y que luego, sean destinados a otros usos.

En el caso de los Subproductos de Origen Animal no destinados a Consumo Humano (SANDACH) que se obtienen de piscifactorías, objeto del desarrollo de este trabajo investigador, su eliminación requiere el transporte a incineradoras homologadas, lo que genera un coste muy elevado. Además, los descartes de pesquería, antes de llegar a puerto, suponen una cuarta parte de la pesca mundial, principalmente por tratarse de especies no comercializables.

Por tanto, el desarrollo de una tecnología de tratamiento (deshidratación o eliminación) in situ de estos desechos con aplicadores de microondas puede contribuir a una importante reducción de costes y a una mejora medioambiental.

A lo largo de toda la cadena de producción y distribución de alimentos y productos de origen animal se genera una serie de subproductos que, si bien tradicionalmente han sido empleados en la alimentación animal, pueden ser objeto de otros usos como material para películas y fotografía, pinturas, instrumentos de cuerda, textiles, etc.

Sin embargo, una serie de crisis alimentarias y sanitarias ocurridas a lo largo de los años noventa en España, entre las que podemos destacar la crisis de las encefalopatías espongiformes transmisibles (EET), como la encefalopatía espongiforme bovina (EEB), y la presencia de dioxinas en los piensos, evidenciaron las consecuencias del uso indebido de algunos subproductos animales para la salud pública y la salud animal, para la seguridad de la cadena alimentaria humana y animal y para la confianza de los consumidores. Por todo ello, se hizo necesario llevar a cabo una regulación normativa de estos subproductos con el fin de garantizar la seguridad de los procesos. La actual normativa (Real Decreto 1528/2012, de 8 de noviembre), con su última modificación de 15 de marzo de 2017, recoge los procedimientos y restricciones aplicables al tratamiento para este tipo de productos [11]. 
El presente trabajo de investigación está dirigido, en última instancia, al tratamiento de los desechos de piscifactoría o descartes de pesca, es decir, cadáveres de peces retirados diariamente de la producción, pertenecientes, por tanto, a la Categoría 3, dentro de los epígrafes "animales acuáticos y parte de los mismos, salvo mamíferos marinos, que no presenten signos de enfermedad transmisible" y "subproductos de animales acuáticos procedentes de establecimientos o plantas que fabriquen productos para el consumo humano", dentro del Nuevo Marco Legal de SANDACH, publicado por el Ministerio de Agricultura y Pesca en Abril de 2013 [12].

Esta propuesta plantea la utilización de tecnología de microondas como alternativa a los procesos tradicionales de esterilización de material biológico. Para acotar el problema se ha estudiado su viabilidad, en concreto, con la eliminación/valorización de desechos de piscifactoría y pesca. La esterilización requiere uniformidades de calentamiento extremadamente altas, de tal manera que se llegue a un compromiso entre eliminación total de patógenos en el producto mediante un régimen de temperatura-tiempo adecuado, y conservación de características nutricionales y organolépticas. Existen métodos convencionales con grandes desventajas frente a las microondas, pero éstas han fracasado hasta la fecha en obtener un calentamiento homogéneo.

Éste ha sido uno de los requisitos de la investigación tecnológica propuesta, sin perder las demás características diferenciadoras de las microondas: bajos tiempos de procesamiento, eficiencia energética o mayor control del proceso (menores inercias térmicas). La conformación de campo eléctrico sobre la muestra se realiza mediante cambios en la geometría del aplicador microondas, diferentes estrategias de multialimentación del aplicador y la utilización de elementos dieléctricos en su interior.

Para garantizar la seguridad alimentaria se ha diseñado un biosensor basado en microorganismos que permita conocer de forma precisa la variabilidad de calentamiento en todo el producto y cuantificar los niveles de seguridad. Estos desarrollos tienen también aplicación en otros procesos industriales, no sólo en esterilización de alimentos.

El desarrollo de un biosensor es totalmente novedoso en el ámbito de microondas, dado 
que no se ha estudiado la interacción de los materiales con dicha tecnología. Además, la combinación de dos áreas consideradas totalmente diferentes hace que esta tesis haya podido abordar retos mayores al interconectar el conocimiento y experiencia de la tecnología de microondas, con la de los sensores biológicas en muestras para procesar, permitiendo establecer de forma cuantitativa la variabilidad de la temperatura en un muestreo importante del producto configurándolo de forma laminar. Este desarrollo ha presentado gran dificultad, dado que los materiales que se utilizan habitualmente gelifican en presencia de iones $\mathrm{Ca} 2+$, lo que puede dar lugar a desviaciones en el calentamiento por microondas (que podría ser más intenso) respecto al del alimento.

La transformación del SANDACH en harina de pescado, por ejemplo, permite generar un producto obtenido del procesamiento de pescados, eliminando su contenido de agua y aceite. Con un $70 \%$ a $80 \%$ del producto en forma de proteína y grasa digerible, su contenido en energía es notablemente mayor que muchas otras proteínas animales o vegetales, ya que proporciona una fuente concentrada de proteína de alta calidad y una grasa rica en ácidos grasos Omega-3, DHA y EPA, indispensables para el rápido crecimiento de los animales.

Respecto a las plantas de transformación, la normativa en materia de subproductos animales establece las diferentes condiciones que tienen que cumplir tanto en materia de higiene, como en lo relativo a la ubicación y a las instalaciones. Las figuras 2.1-2.3 muestran una instalación de transformación de SANDACH de piscifactoría en Chile, uno de los países líderes en producción de este subproducto derivado del salmón.

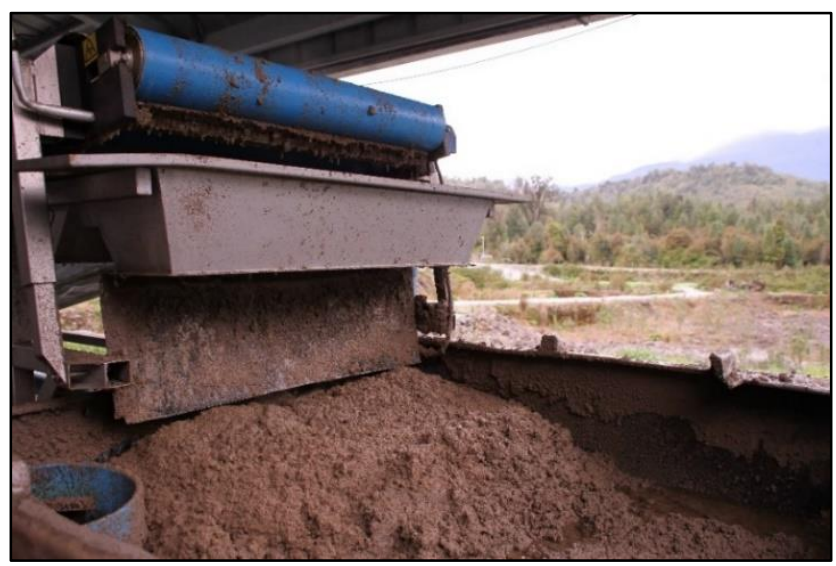

Figura 2.1 Proceso de triturado de SANDACH derivado de piscifactorías de salmón (Chile). 


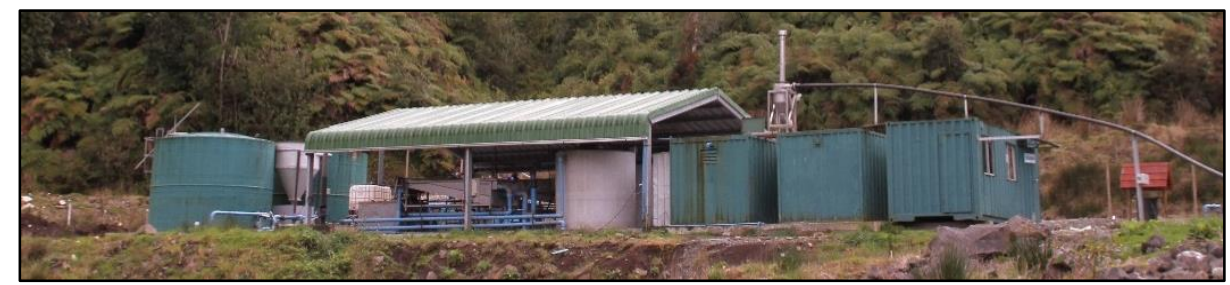

Figura 2.2 Planta de tratamiento de SANDACH de piscifactoría (Chile)

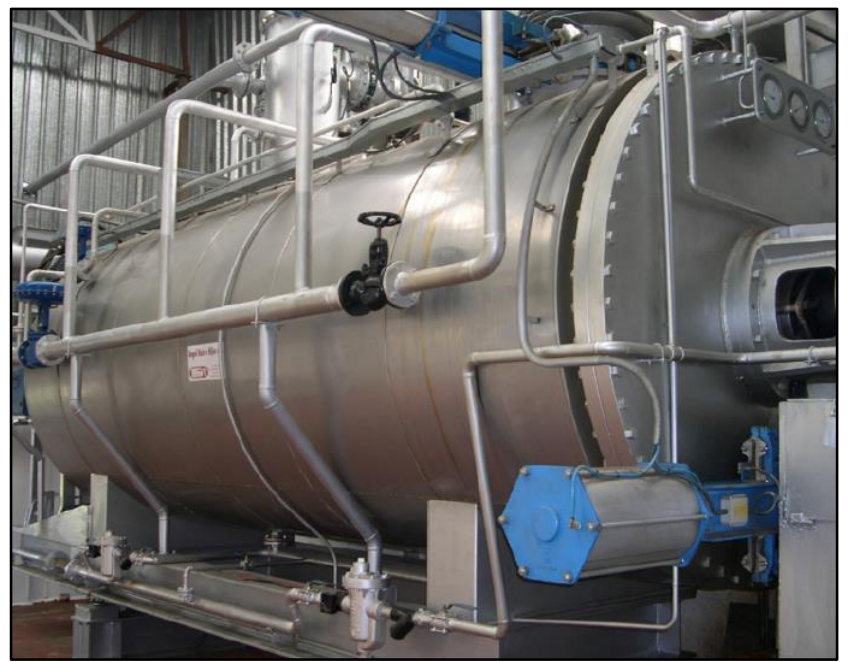

Figura 2.3 Equipo industrial de esterilización con calentamiento convencional.

La normativa anterior contempla siete métodos estándar, de transformación de estos desechos en los cuáles el proceso de esterilización es exigido. En concreto, el método 7 consiste en cualquier método autorizado por la autoridad competente en base al cumplimiento de dos requisitos:

- La identificación de peligros y riesgos, y la capacidad del método para reducirlos.

- El muestreo diario durante 30 días para el cumplimiento de criterios microbiológicos relativos a Clostridium perfringens, Salmonella y Enterobacteriaceae.

Estudios recientes han demostrado mejores resultados para la pasteurización o esterilización de alimentos, en términos de la retención de la calidad de los 
nutrientes [13] y la eliminación microbiana [14], cuando la tecnología de microondas es utilizada en comparación con los métodos tradicionales.

Pero para evaluar el comportamiento de la inactivación microbiológica en la transformación o eliminación de SANDACH con procesos de esterilización o pasteurización con microondas, se debe asegurar un calentamiento lo más uniforme posible o que establezca una relación entra dicha inactivación y las características dieléctricas y físicas de la muestra [15-17]. Este es, precisamente, uno de los puntos débiles que impiden hoy en día el uso de microondas en estos procesos.

El calentamiento no uniforme del producto viene determinado por dos motivos independientes. En primer lugar, la energía microondas decae exponencialmente conforme la onda penetra en el material y su potencia se disipa en forma de calor. De esta manera, ante productos como los biológicos, con elevadas pérdidas y altas conductividades, la onda se atenúa rápidamente y por ello se deben conformar productos laminares, con un espesor en torno a $1-2 \mathrm{~cm}$ si se quiere tener una buena uniformidad de calentamiento.

Por otra parte, el campo eléctrico presenta una alta variabilidad en el interior de una cavidad resonante, resultado de la combinación lineal de los diferentes modos de campo electromagnético que son excitados por la fuente de microondas, lo que repercute en un calentamiento no homogéneo. Los intentos en la mejora de esta uniformidad se han basado tradicionalmente en mecanismos de movimiento del producto (plato giratorio en hornos domésticos o movimiento de vaivén o continuo de cinta transportadora en hornos industriales) o en agitadores de modos [18], esto es, estructuras metálicas en movimiento que modifican las condiciones de contorno de la cavidad, variando el patrón de campo eléctrico con el tiempo. Con estas soluciones se pretende que la energía disipada, en media temporal, sea similar en todos los puntos de la muestra, pero no garantiza una uniformidad de temperatura como la 
requerida en los procesos de esterilización o en otros procesos industriales de calentamiento.

En los últimos años se ha estudiado el uso de tecnología microondas a $915 \mathrm{MHz}$ [19], frente a la más desarrollada y barata a $2,45 \mathrm{GHz}$, para paliar este problema. Aunque la utilización de frecuencias más bajas mejora indudablemente la uniformidad del campo eléctrico dentro del aplicador y también permite una mayor penetración de la onda en el material, esta tecnología es mucho más cara, sobre todo en las fuentes de microondas, lo que dificulta su transferencia a la industria.

También se han simulado desarrollos específicos para esterilización de procesos [20] o el uso de potencias de microondas muy altas en una cavidad cilíndrica [21] para medir el efecto de la esterilización en una muestra de alimento específica. Sin embargo, aunque este proceso de esterilización se realiza utilizando sistemas de microondas, no queda garantizado un perfil de uniformidad de temperatura en la muestra.

Las combinaciones de los biosensores con el calentamiento por microondas van a permitir abordar un nuevo estudio científico que, aplicado al SANDACH, pueda obtener resultados válidos a corto plazo para una transferencia de tecnología en piscifactorías y empresas de gestión de residuos que suponga una mejora medioambiental, una reutilización de recursos y una garantía para la salud.

En la actualidad, la consecución de distribuciones de campo eléctrico uniformes sobre la superficie del producto tratado en un aplicador multimodo, incluso presentando propiedades electromagnéticas homogéneas, es una barrera tecnológica que limita la aplicación de las microondas a una gran cantidad de procesos de calentamiento industrial, incluidos los procesos de esterilización. Nos encontramos, por tanto, en un estado del desarrollo de la tecnología microondas en el que existe un bloqueo tecnológico que limita, cuando no invalida, su uso para un gran número de aplicaciones de calentamiento industrial. 
La comunidad científica, después de los intentos de mejora enunciados anteriormente, considera actualmente esta limitación como algo inherente a las microondas $y$, por tanto, a día de hoy no puede reducirse más allá de lo conseguido con las técnicas enunciadas.

Otra limitación para garantizar la uniformidad es la ausencia de métodos biológicos adaptados a microondas que permitan determinar el grado de variabilidad en el calentamiento alcanzado, en base a la inactivación microbiana en cada punto del alimento. Ésta es la exigencia legislativa en la actualidad por parte de la EFSA (Autoridad Europea de Seguridad Alimentaria) para su implantación a nivel industrial y de tratamiento de subproductos de origen animal/marino, como las explotaciones acuícolas. Este aspecto se dificulta con respecto a los biosensores existentes, dado que la concentración de moléculas con carga (como el ión calcio, muy utilizado) influyen en la intensidad de calentamiento por microondas, pudiendo dar un falso resultado de esterilización (falso negativo), que puede suponer un riesgo para la salud pública y salud animal. Por ello es necesario, también, desarrollar una nueva gama de biosensores, que se calienten de manera análoga al alimento.

\subsection{Normativa Legal}

\subsubsection{Antecedentes normativos}

A lo largo de toda la cadena de producción y distribución de alimentos y productos de origen animal se genera toda una serie de subproductos, que, si bien tradicionalmente han sido empleados en la alimentación animal, pueden ser objeto de otros usos.

Sin embargo, una serie de crisis alimentarias y sanitarias ocurridas a lo largo de los años noventa, entre las que podemos destacar la crisis de las encefalopatías espongiformes transmisibles (EET), como la encefalopatía espongiforme bovina (EEB), y la presencia de dioxinas en los piensos, han evidenciado las consecuencias del uso indebido de algunos subproductos animales para la salud 
pública y la salud animal, la seguridad de la cadena alimentaria humana y animal y la confianza de los consumidores. Por todo esto se hizo necesario llevar a cabo una regulación normativa de estos subproductos, con el fin de garantizar la seguridad de los procesos.

Así, en el año 2002 se publicó el Reglamento (CE) n 1774/2002 [22], que regula las condiciones de aplicación de la normativa comunitaria en materia de subproductos de origen animal no destinados al consumo humano (SANDACH), que dio lugar a más de treinta disposiciones legislativas que modifican o aplican el reglamento.

A nivel nacional, el Real Decreto 1429/2003 [23] estableció pautas armonizadas de aplicación del citado Reglamento CE.

Sobre la base de asesoramiento científico y a modo de acción de conformidad con el Libro Blanco de la Comisión sobre seguridad alimentaria, de 12 de enero de 2000, ese Reglamento introdujo un conjunto de normas destinadas a preservar la seguridad de la cadena alimentaria humana y animal, que es complementario de la legislación comunitaria sobre alimentos y piensos. Esas normas mejoraron notablemente el nivel de protección en la Comunidad contra los riesgos derivados de los subproductos animales.

Conforme a lo establecido por el propio Reglamento, la Comisión Europea presentó, el 21 de octubre de 2005, un informe al Parlamento Europeo y al Consejo [24], sobre las medidas adoptadas por los Estados miembros para garantizar el cumplimiento de dicho Reglamento. Este informe destacaba que debían mantenerse los principios del citado texto, pero también los ámbitos en que era necesario introducir modificaciones del mismo.

Las conclusiones de la Presidencia del Consejo sobre el informe de la Comisión de octubre de 2005, adoptadas en diciembre de 2005 y las posteriores consultas de la Comisión destacaron que debían mejorarse las normas establecidas en el 
Reglamento (CE) no 1774/2002 con el fin de permitir alcanzar unos objetivos, como son el control de riesgos para la salud pública y la salud animal y la seguridad de la cadena alimentaria humana y animal.

En consecuencia, se hizo necesario establecer un nuevo marco normativo que entró en vigor el 4 de marzo de 2011 y que está compuesto por el Reglamento (CE) n 1069/2009, del Parlamento Europeo y del Consejo, de 21 de octubre de 2009, por el que se establecen las normas sanitarias aplicables a los subproductos animales y los productos derivados no destinados al consumo humano y por el que se deroga el Reglamento (CE) 1774/2002, y el Reglamento (UE) no 142/2011 de la Comisión, de 25 de febrero de 2011 [25], que desarrolla al anterior.

La última modificación del Reglamento (UE) n 142/2011 es el Reglamento de Ejecución (UE) nº 1097/2012 de la Comisión, de 23 de noviembre de 2012 [26], que modifica el Reglamento (UE) $n^{\circ}$ 142/2011, por el que se establecen las disposiciones de aplicación del Reglamento (CE) n 1069/2009 del Parlamento Europeo y del Consejo por el que se establecen las normas sanitarias aplicables a los subproductos animales y los productos derivados no destinados al consumo humano, y la Directiva 97/78/CE del Consejo en cuanto a determinadas muestras y unidades exentas de los controles veterinarios en la frontera en virtud de la misma.

Finalmente, en el Real Decreto 1528/2012, de 8 de noviembre, por el que se establecen las normas aplicables a los subproductos animales y los productos derivados no destinados al consumo humano, se desarrollan los aspectos que pueden ser regulados por la normativa propia.

\subsubsection{Objetivos de la legislación vigente}

La nueva Reglamentación de subproductos establece claramente tres Objetivos: 
1. Prevenir y reducir al mínimo los riesgos para la salud pública, la salud animal y el medio ambiente.

2. Preservar la seguridad de la cadena alimentaria humana y animal.

3. Establecer normas en materia de salud pública y salud animal aplicables a los subproductos animales y los productos derivados.

Todas sus disposiciones deben permitir alcanzar estos objetivos. Para ello se ha simplificado la normativa, flexibilizándola, relacionándola con otros reglamentos, y adoptando medidas proporcionales a la evaluación de riesgo de estos subproductos, rebajando las cargas administrativas para los operadores y aumentado los sistemas de control. A modo de resumen, la regulación vigente, establece:

- Las normas generales proporcionales al riesgo que entrañan los subproductos animales cuando los manipulan los explotadores en las distintas fases de la cadena, desde la recogida hasta su uso o eliminación.

- La categorización de los subproductos. Los clasifica en tres categorías que reflejan el grado de riesgo que suponen para la salud pública y la salud animal, basándose en evaluaciones de riesgo.

- En qué condiciones pueden emplearse los subproductos animales para la alimentación animal y otros usos como en cosmética, medicamentos y usos técnicos.

- Las obligaciones que deben cumplir los operadores en lo que respecta a la manipulación de subproductos animales dentro de establecimientos y plantas sometidos a control oficial. Los explotadores deben garantizar la trazabilidad de los subproductos animales y los productos derivados en todas las fases de la cadena de fabricación, uso y eliminación, para evitar perturbaciones innecesarias del mercado interior en caso de riesgo para la salud pública o animal. Por ello, la trazabilidad no debe garantizarla exclusivamente los explotadores que generan, 
recogen o transportan subproductos animales, sino también los que eliminan los subproductos animales o productos derivados por incineración, coincineración o eliminación en vertedero.

- Las normas detalladas para la manipulación de los subproductos animales y productos derivados, como las normas aplicables a la transformación, las condiciones higiénicas y el formato de los documentos que deben acompañar a los envíos de subproductos animales y productos derivados a los efectos de garantizar la trazabilidad.

- Las normas detalladas de uso y eliminación de subproductos animales.

\subsubsection{Control de la cadena alimentaria y Consideraciones finales}

Los reglamentos SANDACH inciden en la importancia de la realización de controles oficiales por parte de los Estados miembros en la totalidad de la cadena de subproductos animales y productos derivados de conformidad con el Reglamento (CE) no 882/2004 [27], sobre los controles oficiales efectuados para garantizar la verificación del cumplimiento de la legislación en materia de piensos y alimentos y la normativa sobre salud animal y bienestar de los animales.

En España, cumpliendo el mandato comunitario del Reglamento 882/2004, se estableció el PLAN NACIONAL DE CONTROL OFICIAL DE LA CADENA ALIMENTARIA 2011-2015. Fue un Plan Plurianual Integrado de Controles, en donde se incluyeron varios programas de control oficial que afectan a los SANDACH. Estos programas son:

- Programa de control de subproductos, incluido en el programa general de control de empresas alimentarias.

- Programa de control oficial de establecimientos, plantas y operadores sandach.

- Programa de control oficial en alimentación animal. 
Según dicho Plan Nacional, es necesario utilizar un sistema de controles propios (autocontroles) para garantizar el cumplimiento del Reglamento SANDACH dentro de un establecimiento o una planta. Durante los controles oficiales, las autoridades competentes deben tener en cuenta la correcta realización de los controles propios (autocontroles). A este respecto, las guías nacionales de buenas prácticas pueden ser una herramienta útil para facilitar la aplicación práctica de los principios APPCC (Análisis de Peligros y Puntos Críticos de Control) y de otros aspectos de la normativa.

La eliminación de subproductos animales y productos derivados, debe llevarse a cabo de acuerdo con la legislación medioambiental relativa al vertido y la incineración de residuos.

\subsection{Esterilización de SANDACH. Metodología del trabajo de investigación}

Como se ha descrito, este trabajo aborda la utilización de tecnología de microondas como alternativa a los procesos tradicionales de esterilización de material biológico. Para acotar el problema se ha estudiado su viabilidad en dos procesos concretos:

- La esterilización de alimentos y su caracterización microbiológica.

- La eliminación/valorización de desechos de piscifactoría y pesca con ausencia de microorganismos en sistemas industriales por microondas.

La esterilización requiere uniformidades de calentamiento extremadamente altas, de tal manera que se llegue a un compromiso entre eliminación total de patógenos en el producto mediante un régimen de temperatura-tiempo adecuado y la conservación de características nutricionales y organolépticas. Los métodos convencionales (químicos por óxido de etileno, aldehídos o gas-plasma y físicos por calor, filtración o agentes esterilizantes) [28] presentan importantes desventajas frente a las microondas (mayor consumo energético, menor control del proceso, mayores tiempos de procesado, etc.), pero éstas han fracasado, hasta la fecha, en conseguir un calentamiento homogéneo. 
Para validar esta nueva metodología se ha desarrollado un biosensor específico basado en microorganismos, en este caso las bacterias de Bacillus spp [29], como elemento sensor, que permite establecer de forma cuantitativa la variabilidad de la temperatura en todos los puntos del producto. Este desarrollo presenta gran dificultad, dado que los materiales que se utilizan habitualmente gelifican en presencia de iones $\mathrm{Ca} 2+$, lo que puede dar lugar a desviaciones en el calentamiento por microondas (que podría ser más intenso) respecto al del alimento.

Así, en este trabajo se abordada el desarrollo y prueba de concepto de nuevos métodos de secado por microondas que garanticen un alto nivel de uniformidad de calentamiento en todo el volumen del producto, con dos objetivos:

- Por una parte, el desarrollo de un nuevo sistemas de calentamiento por microondas mediante el estudio de la geometría, movimiento de muestra y adaptación.

- Y por otra parte disponer del conocimiento necesario sobre la relación entre la inactivación microbiológica y la exposición a fuentes de calentamiento por microondas.

Para ello, el desarrollo de nuevos biosensores se muestra fundamental para establecer la seguridad alimentaria del producto final en su totalidad, con una información precisa de distrubución en el alimento o producto (y no sólo un dato global o promediado), lo que supone garantizar la ausencia de microorganismos patógenos y de sustancias tóxicas para el consumidor o para el subproducto transformado [30].

Los biosensores microbiológicos se han utilizado para validar procesos térmicos de esterilización convencionales en los que se conoce, al menos aproximadamente, los puntos más fríos [31]. En el caso del calentamiento por microondas la incertidumbre sobre los puntos fríos es el principal reto para garantizar la seguridad de los alimentos o productos tratados, por lo que esta nueva generación de biosensores se caracterizarán por ser de pequeño tamaño para poder realizar una amplia distribución de los mismos 
en el producto, de forma que se distribuyan espacialmente para modelar la temperatura en base a datos biológicos en cada punto de la matriz configurada para ello. Para ello, se han utilizado dos elementos sensores (microorganismos de diferentes especies), de manera que se pueda controlar la variabilidad biológica y garantizar que se alcanza la esterilidad de forma real.

\subsection{Referencias}

[1] Silindir, M., \& Özer, A. Y. (2009). Sterilization methods and the comparison of e beam sterilization with gamma radiation sterilization. Fabad Journal ofPharmace utical Sciences, 34, 43.

[2] Morris, C., Brody, A. L., \& Wicker, L. (2007). Non-thermal food processing/preservation technologies: A review with packaging implications. Packaging Technology and Science: International Journal, 20, 275-286.

[3] Hong, W., \& Yan, L. (2005). Non-thermal sterilization technologies in food processing [J]. Journal of Cereals \& Oils, 5.

[4] Wood, R. T. (2002). Fundamentals of thermal sterilization processes. Development and manufacture of protein pharmaceuticals (pp. 191-212). Springer.

[5] Soni, A., Oey, I., Silcock, P., \& Bremer, P. (2016). Bacillus spores in the food industry: A review on resistance and response to novel inactivation technologies. Comprehensive Reviews in Food Science and Food Safety, 15, 1139-1148.

[6] Tang, J. (2015b). Unlocking potentials of microwaves for food safety and quality. Journal of Food Science, 80, E1776-E1793.

[7] Tang, Liu, F., Pathak, S., \& Eves, E., II (2006). Apparatus and method for heating objects with microwaves, Vol. 7. Washington State University Research Foundation. 
[8] Barbosa-Cánovas, G. V., Medina-Meza, I., Candoğan, K., \& Bermúdez-Aguirre, D. (2014). Advanced retorting, microwave assisted thermal sterilization (MATS), and pressure assisted thermal sterilization (PATS) to process meat products. Meat Science, $98,420-434$.

[9] Luan, D., Tang, J., Pedrow, P. D., Liu, F., \& Tang, Z. (2015). Performance of mobile metallic temperature sensors in high power microwave heating systems. Journal of Food Engineering, 149, 114-122.

[10] REGLAMENTO (CE) No 1069/2009 DEL PARLAMENTO EUROPEO Y DEL CONSEJO de 21 de octubre de 2009.

[11] Real Decreto 1528/2012, de 8 de noviembre, por el que se establecen las normas aplicables a los subproductos animales y los productos derivados no destinados al consumo humano.

[12] Ministerio de Agricultura, Alimentación y Medio Ambiente. SANDACH: Subproductos de Origen Animal no Destinados a Consumo Humano. Nuevo Marco Legal. Madrid, 2013.

[13] Kothari, V.; Patadia, M.; Trivedi, N. Microwave sterilized media supports better microbial growththan autoclaved media. Res. Biotechnol. 2011, 2, 63-72. Sensors 17, 1309, 2017.

[14] Neetoo, H.; Chen, H. Alternative Food Processing Technologies. In Food Processing: Principles and Applications, 2nd ed.; Clark, S., Jung, S., Lamsal, B., Eds.; John Wiley \& Sons, Ltd.: New York, USA, pp. 137-169. 2014.

[15] Ejiri, K.; Tomizuka, Y.; Ichihara, G.; Sato, H.; Uchida, Y.; Ohno, T.; Uehara, M. A study on uniform heating of food in microwave oven by using phase difference of power output from two ports. In Proceedings of the Electromagnetic Research Symposium (PIERS), Shanghai, China, 8-11 August 2016. 
[16] Cordes, B.G.; Eves, E.E.; Yakovlev, V.V. Modeling-based minimization of time-touniformity microwave heating systems. In Proceedings of the 11th AMPERE Conference on Microwave and High Frequency Heating, Oradea, Romania, pp. 305308. 2007.

[17] Gu, X.W.; Lin, M.; Yiqin, S. Electromagnetic field optimisation procedure for the microwave oven. Int. J. Electron. 97, 339-347, 2010.

[18] Ashim K. Datta and Ramaswamy C. Anantheswaran, Handbook of Microwave Technology for Food Applications, Ed. Marcel Dekker, 2001.

[19] Zhongwei Tang et al., Microwave sterilization of sliced beef in gravy in 7-oz trays, Journal of Food Engineering 89, 375-383, 2008.

[20] Resurreccion, F.P.; Luan, D.; Tang, J.; Liu, F.; Tang, Z.; Pedrow, P.D.; Cavalieri, R. Effect of changes in microwave frequency on heating patterns of foods in a microwave assisted thermal sterilization system. Journal of Food Engineering, 150, 99-105. 2015.

[21] Steed, L.E.; Troung, V.D.; Simunovic, J.; Sandeep, K.P.; Kumar, P.; Cartwright, G.D.; Swartzel, K.R. Continuous Flow Microwave-Assisted Processing and Aseptic Packaging of Purple-Fleshed Sweet potato Purees. Journal of Food Science 73, 455462. 2008.

[22] REGLAMENTO (CE) No 1774/2002 DEL PARLAMENTO EUROPEO Y DEL CONSEJO de 3 de octubre de 2002 por el que se establecen las normas sanitarias aplicables a los subproductos animales no destinados al consumo humano.

[23] REAL DECRETO 1429/2003, de 21 de noviembre, por el que se regulan las condiciones de aplicación de la normativa comunitaria en materia de subproductos de origen animal no destinados al consumo humano. 
[24] REGLAMENTO (UE) 2015/1910 DE LA COMISIÓN de 21 de octubre de 2015 que modifica los anexos III y V del Reglamento (CE) no 396/2005 del Parlamento Europeo y del Consejo.

[25] REGLAMENTO (UE) No 142/2011 DE LA COMISIÓN de 25 de febrero de 2011 por el que se establecen las disposiciones de aplicación del Reglamento (CE) no 1069/2009 del Parlamento Europeo y del Consejo

[26] REGLAMENTO DE EJECUCIÓN (UE) No 1097/2012 DE LA COMISIÓN de 23 de noviembre de 2012

[27] REGLAMENTO (CE) No 882/2004 DEL PARLAMENTO EUROPEO Y DEL CONSEJO de 29 de abril de 2004

[28] ZANDER, K. 1980. Some safety aspects of wire-wound pressure vessels and press frames for isostatic pressing and industrial applications in general. Proc. 4th Int. Conf. on Pressure Vessel Technology, 549-560.

[29] VILLARREAL-DELGADO, María Fernanda et al.El género Bacillus como agente de control biológico y sus implicaciones en la bioseguridad agrícola. Rev. mex. fitopatol [online]. 2018, vol.36, n.1, pp.95-130. ISSN 20078080. https://doi.org/10.18781/r.mex.fit.1706-5.

[30] Van Zuijlen A., Periago P.M., Amézquita A., Palop A., Brul S., Fernández P.S. Characterization of Bacillus sporothermodurans IC4 spores; putative indicator microorganism for optimisation of thermal processes in food sterilisation, Food Research International 43, 1895-1901. 2010.

[31] Moore, E., Pravda, M., Guilbault, G. G. (2003) Development of a biosensor for the quantitative detection of 2,4,6-trichloroanisole using screen printed electrodes. Analytica Chimica Acta 484, 15-24 


\section{CAPÍTULO 3}

\section{MODELADO DEL CALENTAMIENTO POR MICROONDAS EN CAVIDADES MONOMODO Y MULTIMODO}

\subsection{Características de la tecnología de microondas de calentamiento y secado}

Desde la invención del fuego por la humanidad, la única forma de calentamiento radicalmente diferente a cualquier otra es el calentamiento por microondas. Cualquier tipo de calentamiento convencional implica siempre una trasmisión de calor desde un cuerpo de mayor temperatura (fuente de calor) a otro de temperatura menor. Esta trasmisión de calor puede tener lugar mediante tres tipos de mecanismos diferentes: conducción, convección y radiación, pero en todos los casos implica la existencia de una fuente de calor externa al cuerpo que se calienta. De esta manera, existe siempre un gradiente de temperatura donde las partes más externas, o más expuestas, del cuerpo que se calienta tienen una temperatura superior a las más internas o menos expuestas.

La conducción dentro del propio cuerpo tiende, con el tiempo, a hacer desaparecer este gradiente y homogenizar la temperatura. En el caso del calentamiento mediante radiación de microondas la situación es totalmente diferente. Como se ha descrito anteriormente, las microondas trasmiten energía directamente a las partículas (a aquellas que sean capaces de interaccionar con las microondas) del propio cuerpo. Por tanto, el calentamiento se produce en el interior del cuerpo (lo que se conoce como calentamiento volumétrico) y, en principio, no existe este gradiente de temperaturas. De hecho, y dado que las pérdidas de calor son mayores en las superficies del cuerpo, podríamos considerar que el calentamiento se produce de dentro hacia fuera, al revés que en el calentamiento convencional.

Al igual que los rayos infrarrojos, las microondas comparten la propiedad de hacer vibrar ciertas moléculas de los cuerpos que atraviesan, calentándolos. Dichas moléculas actúan como dipolos eléctricos tratando de orientarse o polarizarse ellas mismas bajo la acción 
del campo. Debido a que el campo cambia de sentido con una frecuencia entre $300 \mathrm{MHz}$ y $300 \mathrm{GHz}$, la fricción interna entre las moléculas es lo que da lugar a su calentamiento [1]. Un átomo o molécula lleva electrones de carga negativa y protones de carga positiva. De forma análoga, situados entre dos placas, los electrones sometidos a una tensión eléctrica serán atraídos por la placa o electrones de polaridad opuesta. Cuando la tensión eléctrica es alterna, con una frecuencia determinada, dichas partículas serán atraídas sucesivamente por ambas placas, lo que dará lugar al calentamiento del material del cual forman parte; dicho calor se genera directamente dentro del material. Es posible, por tanto, obtener una elevación de temperatura más rápida que en el calentamiento convencional. El presente trabajo propone el uso, para el secado de SANDACH, de las ondas electromagnéticas de alta frecuencia (microondas), cuya propiedad es la de hacer vibrar moléculas bipolares, haciendo que éstas se friccionen alcanzando temperaturas elevadas en un tiempo corto, como alternativa a emplear en la esterilización.
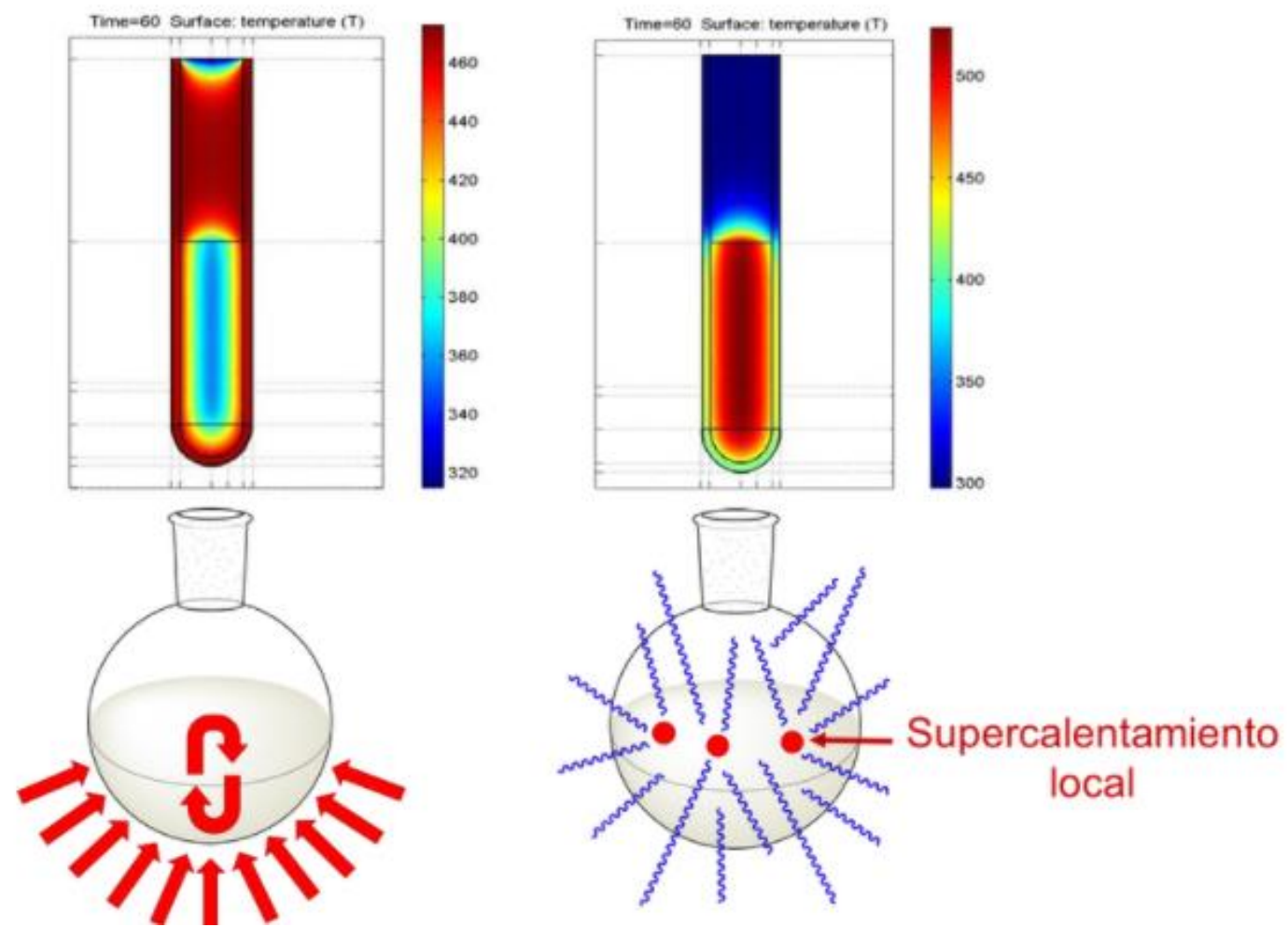

Figura 3.1. Gradiente de temperaturas en el calentamiento convencional (izquierda) y en el calentamiento por microondas o volumétrico (derecha). [2]. 
Esta situación, no obstante, corresponde a una simplificación del fenómeno, ya que la homogeneidad del calentamiento va a estar supeditada a la homogeneidad en la composición del cuerpo a calentar y a la penetración de las microondas en el objeto irradiado [3].

El calentamiento dieléctrico se ha venido utilizando ampliamente en la industria, durante más de 60 años, como un medio de acelerar los procesos de tratamiento térmico de materiales, en los que en muchas ocasiones los procedimientos convencionales son lentos o ineficientes. Debido a sus características inherentes, la energía de microondas puede proporcionar una importante mejora de la eficiencia, de la rapidez y de la calidad del procesado, en particular para los materiales de baja conductividad térmica.

En los sistemas de calentamiento por microondas se convierte directamente la energía en calor sobre el material, produciendo generación de calor en todo el volumen de éste (calentamiento volumétrico). Esto presenta grandes ventajas en cuanto a eficiencia y tiempos de procesado frente a otras tecnologías, donde el calor se transmite por conducción desde el exterior hacia el interior del material [4], [5]. La figura 3.1 muestra estas diferencias entre el calentamiento convencional y el calentamiento dieléctrico.

Con las tecnologías convencionales de calentamiento (aire caliente, infrarrojos, combustión) toda la estructura del horno se mantiene a alta temperatura y por tanto aumentan las pérdidas térmicas, dando como resultado una eficiencia energética mejorable. Por el contrario, en los sistemas de microondas la energía se deposita directamente sobre el material, evitándose en gran medida estas pérdidas de calor y obteniéndose una alta eficiencia energética.

Puesto que el calentamiento se produce directamente en el volumen del material, el tratamiento térmico puede ser mucho más rápido que cuando la transmisión de calor se produce por conducción desde el exterior al interior del material. Esta ventaja es especialmente importante en el procesamiento de materiales de muy baja conductividad térmica, que mediante tecnologías convencionales pueden necesitar tiempos muy largos de calentamiento. 
Otra ventaja importante es el fenómeno de calentamiento selectivo, que ocurre en algunos procesos, del que el ejemplo típico es el calentamiento de agua dentro de un vaso de vidrio en un horno de microondas doméstico: el agua se calienta muy rápidamente, mientras que el vaso no. Este efecto ocurre igualmente en tipos de productos compuestos por varios materiales, algunos de los cuales son más absorbentes de la energía microondas que otros, por lo que el calentamiento de unos puede ser muy superior al de otros, lo que puede ser una gran ventaja en ciertas aplicaciones.

Otro ejemplo son las aplicaciones de secado, donde también se produce el efecto de calentamiento selectivo, y en este caso produce un fenómeno de igualamiento. Las zonas donde existe mayor humedad absorben microondas con mayor eficacia, lo que produce localmente un secado más intenso. Como resultado, la uniformidad en el secado es mayor, y por tanto mayor la calidad del producto del proceso [6].

El procesado de materiales por microondas puede considerarse un proceso limpio, ya que utiliza únicamente energía eléctrica, en comparación con otros procesos donde se genera calor mediante combustión, generalmente de hidrocarburos. Esto permite la posibilidad de utilizar energías renovables para todo el proceso.

Los sistemas de tratamiento térmico convencionales necesitan en muchas ocasiones, de tiempos de puesta en marcha considerablemente largos, del orden incluso de días, lo que en ciertas instalaciones obliga a su funcionamiento ininterrumpido y por tanto escasa flexibilidad en la producción. En cambio, los sistemas de tratamiento térmico por microondas generalmente pueden ser puestos en marcha en cuestión de minutos, ya que no necesitan acondicionar térmicamente grandes estructuras. Esto permite ajustar el volumen de producción en planta, de manera mucho más flexible.

Otra ventaja añadida es que, en general, permite un ahorro de espacio en las plantas de producción frente a otras tecnologías, ya que al ser el tratamiento térmico más rápido se necesita una menor longitud del sistema. Este es un factor económico de alto impacto en la industria. 
Además, el control del proceso se realiza completamente de forma electrónica, mientras que por ejemplo los sistemas basados en combustión necesitan una regulación de otro tipo; y también frente a estos últimos, sobre todo los basados en la combustión de gas, presenta menores costes de implantación y mantenimiento.

En resumen, las ventajas más significativas del uso de microondas serían:

$\checkmark$ Calentamiento volumétrico y selectivo frente al calentamiento superficial de los métodos tradicionales, lo cual le confiere rapidez y adaptabilidad a diferentes necesidades industriales.

$\checkmark$ Método limpio (no genera emisiones) y que conlleva un ahorro de energía entre el $25 \%$ y $75 \%$.

$\checkmark$ Sistema limpio y libre de contaminaciones.

$\checkmark$ Aplicaciones versátiles.

\subsection{Limitaciones en la aplicación de la tecnología microondas}

El uso de energía de microondas, es una tecnología madura en muchos aspectos, pero su implantación en muchos sectores todavía no es tan importante como podría esperarse de sus muchas ventajas competitivas. Existen varias razones para ello.

- En primer lugar, el diseño de sistemas de calentamiento por microondas es un problema complejo y que en muchos casos requiere el dominio de varios campos de conocimiento diferentes (problema multidisciplinar).

- Los mecanismos de funcionamiento del calentamiento dieléctrico, son poco conocidos en el ámbito industrial, lo que muchas veces produce un efecto de rechazo sobre una tecnología que no se comprende bien. 
- Las aplicaciones de procesado por microondas generalmente requieren de un diseño 'a medida' para cada proceso industrial, lo que limita enormemente la reutilización de equipos y diseños de unos procesos a otros. Por ello, los fabricantes de bienes de equipo, necesitan contar con especialistas en el diseño de sistemas de microondas para cada nueva aplicación. En ocasiones, se intenta utilizar un equipo en una aplicación diferente para la que fue diseñado, lo que generalmente conduce al fracaso y produce la idea generalmente equivocada de que 'las microondas no sirven para esta aplicación.

A pesar de las dificultades que presenta el uso de la tecnología de microondas, sus ventajas son muy importantes, por lo que existe durante los últimos años un gran interés en varios sectores por la utilización de la energía de microondas. Por poner únicamente un ejemplo, el sector cerámico está buscando en la actualidad alternativas a los mecanismos tradicionales de fabricación de cerámicas, y la energía de microondas se ha propuesto como una de las mejores soluciones en varios de los procesos implicados.

\subsection{Procedimiento de diseño de aplicadores microondas. Aplicadores monomodo vs multimodo}

Cuando se aborda el diseño de un sistema de procesado de materiales por microondas, la primera y generalmente más importante cuestión que surge es el tipo de aplicador más indicado para el proceso.

Los aplicadores microondas son estructuras, en su mayor parte metálicas, que confinan la energía microondas en el volumen donde se ubica el material que se desea procesar. Estas estructuras se suelen subdividir en dos grupos básicos: aplicadores multimodo y aplicadores monomodo.

De una forma genérica podríamos decir que los dispositivos usados en calentamiento con microondas constan de tres etapas principales: generación, propagación y aplicación de las microondas [5]. Aunque existen varios dispositivos para generar microondas, el más usado en calentamiento con microondas es, con diferencia, el magnetrón. 
Además, la mayoría de los magnetrones comerciales trabajan a dos tipos de frecuencia $915 \mathrm{MHz}$, usados en aplicaciones industriales donde se requiere calentar volúmenes grandes y $2.450 \mathrm{MHz}$, de uso generalizado en hornos domésticos e industriales. Algunas de las características de estos dos tipos de magnetrones se resumen a continuación:

- Un solo magnetrón de $915 \mathrm{MHz}$ puede proporcionar hasta $100 \mathrm{KW}$, mientras que la potencia máxima de los magnetrones comerciales de $2.450 \mathrm{MHz}$ es de $30 \mathrm{KW}$.

- La eficiencia en lo que se refiere a la conversión de energía eléctrica en calor puede llegar hasta un $80 \%$ en el caso de $915 \mathrm{MHz}$ frente al $55-70 \%$ que, como máximo, puede obtenerse usando magnetrones de 2,450 MHz. Lo cual se traduce en unos menores costes de funcionamiento.

- La profundidad de penetración de la energía de microondas a $915 \mathrm{MHz}$ es aproximadamente tres veces más grande que a $2.450 \mathrm{MHz}$.

- Los magnetrones de estas frecuencias, con potencias bajas, desarrollados a partir de la proliferación de los hornos de microondas domésticos, son muy baratos y fácilmente disponibles. Esto hace que sean ideales para su uso en investigación y desarrollo.

- El tamaño de los magnetrones y guías de onda para un sistema de $2.450 \mathrm{MHz}$ es considerablemente más pequeño que los utilizados en unidades de $915 \mathrm{MHz}$. Esto hace que sean adecuadas para instalaciones de pequeña escala. Aunque las microondas pueden trasmitirse en el espacio libre o usando cables coaxiales, la forma más habitual de conducir las microondas desde el generador hasta el lugar donde se quieren aplicar son las guías de onda. Las guías de ondas son tubos metálicos, generalmente de sección rectangular, aunque son posibles otras geometrías. Las paredes conductoras del tubo confinan las microondas en el interior, de esta forma las pérdidas de potencia por el material metálico de la guía o por el aire que rellena la guía son muy bajas. Cuando la guía de ondas tiene unas dimensiones apropiadas, las microondas se desplazan en su interior por 
sucesivas reflexiones en las paredes. La aplicación de las microondas al material a calentar, tiene lugar en una cavidad microondas que, por lo general, es una estructura metálica cerrada, o cerrada en su mayoría, que confina en su interior el campo electromagnético. Este tipo de cavidades suelen ser resonantes; es decir, la geometría es tal que refuerza las ondas de una determinada frecuencia incrementando su intensidad. Un símil podría ser una campana o el cuerpo de una guitarra en el que los sonidos se refuerzan por resonancias.

Por otro lado, las cavidades pueden ser monomodo o multimodo [7]. En las primeras se busca la interferencia constructiva de las microondas, de una única frecuencia, produciendo un patrón de ondas estacionarias, formadas por la interferencia de dos ondas que avanzan en sentidos opuestos. En las ondas estacionarias existen ciertos puntos que no vibran (nodos) y que permanecen inmóviles o estacionarios; mientras que otros (vientres o antinodos) lo hacen con una amplitud de vibración máxima e igual al doble de la de las ondas que interfieren, y con una energía máxima.

En el caso de las cavidades multimodo, se busca, por el contrario, generar un campo de microondas homogéneo en todas las direcciones y en todos los lugares de la cavidad. En cualquiera de los dos casos, el diseño de la geometría de la cavidad es determinante para que el calentamiento se produzca de una forma eficaz. Además, la presencia del material a calentar puede producir modificaciones en el campo eléctrico, por lo que las cavidades monomodo son mucho más sensibles a la posición, tamaño y geometría del material a calentar que las multimodo.

Debido a esto, las cavidades multimodo, aunque menos eficientes para el calentamiento, son mucho más fáciles de escalar que las monomodo. En la Figura 3.2 se muestra de forma esquemática ambos tipos de cavidades. 


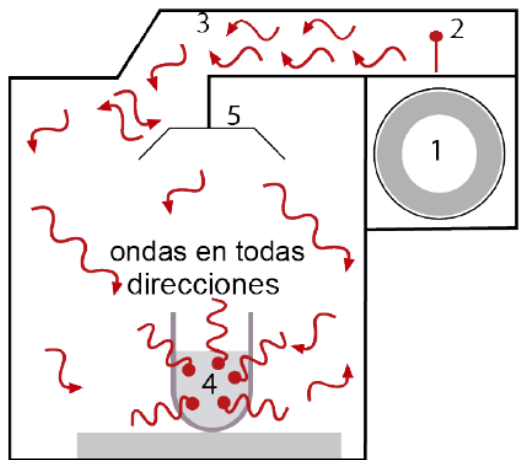

cavidad multimodo

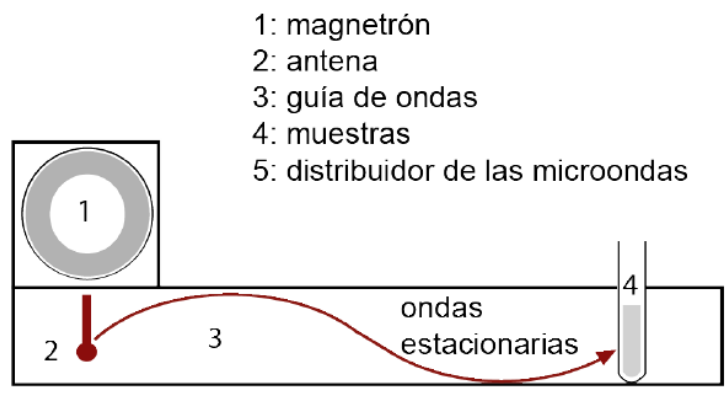

cavidad monomodo

Figura 3.2. Esquemas de un horno de microondas multimodo y un horno de microondas monomodo. [7]

Los aplicadores multimodo son estructuras metálicas (no tienen por qué ser resonantes) de un tamaño considerablemente superior a la longitud de onda, y que presentan en su interior múltiples zonas de máximos y mínimos de campo eléctrico. Estos patrones de campo eléctrico están generados por interferencia entre los múltiples modos presentes en su interior. El ejemplo más conocido es el horno microondas doméstico, como el mostrado en la figura 3.3.

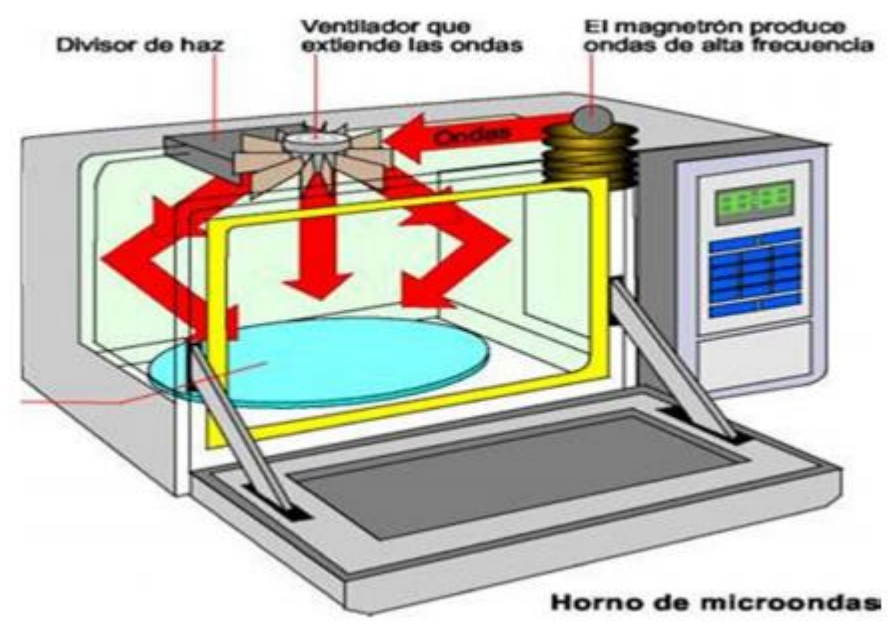

Figura 3.3 Horno Doméstico como ejemplo de aplicador multimodo.

Como ventajas más evidentes de este tipo de aplicadores, podemos mencionar que son sistemas polivalentes, al ser menos sensibles a las propiedades del material en su interior. También es importante indicar que permiten procesar tamaños de muestra 
generalmente más grandes que otros tipos de aplicadores. Son más sencillos de diseñar ya que, como se ha mencionado, su respuesta es menos dependiente del material que se introduce en su interior o a pequeñas variaciones en sus dimensiones.

En cambio, la principal desventaja que presenta este tipo de aplicadores es la escasa uniformidad de campo eléctrico debido a la existencia de múltiples zonas de máximos y mínimos de campo. Teniendo en cuenta el material, no suele ser posible encontrar soluciones analíticas sencillas para los campos en estas estructuras y en este caso las soluciones numéricas solamente son aproximadas. Otra importante desventaja es la dificultad de controlar de forma precisa la energía absorbida sobre el material, ya que generalmente es complicado mantener a lo largo del proceso una eficiencia energética elevada, debido a los efectos de desadaptación de impedancias.

Se denominan aplicadores monomodo aquellas estructuras cerradas de microondas donde solamente se excita (o se propaga) un modo electromagnético. Generalmente son estructuras de tamaño comparable a la longitud de onda. Como ventajas se puede decir que en ellas se puede calcular de manera más precisa, incluso por técnicas analíticas, la distribución de campo eléctrico en la estructura e incluso el material, y por tanto es posible ubicar la muestra donde sea interesante, que generalmente es donde el campo eléctrico es máximo y presenta un patrón más uniforme.

Como desventaja principal se debe mencionar la limitación importante en el tamaño del material que puede ser tratado. Otra desventaja es la necesidad de utilizar sistemas de ajuste, especialmente de sintonización, ya que incluso una pequeña variación en las propiedades de la muestra a lo largo de su procesado producirá una variación en la frecuencia de trabajo del aplicador (cambios de la frecuencia de resonancia si el aplicador es una cavidad resonante). [8].

\subsection{Conceptos básicos de diseño de cavidades microondas multimodo}

Las microondas se pueden definir como la parte del espectro electromagnético comprendida entre $300 \mathrm{MHz}$ y $300 \mathrm{GHz}$ o, en términos de longitudes de onda, la banda 
del espectro cuyas longitudes de onda se encuentran entre $1 \mathrm{~mm}$ y $1 \mathrm{~m}$. Su origen se remonta a la predicción matemática de Maxwell sobre la existencia y comportamiento de las ondas de radio (trabajando sobre las hipótesis de Faraday), predicción verificada experimentalmente por Hertz.

Es, precisamente, su característica de generación de calor la que permite utilizar las microondas en aplicaciones diferentes a las comunicaciones, estas aplicaciones abarcan sectores como la industria, la agricultura y la medicina. También es aplicada en temas de secado, desinsectación o métodos de cura de enfermedades.

Este tipo de energía tiene dos ventajas sobre los medios convencionales de calentamiento:

- La energía de microondas constituye una fuente de calor volumétrica, esto es, el calor se genera en todo punto del volumen del material que se va a calentar, dependiendo de la amplitud del campo eléctrico en cada punto y de las propiedades dieléctricas de material procesado.

- La generación de calor a partir de la energía de microondas es selectiva, esto es, se genera más calor en aquellas zonas del material que son capaces de absorber más energía del campo eléctrico y transformarla en energía térmica. En particular, la generación de calor por microondas es significativamente alta en medios con alto contenido en agua, como es el caso de los materiales que se procesan en este trabajo de investigación.

El calentamiento con microondas es un proceso muy complejo, ya que depende tanto de las propiedades térmicas del mismo como de la distribución de la energía de microondas absorbida. La energía absorbida depende de varios factores como pueden ser: el volumen, el área, la forma, el tamaño, las propiedades (térmicas y dieléctricas), la densidad y el cambio de temperatura. 
La explicación física para la generación del calor mediante microondas se basa en que las ondas penetran en los materiales generando un efecto de polarización sobre las moléculas polares. Posteriormente, éstas tratan de alinearse con el campo que está cambiando constantemente de orientación y por tanto la energía electromagnética perdida en ese trabajo se transforma en el movimiento de dichas moléculas $y$, a su vez, este movimiento se manifiesta en forma de calor. Sus propiedades y aplicaciones son variadas [9].

En cuanto a su interacción con la materia, cuando una onda incide sobre un material a la frecuencia de resonancia de éste, el material absorbe energía de la onda. Estas frecuencias dependen de la composición molecular del material y, por tanto, esta capacidad de interacción onda-materia, da lugar a aplicaciones de las microondas como el calentamiento o la detección y análisis de materiales. Para entender esto, hay que considerar el concepto de radiación no ionizante. La energía de un fotón es proporcional a la frecuencia de radiación:

$$
\left.\mathrm{E}=\mathrm{h} \cdot \mathrm{f} \text {, (donde } h \text { es la constante de Planck }=6,63 \cdot 10^{-34} \mathrm{~J} \cdot \mathrm{s}\right)
$$

A frecuencias de microondas, los fotones no cuentan con la energía suficiente para romper un enlace químico y, por tanto, ionizar un material. Sí son ionizantes las radiaciones por encima del espectro visible, como los rayos $\mathrm{X}$ o los rayos $\mathrm{Y}$.

\subsubsection{Generación de calor por microondas}

Es sabido que los campos electromagnéticos pueden propagarse a través de cualquier medio dieléctrico o magnético siguiendo las leyes de Maxwell:

$$
\begin{gathered}
\nabla x \vec{E}=-\frac{\partial \vec{B}}{\partial t} \\
\nabla \cdot \vec{D}=\rho
\end{gathered}
$$




$$
\begin{gathered}
\nabla \cdot \vec{B}=\partial \vec{D} \\
\nabla x \vec{H}=\vec{J}+\frac{\partial \vec{D}}{\partial t}
\end{gathered}
$$

donde $\vec{E}$ es el vector intensidad de campo eléctrico, $\vec{D}$ es el desplazamiento eléctrico, $\vec{B}$ es la intensidad de campo magnético, $\vec{H}$ es la densidad de carga volumétrica y $\vec{J}$ es la densidad superficial de corriente.

Será necesario recordar las ecuaciones constitutivas, que para materiales lineales e isotrópicos se formulan según:

$$
\begin{aligned}
& \vec{D}=\varepsilon \vec{E} \\
& \vec{B}=\mu \vec{H}
\end{aligned}
$$

donde $\varepsilon$ es la permitividad compleja del medio dieléctrico y $\mu$ su permeabilidad compleja, parámetros estos de vital importancia.

Y si deseáramos obtener la potencia de microondas que absorbe un material dieléctrico durante un proceso de calentamiento, se deriva la potencia que fluye a través de una superficie cerrada, a través de la integración del vector de Poynting:

$$
\vec{S}=\vec{E} \times \vec{H}
$$

En este caso el término de calentamiento volumétrico generado por microondas se expresa como:

$$
Q_{g e n}=2 \pi f \varepsilon_{o} \varepsilon^{\prime \prime}\left|\vec{E}_{r m s}\right|^{2}
$$

donde $Q_{g e n}\left(\mathrm{~W} / \mathrm{m}^{3}\right)$ representa el calor volumétrico generado por la energía de microondas, $f$ la frecuencia expresada en $\mathrm{Hz}$ y $\vec{E}_{r m s}$ el campo eléctrico que viene dado según su valor eficaz en esta expresión. 
La intensidad de campo eléctrico a lo largo del cuerpo tampoco tiene por qué ser constante. Por lo tanto, la generación de calor puede ser muy distinta de un punto a otro del cuerpo en función del diseño del horno.

\subsubsection{Factores del calentamiento por microondas}

Las propiedades que determinan si un material se puede calentar con éxito mediante energía de microondas son sus propiedades dieléctricas, tales como: la constante dieléctrica relativa $\left(\varepsilon^{\prime}\right)$, tangente de pérdida o factor de disipación (tan $\delta$ ) y el factor de pérdida $\left(\varepsilon^{\prime \prime}\right)$ [10]. Por ello, el calentamiento con energía microondas resulta más útil y atractivo para los materiales que presentan excelentes propiedades dieléctricas. Estos materiales deben ser capaces de absorber la energía microondas y convertirla en calor, de una forma muy eficiente. El mecanismo y la dirección de la transferencia de calor del calentamiento con energía microondas, difieren de forma significativa respecto a los métodos de calentamiento convencionales, con los que tradicionalmente se realiza este proceso. En los métodos convencionales de calentamiento, el material se calienta mediante una fuente externa de calor (desde el exterior del material a calentar), y el calor se transmite desde la superficie exterior del material hacia su interior, como ya se ha comentado anteriormente.

Por ello, estos métodos dependen del lento proceso de esta transferencia de calor. Este proceso es controlado por la diferencia de temperatura existente, entre la temperatura de la superficie externa del material (de mayor temperatura) y la temperatura en su interior (de más baja temperatura). Por el contrario, el calentamiento por microondas se basa en la rápida polarización y despolarización de grupos cargados cuando el material se somete a un campo de microondas, lo que resulta en una generación de calor simultánea en su interior. Por ello, el calentamiento con energía microondas es un calentamiento volumétrico, en el que el campo electromagnético interactúa con el material, como un todo.

El calentamiento en volumen es directamente proporcional a la frecuencia usada. Lo que implica que, utilizando una potencia radiada constante dentro del horno de microondas, 
el calentamiento será mayor cuanto mayor sea la frecuencia. De esto se deduciría que la mejor opción sería entonces subir en frecuencia, al máximo que permitiese la tecnología, pero hay que tener en cuenta que a mayor frecuencia la penetración de la energía electromagnética es menor y que por tanto el calentamiento se vuelve más superficial. Así, cuando los materiales adquieren un grosor considerable, puede ser conveniente usar frecuencias menores para poder calentarlo de forma más uniforme.

Por último, hay que tener en cuenta que los sistemas de microondas no pueden usar las frecuencias que deseen, sino que deben restringirse a las frecuencias permitidas por los gobiernos para este tipo de equipos, que para uso industrial, científico y médico son 2,45GHz y $915 \mathrm{MHz}$.

Por su parte la capacidad del material dieléctrico de absorber energía de microondas, viene determinada por el factor de pérdidas, por lo que cuanto mayor sea el factor de pérdidas de un material mayor absorción de microondas se producirá. Hay que resaltar que el factor de pérdidas no tiene porqué ser constante a lo largo del cuerpo irradiado, ya que existen materiales heterogéneos cuya distribución de permitividades no es constante a lo largo del espacio. Tampoco tiene por qué ser constante la temperatura a lo largo del cuerpo y dado que el factor de pérdidas es muy sensible a la composición química y a la temperatura del cuerpo en general no será constante dentro del mismo.

La proporcionalidad del calentamiento por microondas es el cuadrado del módulo del campo eléctrico, lo que implica que cuanto mayor sea el campo eléctrico en un punto del material, mayor será su subida de temperatura. En general, interesará que la distribución de campo eléctrico sea lo más uniforme posible en el material para que el calentamiento sea también uniforme a lo largo del mismo. Cuando esto no sucede así, puede ocurrir que partes del cuerpo se calienten en exceso mientras que otras partes se mantienen frías o a menor temperatura. Se habla en este caso de 'hot spots' y 'cold spots' respectivamente.

También hay que tener presentes, que la conductividad térmica, el calor específico y 
la densidad del material afectarán a la evolución de la temperatura en el interior del cuerpo, aunque no tiene influencia sobre cómo se genera el calor por microondas.

\subsubsection{Estudio predictivo con ondas planas}

Las ondas monodimensionales, son ondas de frecuencia constante, cuyos frentes de onda (superficies con fase constante) son planos paralelos de amplitud constante normales al vector velocidad de fase. Es decir, son aquellas ondas que se propagan en una sola dirección a lo largo del espacio, como por ejemplo las ondas en los muelles o en las cuerdas. Si la onda se propaga en una dirección única, sus frentes de ondas son planos y paralelos.

La capacidad predictiva de estas, nos ayudará a predecir cómo se calentará un material, siendo de vital importancia poder calcular el campo eléctrico en el material; su estudio nos puede dar una idea bastante clara de cómo se propaga la energía electromagnética en un dieléctrico. Si se parten de las Leyes de Maxwell, se puede llegar a la conocida ecuación de onda de Helmholtz:

$$
\nabla^{2} \vec{E}+k^{2} \vec{E}=0
$$

donde $k$ es el número de onda del medio de propagación considerado. Resolviendo esta ecuación por separación de variables, para cada una de las componentes del espacio $(x, y, z)$, se puede demostrar que la solución del campo eléctrico para cada una de las componentes toma la forma:

$$
\begin{aligned}
& E_{x}=A_{x} e^{-j k_{x} x}+B_{x} e^{j k_{x} x} \\
& E_{y}=A_{y} e^{-j k_{y} y}+B_{y} e^{j k_{y} y} \\
& E_{z}=A_{z} e^{-j k_{z} z}+B_{z} e^{j k_{z} z}
\end{aligned}
$$

donde las constantes son, generalmente, complejas y $\vec{k}=k_{x} \hat{x}+k_{y} \hat{y}+k_{z} \hat{z}$ es el vector de onda. 
La distancia mínima entre planos de cada fase viene dada por la denominada longitud de onda ():

$$
\lambda=\frac{2 \pi}{k}=\frac{2 \pi}{\omega \sqrt{\mu \varepsilon}}=\frac{1}{f \sqrt{\mu \varepsilon}}
$$

donde $\omega$ es la frecuencia angular de la onda, $\mu$ es la permeabilidad magnética del medio y $\varepsilon$ es su permitividad eléctrica. Dado que son medios sin pérdidas, tanto $\mu$ como $\varepsilon$ serán reales.

En la Figura 3., podemos observar la evolución espacial del campo para diferentes instantes. Puede observarse que la amplitud del campo decrece exponencialmente a medida en que avanzamos en la dirección de propagación (en este caso z).

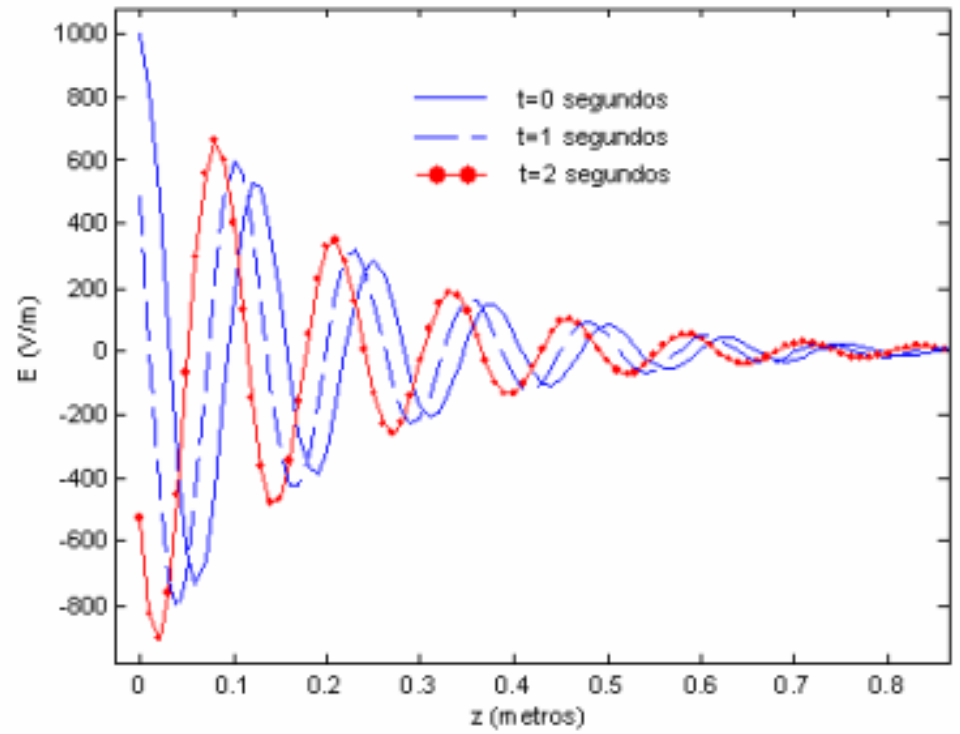

Figura 3.1. Evolución temporal y espacial para una onda plana en un dieléctrico con pérdidas [9]

Por otro lado, las constantes de propagación y atenuación se definen como:

$$
\alpha=\omega \sqrt{\mu \varepsilon^{\prime}}\left[\frac{\sqrt{1+\left(\frac{\varepsilon^{\prime \prime}}{\varepsilon^{\prime}}\right)^{2}}-1}{2}\right]^{\frac{1}{2}}
$$




$$
\beta=\omega \sqrt{\mu \varepsilon^{\prime}}\left[\frac{1+\sqrt{1+\left(\frac{\varepsilon^{\prime \prime}}{\varepsilon^{\prime}}\right)^{2}}}{2}\right]^{\frac{1}{2}}
$$

siendo la relación entre el factor de pérdidas y la constante dieléctrica, denominada tangente de pérdidas:

$$
\tan (\delta)=\left(\frac{\varepsilon^{\prime \prime}}{\varepsilon^{\prime}}\right)
$$

Del estudio de las ecuaciones anteriores se deduce:

1. La atenuación aumenta proporcionalmente con la frecuencia.

2. La atenuación aumente proporcionalmente con el factor de pérdidas.

3. La atenuación es proporcional a la permeabilidad del material.

Si el dieléctrico presenta pérdidas, la onda plana disminuye su energía al propagarse, y esta pérdida de energía, es transformada en el cuerpo en forma de calor. Es decir, a medida que la onda se propaga, cede energía al cuerpo, que la transforma en calor y aumenta su temperatura. Por lo tanto, cuando una onda plana se propaga a través de un dieléctrico con pérdidas, las zonas interiores del cuerpo recibirán menos calor que las exteriores, siempre que no existan fenómenos de interferencia debidos a reflexiones del entorno.

Otra cuestión importante es qué ocurre cuando las pérdidas dieléctricas aumentan en el cuerpo. 
Figura 3.1, muestra qué ocurre para diferentes coeficientes de atenuación. Se puede apreciar que a mayor $\alpha$, la atenuación de la onda es también mayor y por lo tanto, las zonas interiores reciben menos campo eléctrico, por lo que, a mayores pérdidas dieléctricas, más se calentará el exterior del cuerpo en comparación con el interior del mismo.

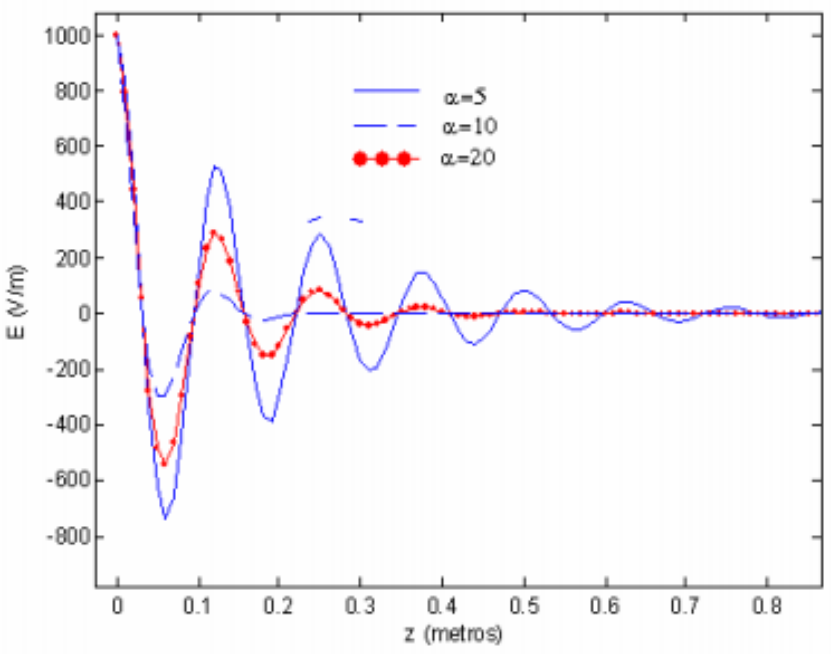

Figura 3.1 Distribución de campo eléctrico en un dieléctrico con pérdidas para distintas atenuaciones [9]

Por último, resulta interesante señalar que cuando el coeficiente de propagación, $\beta$, aumenta en el cuerpo, las oscilaciones del campo eléctrico dentro del cuerpo también aumentan, aunque sin embargo, las pérdidas de la onda plana se mantienen iguales en todos los casos. Es decir, $\beta$, tiene relación con la longitud de onda dentro del material, pero no influye en la pérdida de potencia, de modo que, cuanto mayor sea la constante dieléctrica del material, menor será su longitud de onda, lo que conllevará a un acercamiento de máximos y mínimos dentro del cuerpo. Como muestra la Figura 3.3. 


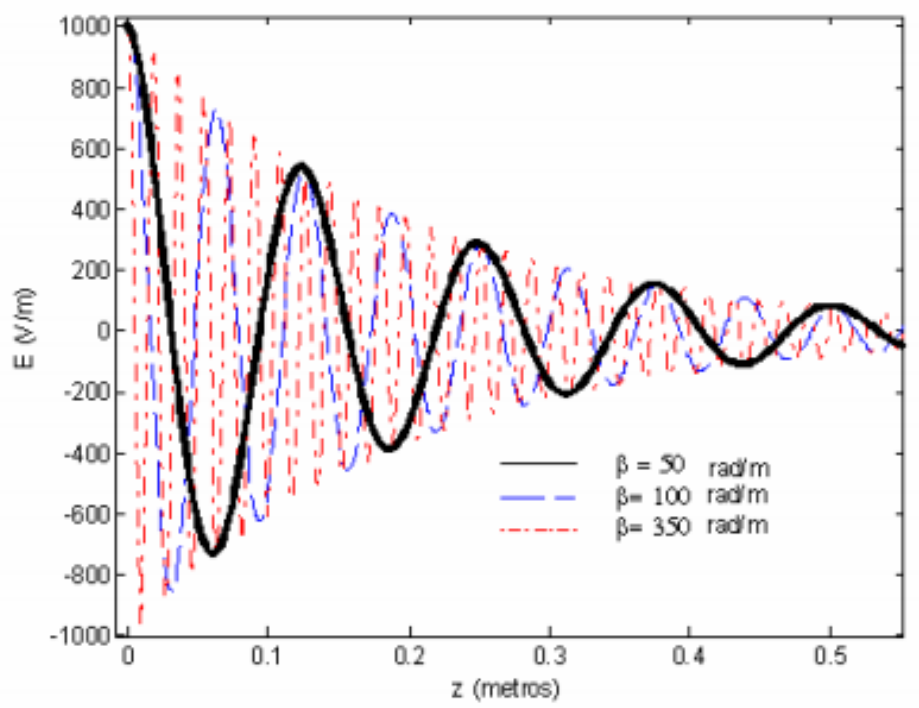

Figura 3.2. Campo eléctrico en un dieléctrico con pérdidas para distintas constantes de fase. [9]

\subsubsection{Permitividad relativa compleja: constante dieléctrica y factor de pérdidas}

El comportamiento de un cuerpo dieléctrico frente a un campo electromagnético es descrito a través de la magnitud, permitividad compleja, definida como:

$$
\varepsilon_{r}=\varepsilon^{*}=\varepsilon^{\prime}-j \varepsilon^{\prime \prime}
$$

siendo $\varepsilon^{\prime}$ es la denominada constante dieléctrica y $\varepsilon^{\prime \prime}$ es el llamado factor de pérdidas.

El factor de pérdidas indica, la capacidad del material para disipar la energía de microondas en forma de calor, mientras que la constante dieléctrica indica la manera en la que la energía se almacenará o distribuirá en el seno del material dieléctrico.

Existen dos mecanismos de polarización básicos: el electrónico (movimiento de los electrones alrededor de su núcleo) asociado a la conductividad del material y el molecular (distribuciones de carga en los átomos y moléculas no uniforme). La interacción de un campo eléctrico con un dieléctrico tiene su origen en la respuesta de las partículas con carga frente a dicho campo. De hecho, ante el campo eléctrico las partículas se moverán a partir de su posición de equilibrio. 
El mecanismo de polarización, a su vez, puede tener tres orígenes:

- Polarización inducida debida al desplazamiento del núcleo frente al electrón

- Polarización permanente que se produce porque los dieléctricos contienen moléculas polares, con una distribución de carga asimétrica (agua)

- Polarización en las interfaces de diferentes dieléctricos en contacto (carga superficial o mecanismos de Maxwell-Wagner)

\subsubsection{Comportamiento en frecuencia de la permitividad: la ecuación de Debye}

En este aparatado nos centraremos en la respuesta dieléctrica de relajación de una población ideal de dipolos, que no interactúan unos con otros cuando están sometidos a un campo alterno externo (Modelo de Debye). La caracterización frecuencial de la rotación de las moléculas dipolares se lleva a cabo, a partir de la rotación de un dipolo esférico que está en un medio viscoso. Este modelo se relaciona con los tipos de materiales, utilizados en esta tesis; que se definirán en capítulos posteriores. Así Debye llegó a la conclusión para electrolitos de que la dependencia de la permitividad con la frecuencia seguía la forma:

$$
\varepsilon^{*}(\omega)=\varepsilon_{\infty}+\frac{\varepsilon_{s}-\varepsilon_{\infty}}{1+j \omega \tau}
$$

donde $\varepsilon_{S}$ y $\varepsilon_{\infty}$ son las constantes dieléctricas a corriente continua y a muy altas frecuencias y $\tau$ es el llamado tiempo de relajación del sistema que controla el mecanismo de polarización. Separando la parte real e imaginaria para la permitividad se obtiene:

$$
\begin{gathered}
\varepsilon^{\prime}(\omega)=\varepsilon_{\infty}+\frac{\varepsilon_{s}-\varepsilon_{\infty}}{1+\omega^{2} \tau^{2}} \\
\varepsilon^{\prime \prime}(\omega)=\frac{\left(\varepsilon_{s}-\varepsilon_{\infty}\right) \omega \tau}{1+\omega^{2} \tau^{2}}
\end{gathered}
$$


Interpretando estas fórmulas podemos ver que, a baja frecuencia, los dipolos tienen bastante tiempo para seguir las variaciones de campo eléctrico, por lo que el factor de pérdidas es muy pequeño. Por otra parte, la constante dieléctrica toma su máximo valor, porque la carga ligada toma su máximo valor, y toda la energía consigue almacenarse.

Si la frecuencia aumenta los dipolos son incapaces de seguir los cambios del campo eléctrico por lo que no pueden volver a su posición original. Así el vector de polarización va por detrás del campo eléctrico y se llega a alcanzar un punto en el que el dipolo no puede realinearse, contribuyendo menos a la polarización total. Esto hace que la constante dieléctrica total decrezca y que las pérdidas suban, lo cual indica que el material disipará energía en forma de calor.

Esta pérdida de energía en el material a favor del calentamiento es explicada por Debye mediante la introducción de una fricción entre los dipolos y el medio que lo rodea. De hecho, a partir de esta suposición el tiempo de relajación lo halló, en función de la viscosidad del medio $\left(n_{v}\right)$, el radio del dipolo $(r)$, la constante de Boltzmann $(K)$ y la temperatura $(T)$ :

$$
\tau=\frac{4 \pi r^{3} n_{v}}{K T}
$$

\subsubsection{Conducta de la permitividad ante materiales húmedos}

La caracterización de la permitividad en función del contenido de humedad resulta fundamental para el diseño de los dispositivos de secado asistido por microondas. En general, se debe indicar que a mayor contenido de agua mayor constante dieléctrica y mayor factor de pérdidas.

Si queremos caracterizar la cantidad de agua presente en un cuerpo frente a su masa seca (sin agua), se utiliza el contenido de humedad en base seca: 


$$
X=\frac{m-m_{s}}{m_{s}}
$$

donde $X$ es el contenido de humedad en base seca, $m$ la masa total del cuerpo en un instante determinado del proceso de deshidratación y $m_{s}$ es la masa de la matriz sólida de este mismo cuerpo.

Normalmente se puede representar tanto el factor de pérdidas como la constante dieléctrica con una relación cuadrática tal y como se muestra en la ecuación:

$$
\varepsilon^{\prime \prime}=\varepsilon_{o}^{\prime \prime}+A X+B X^{2}
$$

donde $A, B$ y $\varepsilon_{o}{ }^{\prime \prime}$ son constantes que ajustan el comportamiento experimental medido.

\subsubsection{Conducta de la permitividad con la temperatura}

Está demostrada a través de infinidad de estudios la dependencia de la permitividad con la temperatura en alimentos, agua, madera, etc. [11]. Por ejemplo, para dos tipos distintos de tejido textil, al aumentar la temperatura aumenta también el factor de pérdidas y su constante dieléctrica.

Sin embargo, otro tipo de materiales presentan un comportamiento contrario. Por ejemplo, ciertos cauchos como el SBR en el rango de temperaturas de 30 a $120{ }^{\circ} \mathrm{C}$ o ciertas mezclas de polietileno y carbón presentan una disminución de la constante dieléctrica y el factor de pérdidas con la temperatura [12]. Además, para cada material existe una temperatura crítica, a la cual el material experimenta un cambio en sus propiedades dieléctricas muy acusado frente a la temperatura.

\subsubsection{Mecanismos de transferencia de calor}

La temperatura es una magnitud física que se refiere a la sensación de frío o caliente al tocar alguna sustancia. En cambio, el calor es una transferencia de energía de una parte 
a otra de un cuerpo, o entre diferentes cuerpos, producida por una diferencia de temperatura. El calor es energía en tránsito; siempre fluye de una zona de mayor temperatura a otra de menor temperatura, con lo que eleva la temperatura de la zona más fría y reduce la de la zona más cálida, siempre que el volumen de los cuerpos se mantenga constante. La energía no fluye desde un objeto de temperatura baja a otro de temperatura alta si no se realiza trabajo. La materia está formada por átomos o moléculas que están en constante movimiento, por lo tanto, tienen energía de posición o potencial y energía de movimiento o cinética. Los continuos choques entre los átomos o moléculas transforman parte de la energía cinética en calor, cambiando la temperatura del cuerpo.

Cuando dos cuerpos que tienen distintas temperaturas se ponen en contacto entre sí, se produce una transferencia de calor desde el cuerpo de mayor temperatura al de menor temperatura. La transferencia de calor se puede realizar por tres mecanismos físicos: conducción, convección y radiación.

\subsubsection{Conducción de calor}

La conducción es el mecanismo de transferencia de calor en escala atómica a través de la materia por actividad molecular, por el choque de unas moléculas con otras, donde las partículas más energéticas le entregan energía a las menos energéticas, produciéndose un flujo de calor desde las temperaturas más altas a las más bajas. Los mejores conductores de calor son los metales. El aire es un mal conductor del calor. Los objetos malos conductores como el aire o plásticos se llaman aislantes. La conducción de calor sólo ocurre si hay diferencias de temperatura entre dos partes del medio conductor. Para un volumen de espesor $\Delta x$, con área de sección transversal A y cuyas caras opuestas se encuentran a diferentes $\mathrm{T} 1$ y $\mathrm{T} 2$, con $\mathrm{T} 2>\mathrm{T} 1$, como se muestra en la figura 2 , se encuentra que el calor $\Delta Q$ transferido en un tiempo $\Delta t$ fluye del extremo caliente al frío. Si se llama $H$ (en Watts) al calor transferido por unidad de tiempo, la rapidez de transferencia de calor $H=\Delta Q / \Delta t$, está dada por la ley de la conducción de calor de Fourier. 


$$
\mathrm{dq} / \mathrm{dt}=-\mathrm{kAdT} / \mathrm{dz}
$$

donde $\mathrm{k}$ (en $\mathrm{W} / \mathrm{mK}$ ) se llama conductividad térmica del material, magnitud que representa la capacidad con la cual la sustancia conduce calor y produce la consiguiente variación de temperatura; y dT/dx es el gradiente de temperatura. El signo menos indica que la conducción de calor es en la dirección decreciente de la temperatura.

\subsubsection{Convección}

La convección es el mecanismo de transferencia de calor por movimiento de masa o circulación dentro de la sustancia. Puede ser natural producida solo por las diferencias de densidades de la materia; o forzada, cuando la materia es obligada a moverse de un lugar a otro, por ejemplo, el aire con un ventilador o el agua con una bomba. Sólo se produce en líquidos y gases donde los átomos y moléculas son libres de moverse en el medio. En la naturaleza, la mayor parte del calor ganado por la atmósfera por conducción y radiación cerca de la superficie, es transportado a otras capas o niveles de la atmósfera por convección. Un modelo de transferencia de calor $\mathrm{H}$ por convección, llamado ley de enfriamiento de Newton, es el siguiente:

$$
H=h \cdot A\left(T_{A}-T\right)
$$

donde $h$ es el coeficiente de convección, en $\mathrm{W} /\left(\mathrm{m}^{2} \mathrm{~K}\right), A$ es la superficie que entrega calor con una temperatura $T_{A}$ al fluido adyacente, que se encuentra a una temperatura $T$.

El flujo de calor por convección es positivo $(H>0)$ si el calor se transfiere desde la superficie de área $A$ al fluido $\left(T_{A}>T\right)$ y negativo si el calor se transfiere desde el fluido hacia la superficie $\left(T_{A}<T\right)$.

\subsubsection{Radiación}

La radiación térmica es energía emitida por la materia que se encuentra a una temperatura 
dada, se produce directamente desde la fuente hacia afuera en todas las direcciones. Esta energía es producida por los cambios en las configuraciones electrónicas de los átomos o moléculas constitutivos y transportada por ondas electromagnéticas o fotones, por lo recibe el nombre de radiación electromagnética. La masa en reposo de un fotón (que significa luz) es idénticamente nula. Por lo tanto, atendiendo a relatividad especial, un fotón viaja a la velocidad de la luz y no se puede mantener en reposo. (La trayectoria descrita por un fotón se llama rayo). La radiación electromagnética es una combinación de campos eléctricos y magnéticos oscilantes y perpendiculares entre sí, que se propagan a través del espacio transportando energía de un lugar a otro.

A diferencia de la conducción y la convección, o de otros tipos de onda, como el sonido, que necesitan un medio material para propagarse, la radiación electromagnética es independiente de la materia para su propagación, de hecho, la transferencia de energía por radiación es más efectiva en el vacío. Sin embargo, la velocidad, intensidad y dirección de su flujo de energía se ven influidos por la presencia de materia. Así, estas ondas pueden atravesar el espacio interplanetario e interestelar y llegar a la Tierra desde el Sol y las estrellas. La longitud de onda $(\lambda)$ y la frecuencia $(v)$ de las ondas electromagnéticas, relacionadas mediante la expresión $\lambda v=c$, son importantes para determinar su energía, su visibilidad, su poder de penetración y otras características. Independientemente de su frecuencia y longitud de onda, todas las ondas electromagnéticas se desplazan en el vacío con una rapidez constante $c=299792 \mathrm{~km} / \mathrm{s}$, llamada velocidad de la luz.

Los fotones son emitidos o absorbidos por la materia. La longitud de onda de la radiación está relacionada con la energía de los fotones, por una ecuación desarrollada por Planck:

$$
E=h_{c} / \lambda
$$

donde $h$ se llama constante de Planck, su valor es $h=6,63 \times 10$-34 J.s.

\subsubsection{Patrones para el secado por microondas}


El secado asistido con energía microondas ha surgido y se ha desarrollado como un método alternativo a los métodos convencionales de secado, debido a todas las ventajas que ofrece, y en la actualidad se utiliza en muchos procesos industriales para el secado de diversos materiales y productos.

El calor generado también puede utilizarse en el cuerpo para evaporar la humedad que éste contenga. Por lo que se puede producir una transferencia de masa desde el interior del material hasta su superficie lugar donde pasa a formar parte del medio externo.

Si el contenido inicial de humedad del producto a secar es muy alto y la presión dentro de él se eleva rápidamente, el líquido se puede eliminar de la muestra bajo la influencia de un gradiente de presión total. Cuanto mayor sea la humedad inicial del producto a secar, mayor es la influencia del gradiente de presión en la eliminación de masa total. Por lo tanto, existe, una especie de acción de bombeo, que fuerza al líquido hacia la superficie, por lo general en forma de vapor. Esto origina un secado muy rápido, sin la necesidad de recalentar la atmósfera ni causar el endurecimiento u otros fenómenos de sobrecalentamiento en la superficie.

La deshidratación de un material es uno de los procesos industriales que requieren mayor gasto de energía. Los secadores industriales más usados, por su simplicidad, son aquellos que emplean aire caliente y ventilación forzada (transmisión de calor convectiva) para transmitir calor al material y eliminar la humedad del producto tratado.

Sin embargo, las técnicas convencionales tienen la desventaja de que el calor requerido para que la humedad sea evaporada, se debe transferir hasta el interior del material a través de su superficie. En materiales donde la conductividad térmica es baja, o donde las dimensiones son considerables, este tipo de transmisión de calor es, a menudo, poco eficiente y lento.

Además, en el secado con aire forzado, la evaporación del agua se produce principalmente en la superficie del producto por lo que la humedad debe viajar desde el centro del material hasta la superficie para poder ser extraída. Este proceso de migración 
se produce por diversos mecanismos: difusión de la fase líquida o del vapor de agua, capilaridad, termomigración, evaporación y condensación, etc., los cuales son intrínsecamente lentos y, por consiguiente, condicionan la velocidad de secado.

Por otro lado, las condiciones ambientales pueden limitar la tasa de evaporación puesto que marcan la velocidad a la que el agua superficial se evapora y el contenido de humedad en equilibrio del material. Los datos relativos al secado deben expresar claramente la pérdida de humedad en el cuerpo en relación con el paso del tiempo. Habitualmente, no se utiliza la pérdida de peso sino el contenido de humedad en base $\operatorname{seca}(X)$.

Lo más habitual es definir la velocidad de secado como la variación de humedad global con respecto al tiempo $d X(t) / d t$, o bien, si se quiere independizar del área expuesta al secado como indica la siguiente ecuación:

$$
N_{w}=\frac{m_{d}}{A} \cdot\left(-\frac{d X}{d t}\right)
$$

donde $N_{w}$ es la densidad superficial de flujo evaporado, y $A$ es el área de la muestra expuesta al secado.

Se pueden definir varios periodos en el secado, los cuales no siempre aparecen para todos los materiales. Esto induce a pensar que se producen varios mecanismos de secado y que en cada periodo un mecanismo es el dominante:

- Periodo de calentamiento o de inducción: es un periodo de calentamiento que transcurre desde que comienza el proceso hasta que el material alcanza la temperatura necesaria para iniciar el secado a la tasa constante.

- Periodo de evaporación constante: tiene lugar si el porcentaje de humedad en el sólido es elevado. La evaporación ocurre superficialmente o el interior del material a velocidad constante si las condiciones de operación se mantienen. El 
agua superficie es remplazada por agua interior gracias a algunos de los mecanismos de transferencia de masa.

- Periodo de tasa de secado a velocidad decreciente: en él, la velocidad de secado disminuye. Suele darse a bajos contenidos de humedad, y se produce si los mecanismos de transferencia de masa en el interior del sólido son incapaces de saturar la superficie con agua. Así, la migración interna de la humedad no puede igualar la velocidad de evaporación del agua en la superficie. Por ello, en este periodo el secado está controlado por los mecanismos internos.

Por último, es importante destacar que los hornos para secado, generalmente, tienen en su interior flujos de aire para permitir evacuar el vapor de agua que se genera en los materiales que están siendo secados. Dicho flujo de aire debe ser renovado para que el ambiente dentro del secadero no se sature e impida una correcta ejecución del proceso de secado puesto que un aire saturado no puede absorber más agua.

\subsection{Conclusiones}

Las microondas son una radiación electromagnética no ionizante que ocupa en el espectro electromagnético una banda de frecuencias situada entre el infrarrojo y las radiofrecuencias. Esta radiación es capaz de interaccionar con materiales y sustancias dieléctricas de forma tal que la energía transportada por las microondas se disipa dentro de la sustancia en forma de calor elevando su temperatura. Este tipo de calentamiento tiene múltiples aplicaciones industriales en campos tan diversos como son: el secado de materiales, síntesis de polímeros, acelerador de reacciones químicas, pirolisis de residuos y un largo etcétera. Incluso materiales con constantes dieléctricas bajas, que no se calentarían de forma natural con la radiación microondas pueden llegar calentarse en hornos microondas cuando se mezclan un susceptor de microondas apropiado.

Dado que el calentamiento con microondas se produce en el interior de las sustancias, las pérdidas de calor por convención o radiación son mínimas, por lo que este tipo de calentamiento puede resultar mucho más eficaz que el calentamiento convencional. No 
obstante, a pesar de esta y otras ventajas del calentamiento con microondas, el mayor inconveniente en la actualidad, a la hora de usar calentamiento con microondas en procesos a gran escala, es la dificultad de escalar los hornos microondas para tratar grandes volúmenes, por lo que las mejoras en los diseños de los equipos microondas suponen el mayor reto a vencer a la hora de aplicar calentamiento con microondas en algunos procesos industriales, especialmente aquellos en los que se ha procesar grandes cantidades de material por unidad de tiempo.

\subsection{Referencias}

[1] Astigarraga U.J y Astigarraga. O.J. (1995). Hornos de alta frecuencia y microondas. Segunda Edición. España. pp.7- 9.

[2] a) Microwaves in Organic Synthesis, 3rd, ed. A. de la Hoz and A. Loupy, Wiley, Weinheim, 2012. b) C. O. Kappe and A. Stadler, Microwaves in Organic and Medicinal Chemistry, 2nd Ed., Wiley-VCH, Weinheim, 2012. c) O. Kappe Angew. Chem. Int. Ed., 2004, 43, 62506284. d) A. de la Hoz, A. Díaz-Ortiz, J. R. Carrillo and M. A. Herrero, Selectivity under the action of microwave irradiation, in Microwaves in Organic Synthesis, 3rd Ed., ed. A. de la Hoz and A. Loupy, Wiley, Weinheim, 2012.

[3] Thostenson, E.T., Chou, T.-W. (1999). Microwave processing: fundamentals and applications. Composites Part A, 30, 1055-1071.

[4] Mujumdar AS (1995) Handbook of Industrial Drying, 2nd Ed. Nueva York.

[5] Meredith RJ (1998) Manual de ingenieros de calefacción industrial por microondas. IEE Power Series 25. Institución de ingenieros eléctricos, Londres.

[6] Monzó-Cabrera, J. "Estudio Del Secado Asistido Por Microondas En Los Materiales Laminares". Tesis doctoral (2002).

[7] Ondruschka, et al. Chem. Eng. Technol. 2003, 26, 12. 
[8] Menéndez, J.A., Moreno, A.H. (Eds.). (2017). Aplicaciones industriales del calentamiento con energía microondas. Latacunga, Ecuador: Editorial Universidad Técnica de Cotopaxi, Primera Edición, pp 315. ISBN: 978-9978-395-34-9.

[9] Juan Monzó Cabrera, Alejandro Díaz Morcillo, Juan Luis Pedreño Molina, José Manuel Catalá Civera, Antonio José Lozano Guerrero, Francisco Javier Clemente Fernández, "Aplicaciones Industriales del Calentamiento asistido por microondas", Ed. Universidad Politécnica de Cartagena, 2009.

[10] Schiffmann, R. F. (2015). Microwave and Dielectric Drying. En: Handbook of Industrial Drying, Fourth Edition. A. S. Mujumdar. Boca Raton, FL, CRC Press, Chapter 13, 283-301.

[11] J. M. Miranda, J. L. Sebastián, M. Sierra, J. Margineda, "Ingeniería de microondas: técnicas experimentales". Prentice Hall, 2002. ISBN: 8420530999.

[12] S.Chao, "Measurements of microwave conductivity and dielectric constant by the cavity perturbation method and their errors", IEEE Trans. Microw. Theory Tech., vol. 33, no. 6, Jun 1985. 


\section{CAPÍTULO 4}

\section{DESARROLLO DE UNA NUEVA GENERACIÓN DE BIOSENSORES MICROBIOLÓGICOS ESPECÍFICOS PARA VALIDAR PROCESOS DE ESTERILIZACIÓN POR MICROONDAS}

\subsection{Introducción}

En este capítulo se describen los trabajos desarrollados para sintetizar físicamente, a nivel microbiológico, los biosensores que se utilizarán para identificar el grado de uniformidad en la inactivación de los microorganismos presentes en las muestras a procesar con tecnologías por microondas a $2,45 \mathrm{GHz}$.

Muchas materias primas e ingredientes utilizados para la producción de alimentos son medios ricos donde los microorganismos patógenos pueden sobrevivir $y$, en muchos casos, crecer. Además, la mayoría de estos microorganismos pueden sobrevivir en superficies, contaminando potencialmente el producto durante su manipulación. Por lo tanto, la transformación del producto alimenticio para reducir la carga microbiana por debajo del nivel de peligro, es esencial para garantizar la seguridad del consumidor [1]. Esto se ha hecho tradicionalmente a través del tratamiento térmico y/o la acidificación.

No obstante, estos procesos también afectan a otros compuestos del producto alimenticio y, por tanto, pueden tener efectos no deseados en las propiedades organolépticas y nutricionales del producto [2]. Se han sugerido varias tecnologías como alternativa al procesamiento térmico convencional, debido a su menor impacto en las propiedades sensoriales del producto alimenticio y su versatilidad [3]. En este sentido, la energía de microondas puede proporcionar calentamiento eficiente, ya que se transmite a través del aire y el vacío y no necesita calentar el ambiente alrededor de los alimentos. Como resultado, el calor se puede transferir al producto muy eficientemente tanto para productos homogéneos como heterogéneos, lo que podría reducir el exceso 
de cocción y mejorar la calidad del producto [4]. Hay, sin embargo, cuestiones prácticas relacionadas con la homogeneidad de la distribución de calor, para garantizar la inactivación microbiana y enzimática.

Durante los últimos años se han dedicado varios trabajos de investigación para la homogeneidad de temperatura durante el procesamiento por microondas. La fabricación a escala en el laboratorio de hornos de microondas, basados en cavidades monomodo, pueden obtener una buena homogeneidad de temperatura en el producto, pero se limitan a muestras de pequeño volumen, es decir, 1-2 $\mathrm{cm}^{3}$ [5]. Para hornos de microondas a escala industrial basados en aplicadores multimodo, los problemas con la homogeneidad de la temperatura surgen, obstaculizando la capacidad de esta tecnología para obtener una inactivación microbiana y enzimática total sin reducir la calidad del producto tratado.

Algunas referencias han propuesto una variedad de métodos para mejorar la uniformidad de la distribución de campo en todo el producto, obteniendo así una distribución de temperatura homogénea. A modo de ejemplos, se pueden encontrar platos giratorios, agitadores de modo [6], alimentación múltiple por microondas [7], o capas dieléctricas que rodean la muestra. Sin embargo, salvo los agitadores de modos, la mayoría de estas soluciones sólo son aplicables a una escala doméstica y no son adecuadas en entornos industriales. Así mismo, los agitadores de modos no pueden solventar todos los problemas de uniformidad de calentamiento, especialmente cuando los materiales presentan altas pérdidas.

Los aplicadores industriales de microondas, para proporcionar funcionamiento continuo, se basan generalmente en una configuración de túnel. En este caso, la forma más práctica de mejorar la uniformidad en el calentamiento, es aprovechar el desplazamiento del producto a través del aplicador [4]. Sin embargo, todavía hay grandes incertidumbres relacionadas con el diseño de tratamientos de microondas basados en una configuración de túnel. Uno de los más relevantes es la falta de métodos prácticos para controlar la temperatura en el producto (cambios en tiempo y espacio) durante el proceso. La 
mayoría de los sensores de temperatura tienen partes metálicas que no pueden ser introducidos en el horno de microondas. Por lo tanto, las medidas de temperatura se limitan generalmente al momento en el que el producto está fuera de la cavidad resonante mediante el uso de cámaras termográficas. Por lo tanto, para validar alternativas a los tratamientos de pasteurización se necesita un control de temperatura distinto al tradicional utilizando esta tecnología de biosensorización.

Un enfoque alternativo para estudiar la inactivación causada en un proceso, es el uso de Indicadores de Inactivación Biológica (IIB) [8]. Consisten en una encapsulación de un microorganismo de interés ( $p$. ej., esporas bacterianas) que pueden colocarse en el producto alimenticio y recuperarse después del tratamiento, proporcionando una medición de la inactivación microbiana. Tiene varias ventajas con respecto a otros enfoques:

- Al ubicar varios IIBs en el producto, se puede medir heterogeneidades en la inactivación microbiana.

- Además, proporciona una medición directa de la variable de interés (la reducción microbiana), sin utilizar una medida intermedia.

En este trabajo, utilizamos IIBs basados en un recubrimiento de alginato, el cual ha sido ampliamente utilizado para encapsular bacterias y esporas para diferentes usos relacionados con alimentos [9]. Es un biopolímero eficiente para el recubrimiento, ya que evita la difusión de las bacterias al tiempo que permite una eficiente transferencia de calor [10] o protección contra las condiciones de estrés [11].

En este estudio se ha trabajado en el desarrollo de un método experimental para analizar la eficacia, a través de tratamiento por microondas para la pasteurización de productos alimenticios, incluidos los productos intrínsecos y extrínsecos y su variabilidad. Para ello, se han utilizado dos productos como caso de estudio: un subproducto de pescado (FBP) y una sopa vegetal. 
La piscicultura es una industria emergente con un gran potencial y un crecimiento sustancial en los últimos años (OCDE 2020) [12]. Sin embargo, produce subproductos que necesitan ser tratados adecuadamente antes de que puedan destinarse a usos alternativos distintos del consumo humano. Calentar estos subproductos puede ser una solución para el necesario acondicionamiento de subproductos animales de la industria piscícola que permita su uso posterior. Son tres las categorías de subproductos animales según el Reglamento de la Comisión Europea (CE) 1069/2009, comentado en el capítulo anterior. Los descartes de pescado o los productos de las piscifactorías no son válidos para el consumo humano incluido en la categoría 3 (el de menor riesgo). En el caso que borda este trabajo investigador, estos materiales (como los peces muertos retirados diariamente de la producción) pertenecen a esta categoría como "animales acuáticos y partes de ellos, excepto mamíferos marinos, que no presentan signos de enfermedad transmisible" y "productos de animales acuáticos procedentes de establecimientos o plantas de transformación que se preparan para consumo humano". La correcta transformación de estos productos plantea un grave problema a las empresas y puede tener implicaciones ambientales. Hay varios métodos estándar para procesar estos subproductos, por ejemplo, el tratamiento térmico, siempre que muestre que los potenciales peligros y riesgos pueden ser controlados, existiendo un plan de muestreo que considera microbiológicamente criterios que lo demuestran (Reglamento de la Comisión Europea, 2009).

El diseño de un tratamiento de procesado optimizado en entornos industriales requiere un conocimiento preciso de la cinética de inactivación de los microorganismos pertinentes. Además, la variabilidad es inherente a cada proceso biológico y puede ser muy relevante para la seguridad alimentaria [13]. En este contexto, la variabilidad se refiere a las variaciones que son inherentes al sistema. Esto incluye fuentes intrínsecas de variabilidad, como las relacionadas con diferencias entre la respuesta de las células individuales al tratamiento (p.e., diferencias entre cepas de la misma especie), así como fuentes extrínsecas de variabilidad (p.e., heterogeneidades especiales en la distribución de la temperatura a través del alimento) que, si no se tiene en cuenta, podrá conducir a interpretaciones erróneas sobre la seguridad de los productos [14]. 
La cuantificación de variabilidad para un proceso de inactivación industrial de calentamiento por microondas es especialmente desafiante porque tanto la variabilidad intrínseca como la extrínseca son muy relevantes. En este trabajo, se han utilizado IIBs para analizar la inactivación microbiana en puntos diferentes del producto [15]. Estos elementos se componen de un elemento sensor que presenta cambios en el rango de condiciones probadas y una matriz que contiene el elemento sensor dentro de un espacio limitado, para que pueda ser recuperado y medido. Por lo tanto, la aplicación de varios IIBs a diferentes puntos de la matriz alimentaria permite un análisis detallado de la variabilidad implicada en el proceso de inactivación.

Sin embargo, hay que destacar que el uso de estos biosensores introduce una fuente adicional de incertidumbre en el análisis, relacionada con la capacidad para recuperar las células microbianas inicialmente inoculadas y cuya contribución debe ser evaluada de forma independiente. Las bacterias de Bacillus spp son adecuados debido a su alta resistencia térmica compatible con la pasteurización y la esterilización de procesos. El Bacillus sporothermodurans ha sido descrito como un microorganismo adecuado para evaluar los procesos de esterilización [16], mientras que la Bacillus cereus, aunque está relacionada con una enfermedad de transmisión alimentaria patogénica leve [17], incluye algunas cepas que tienen un valor adecuado a temperaturas de pasteurización [18]. Esto los hace útiles para la validación de tratamientos de pasteurización.

El objetivo del actual capítulo es el de evaluar la variabilidad de esporas Bacillus spp., integradas en IIBs y, así, validar la pasteurización de alimentos tratados en un horno de microondas con esporas de Bacillus cereus, fijadas como elementos sensores en IIBs, a base de alginato, en una sopa vegetal y en un preparado a base de pescado. La necesidad de que las estructuras que contienen los IIBs posean unas propiedades térmicas y electromagnéticas similares a la matriz alimentaria, ha requerido innovaciones tecnológicas respecto a la metodología existente. Por este motivo, se ha ensayado la estabilidad de la matriz en las condiciones de procesado y la lixiviación potencial de esporas bacterianas de la misma, evaluando el uso de indicadores colorimétricos que permitan valorar de forma rápida la eficacia (o no) de los tratamientos. 
Por otro lado, para conocer con exactitud la variabilidad del calentamiento por microondas ha sido necesario establecer la inactivación que alcanzan los sensores en función de la posición en el horno. Para ello, se ha establecido una distribución espacial para modelar la temperatura en la masa de material biológico, en base a la respuesta de los dos microorganismos diferentes fijados en el mismo punto, evaluando la efectividad de la respuesta a un indicador colorimétrico para la determinación rápida, de si se ha alcanzado o no un nivel de esterilización adecuado. En base a los resultados obtenidos, se ha realizado una distribución superficial de la intensidad de calentamiento y su variabilidad dentro del horno microondas, cuyos detalles se describen posteriomente.

El procesamiento de microondas puede ser una alternativa válida al calentamiento convencional para diferentes tipos de productos, permitiendo un calor más eficiente en la transferencia a la matriz alimentaria, dando como resultado, productos de mayor calidad.

Sin embargo, para muchos productos alimenticios una distribución uniforme de la temperatura no es posible debido a las heterogeneidades en sus propiedades físicas y la no uniformidad en el patrón de campos eléctricos. Por lo tanto, la eficacia de los tratamientos de inactivación por microondas está influenciada por ambos, variabilidad intrínseca (diferencias entre células) y variabilidad extrínseca (temperatura no uniforme). Interpretar los resultados del proceso y considerar su impacto en la inactivación microbiana es esencial para garantizar un procesamiento eficiente.

En este trabajo, se ha cuantificado la variabilidad en la inactivación microbiana obtenida en un tratamiento de pasteurización con un horno túnel por microondas, cuya configuración se hizo a medida para las pruebas experimentales de laboratorio, aunque la configuración del equipo no permite medir la temperatura del producto durante el tratamiento.

Por esa razón, la variabilidad en los recuentos microbianos se ha medido utilizando IIB, basados en partículas esféricas de alginato inoculado con esporas de Bacillus spp, como ya se ha comentado. La estabilidad de los IIBs y la incertidumbre asociada a ellos, se han 
evaluado utilizando experimentos preliminares en un termorresistómetro. Posteriormente, éstos fueron introducidos en el producto alimenticio para analizar la inactivación microbiana en diferentes puntos de la superficie del material durante el tratamiento por microondas.

Los resultados mostrarán que la variación en los recuentos microbianos es mayor de lo esperado sobre la base de la variabilidad biológica estimada en el termorresistómetro y la incertidumbre de los IIBs, debido a las heterogeneidades en el campo de temperatura (medidas mediante una cámara termográfica).

Por lo tanto, para el proceso estudiado, la variabilidad extrínseca ha sido más relevante que la variabilidad intrínseca. La metodología presentada en este trabajo puede ser un método válido para evaluar los tratamientos de pasteurización de los alimentos procesados por calentamiento, proporcionando información valiosa de la inactivación microbiología lograda, pudiendo contribuir al diseño de procesos de microondas para diferentes tipos de productos y para la optimización de los mismos.

\subsection{Materiales y métodos}

\subsubsection{Microorganismos}

Selección de sensores biológicos. Para este apartado, se han seleccionado diferentes microorganismos esporulados del género Bacillus y se ha evaluado la resistencia térmica para establecer su utilidad como indicadores de la intensidad y uniformidad del calentamiento por microondas. A priori, se han considerado idóneos, microorganismos del género Bacillus spp., por ser más sencilla su manipulación en laboratorio al ser aerobios. Se descartaron, sin embargo, los del género Clostridium spp., puesto que aumentan la variabilidad asociada a los estudios de termorresistencia, dificultando la interpretación de los resultados de inactivación por microondas, como ya se ha comentado. [19]

Mediante un termorresistómetro Mastia [20], patentado por la Universidad Politécnica 
de Cartagena, se ha podido realizar el estudio de la inactivación térmica microbiana en condiciones muy controladas y precisas, y se ha utilizado como control respecto a las medidas realizadas en el horno de microondas.

Además, se han utilizado dos microorganismos esporulados: Bacillus cereus (de la cepa INRA AVTZ415, suministradas por INRA-Avignon), como indicador de alto tratamiento de pasteurización (en el rango de $90^{\circ} \mathrm{C}$ ) y Bacillus sporothermodurans como indicador de microorganismos en tratamientos de esterilización [21]. Ambos microorganismos fueron considerados indicadores adecuados para procesos térmicos, dependiendo de la intensidad de calentamiento requerida.

Las esporas fueron esporuladas en agar nutriente fortificado. Las células vegetativas de Bacillus cereus se cultivaron en caldo nutritivo a $37^{\circ} \mathrm{C}$ y, posteriormente, fueron inoculadas en placas por medio de esporulación (agar nutriente fortificado) e incubados durante una semana a $37^{\circ} \mathrm{C}$. Una vez alcanzada una tasa de esporulación superior al $90 \%$, utilizando agua destilada estéril (DW) y centrifugada dos veces a $4.000 \mathrm{~g}$ durante 15 minutos en agua destilada estéril, se almacenaron en $20 \mathrm{ml}$ de volumen utilizando tubos estériles. Con una concentración aproximada de $5 \times 109$ UFC/ml, se almacenaron inmediatamente a $4^{\circ} \mathrm{C}$ hasta su uso.

Las esporas Bacillus cereus se utilizaron directamente de los tubos almacenados y el inóculo fue estandarizado por dilución para obtener una concentración bacteriana de 109 UFC/ml. Las poblaciones de bacterias se estimaron, distribuyendo alícuotas diluidas, adecuadas en placas de nutrientes de agar (Cultimed), seguidas de una incubación a $37^{\circ} \mathrm{C}$, durante $24 \mathrm{~h}$.

La Bacillus sporothermodurans IC4 se obtuvo de la colección de cultivos de I+D de Unilever, Países Bajos, siendo esporulada igualmente en agar nutriente fortificado y almacenada $a 4^{\circ} \mathrm{C}$ hasta su uso, realizando varias esporulaciones para asegurar una alta resistencia al calor. Posteriormente, se seleccionaron dos cultivos de esporas, con diferente resistencia al calor (B. sporothermodurans - $A$ y $B$. sporothermodurans - $B$ ). Las 
esporas se inocularon en agar nutriente (Cultimed, España) y los inóculos fueron estandarizados por dilución, para obtener una concentración de 178 UFC/ml.

\subsubsection{Preparación de la muestra para tratamiento por microondas}

Para los primeros ensayos, se configuró una muestra utilizando una sopa refrigerada pasteurizada comercial como sustrato alimentario, compuesta por una mezcla de patata (19\%), zanahorias (4\%), nabo (2\%), calabaza (2\%), apio, cebollas, tomate, almidón de maíz, especias y leche deshidratada, mantenida refrigerada $\left(4,5^{\circ} \mathrm{C}\right)$ hasta su uso.

La segunda muestra que se utilizó, consistió en una pasta de pescado homogeneizada, producida a partir de Dicentrarchus labrax, obtenida utilizando un homogeneizador de laboratorio $\mathrm{F}-\mathrm{BP}$, congelada a $-20^{\circ} \mathrm{C}$ en porciones y un proceso posterior de descongelación y refrigeración el día previo a los experimentos.

\subsubsection{Preparación de indicadores de inactivación biológica. (IIBs)}

Los IIBs se prepararon mezclando 0,2g de alginato sódico en polvo (SANOFI, España, empresa biofarmaceútica) en $4,8 \mathrm{ml}$ de agua destilada agitando durante $2 \mathrm{~h}$, previamente al paso de la mezcla por autoclave. Una vez refrigerados, $5 \mathrm{ml}$ de suspensión de esporas $B$. cereus o $B$. sporthermodurans y $0,5 \mathrm{~g}$ de polvos de carbón, se añadieron en condiciones estériles y se homogeneizaron durante 30 minutos a $100 \mathrm{rpm}$. El polvo de carbón proporcionó un color negro a las muestras resultantes para permitir la identificación cuando se mezcle con los alimentos. Posteriormente, la mezcla se separó usando una jeringa en solución estéril de $\mathrm{Ca}_{2} \mathrm{Cl}(2 \% \mathrm{w} / \mathrm{v})$ para encapsular las esporas en las muestras de alginato. El Alginato gelificado en presencia de iones $\mathrm{Ca}_{2}+$, se formó en perlas de aproximadamente $2 \mathrm{~mm}$ de diámetro que se almacenaron refrigeradas hasta su uso.

\subsubsection{Enumeración de microorganismos}

Los IIBs se suspendieron individualmente en tubos con 10ml de citrato sódico estéril (1\%) que disolvió el gel, con un proceso de agitación durante 10 minutos para asegurar la 
resuspensión de las esporas en la solución. Las diluciones en serie de las diferentes muestras inoculadas, inmediatamente después del tratamiento y con tiempos de muestreo preestablecidos, se realizaron en forma estéril con peptona de agua (Scharlab Chemie S.A., España).

El medio utilizado para recuperar las células viables de las muestras de $B$. cereus fue agar selectivo (Scharlab Chemie S.A., España) y para B. sporothermodurans fue agar nutriente (Cultimed, España).

Finalmente, se inocularon diluciones en placas e incubaron a $37^{\circ} \mathrm{C}$, durante $48 \mathrm{~h}$ para ambos microorganismos. Los recuentos se expresaron como el logaritmo decimal de las diluciones ( $\log 10$ de UFC/ml), siendo UFC un indicador de las Unidades Formadoras de Colonias.

\subsubsection{Tratamiento térmico en el termorresistómetro Mastia}

Inicialmente, se realizaron tratamientos térmicos en condiciones controladas en un termorresistemetro Mastia [20]. Se trata de un equipo de laboratorio que se puede programar en diferentes temperaturas de inactivación (perfiles isotérmicos o dinámicos)

y está controlado por un controlador lógico programable (PLC), conectado a un controlador de temperatura avanzado. La figura 4.1 muestra una fotografía de dicho equipo.

El recipiente para el tratamiento tiene un volumen de $400 \mathrm{ml}$ y se puede llenar con diferentes sustratos que son agitados durante dicho tratamiento para asegurar un calentamiento homogéneo, pudiendo ser presurizado para alcanzar temperaturas hasta $150^{\circ} \mathrm{C}$. El recipiente fue llenado con $350 \mathrm{ml}$ de caldo de soja triptónica (TSB), como líquido de suspensión. Los IIBs se mantuvieron en un tejido estéril, fijado dentro del vaso para garantizar una distribución homogénea y así poderlos recuperar después del calentamiento. 


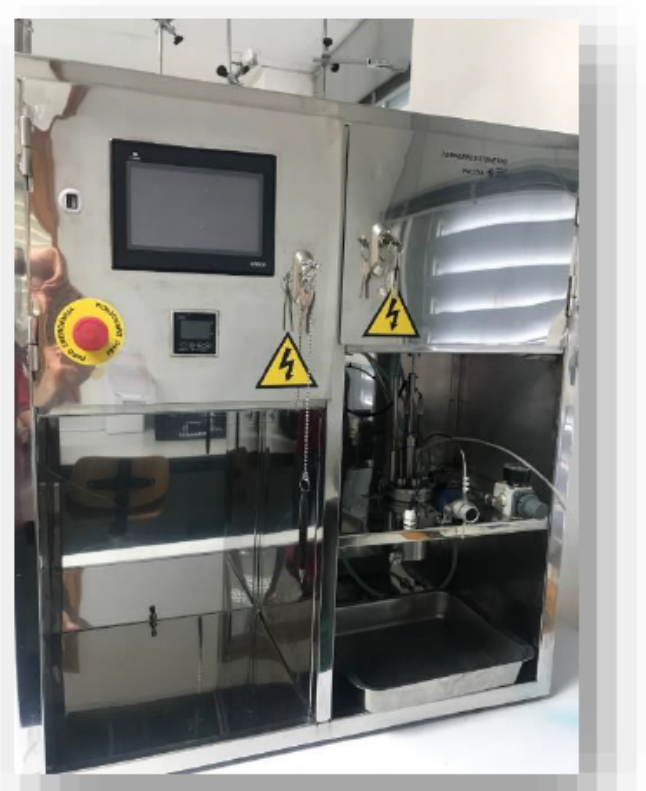

Figura 4.1 Fotografía del Termorresistometro Mastia en el laboratorio de calidad y seguridad alimentaria de la Escuela Técnica de Ingenieros Agrónomos en la Universidad Politécnica de Cartagena.

\subsubsection{Tratamiento con tecnología de microondas}

En los procesos de calentamiento por microondas, la propiedad clave del material tratado es su permitividad compleja $(\varepsilon)$,

$$
\varepsilon=\varepsilon_{0} \varepsilon_{\mathrm{r}}=\varepsilon_{0}\left(\varepsilon^{\prime}-\mathrm{j} \varepsilon^{\prime \prime}\right)
$$

donde $\varepsilon_{0}=8.8542 \cdot 10^{-12} \mathrm{~F} / \mathrm{m}$ es la permitividad eléctrica del espacio libre, $\varepsilon_{\mathrm{r}}$ es la permitividad relativa eléctrica, $\varepsilon^{\prime}$ es la constante dieléctrica,

La permitividad eléctrica cuantifica el comportamiento del material cuando un campo eléctrico es aplicado. La constante dieléctrica indica cómo el material almacena la energía eléctrica, y el factor de pérdidas expresa la disipación de la energía eléctrica en el material. Así, la forma en que las microondas se transforman en calor en un punto dado de un cuerpo dieléctrico se describe a través de la ecuación (4.2)

$$
P=2 \pi f \varepsilon_{0} \varepsilon^{\prime \prime}\left|E_{r m s}\right|^{2}
$$


donde $f(\mathrm{~Hz})$ es la frecuencia de funcionamiento y $E_{r m s}(\mathrm{~V} / \mathrm{m})$ es la media cuadrática de la intensidad de campo eléctrico. La distribución espacial del campo eléctrico está determinada por la geometría del aplicador, su alimentación y la constante dieléctrica y la geometría del material implicado en el proceso.

En términos de calentamiento por microondas, una constante dieléctrica inferior permite una mejor penetración de la onda en el material, y cuanto mayor sea el factor de pérdidas, mayor será el calor generado por el campo eléctrico en el material. En productos biológicos un valor de factor de pérdidas alto está normalmente relacionado con un alto valor en la constante dieléctrica, y esto dificulta la penetración de la onda dentro del muestra, disminuyendo exponencialmente la intensidad del campo eléctrico en su interior.

Los productos biológicos, debido a su alto contenido de agua, tienen valores altos para la constante dieléctrica y el factor de pérdidas (para el agua, $\varepsilon^{\prime}=59$ a 77 y $\varepsilon^{\prime \prime}=3,6$ a 10,6 en el rango $25-90^{\circ} \mathrm{C}$ ). Las muestras de ambos productos, sopa de verduras y F-BP, se depositaron en bandejas de vidrio de borosilicato (24,7 x 16 × 4 cm., Pyrex, Francia), siendo el rango de funcionamiento térmico de las bandejas de -40 a $260^{\circ} \mathrm{C}$ y las propiedades dieléctricas de su material (constante dieléctrica $\varepsilon^{\prime}=4,3$ y factor de pérdida $\left.\varepsilon^{\prime \prime}=0,02\right)$ las hacen casi transparentes a las microondas.

Los IIBs se distribuyeron en diferentes puntos del producto antes de procesarlo en el horno microondas. Con el fin de garantizar que los IIBs se encontraran en la misma posición en diferentes series del experimento, se cortó una capa de plexiglás para ajustarse a los bordes de las bandejas de vidrio., siendo perforada en veinte puntos diferentes en una cuadrícula regular $(4,12 \mathrm{~cm}$ de distancia en la dirección del túnel, $3,2 \mathrm{~cm}$ de distancia en la dirección perpendicular). Los IIBs se introdujeron a través de estos agujeros, que fueron codificados según las filas (A-D) y las columnas (1-5) donde fueron insertados. La figura 4.2, muestra una vista superior de las bandejas, así como la inactivación en cada una de las cuadrículas. 
Para que una muestra se procese en el aplicador del túnel, primero debe cruzar el filtro de entrada y luego entrar en la zona de calentamiento (módulos de cavidad resonante). La geometría de las cavidades, posición y orientación de las guías de onda de alimentación se diseñaron para maximizar la uniformidad de los patrones de campo eléctrico, con el fin de obtener un calentamiento uniforme en todas las muestras.

El calentamiento uniforme es una característica muy deseable en el proceso de pasteurización para garantizar una temperatura mínima en toda la muestra evitando los puntos calientes. Debido a la naturaleza de los diferentes modos (ondas) resonando dentro del aplicador, la uniformidad perfecta no se puede alcanzar, pero se puede mejorar con una ubicación y orientación inteligentes de las guías de onda que conectan la cavidad con las fuentes de microondas (magnetrones). Además, el movimiento de las muestras a lo largo del túnel ayuda a homogeneizar el calentamiento durante el proceso. 
A
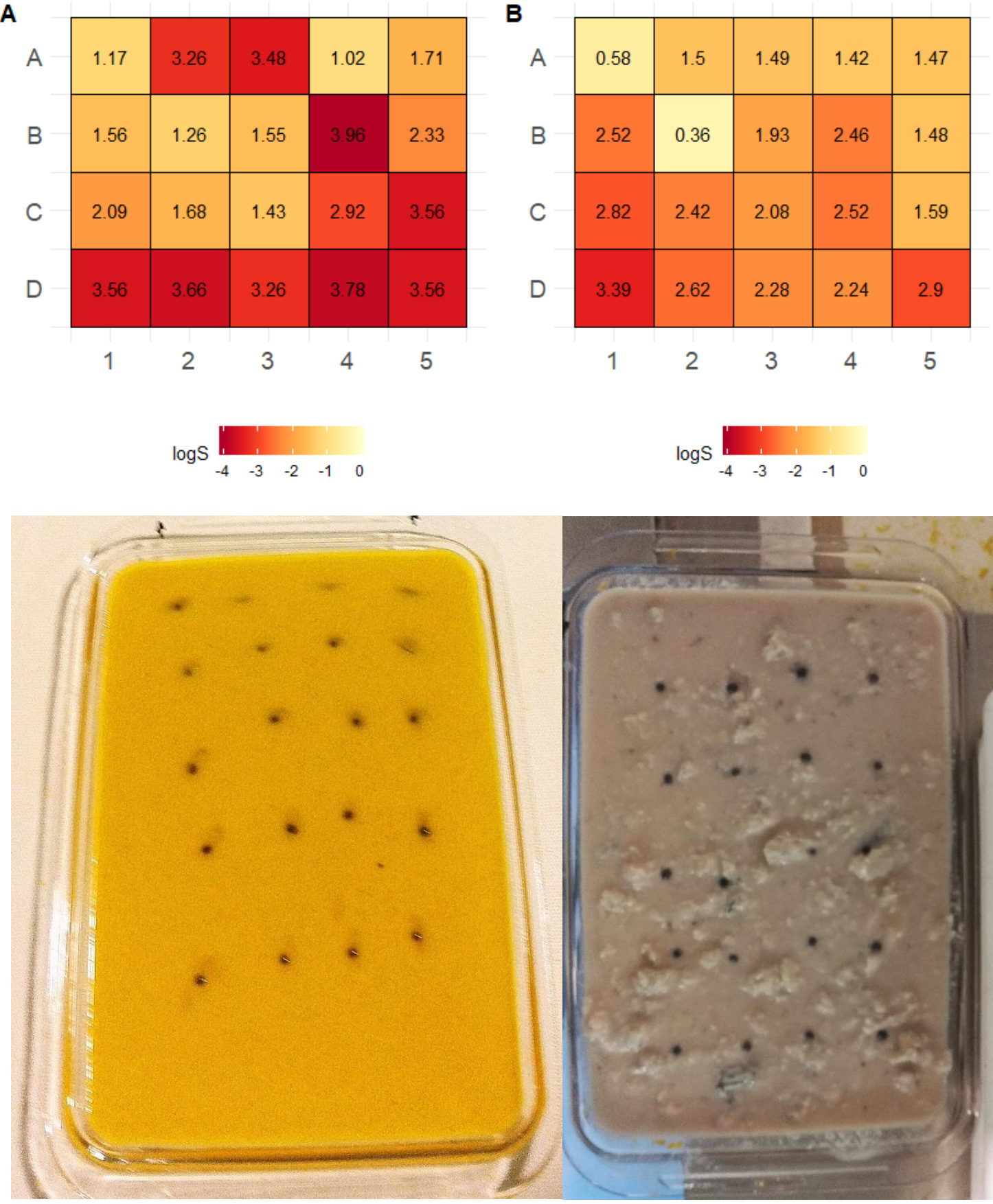

B

\begin{tabular}{|c|c|c|c|c|}
\hline 0.58 & 1.5 & 1.49 & 1.42 & 1.47 \\
\hline 2.52 & 0.36 & 1.93 & 2.46 & 1.48 \\
\hline 2.82 & 2.42 & 2.08 & 2.52 & 1.59 \\
\hline 3.39 & 2.62 & 2.28 & 2.24 & 2.9 \\
\hline
\end{tabular}

$\begin{array}{lllll}1 & 2 & 3 & 4 & 5\end{array}$

$\log S \begin{array}{llllll}1 & 1 & 1 & & & \\ -4 & -3 & -2 & -1 & 0\end{array}$

Figura 4.2 Distribución de la inactivación medida en IIB individuales, colocados en bandejas que contienen sopa (A) o subproducto de pescado (B), en el horno de microondas continuo.

Los principales parámetros de funcionamiento del túnel son la energía radiada de microondas y la velocidad de la cinta transportadora (que determina el tiempo de funcionamiento). Las configuraciones óptimas de estos parámetros se determinaron a priori, mediante simulaciones numéricas en plataforma CST Studio. La tabla 4.1 muestra 
los valores de las propiedades de la sopa de verduras y otros parámetros utilizados para las simulaciones.

$\begin{array}{lc}\text { Permitividad eléctrica relativa } & \mathcal{E}^{\prime}=61,2 \quad \mathcal{E}^{\prime}=16,3 \\ \text { Calor específico }\left(\mathrm{J} / \mathrm{Kg}^{\circ} \mathrm{C}\right) & 1,0121 \\ \text { Densidad }(\mathrm{kg} / \mathrm{l}) & 0,2 \\ \text { Masa }(\mathrm{kg}) & 0,1976 \\ \text { Volumen (l) } & 22 \\ \text { Temperatura inicial del producto }\left({ }^{\circ} \mathrm{C}\right) & 22 \\ \text { Temperatura inicial de bandeja }\left({ }^{\circ} \mathrm{C}\right) & 22\end{array}$

Tabla 4.1. Parámetros de materiales y temperatura inicial para la sopa vegetal.

Para simplificar el cálculo, estas simulaciones se hicieron como una aproximación de primer orden, asumiendo que las propiedades físicas son constantes en el rango de operación de temperatura. El comportamiento de la sopa de verduras y FBP con la temperatura se puede encontrar en [5].

Los aplicadores de túnel precisan simulaciones basadas en acoplamiento electromagnético con transferencia de calor y masa, los cuales no son asequibles debido a su alto costo computacional. No es sólo por el gran tamaño del aplicador, sino también por el recorrido del producto por todo el horno, lo que lleva a una distribución diferente del campo eléctrico en todo el aplicador y, por lo tanto, en el producto, en cada localización de la muestra. Esto haría necesaria una simulación por centímetro de avance, al menos, con el fin de obtener resultados precisos. 
Para probar el tratamiento de pasteurización de microondas, fue diseñada una configuración de aplicador industrial de túnel de microondas, cuyas características y funcionalidades se abordarán en el capítulo 6, con mayor detalle.

La zona de calentamiento del aplicador está compuesta por tres cavidades rectangulares multimodo (módulos), cada una de ellas con cuatro magnetrones de $1 \mathrm{~kW}$, para un total de $12 \mathrm{~kW}$ a potencia máxima (ajustable), con los adecuados filtros de entrada y salida del túnel para evitar la fuga de microondas fuera del horno, así como el cumplimiento de la normativa vigente, la norma UNE EN 55011, para estos equipos industriales de microondas.

La distribución de la temperatura en el producto a la salida del equipo fue medida con una cámara termográfica Fluke TI25. Sin embargo, debido a la presencia del banco de filtros de salida, estas fotos fueron tomadas unos segundos después de terminar el tratamiento de calentamiento por microondas (salida de la última cavidad resonante modular en el aplicador). Este tiempo de enfriamiento introduce un error en el patrón de temperatura registrado por la cámara termográfica cofrente a la distribución de la temperatura real en la superficie de la muestra cuando termina la irradiación de microondas, que es compensada posteriormente.

\subsubsection{Modelización matemática y análisis estadístico de la cinética de inactivación bacteriana}

La variabilidad en la recuperación de esporas de B. sporothermodurans y B. cereus en cada IIB, se evaluó utilizando una prueba de normalidad de Shapiro-Wilkinson [22], a tres conjuntos de datos con un nivel alfa de 0,05. Un caso específico de ajuste a una distribución teórica es la correspondiente a la distribución normal, tal y como se ha desarrollado. Este contraste se realiza para comprobar si se verifica la hipótesis de normalidad necesaria para que el resultado de algunos análisis sea fiable, como por ejemplo para el ANOVA, que es el que nos aplica. el Test de Shapiro-Wilk, se usa para contrastar la normalidad de un conjunto de datos. Se plantea como hipótesis nula que una muestra $x 1, \ldots, x n$ proviene de una población normalmente distribuida. Siendo la 
hipótesis nula que la población está distribuida normalmente, si el p-valor es menor a alfa (nivel de significancia) entonces la hipótesis nula es rechazada (se concluye que los datos no vienen de una distribución normal). Si el p-valor es mayor a alfa, se concluye que no se puede rechazar dicha hipótesis.

La normalidad se verifica confrontando dos estimadores alternativos de la varianza $\sigma^{2}$ :

- un estimador no paramétrico al numerador, y

- un estimador paramétrico (varianza muestral), al denominador.

La cinética de inactivación de $B$. cereus dentro de los integradores de tiempo y temperatura, como la función de la temperatura de calentamiento, se ha descrito mediante bioinactivación [23]. Esta prueba permite ajustar los modelos predictivos más comunes, utilizados para describir inactivación microbiana. En este caso se utilizó el modelo Mafart, basado en la distribución de Weibull, mostrado en la ecuación (4.3)

$$
\log N=\log N_{0}-\left(\frac{t}{\delta(T)}\right)^{p}
$$

donde $\mathrm{N}$ es el recuento microbiano en un tiempo t y $N_{0}$ es el recuento microbiano inicial. En este, la cinética de inactivación se describe por el valor, $\delta(T)$,que es igual al tiempo de tratamiento necesario para reducir el recuento microbiano un 90\%. La dirección de curvatura de la curva de superviviente se describe por el valor, $p$

Los valores de $p>1$ resultan en curvas de superviviente, con curvatura hacia abajo (efecto hombro), mientras que los valores de $p<1$ resultan en curvas de superviviente con curvatura hacia arriba (efecto de cola).

Este modelo considera una relación log-lineal entre el valor $\delta$ y la temperatura del tratamiento, T, como se muestra en la ecuación (4.4).

$$
\log \delta=\log \delta_{r e f}-\frac{T-T_{r e f}}{Z}
$$


donde la sensibilidad de la cinética microbiana a cambios de temperatura se describe por el valor z, que indica el aumento de temperatura necesario para causar una reducción de diez veces del valor $\delta$ y se utiliza una referencia temperatura, $T_{\text {ref, }}$ que carece de un significado biológico, pero que mejora la identificabilidad de los parámetros.

Los parámetros del modelo se estimaron utilizando un enfoque en un solo paso, ajustando el modelo, utilizando $T_{\text {ref }}$, mediante regresión no lineal [24], y la validación del modelo realizado, mediante la inspección de la desviación de los residuos, con respecto a las hipótesis de regresión no lineal (normalidad, independencia y homocedasticidad) según las pautas habituales [25].

Se utilizó una prueba de normalidad Shapiro-Wilk de los residuos y gráficas de representación habituales (histogramas, gráficos q-q, gráficos de dispersión de valores ajustados vs observados...) y se compararon los parámetros cinéticos obtenidos, con los ya publicados siguiendo el protocolo habitual (p.ej. sin el uso de IIBs) [18]. Todos estos cálculos se llevaron a cabo en la versión 3.5.3 del lenguaje de programación R Core Team (2016).

\subsection{Resultados y discusión}

\subsubsection{Cuantificación de la incertidumbre asociada al procedimiento de enumeración basado en los IIBs}

Las $B$. cereus y $B$. sporothermodurans se han utilizado como microorganismos indicadores en tratamientos de pasteurización y esterilización respectivamente y por esta razón fueron seleccionados como elementos de sensor adecuados para IIBs [referencias]. (no se ha explicado la diferencia entre pasteurización y esterilización).

Sin embargo, el uso de este método para medir los recuentos microbianos puede introducir incertidumbre en el estudio. La figura 4.2, ilustra la distribución de los recuentos microbianos recuperados de los IIBs, sin la aplicación de ningún tratamiento de inactivación (sólo un choque de calor para activar las esporas) para B. cereus (26 muestras), B. sporothermodurans-A (34 muestras) y B. sporothermodurans-B (18 muestras). 
Figura 4.3 Diagrama de caja que muestra la variabilidad en los recuentos logarítmicos de esporas de $B$. cereus y $B$. sporothermodurans, en integradores de tiempo-temperatura. $B C$ : $B$. cereus; $B S \_A$ : cultivo $A$ de $B$. sporothermodurans; $B S_{-} B$ : $B$. cultivo de sporothermodurans $B$.

También se analizó la normalidad de los recuentos con una prueba de normalidad de Shapiro-Wilk [22]. Un valor $p$ de 0,46; 0,29 y 0,35 fueron obtenidos para cada microorganismo. Por lo tanto, se llegó a la conclusión de que no había suficiente evidencia para descarta la hipótesis de que los recuentos recuperados de los IIBs se distribuyeran normalmente.

Los recuentos microbianos medios recuperados de los IIBs fueron de 6,88 log UFC/ml, 6,16 log UFC/ml y 5,90 log UFC/ml para los cultivos B. sporothermodurans y de B. cereus, respectivamente. Estos valores están cerca de la concentración microbiana máxima de estos microorganismos después de la incubación.

Los errores estándar de los recuentos recuperados fueron de 0,25; 0,17 y 0,11 log UFC/ml, respectivamente. Por lo tanto, se comprueba la incertidumbre asociada a la metodología propuesta para cuantificar el recuento microbiano como metodología convencional basada en la dilución en serie [26]. En consecuencia, se considerará que un tratamiento causa inactivación sólo si se reduce el recuento microbiano más allá de 0,5log UFC/ml. 


\subsubsection{Procesamiento térmico mediante un sistema de microondas de túnel de planta piloto}

Para el tratamiento de microondas, la sopa de verduras y el F-BP, fueron tratados con sólo dos magnetrones activos $(1 \mathrm{Kw})$ por cavidad. Un mayor contenido de agua y un menor contenido de grasa en la sopa de verduras con respecto a la F-BP, conducen a un calentamiento más rápido en la sopa. Por lo tanto, para alcanzar una temperatura final similar, el tiempo de tratamiento para la sopa es menor que para el F-BP.

Para las muestras de sopa, basadas en los resultados de las simulaciones numéricas preliminares, la velocidad de la cinta transportadora se fijó en 1,2 $\mathrm{m} / \mathrm{min}$ para un tiempo de calentamiento total de 175 s. Para la muestra F-BP, la velocidad de la cinta se fijó en $0,5 \mathrm{~m} / \mathrm{min}$ para un tiempo de calentamiento total de $420 \mathrm{~s}$.

El modelo de regresión no lineal proporciona una estimación de la incertidumbre y variabilidad asociada a los parámetros cinéticos del modelo. La figura 4.4, ilustra las regiones de confianza para los tres parámetros del modelo Mafart. Usando (por ejemplo) simulaciones de Montecarlo, estas regiones se pueden utilizar para predecir la inactivación microbiana durante un tratamiento térmico considerando estas fuentes de incertidumbre y variabilidad.

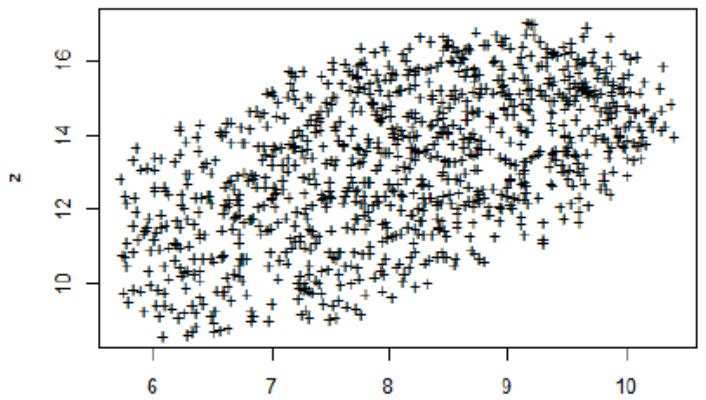

delta_ref
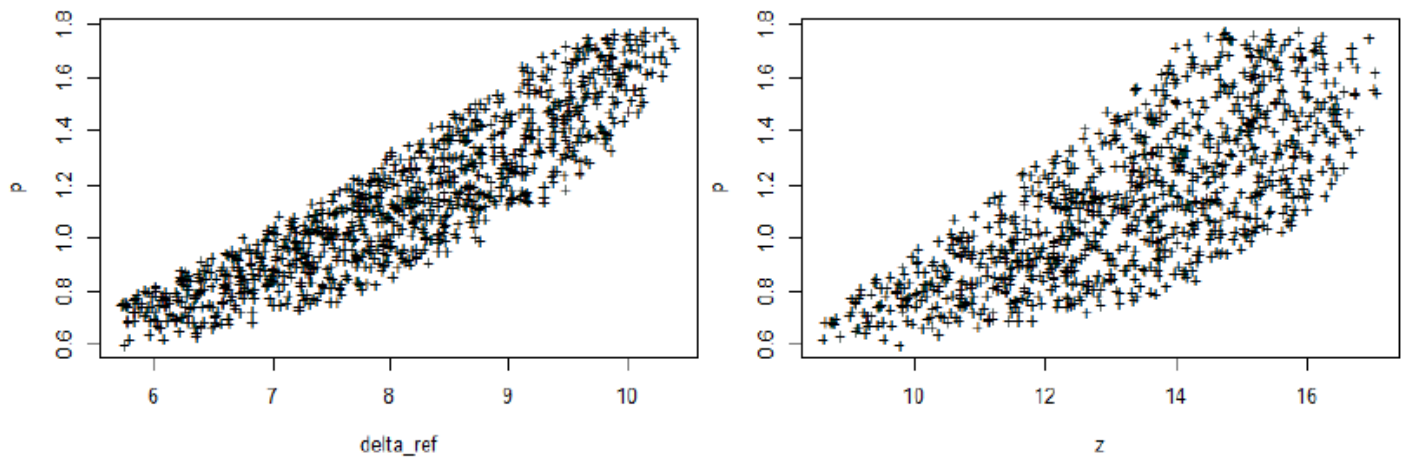

Figura 4.4. Regiones de confianza conjunta para los tres parámetros del modelo Mafart aplicado a los datos de inactivación de B. cereus 
Por ejemplo, un tratamiento de 420 s a $100^{\circ} \mathrm{C}$ daría lugar a una reducción microbiana esperada de 2,10 log UFC/ml con un error estándar de 0,21 log UFC/ml. Sin embargo, como se ilustra en la figura 4.5, la temperatura del producto en la salida del dispositivo de microondas está lejos de ser uniforme. En ambos productos, la temperatura en el perímetro exterior de la muestra era mayor que en el centro del área. Esto es causado por el llamado "efecto de frontera", que está relacionado con la fuerte variación en la permitividad eléctrica en la interfaz entre el producto alimenticio y la bandeja y por la atenuación de las microondas al atravesar el material que provoca que el material se caliente preferentemente en las esquinas y bordes laterales.

A

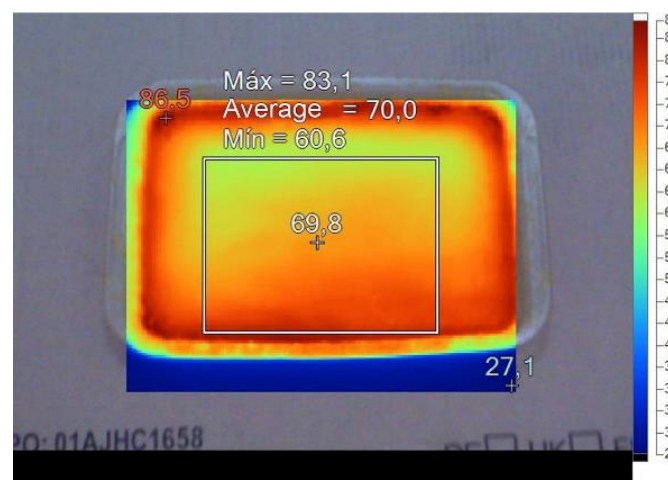

B

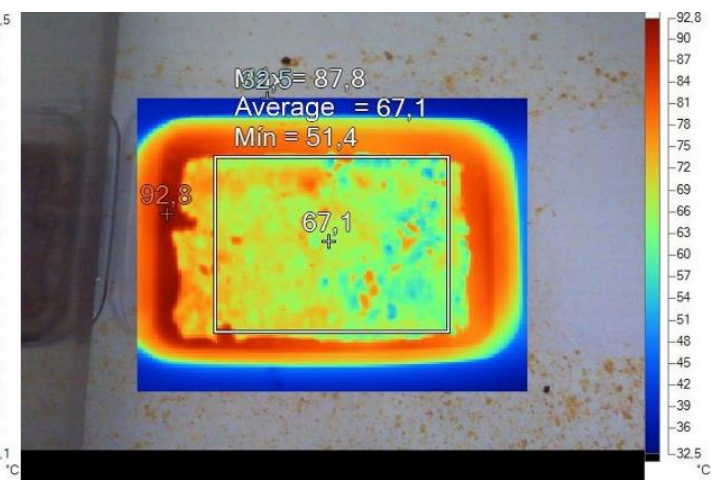

Figura 4.5. Patrón de temperatura después del final del calentamiento por microondas para sopa (A) y subproducto animal de pescado (B).

La distribución de la temperatura en la sopa fue más uniforme que en el subproducto de pescado, aunque la mitad tenía una temperatura más alta que la otra. Como se muestra en la Figura 4.5, el F-BP mostró varios puntos fríos y calientes en la parte central de la muestra, mientras que la distribución de temperatura en la sopa era suave, causado por la heterogeneidad en las propiedades de cada producto.

Aunque la sopa se hace de una variedad con diferentes componentes físicos, éstos se mezclan finamente antes de introducirlos en el dispositivo, lo que resulta de una baja variabilidad en las propiedades físicas del producto. El subproducto del pescado, por otro lado, contiene una amalgama de tejidos (órganos, huesos...) que permanecen 
separados. Como resultado, la variabilidad en la permitividad eléctrica, el calor específico y la conductividad del producto es muy relevante. Además, el mayor contenido de agua de la sopa produce una mayor conductividad por flujos convectivos, lo que permite una distribución de temperatura más suave.

Como se explicó anteriormente, debido al banco de filtros de salida, la captura termográfica para la sopa de verduras (figura 4.5) se hizo 55 s después de la salida del tratamiento de microondas. En el caso del F-BP, la imagen (figura 4.5), fue tomada $131 \mathrm{~s}$. después. No hay métodos que permitan una medición física de la evolución de la temperatura con el tiempo durante el proceso de calentamiento en hornos de microondas continuos. Por eso razón, se han utilizado IIBs. Estos componentes proporcionan una medición directa de la inactivación microbiana, a diferencia de TTIs o medidores de temperatura donde esta medida es indirecta.

Como se ha comentado los IIBs registran la inactivación en un punto particular del producto, lo que permite medir el nivel global de seguridad obtenido en diferentes partes de los alimentos procesados, aunque no proporcionan información sobre la evolución de la temperatura con el tiempo. Por lo tanto, los IIBs son los únicos adecuados como alternativa para medir la inactivación microbiana en procesos donde la distribución de la temperatura no se puede medir con suficiente precisión.

La figura 4.3, ilustraba los recuentos microbianos de B. cereus recuperados de las muestras en la salida del equipo de procesamiento. La inactivación microbiana fue más homogénea en el tratamiento en el producto de sopa, aunque la inactivación fue mayor en algunas partes de la bandeja. La inactivación medida osciló entre 1,02 log UFC/ml y 3,96 log UFC/ml para la sopa, mientras que oscilaba entre 0,36 y 3,39 log UFC/ml para el F-BP.

La inactivación en el producto de la sopa es más homogénea que en el F-BP y la esquina inferior derecha de la bandeja de sopa tenía una mayor inactivación. La razón de esto es la distribución desigual del calor en la bandeja, con una mitad que tiene una temperatura 
más alta que la otra, detectándose algunos puntos calientes con alta inactivación (especialmente en la parte inferior) y zonas donde sólo se redujo un ciclo logarítmico.

Para el F-BP procesado por microondas también se logró un calentamiento homogéneo en uno de los lados de las bandejas (Figura 4.5). Para las filas central e inferior, se observó un patrón más irregular observado otra vez, con inactivación media más baja y algunos puntos calientes típicos del calentamiento por microondas. De hecho, dos Blls en el F-BP tenían una inactivación inferior al umbral mínimo definido como mínimo para la inactivación microbiana en este método (1 log UFC/ml). Esta alta variabilidad se puede atribuir a la inactivación microbiana alcanzada en la parte central de la bandeja a la distribución desigual de la temperatura (Figura 4.5) causada por la variabilidad en las propiedades físicas del producto. En general, en el F-BP la inactivación máxima sólo se alcanzó en dos puntos calientes, y en algunos puntos fríos se registró baja inactivación.

Si consideramos que, para alcanzar la pasteurización, debe alcanzarse en todo el producto al menos un log10 de inactivación, en el caso de la sopa podría considerarse que fue alcanzado. Sin embargo, se observa una variabilidad considerable en los niveles de inactivación (de 1 a más de 4 reducciones logarítmicas) en la Figura 4.3_BSA. Una observación similar se hizo para espárragos recolectados y pasteurizados con microondas [27].

En el caso del F-BP, no se pudo garantizar la pasteurización, ya que había áreas donde la inactivación fue inferior a 0,25 reducciones logarítmicas (el umbral considerado teniendo en cuenta la variabilidad en los recuentos de IIBs). Por lo tanto, hubo partes del producto que no alcanzaron una inactivación significativa. Para este producto, se observó una amplia variabilidad en la inactivación microbiana (por debajo de la detección hasta 4 reducciones de log (Figura 4.2B). Se ha demostrado, por tanto, que el recubrimiento de alginato es una técnica eficiente que permite medir la inactivación térmica en las diferentes áreas del horno de microondas durante todo el proceso y permite interpretar su eficiencia y variabilidad.

Durante los últimos años se han dedicado muchos esfuerzos de investigación para 
cuantificar impacto de la variabilidad biológica en la inactivación microbiana [28]. Sin embargo, como se evidencia en este trabajo de investigación, fuentes extrínsecas de variabilidad (p. ej., variaciones en la composición de los alimentos o en el desnivel electromagnético campo) puede ser más relevante que las fuentes intrínsecas para algunos tratamientos.

En las observaciones derivadas de los ensayos experimentales, las simulaciones para un perfil de temperatura ideal, considerando la variabilidad e incertidumbre asociados a los parámetros cinéticos estimados mediante tratamientos térmicos, explicaría una variación de aproximadamente $0,41 \mathrm{log}$ UFC/ml. Sin embargo, los resultados muestran variaciones dentro del mismo tratamiento de varios ciclos logarítmicos. Esta gran desviación con respecto al resultado ideal es debido a la gran relevancia de las fuentes extrínsecas de variabilidad en este tratamiento como es la desigual distribución de la temperatura en el producto.

Estas fuentes de variabilidad están relacionadas no solo con variaciones en la composición del producto alimenticio (p. ej., variaciones en la cantidad de tejido graso en diferentes puntos de la F-BP), sino también con el diseño del aplicador y la no uniformidad intrínseca del patrón de campo eléctrico en toda la muestra. Estos parámetros afectan tanto a la transferencia de calor como a la cinética de inactivación que apenas se pueden describir utilizando los modelos matemáticos actuales. Por esta razón, para métodos de variabilidad alternativos de análisis se requiere validar este tipo de proceso desde el punto de vista microbiano y de seguridad alimentaria.

\subsection{Conclusiones}

En este trabajo, se ha desarrollado un sistema que se puede utilizar para evaluar y optimizar la pasteurización de microondas a escala industrial. Se basa en las esporas de B. cereus como elemento del sensor retenido en una matriz de alginato. Este método puede establecer eficientemente las zonas frías y calientes, para el proceso de inactivación total, dentro del producto procesado basado en los resultados de la inactivación microbiana. 
Debido a las dificultades para obtener simulaciones electromagnéticas y de transferencia de calor y masa precisas en este escenario, y la forma no práctica de obtener información sobre la distribución de la temperatura durante el proceso de calentamiento, la matriz espacial de Bacillus cereus surge como un práctico indicador sobre el grado de inactivación obtenido en todo el producto.

Los resultados obtenidos muestran que, para este proceso, las fuentes extrínsecas de variabilidad (heterogeneidades en la temperatura a lo largo de la matriz alimentaria) son más relevantes que las fuentes intrínsecas de variabilidad (diferencias biológicas entre las células bacterianas). En consecuencia, las consideraciones de fuentes extrínsecas de variabilidad son esenciales para la validación de tratamientos de pasteurización para este tipo de proceso.

\title{
4.5. Publicaciones generadas
}

Los trabajos descritos en este capítulo han dado lugar a la publicación:

\begin{abstract}
Alberto Garrea, Alejandro Acosta, Juan D. Reverte-Ors, Paula M. Periago, Alejandro Diaz-Morcillo, Arturo Esnoz, Juan L. Pedreño-Molina, Pablo S. Fernandez. "Microbiological and process variability using biological indicators of inactivation (BIls) based on Bacillus cereus spores of food and fish-based animal by-products to evaluate microwave heating in a pilot plant". "Food Research International". Volumen 137, noviembre de 2020, 109640.
\end{abstract}

Y a los posters en un Congreso Internacional:

Juan Antonio Sotomayor, Juan D. Reverte-Ors, Alberto Garre, Asunción Iguaz, Alejandro Díaz, Pablo S. Fernández, Juan L. Pedreño-Molina y Paula M. Periago. "Modelling microbial inaxtivation by microwave heating". Q-Safe International Conference. Quantitive tools for sustainable Food and Energy in the Food Chain. Ermoupoli (Syros island). GREECE. 10-12 Abril 2017. 
Alberto Garre, Juan D. Reverte-Ors, José A. Egea, Paula m. Periago, Juan Luis Pedreño-Molina, Pablo S. Fernández. "A novel tool to model dynamic microbial inactivation followin a probabilistic approach". Q-Safe International Conference. Quantitive tools for sustainable Food and Energy in the Food Chain. Ermoupoli (Syros island). GREECE. 10-12 Abril 2017.

\subsection{Referencias}

[1] Membré, J.-M. \& Boué, G., 2018. Quantitative microbiological risk assessment in food industry: Theory and practical application. Food Res. Int. 106, 1132-1139.

[2] Peng, J., Tang, J., Barrett, D.M., Sablani, S.S., Anderson, N. \& Powers, J.R. (2017). Thermal pasteurization of ready-to-eat foods and vegetables: Critical factors for process design and effects on quality. Crit. Rev. Food Sci. Nutr., 57, 2970-2995.

[3] Rajkovic, A., Smigic, N. \& Devlieghere, F., (2010). Contemporary strategies in combating microbial contamination in food chain. International Journal of Food Microbiology. 141, S29-S42.

[4] Schubert, H. \& Regier, M. (Eds.), (2005). The microwave processing of foods. Woodhead Publishing in Food Science and Technology. CRC Press, Boca Raton, Fla.

[5] Reverte-Ors, J.D., Pedreño-Molina, J. L., Fernández, P.S., Lozano-Guerrero A. J., Periago P. M. \& Díaz-Morcillo A. (2017). A Novel Technique for Sterilization Using a Power Self-Regulated Mono-Mode Microwave Cavity". Sensors, 17, 1309-1321.

[6] Plaza-Gonzalez, P., Monzó-Cabrera, J. \& Catalá- Civera, J. M. (2005). Effect of modestirrer configurations on dielectric heating performance in multimode microwave applicators. IEEE Trans. Microw. Theory Tech., 53 (5), 1699-1706.

[7] Domínguez-Tortajada, E., Plaza González, P., Díaz Morcillo, A. \& Balbastre Tejedor, J. V. (2007). Optimisation of Electric Field Uniformity in Microwave Heating Systems 
by means of Multi feeding and Genetic Algorithms. Int. J. Materials and Product Technol., 29, 149-162.

[8] H Albert, DJ Davies. "Biological Indicators for Steam Sterilization: Characterization of a rapid biological indicator utilizing $B$. Stearthermophilus spore associated alpha-glucosidase enzyme," Journal of applied Microbiology, 1998: 65, 66.

[9] Frakolaki, G., Giannou, V., Kekos, D. \& Tzia, C., (2020). A review of the microencapsulation techniques for the incorporation of probiotic bacteria in functional foods. Crit. Rev. Food Sci. Nutr.

[10] Ocio, M.J., Fiszman, S.M., Gasque, F., Rodrigo, M. \& Martínez, A. (1997). Development of a restructured alginate food particle suitable for high temperature short time process validation. Food Hydrocolloids 11, 423-427.

[11] Lopes, L.A.A., Carvalho, R.S.F., Magalhaes, N.S.S., Madruga, M.S., Athayde, A.J.A.A., Portela, I.A., Barao, C.E., Pimentel, T.C., Magnani, M. and Stamford, T.C.M. (2020). Microencapsulationof Lactobacillus acidophilus La-05 and incorporation 564 in vegan milks: Physicochemical characteristics and survival during storage, exposure to stress conditions, and simulated gastrointestinal digestion. Food Res. Int., 135, 109295.

[12] OCDE-FAO Perspectivas Agrícolas 2019-2028.

[13] Aspridou, Z. \& Koutsoumanis, K.P., (2015). Individual cell heterogeneity as variability source in population dynamics of microbial inactivation. Food Microbiol., 45, Part B, 216-221.

[14] Messens, W., Fernandez Escamez, P. S., Lees, D., Lindqvist, R., O'Mahony, M., Suffredini, E., Cortiñas Abrahantes, J., Chantzis, E. \& Koutsoumanis, K. (2018). Thermal processing of live bivalve molluscs for controlling viruses: on the need for 
a risk-based design. Critical Reviews in Food Science and Nutrition, 58(16):28542865.

[15] López, M.D., García P., Muñoz-Cuevas, M., Fernández, P.S. \& Palop, A. (2011). Thermal inactivation of Alicyclobacillus acidoterrestris spores under conditions simulating industrial heating processes of tangerine vesicles and its use in Time Temperature Integrators. European Food Res. Technol., 232, 821-827.

[16] van Zuijlen, A., Periago, P.M., Amézquita, A., Palop, A., Brul, S. \& Fernández, P.S. (2010). Characterization of Bacillus sporothermodurans IC4 spores; putative indicator microorganism for optimisation of thermal processes in food sterilisation. Food Res. Int., b43: 1895-1901.

[17] EFSA BIOHAZ Panel (EFSA Panel on Biological Hazards), (2016). Scientific opinion on the risks for public health related to the presence of Bacillus cereus and other Bacillus spp. Including Bacillus thuringiensis in foodstuffs. EFSA Journal, 14(7), 4524, 93 pp. doi: 10.2903/j.efsa.2016.4524

[18] Fernández, A., Ocio, M.J., Fernandez, P.S. \& Martınez, A. 536 (2001). Effect of heat activation and inactivation conditions on germination and thermal resistance parameters of Bacillus cereus spores. Int. J. Food Microbiol., 63, 257-264.

[19] CASTILLO COLOMBO, C; SOSA BRICENO, ; SCORZA, J. Evaluación de la termorresistencia en metabolitos antifúngicos producidos por esporulados del género Bacillus. Rev. Soc. Ven. Microbiol., Caracas , v. 24, n. 1-2, p. 6567, enero 2004 .

[20] Conesa, R., Andreu, S., Fernández, P. S., Esnoz, A., \& Palop, A. (2009). Nonisothermal heat sistance determinations with the thermoresistometer Mastia. J. Appl. Microbiol., 107(2), 506-513. doi: 10.1111/j.1365-2672.2009.04236.x 
[21] Owusu-Darko, R ;Allam, M .; Ismail, A ;Ferreira, CAS; Oliveira, SD; Buys, EM Análisis comparativo del genoma de Bacillus sporothermodurans con su vecino filogenético más cercano, Bacillus oleronius y Bacillus cereus y Bacillus subtilis Grupos. Microorganismos 2020 , 8, 1185.

[22] Shapiro, S.S. \& Wilk, M.B., (1965). An analysis of variance test for normality (complete samples). Biometrika 52, 591-611.

[23] Garre, A., Clemente, M., Fernandez, P.S., Lindqvist, R \& Egea, J. A. (2018). Bioinactivation FE: Software for modelling dynamic microbial inactivation. Food Res. Int.,112, 353-360. Garre, A., Fernandez, P.S., Lindqvist, R \& Egea, J. A. (2017). Bioinactivation: Software for modelling dynamic microbial inactivation. Food Res. Int., 93, 66 - 74 .

[24] Fernández, A., Ocio, M.J., Fernández, P.S., Rodrigo, M. \& Martinez, A., (1999). Application of nonlinear regression analysis to the estimation of kinetic parameters for two enterotoxigenic strains of Bacillus cereus spores. Food Microbiology 16, 607-613. https://doi.org/10.1006/fmic.1999.0282

[25] Douglas M Bates, Donald G Watts, (2007). Nonlinear Regression Analysis and Its Applications.

[26] Jarvis, B., (2008). Statistical aspects of the microbiological examination of foods. Elsevier Academic Press, S.I.

[27] Lau, M.H. \& Tang, J. (2002). Pasteurization of pickled asparagus using $915 \mathrm{MHz}$ microwaves. J.Food Eng., 51, 283-290.

[28] den Besten, H.M.W., Wells-Bennik, M.H.J. \& Zwietering, M.H., 2018. Natural Diversity in Heat Resistance of Bacteria and Bacterial Spores: Impact on Food Safety and Quality. Annual Review of Food Science and Technology 9, 383-410. 
CAPÍTULO 4. DESARROLLO DE UNA NUEVA GENERACIÓN DE BIOSENSORES MICROBIOLÓGICOS ESPECÍFICOS PARA VALIDAR PROCESOS DE ESTERILIZACIÓN POR MICROONDAS

[29] Domínguez Tortajada, E., Monzó Cabrera, J. \& Díaz Morcillo, A. (2007). Uniform Electric Field Distribution in Microwave Heating Applicators by Means of Genetic Algorithms Optimization of Dielectric Multilayer Structures. IEEE Trans. Microw. Theory Tech., vol. 55 (1), 85-9,12007. 


\section{CAPÍTULO 5}

\section{DISEÑO DE UNA SOLUCIÓN DE ESTERILIZACIÓN CON MICROONDAS EN CAVIDAD MONOMODO}

\subsection{Introducción}

Los procedimientos convencionales de esterilización de alimentos envasados, se basan en tratamientos en botes, vasijas o contenedores que son sometidos a altas presiones y temperaturas superiores a $100^{\circ} \mathrm{C}$ para garantizar su seguridad. Para asegurar la ausencia de microorganismos patógenos, así como de sustancias tóxicas para el consumidor, es necesario establecer la seguridad alimentaria del producto final que se consumirá [1].

El tratamiento de los subproductos alimentarios (residuos), también es de suma importancia para reducir su impacto ambiental de manera eficiente. Es por ello que el uso de microondas para procesos de esterilización puede resultar, en muchos casos, muy restrictivo, siendo bien conocidos $[2,3]$ los problemas de esterilización o pasteurización de alimentos con microondas en el ámbito industrial.

Como ya hemos comentado; estos productos esterilizados presentan una pérdida significativa de nutrientes en comparación con los procesados con métodos convencionales, ya que para garantizar la esterilización en el producto es necesario aumentar la temperatura y el tiempo de exposición en toda la muestra. El problema que se encuentra aquí es la dificultad de obtener un calentamiento uniforme en todo el producto utilizando la tecnología de microondas $[4,5]$. En los procesos de esterilización o desperdicio de alimentos, este control de uniformidad es la clave para obtener un producto seguro y mantener su calidad nutricional. Este es el principal obstáculo en el uso de microondas, así como la definición de criterios de proceso para microorganismos, como Clostridium perfringens, Salmonella y Enterobacteriaceae.

El calentamiento no uniforme del producto se debe a dos razones fundamentales. Primero, la energía de microondas decae exponencialmente a medida que la onda 
ingresa al material y su potencia se disipa en forma de calor. Por lo tanto, en el caso de productos con altas pérdidas dieléctricas, como las biológicas, la onda se atenúa rápidamente. Como consecuencia de este hecho, deben formarse productos, con un espesor de alrededor de 1-2 cm, si se desea una buena uniformidad de calentamiento.

Por otro lado, el campo eléctrico tiene una alta variabilidad dentro de una cavidad resonante, resultado de la combinación de los diferentes modos resonantes que son excitados por la fuente de microondas, lo que resulta en un calentamiento no homogéneo. Los intentos de mejorar esta uniformidad se han basado tradicionalmente en mecanismos de movimiento del producto (plataforma giratoria o cinta transportadora continua) o agitadores de modo [2], que modifican las condiciones de contorno de la cavidad, produciendo una variación temporal del patrón del campo eléctrico. Con estas dos soluciones, no obstante, no se garantiza una uniformidad de temperatura como se requiere en los procesos de esterilización, sobre todo en los materiales con altas pérdidas dieléctricas.

Algunas técnicas recientes para la uniformización de calentamiento en plataformas de simulación para cavidades multimodo, se basan en el uso de múltiples puertos con diferentes alimentaciones de fase [6], optimización por variación de parámetros con tecnología CAD de microondas $[\mathbf{7}, \mathbf{8}]$, determinación del punto óptimo de una muestra para minimizar la desviación de un patrón de calentamiento [9] o uso de agitadores [10]. Sin embargo, cuando se requiera el proceso de esterilización con temperaturas superiores a $100^{\circ} \mathrm{C}$, se deben controlar las condiciones de calentamiento por microondas para minimizar la desviación de temperatura esperada.

También se han simulado desarrollos específicos para procesos de esterilización como los mostrados en [11]. En [12] se empleó una potencia de microondas muy alta en una cavidad cilíndrica para medir el efecto de la esterilización en una muestra de alimento específica.

En este capítulo se ha diseñado y validado una instalación real basada en una cavidad resonante monomodo para el tratamiento en tubo de ensayo y en condiciones de 
presión de pequeñas muestras, de tal modo que se garantice la uniformidad de calentamiento en la muestra a altas temperaturas, monitorizando el proceso con sensores de temperatura de fibra óptica en el interior del material. Para ello, se ha utilizado el simulador electromagnético Microwave CST Studio, obteniendo las curvas de resonancia de las muestras a procesar y su posterior verificación con el diseño seleccionado. Este dispositivo ha permitido identificar el régimen óptimo de radiación microondas (potencia-tiempo).

Lo más destacable ha sido el desarrollo íntegro no sólo de la propia cavidad con ventana de presión y los elementos necesarios para conseguir una temperatura uniforme en el interior de la muestra, sino el desarrollo del sistema de control tiempo-potenciatemperatura, que ha permitido disponer de un sistema robusto para ésta y futuras aplicaciones en el campo de las microondas.

Con referencia a los sensores biológicos, como ya comentamos en el capítulo 2, otro objetivo de este trabajo es obtener y verificar, midiendo las UFC como parámetro, un dispositivo microondas con alta uniformidad de calentamiento volumétrico en procesos de temperatura por encima de $100^{\circ} \mathrm{C}$ para la esterilización de alimentos y desechos animales. Para ello, se ha diseñado una geometría específica de aplicador, en condiciones de presión, con mecanismos de movimiento interno, y con biosensores. El sistema está controlado en línea por el software Matlab ${ }^{\circledR}$ que determina continuamente el perfil de la curva tiempo-potencia para minimizar la desviación final de la temperatura objetivo y garantizar la inactivación de los patógenos.

Por otro lado, el desarrollo de biosensores es necesario para establecer la inocuidad alimentaria del producto completo final, con información veraz de los principales puntos representativos de la muestra, lo que asegura la ausencia de microorganismos patógenos y sustancias tóxicas para el consumo [13]. Se han utilizado biosensores microbiológicos para validar procesos convencionales de esterilización por calor en los que se conocen puntos más fríos [14]. En el caso del calentamiento por microondas, la incertidumbre sobre los puntos fríos es el principal desafío para garantizar la seguridad de los alimentos 
o productos tratados $y$, por lo tanto, caracterizar un microorganismo adecuado que pueda evaluar la uniformidad en diferentes sustratos fue un paso clave.

\subsection{Materiales, métodos y configuración experimental}

\subsubsection{Diseño del sistema monomodo de microondas}

\subsubsection{Medida de las Propiedades Dieléctricas de los Materiales Tratados}

Se ha estudiado la respuesta electromagnética de diferentes muestras de sopas y desechos de pescado y se ha caracterizado la permitividad eléctrica en función de la temperatura a una frecuencia cercana a $2,45 \mathrm{GHz}$ mediante el dielectrómetro de ITACA (Mod. Dialkitv). En el apartado 5.3.1 se mostrarán los resultados para estas propiedades dieléctricas.

\subsubsection{Diseño de la cavidad monomodo}

A partir de las mediciones de permitividad, la cavidad resonante monomodo, ha podido ser diseñada para realizar pruebas de calentamiento a presión con muestras pequeñas introducidas en tubos de ensayo de tal manera que se garantice la uniformidad del calentamiento en la muestra. Se han incluido sensores de temperatura que monitorizan el tratamiento de las muestras a lo largo del tiempo de irradiación de microondas. Para medir la temperatura de forma precisa, se ha introducido en la muestra un dispositivo por fibra óptica Opsens (EQ013 TEMPSENS) para obtener el valor en tiempo real.

Como muestra la figura 5.1 , se ha diseñado y construido una cavidad cilíndrica, sintonizable, con sistema vibratorio, presurizada, y con sistema de apertura-cierre rápido, que permite el calentamiento de muestras de diversos tamaños con un amplio rango de permitividades, así como la monitorización de la temperatura a través de la introducción de fibras ópticas. 


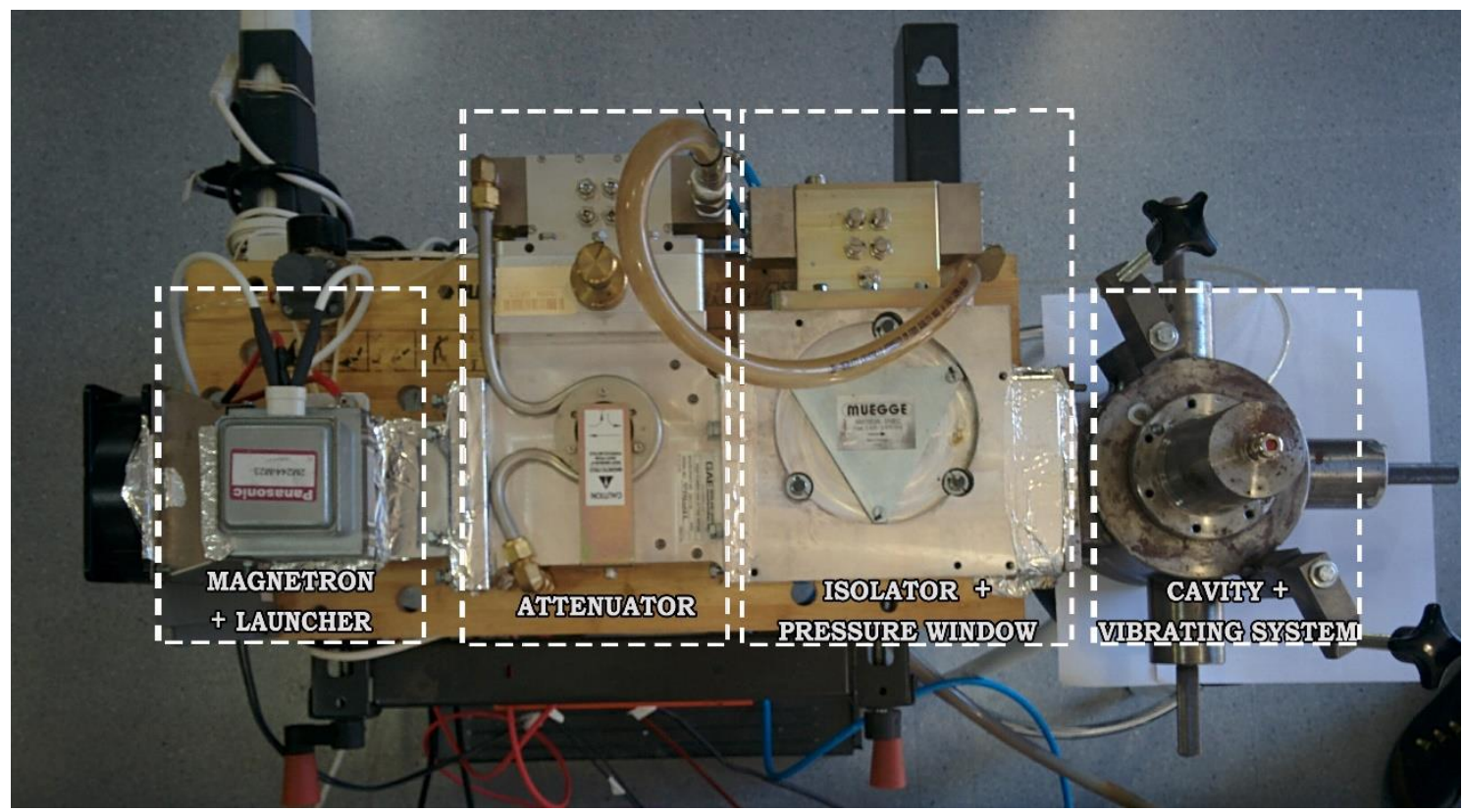

Figura 5.1 Prototipo experimental de cavidad cilíndrica monomodo de microondas para obtener perfiles de temperatura precisos para fines de esterilización.

Como puede comprobarse, el prototipo desarrollado ad-hoc está formado por:

- Fuente de alimentación Muegge (Mod. MX1000C-112KL), que ofrece un control preciso y continuo de la potencia de microondas programada con Matlab.

- Magnetrón estándar de 1kW (Panasonic Mod. 2M244-M23) que transforma la energía eléctrica en energía electromagnética de microondas.

- Launcher para transmitir la energía del magnetrón a la cavidad de microondas. MUEGGE Launcher WR340

- Circulador de agua (Fisher Bioblock Scientific), para refrigerar el circuito.

- Atenuador (GAE GA1118) para adaptar la potencia de microondas a las muestras de alimentos de $3 \mathrm{ml}$.

- Aislador, implementado mediante circulador Muegge (Mod. MM1003A 210EC), para proteger el magnetrón desviando la energía de microondas reflejada para 
ser disipada mediante una carga de agua, con conexión para incluir un detector de potencia entrante.

- Cavidad resonante cilíndrica. Fabricada en el laboratorio, por el Grupo I+D de Electromagnetismo y Materia de la UPCT, a medida para este aplicador.

La cavidad diseñada, mostrada en la Figura 5.2, incluye un sistema de sintonización para adaptar la carga a calentar, un sistema de vibración para obtener una mayor uniformidad de calentamiento y el sistema de presión para alcanzar temperaturas superiores a los $100^{\circ} \mathrm{C}$. Este sintonizador se ha realizado mediante tornillos, lo que permite modificar la frecuencia de resonancia de la cavidad y adaptarla para obtener la mínima reflexión posible y para poder tratar una amplia gama de materiales. La figura 5.3 muestra los planos de dicha cavidad. El sistema vibratorio consta de una placa de PTFE con orificios en su superficie giratoria accionada por un motor, que mueve la muestra hacia arriba y hacia abajo con una frecuencia de aproximadamente 5 veces por segundo, diseñado y construido para mejorar la uniformidad de temperatura al agitar el contenido interno de la muestra.

El sistema de apertura y cierre ha sido diseñado para poder cerrar de forma segura la cavidad cuando se trabaja bajo presión hasta 5 atm, y poder abrirla rápidamente para sacar la muestra (Figura 5.4).

Como se ha comentado, el sistema está presurizado mediante la combinación de tres diseños: juntas tóricas en tornillos y tapa, tabique en los sensores de temperatura de la zona de las fibras y ventana de presión en la sección de conexión del sistema de alimentación de energía con la cavidad resonante, como puede comprobarse en las siguientes figuras y cuyas características se detallan a continuación. La ventana de presión utilizada es: MUEGGE Vacuum-Window 6k 2450MHz WR340 MW0002C-260EC. 
CAPÍTULO 5. DISEÑO DE UN HORNO DE TÚNEL DE MICROONDAS PARA LA ESTERILIZACIÓN Y SECADO DE SANDACH

Figura 5.2. Cavidad diseñada, incluidos los sistemas de sintonización y vibración.

$\mathrm{A}$

Figura 5.3 Plano de Cavidad diseñada (1). 
Figura 5.4 Plano de Cavidad diseñada (2).
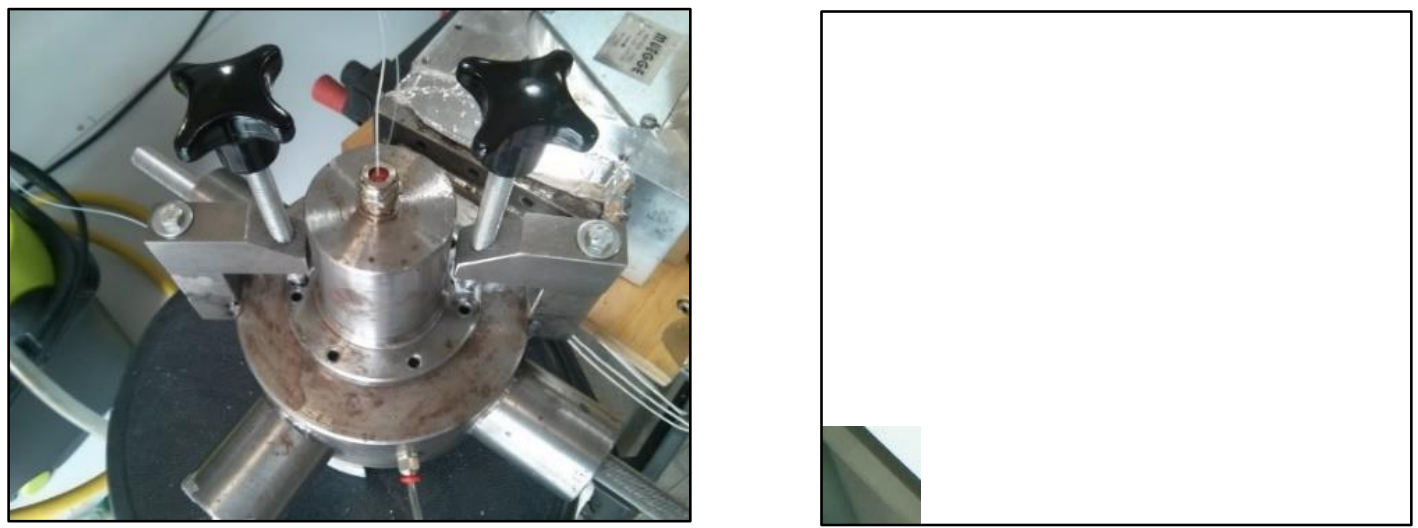

Figura 5.5 Detalle del sistema de apertura y cierre y de la transición de guía rectangular.

El diseño mostrado es cilíndrico para intentar asegurar la mayor eficiencia y homogeneidad en el calentamiento, mientras que el sistema de sintonización se realiza mediante stubs, o tornillos, lo que permite modificar la frecuencia de resonancia de la cavidad y adaptarla lo máximo posible para un amplio rango de materiales.

Tanto las dimensiones de la cavidad como los tornillos se diseñaron mediante CST para poder sintonizar desde agua $\left(\varepsilon_{r}=81,54, \tan d=0,0277\right)$, hasta salmorejo $\left(\varepsilon_{r}=55,32\right.$, $\tan d=0,456)$ 
En cuanto al sistema de apertura y cierre, consta de unas mordazas giratorias ancladas al cuerpo de la cavidad que aprietan la tapa mediante el giro de unos tornillos.

\subsubsection{Diseño e implementación de software de control de perfiles de calentamiento}

Para controlar todo el sistema de calentamiento por microondas, se ha desarrollado una plataforma que incluye la información de los sensores, la actuación y la monitorización del proceso mediante software de control adaptativo. Este control permite ajustar la potencia suministrada de tal forma que la muestra mantenga la temperatura deseada el tiempo que sea necesario. El software permite, además, guardar los resultados del experimento para visualizarlos y analizarlos posteriormente.

En la Figura 5.6 se muestra un diagrama de flujo del procedimiento completo.

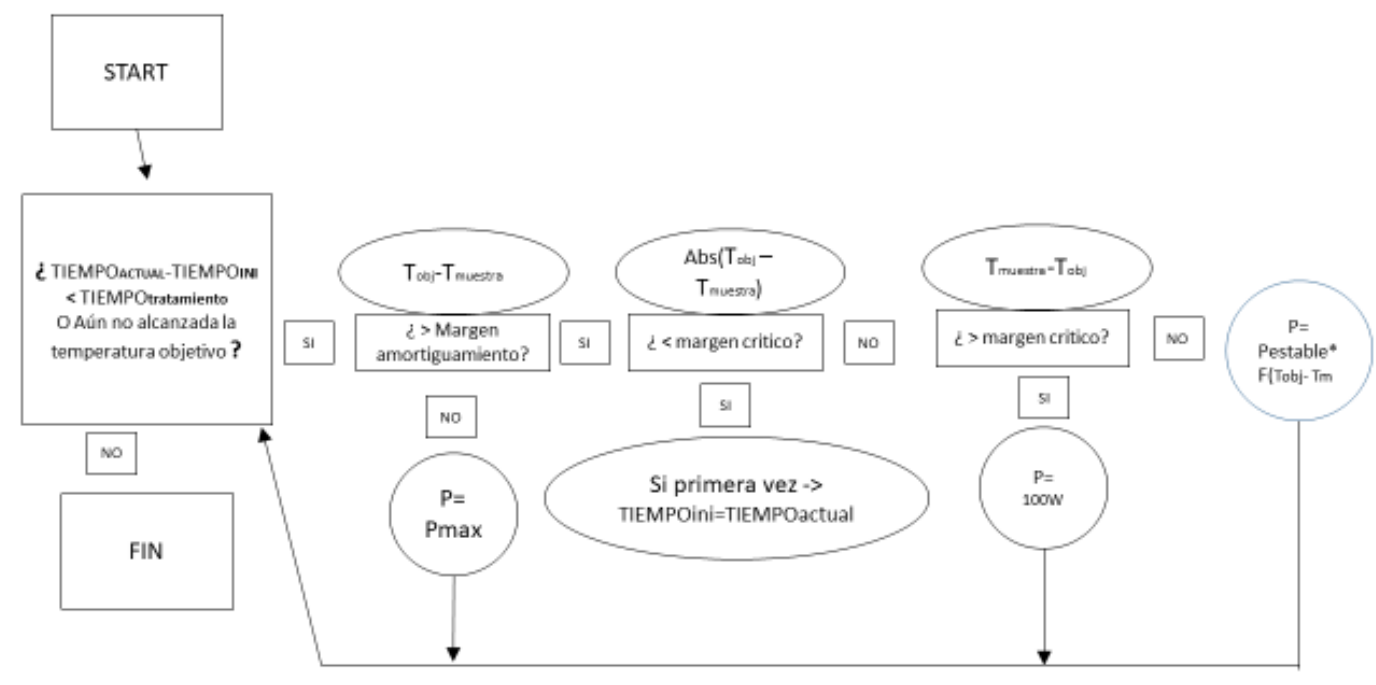

Figura 5.6 Diagrama de flujo del procedimiento adaptativo obteniendo la temperatura deseada durante el tiempo de tratamiento con microondas, considerando el tiempo de procesamiento (TimePro), el tiempo actual (TimeC), el margen crítico (CrMarg), la temperatura de la muestra (TempS) y la temperatura objetivo (TempTarg).

Para el proceso de esterilización se debe realizar un calentamiento por encima de $100^{\circ} \mathrm{C}$. Para ello, se conecta un sistema de aire comprimido a la cavidad para regular la presión, mediante el manómetro (Figura 5.8). El margen crítico se define como el umbral sobre la diferencia entre la temperatura actual y el objetivo final de la muestra. Cuando se alcanza 
este valor, el sistema disminuye de forma autónoma la potencia para entrar en la fase de mantenimiento en la que se ajustan las potencias de estabilización en función de la temperatura de la muestra. Se trata de un ajuste fino de la potencia para mantener la temperatura de la muestra lo más constante posible dentro del umbral inicial definido.

Se ha desarrollado una interfaz gráfica de usuario (GUI) de la guía Matlab $®$ para controlar y monitorizar el proceso, como muestra la Figura 5.7, permitiendo mostrar la temperatura en tiempo real y los perfiles de potencia incidente.

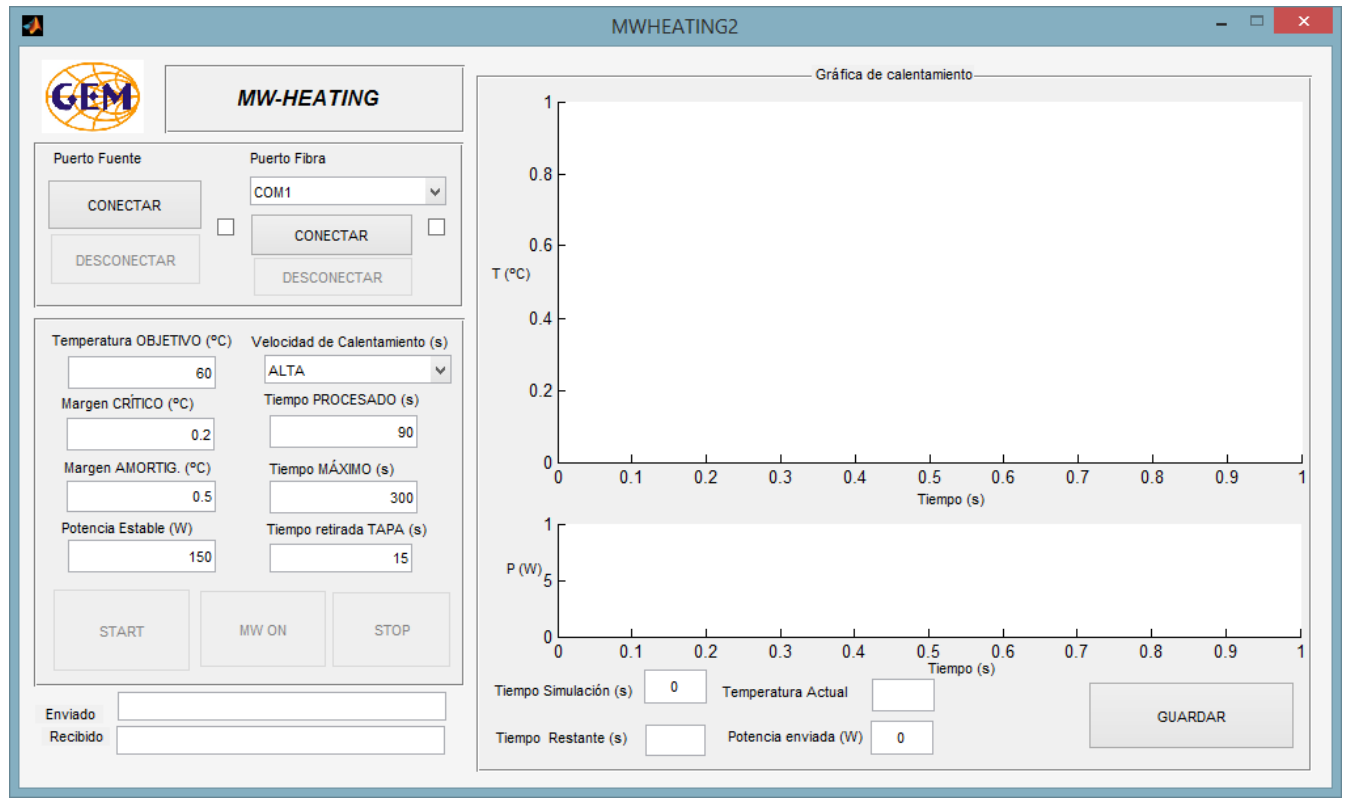

Figura 5.7 Herramienta Software de control.

Con el fin de emplear técnicas de simulación de bajo coste computacional para estudiar los principios de uniformización de campo eléctrico y de temperatura en el material que pueden producir las nuevas estructuras a desarrollar, se ha utilizado el PDE toolbox de Matlab. El control de la fuente de alimentación se realiza para resolver mediante el método de elementos finitos tanto la ecuación electromagnética (5.1), como la ecuación térmica acoplada a ésta (5.2), donde el acoplamiento entre ambas se produce a través del término de energía generada por disipación de las microondas en el material (5.3).

$$
\nabla^{2} \vec{E}+\omega^{2} \mu \varepsilon \vec{E}=0
$$




$$
\begin{gathered}
\frac{\partial T(x, y, z)}{\partial t}=\frac{k_{T}}{\rho \cdot c_{p}} \nabla^{2} T(x, y, z)+\frac{Q_{g e n}(x, y, z)}{\rho \cdot c_{p}} \\
Q_{g e n}(x, y, z)=2 \pi f \varepsilon_{0} \varepsilon^{\prime \prime}\left|\vec{E}_{\text {sample_rms }}(x, y, z)\right|^{2} \\
E_{i}=\sum_{p} A_{p} e^{-j \vec{k}_{p} \cdot \vec{r}}
\end{gathered}
$$

Con el fin de reducir aún más este coste, se ha sustituido la excitación en la guía de onda que alimenta a la cavidad por cuatro ondas planas con polarización TM, de tal manera que representamos el campo incidente en el problema como (5.4). Sin embargo, esta simplificación de sumatorio de ondas planas no es válida para analizar el efecto de la geometría del aplicador ni el uso de lentes dieléctricas, ya que se debe asumir para su uso que los materiales involucrados presentan elevadas pérdidas.

El control de la fuente de alimentación se realiza mediante bus CAN (utilizando el módulo Vehicle Network Toolbox de MATLAB). Este software permite, además, guardar los resultados del experimento para visualizarlos y analizarlos posteriormente. A modo de resumen, se enumeran las etapas básicas de actuación de esta plataforma:

- Selección del puerto y conexión con el medidor de fibras ópticas.

- Selección del puerto y conexión con el adaptador USB-CAN.

- Encendido de la fuente.

- Selección de la temperatura objetivo, la velocidad de calentamiento, el margen crítico (es la diferencia con la temperatura objetivo a partir del cual comienza a contar el tiempo de tratamiento), el margen de amortiguamiento (es la diferencia con la temperatura objetivo a partir de la cual el software entra en la fase de ajuste fino, para evitar grandes sobreimpulsos, ya que no se dispone de sistema de refrigeración controlado- y llevar a la muestra a temperatura 
demasiado elevada antes de estabilizar la misma), el tiempo máximo de procesado, la potencia de estabilización.

- Accionamiento de inicio (START). Aquí, el sistema alimentará inicialmente a la máxima potencia permitida según la velocidad de calentamiento seleccionada. Cuando este valor se aproxime al margen de amortiguamiento, comenzará a reducir la potencia hasta llegar a la temperatura objetivo. En esta situación, se inicia la fase de mantenimiento, que ajustará la potencia de estabilización en función de la temperatura de la muestra para que ésta se mantenga lo más constante posible en la temperatura objetivo durante el tiempo elegido.

La capacidad de la esta plataforma software de control permite la generación de gráficas, así que es posible mostrar la evolución de la temperatura, la potencia, el tiempo de procesado y el tiempo restante de la prueba, pudiendo ser esta información almacenada al terminar el proceso.

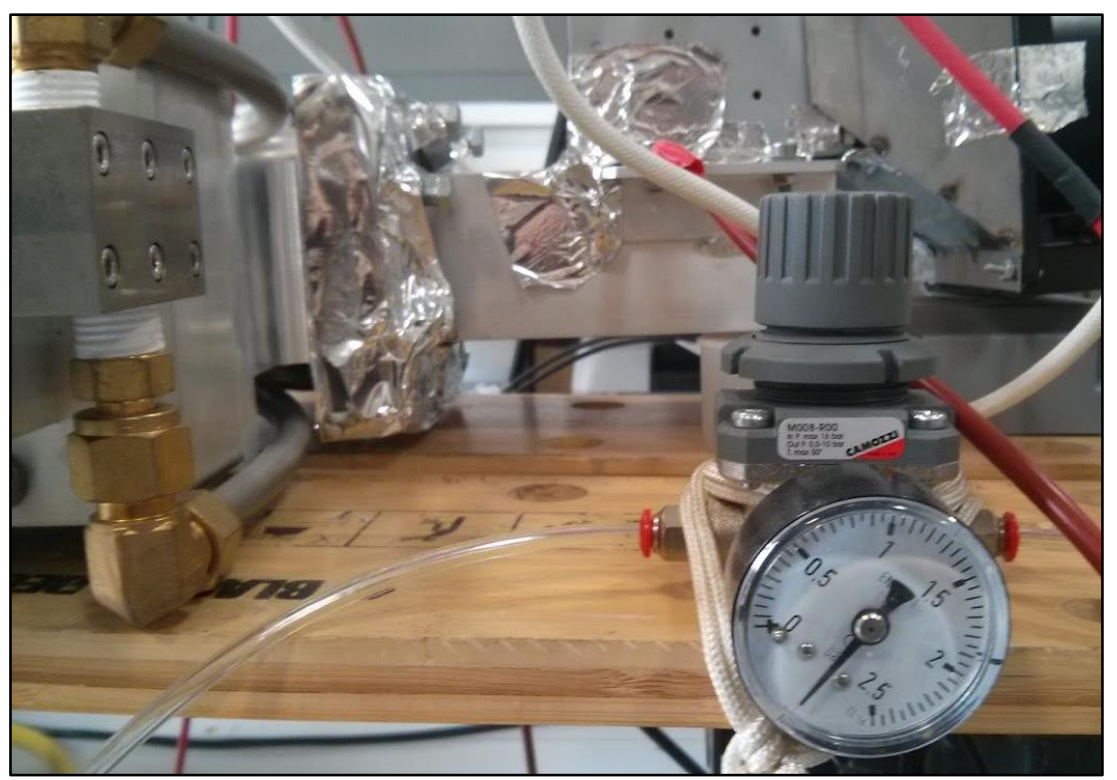

Figura 5.8. Control de presión.

Una vez diseñado el sistema monomodo para validar los resultados de esterilización en condiciones uniformes de temperatura, se ha abordado el proceso inicial de medida y validación de los objetivos de este trabajo enfocado a los procesos industriales, esta vez 
con cavidades multimodo con pruebas a Baja Temperatura. Para ello se ha utilizado un horno microondas doméstico modificado para poder introducir fibras ópticas y medir la temperatura según se está realizando el experimento. Este equipo de laboratorio permite girar de forma solidaria con el plato el sistema de medida de temperatura. Sin embargo, no permite calentar a más de $100^{\circ} \mathrm{C}$, debido a que no está presurizado, así como tampoco controlar la potencia según una temperatura objetivo.

En este sistema experimental, la máxima uniformidad de calentamiento se consigue girando la muestra dentro del mismo y es útil para realizar pruebas con cantidades de muestras elevadas.

Para mostrar su funcionamiento, a continuación, se muestra el resultado de un experimento para validar el sistema de control y monitorización a baja temperatura.

\section{Datos del Experimento:}

Proceso de calentamiento: Bajas Temperaturas

Temperatura Objetivo: $60^{\circ} \mathrm{C}$

Tiempo de mantenimiento de la temperatura: entre 50 y 120 segundos.

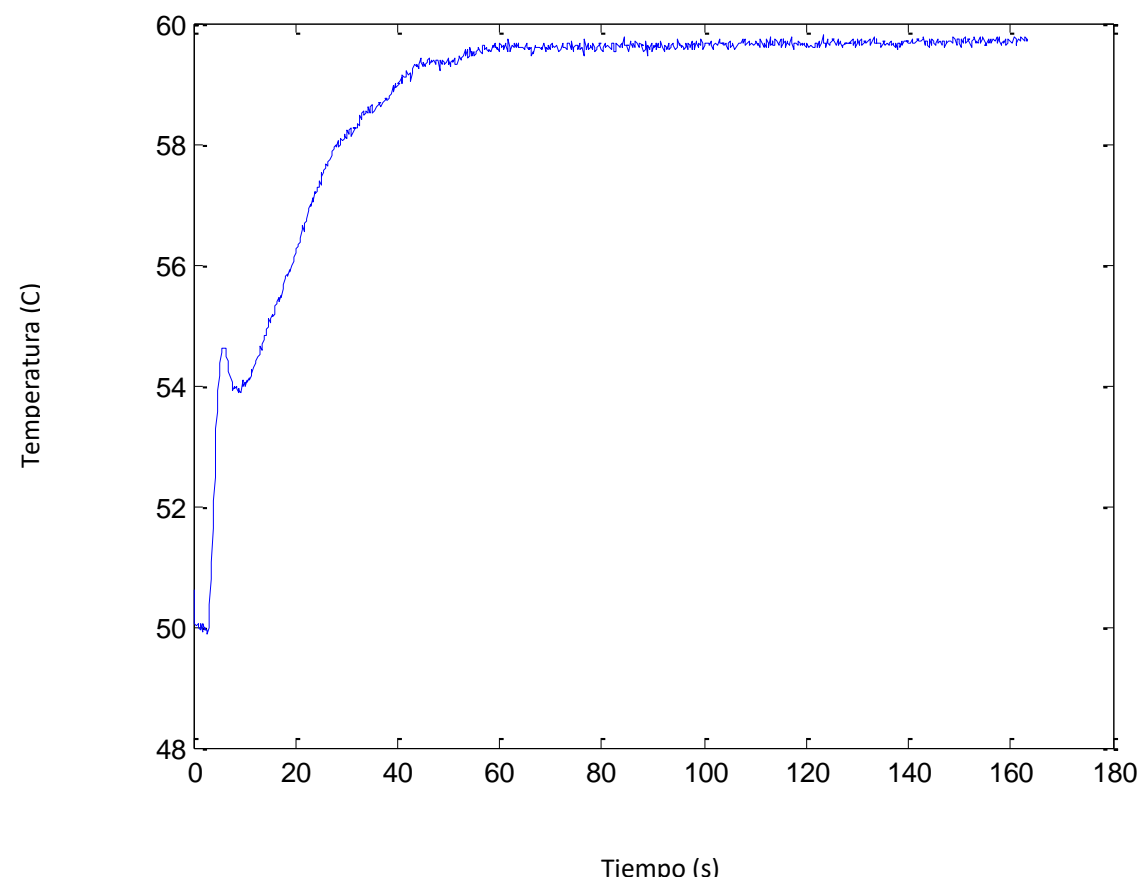

Figura 5.9 Evolución de la Temperatura. Error cometido $+0.1^{\circ} \mathrm{C}$ con offset de $-0.3^{\circ} \mathrm{C}$ 
Puesto que uno de los requisitos fundamentales de la plataforma, para los procesos de esterilización con microondas, debe ser el conseguir altas temperaturas en la muestra y de forma estable durante el periodo indicado, se ha sometido el sistema al funcionamiento en estas condiciones, habiéndose obtenido un funcionamiento adecuado, tal y como se muestra en las siguientes figuras:

\section{Datos del Experimento:}

Temperatura Objetivo: $100^{\circ} \mathrm{C}$

Tiempo de mantenimiento de la temperatura: 50 segundos.

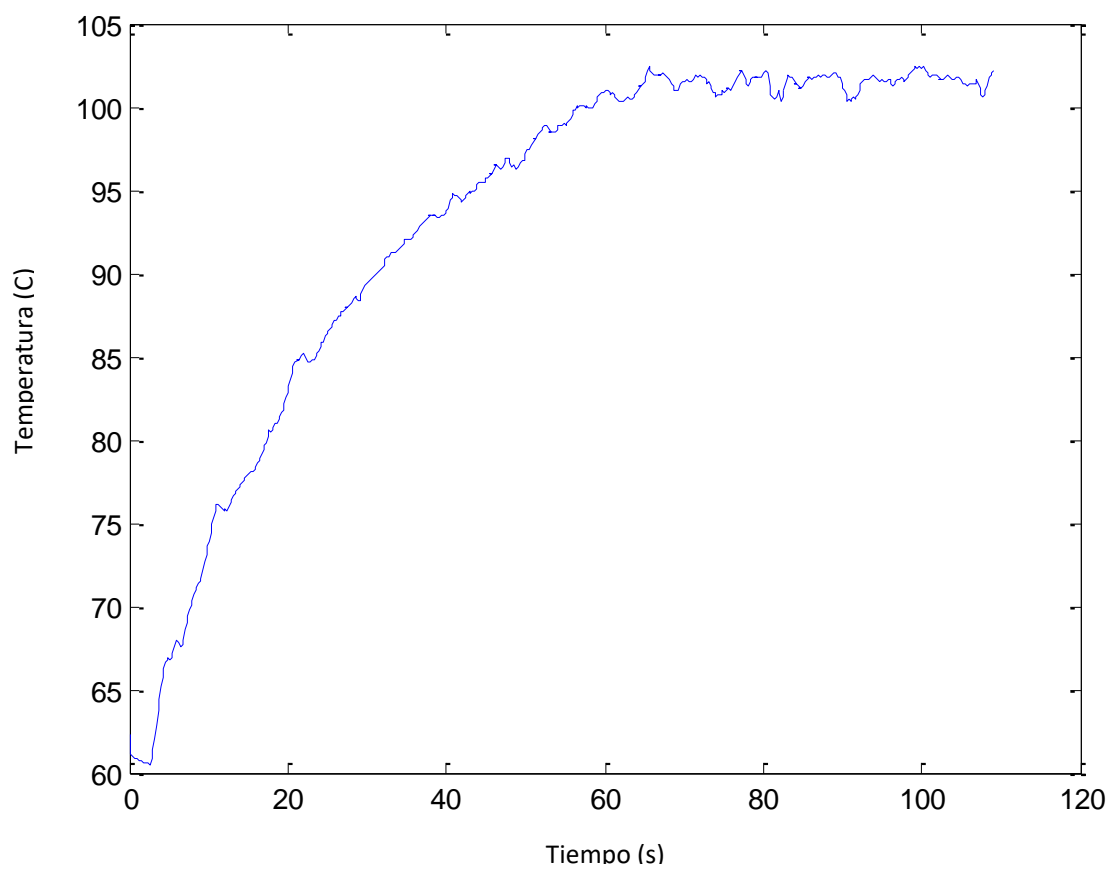

Figura 5.10 Evolución de la Temperatura. Error cometido $-0.5 a+2.5^{\circ}$

\section{Datos del Experimento:}

Temperatura Objetivo: $110^{\circ} \mathrm{C}$

Tiempo de mantenimiento de la temperatura: 50 segundos. 


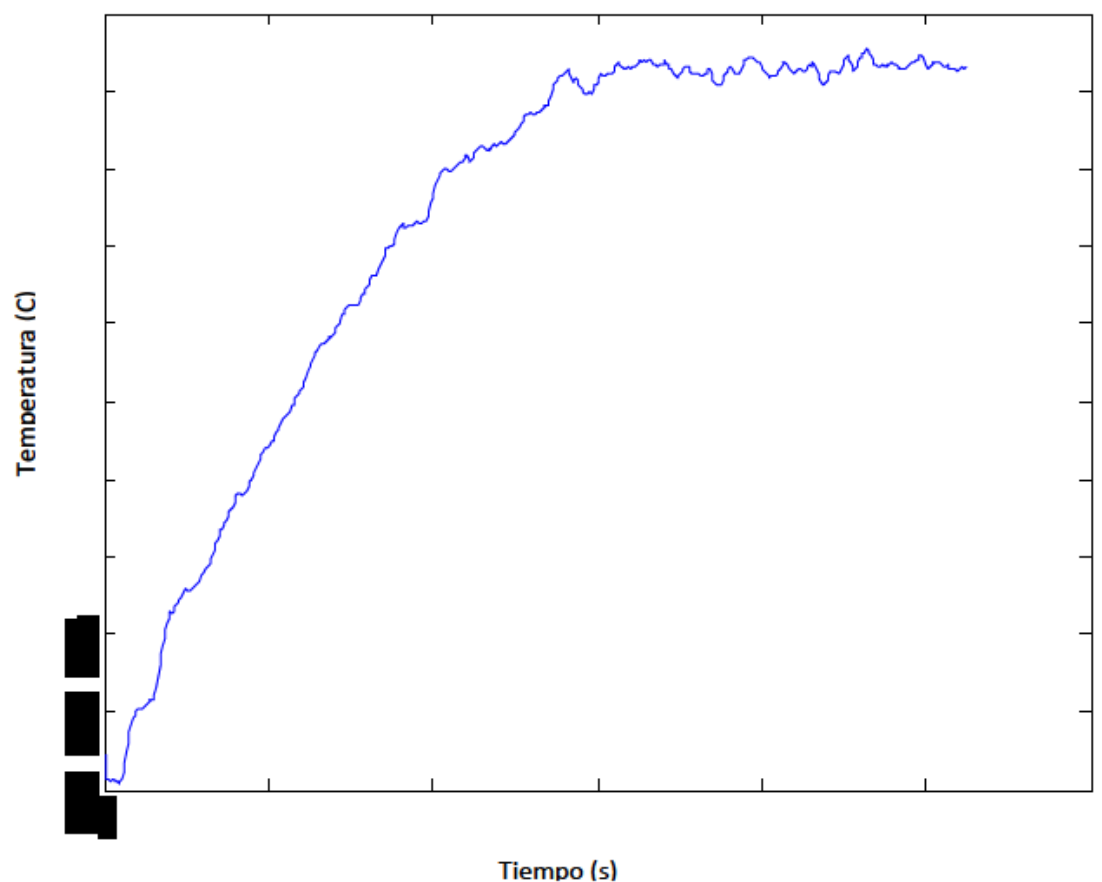

Figura 5.11 Evolución de la Temperatura. Error cometido $-0.2 a+1.7^{\circ}$

Como se puede observar, para lograr el comportamiento deseado para el proceso de esterilización por microondas, se deben seleccionar diferentes parámetros desde el software de interfaz, tal y como se muestra en la Figura 5.12.

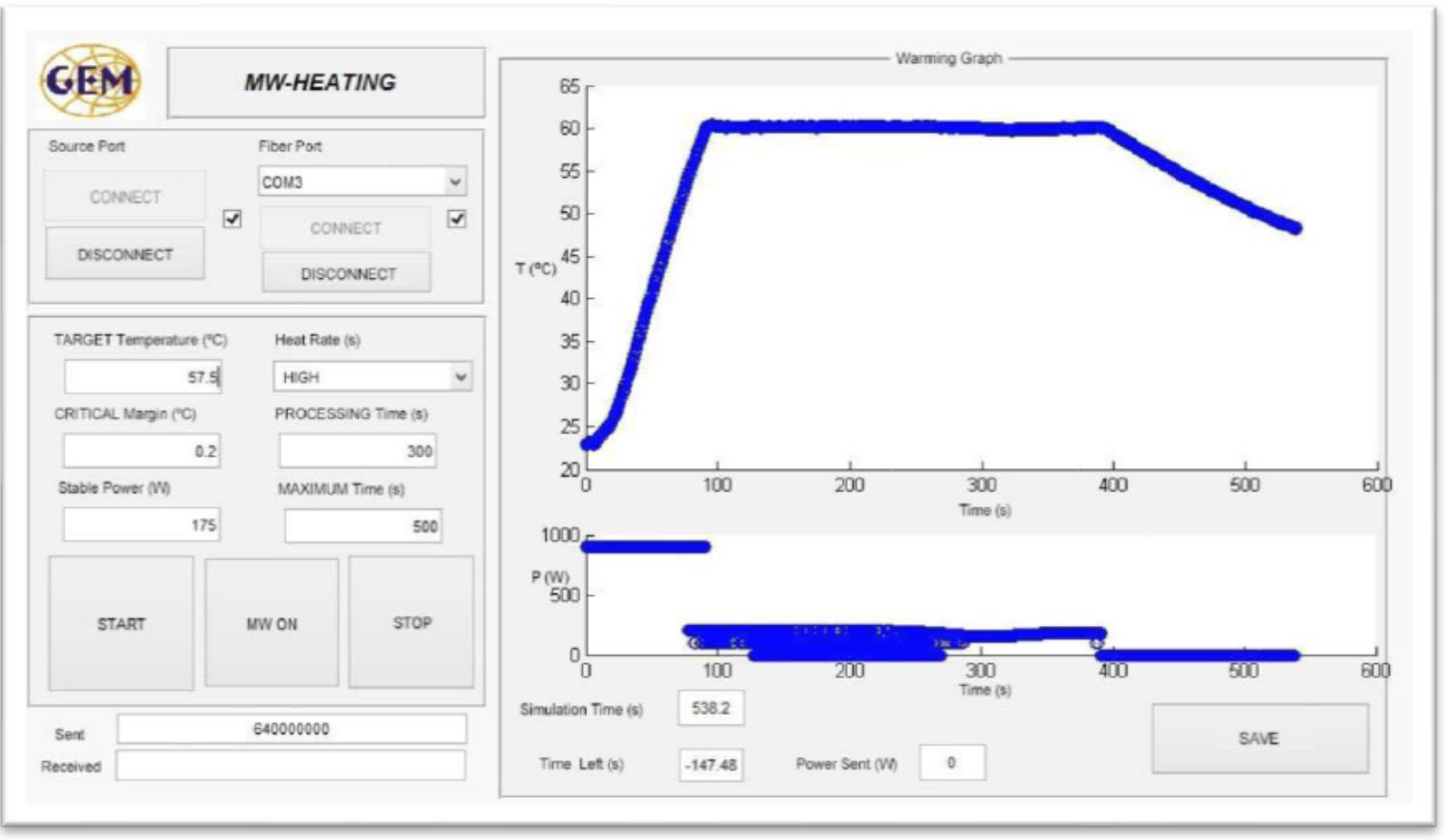

Figura 5.12 Interfaz de la GUI desarrollada para controlar el sistema desarrollado. 
La velocidad de calentamiento permite la selección de un cierto porcentaje sobre la potencia máxima del suministro de microondas. El objetivo principal de incluir el margen crítico es establecer de forma adaptativa el tiempo en el que el sistema software permanece en la fase de puesta a punto fina, con el fin de evitar grandes sobreimpulsos, así como evitar el sobrecalentamiento de la muestra a una temperatura elevada antes de estabilizarse.

\subsubsection{Determinaciones microbianas y sustratos alimentarios}

Para testear los sistemas de esterilización por microondas con los diseños realziados en este trabajo de investigación, se seleccionó como indicador un microorganismo formador de esporas altamente resistente al calor, Bacillus cereus, por ser un contaminante común y patógeno alimentario de diferentes alimentos y en su etapa esporulada presenta alta resistencia al calor.

Se seleccionaron los siguientes sustratos de alimentos (o medios de laboratorio) para los experimentos: caldo de infusión de cerebro y corazón como control; puré de verduras como alimento y un subproducto animal a base de pescado (F-ABP), obtenido a partir del homogeneizado de lubina.

Posteriormente el microorganismo se homogeneizó en los diferentes sustratos ensayados a una concentración conocida y se expuso a diferentes tiempos de calentamiento en la instalación de microondas descrita anteriormente. Las muestras se enfriaron, se diluyeron (diez veces) en agua de peptona estéril y se sembraron en placas de Petri, usando Brain Heart Infusion Agar como medio de recuperación. Una vez solidificado el medio, las placas se incubaron a $37^{\circ} \mathrm{C}$ durante $48 \mathrm{~h}$, procediendo a contar las colonias resultantes, representando los recuentos en escala log10 de supervivientes (expresados como unidades formadoras de colonias, UFC), frente al tiempo de exposición para cada temperatura y cinética de inactivación. 


\subsection{Resultados y discusión}

\subsubsection{Caracterización dieléctrica de la permitividad de las muestras}

Como paso previo al proceamiento de las muestras descritas, se ha estudiado el proceso de esterilización por microondas en pequeñas muestras de sopas, cremas y desechos de piscifactoría triturados, productos que se pueden considerar homogéneos y con un contenido en agua que permite una adecuada absorción de la energía microondas. El uso de pequeñas muestras permite un calentamiento con variaciones pequeñas de temperatura en el volumen de la muestra. Para ello se han diseñado y desarrollado los diferentes métodos y experimentos.

A partir de diferentes muestras y utilizando el resonador del Laboratorio del Grupo I+D GEM -Figura 5.13-, para la medida de las propiedades dieléctricas, se han obtenido y estudiado las respuestas a la exposición electromagnética de estos materiales, para su caracterización dieléctrica en función de la temperatura y a la frecuencia típica de emisión de una magnetrón de microondas de $2,45 \mathrm{GHz}$. Para ello se ha medido la permitividad compleja relativa del material representada por $\varepsilon_{r}$ que describe las propiedades dieléctricas que afectan a la reflexión y absorción de la energía de campo electromagnético en el material, y cuya expresión es $\varepsilon_{r}=\varepsilon^{\prime}-j \varepsilon^{\prime \prime}$, siendo $\varepsilon^{\prime}$ la constante dieléctrica y $\varepsilon^{\prime \prime}$ el factor de pérdidas del material

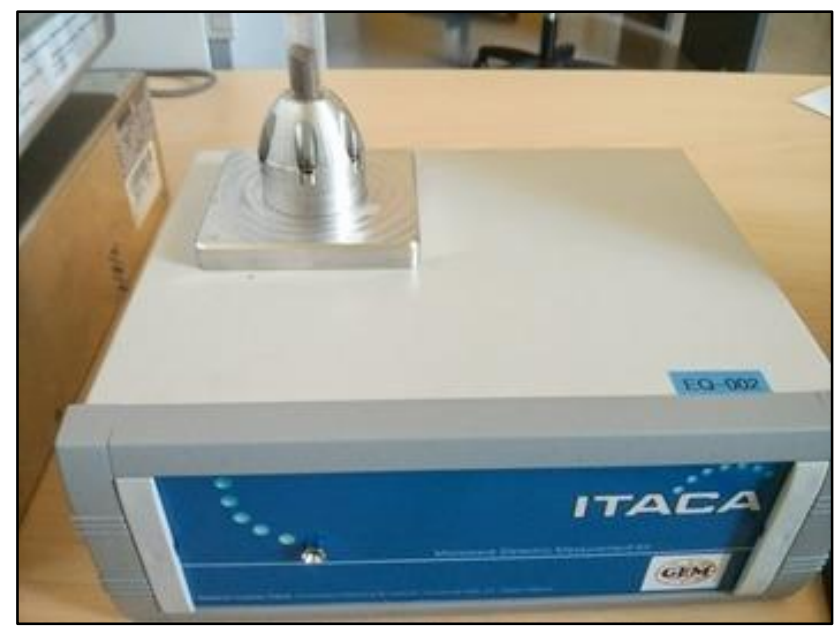

Figura 5.13 Equipo de medida de propiedades dieléctricas del material. 
Esta medida se basa en un método resonante que obtiene el valor de la permitividad eléctrica desde el cambio de la frecuencia de resonancia y la variación del factor de calidad cuando un material dieléctrico material se coloca en el interior de la cavidad [15]. El equipo permite la introducción de un envase estándar de polipropileno de $8 \mathrm{ml}(12 \mathrm{~mm}$ de diámetro y $75 \mathrm{~mm}$ de longitud). Los métodos resonantes se describen en detalle en [16].

La constante dieléctrica (que define el grado de polarización del material a ser sometido a un campo eléctrico) y el factor de pérdidas (que indica la capacidad de absorción de energía de microondas en el material) se muestran para los diferentes materiales estudiados en las Figuras 5.14 y 5.15, respectivamente, dependiendo de la temperatura alcanzada en cada prueba. Los materiales seleccionados han sido caldo de infusión de cerebro y corazón $(\mathrm{BHI})$, subproductos animales a base de pescado (F-ABP) y sopa de verduras.

55

20

Figura 5.14 Constante dieléctrica para las muestras del estudio cerca de los $2.45 \mathrm{GHz}$.

La variación de la constante dieléctrica de la muestra modifica la frecuencia de resonancia de la cavidad, pero el sistema de sintonización permite la modificación de la geometría de la cavidad para mantener la frecuencia de resonancia en $2,45 \mathrm{GHz}$, es decir, la frecuencia de operación con la misma cavidad. Por lo tanto, tanto las dimensiones de la 
cavidad como los tornillos fueron diseñados por CST Microwave Studio para poder ajustar una amplia gama de materiales.

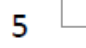

20

Figura 5.15 Factor de pérdidas para las muestras del estudio cerca de los $2.45 \mathrm{GHz}$

\subsubsection{Medidas de resonancia}

El coeficiente de reflexión de BHI y F-ABP se muestra en la Figura 5.16. Las mediciones se han realizado directamente midiendo la cavidad representada en la Figura 5.2 con las muestras correspondientes, utilizando un analizador de red vectorial Rodhe \& Schwarz ZVA 67 en configuración de reflexión en un puerto, utilizando para la calibraciónel kit WR-340 de CONTINENTAL. Los resultados de simulación se han obtenido el software CST Microwave Studio con los valores medidos de permitividad obtenidos de las figuras 5.14 y 5.15 a temperatura ambiente. Las ligeras diferencias pueden deberse a inexactitudes en el modelo CAD o en el modelo de permitividad en todo el rango de frecuencia de 2-3 GHz. El sistema cargado muestra una resonancia clara a frecuencias cercanas a los $2,45 \mathrm{GHz}$ y esta frecuencia se puede alcanzar fácilmente utilizando el sistema de sintonización. 


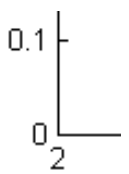

Figura 5.16 Coeficiente de reflexión medido y simulado para BHI y F-ABP.

\subsubsection{Perfiles de Temperatura en el tratamiento por microondas}

La Tabla 5.1 muestra las condiciones para algunos de los experimentos realizados. En estas condiciones, se han obtenido los perfiles de temperatura dibujados en la Figura 5.11 , alcanzando una temperatura objetivo de $60^{\circ} \mathrm{C}$ sin necesidad del sistema de presión. Como se puede comprobar, se ha medido un error de $-0,5 \%$ con una desviación de +/$0,1^{\circ} \mathrm{C}$. Al activarse el sistema de presión, se han desarrollado dos ejemplos para $100{ }^{\circ} \mathrm{C}$ y $110{ }^{\circ} \mathrm{C}$, obteniendo errores de $1,7 \%$ y $2,2 \%$ con desviaciones de $+/-1,0{ }^{\circ} \mathrm{C}$ y $+/-1,1{ }^{\circ} \mathrm{C}$, respectivamente; tal como se aprecia en la Figura 5.17.

\begin{tabular}{llll}
\hline Process & Pressure & Time & Objective \\
\hline Low temp. & No & $100 \mathrm{~s}$ & $60^{\circ} \mathrm{C}$ \\
High temp. & Yes & $50 \mathrm{~s}$ & $100^{\circ} \mathrm{C}$ \\
High temp. & Yes & $50 \mathrm{~s}$ & $110^{\circ} \mathrm{C}$ \\
\hline
\end{tabular}

Tabla 5.1 Condiciones de la experimentación 
Figura 5.17 Perfiles de temperatura de experimentos desarrollados. (a) Proceso de baja temperatura; (b) Proceso de alta temperatura con presión.

\subsubsection{Medidas de Inactivación por calor de Bacillus cereus}

Es este apartado, se midieron los resultados de inactivación biológica, representando gráficamente el número de supervivientes (expresado como log10 UFC/ml) a diferentes tiempos de calentamiento para cada temperatura probada. Se obtuvo una cinética de primer orden, indicando una temperatura constante en todas las temperaturas y sustratos ensayados. La potencia de microondas que se transforma en calor [17] se puede obtener del término que aparece en la ecuación 4.2 , donde $\varepsilon_{0}=8.8542 \cdot 10^{-12} \mathrm{~F} / \mathrm{m}$ es la permitividad eléctrica del espacio libre, $f(\mathrm{~Hz})$ es la frecuencia de operación y Erms $(\mathrm{V} / \mathrm{m})$ es la raíz cuadrada media del campo eléctrico. 
De esta relación, se puede deducir que cuanto mayor sea la intensidad del campo eléctrico y el factor de pérdida, mayores valores de potencia se obtendrán. Sin embargo, en los productos biológicos un valor alto del factor de pérdida se relacionanormalmente con un valor alto en la constante dieléctrica, y esto dificulta la penetración de la onda en el interior de la muestra, disminuyendo la intensidad del campo eléctrico en el interior.

Las figuras 5.18 a 5.20 muestran la evolución de las UFC de las esporas de Bacillus cereus en diferentes tiempos de calentamiento, proporcionando una interpolación log-lineal que predice claramente la evolución del número de supervivientes. Como se puede observar, las temperaturas más altas proporcionan una mejor esterilización en términos de UFC que muestran una pendiente más pronunciada.

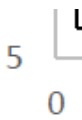

Figura 5.18 Medición de UFC en los sustratos indicados a una temperatura objetivo de $95^{\circ} \mathrm{C}$ 
CAPÍTULO 5. DISEÑO DE UN HORNO DE TÚNEL DE MICROONDAS PARA LA ESTERILIZACIÓN Y SECADO DE SANDACH

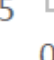

0

Figura 5.19 Medición de UFC en los sustratos indicados a una temperatura objetivo de $100^{\circ} \mathrm{C}$

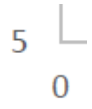

Figura 5.20 Medición de UFC en los sustratos indicados a una temperatura objetivo de $105^{\circ} \mathrm{C}$

La inactivación muestra, como se esperaba, una dependencia de la temperatura: cuanto más alta es la temperatura objetivo, más rápidamente ocurre la inactivación (Figuras 5.18 
a 5.20), indicando hay un control de temperatura preciso en el sistema de microondas. A todas las temperaturas estudiadas $\left(95,100\right.$ y $\left.105^{\circ} \mathrm{C}\right)$, la tasa de inactivación es mayor en BHI y más lenta en F-ABP, existiendoe un elevado coeficiente de correlación log-lineal para todas las curvas de supervivencia obtenidas (siempre superior a 0,9), lo que indica que se obtiene un calentamiento homogéneo [14,18].

A la temperatura objetivo de $105^{\circ} \mathrm{C}$ se observa una inactivación rápida, con reducciones de 3 log decimales en menos de 120 segundos en $\mathrm{BHI}$, mientras que para lograr la misma inactivación en F-ABP es necesario más de 200 segundos, como muestra la Figura 5.18. La sopa de verduras requiere un tiempo intermedio. Las diferencias en la inactivación por calor se pueden explicar por tres razones principales:

- Los factores de pérdida más altos conducen a un aumento gradual de la temperatura en la primera etapa de calentamiento, cuando se aplica una potencia de microondas constante a la cavidad, ya que un factor de pérdida más alto produce una mayor generación de calor. En consecuencia, la muestra alcanza antes de la temperatura objetivo y, por tanto, se trata durante más tiempo. Este razonamiento no se puede aplicar a la etapa de control de calefacción, ya que la potencia se controla para mantener la temperatura objetivo y, por lo tanto, la generación de calefacción no está relacionada directamente con el factor de pérdida.

- La transferencia de calor por conducción dentro de la muestra es mayor con menor contenido de lípidos y menor densidad.

- La presencia de lípidos también puede tener un efecto protector sobre las esporas de Bacillus cereus [19].

\subsection{Conclusiones}

Para este apartado, se ha diseñado una cavidad cilíndrica monomodo en conjunto con un sistema de alimentación autorregulado para alcanzar una temperatura seleccionada 
para estudiar la esterilización de diferentes muestras. Se ha verificado con éxito el correcto funcionamiento de la cavidad diseñada y el sistema autorregulado y se han proporcionado parámetros como la permitividad de las muestras en un amplio rango de temperaturas de 20 a $80^{\circ} \mathrm{C}$.

La aplicación precisa y uniforme de una temperatura seleccionada en el volumen de la muestra con el sistema de microondas desarrollado ha permitido un estudio sistemático de la evolución en los recuentos bacterianos de tres materiales diferentes a esterilizar. Este sistema puede garantizar eficazmente una inactivación microbiana completa y uniforme en los alimentos.

La inactivación por calor mediante calentamiento por microondas en diferentes sustratos (medios de laboratorio y alimentos) se ha probado utilizando una bacteria patógena transmitida por los alimentos, Bacillus cereus, como sensor. Muestra una disminución log-lineal en todas las condiciones probadas (temperaturas entre 95 y $105^{\circ} \mathrm{C}$ ) lo que indica un perfil de temperatura homogéneo. La tasa de inactivación es mayor en BHI y menor en F-ABP, lo que está relacionado con el factor de pérdida de cada producto y, en última instancia, con el contenido de lípidos.

Como alternativa, se podría haber utilizado un generador de microondas de estado sólido. En ese caso, el control de potencia es más preciso y bastante más sencillo, por lo que, probablemente se habrían obtenido variaciones más pequeñas alrededor de la temperatura objetivo. Pero los generadores de microondas de estado sólido tienen una potencia muy limitada (unos cientos de vatios como máximo) y son muy caros, lo que invalida su uso para aplicaciones de alta potencia, es decir, de 1 a $100 \mathrm{~kW}$. Por el contrario, el análisis que aquí se presenta trata de una fuente de magnetrón, lo que permite un sistema escalable.

Las cavidades monomodo, la muestra pequeña y un sistema vibratorio conducen a un perfil de temperatura uniforme a lo largo del material, y el principal desafío es mantener la temperatura constante con el tiempo, como se muestra. El siguiente paso es el diseño de aplicadores multimodo para tratar muestras más grandes a escala industrial. En este 
caso, se prevé trabajar en el futuro para alcanzar una uniformidad espacial de temperatura que garantice la pasteurización o esterilización manteniendo las propiedades nutricionales y organolépticas.

\subsection{Publicaciones obtenidas}

Los trabajos descritos en este capítulo, han dado lugar a la publicación:

J.D. Reverte-Ors, J.L. Pedreño-Molina, P.S. Fernández, A.J. Lozano-Guerrero, Paula M. Periago, Alejandro Díaz-Morcillo, "A Novel Technique for Sterilization Using a Power Self-Regulated Single-Mode Microwave Cavity", Sensors, Volume 17, 1309; doi: 10.3390/s17061309 (June 2017).

\subsection{Referencias}

[1] Martínez-Lopez, A.; Rodrigo, D.; Fernández, P.S.; Pina-Pérez, M.C. and Sampedro, F. Time-Temperature integrators for thermal process evaluation. In Book Thermal Food Processing-New Technologies and Quality Issues, 2nd ed.; CRC Press, 2012; pp. 635-654.

[2] Stanley, R.A.; Petersen, K. Microwave-assisted pasteurization and sterilizationcommercial perspective. In Book The Microwave Processing of Foods, 2nd ed.; Regier, M., Knoerzer, K. and Schubert, H., Eds.; 2017; pp. 200-219.

[3] Bengtsson, N.E.; Ohlsson, T. Microwave heating in the food industry. Proceedings of the IEEE, 1974, Volume. 62, Issue 1, pp. 44-55, 1974.

[4] Vadivambal, R.; Jayas, D.S. Non-uniform temperature distribution during microwave heating of food materials - A review. Food and Bioprocess Technology 2010, Volume 3, pp. 161-171. 
[5] Nguyen, L.T.; Choi, W.; Hyun Lee, S.; Jun, S. Exploring the heating patterns of multiphase foods in a continuous flow, simultaneous microwave and ohmic combination heater. Journal of Food Engineering 2013, Volume 116, pp. 65-71.

[6] Ejiri, K.; Tomizuka, Y.; Ichihara, G.; Sato, H.; Uchida, Y.; Ohno, T. and Uehara, M. A study on uniform heating of food in microwave oven by using phase difference of power output from two ports. Progress in Electromagnetic Research Symposium (PIERS), Shanghai, China, 8-11 Aug. 2016.

[7] Cordes, B.G.; Eves, E.E.; Yakovlev, V.V. Modeling-based minimization of time-touniformity microwave heating systems. 11th AMPERE Conference on Microwave and High Frequency Heating, Oradea,Romania, 3-6 Sep. 2007, pp. 305-308.

[8] Xiaowei,School of Physical Electronics, University of Electronic Science and Technology of China, ChengDu 610065, China ; Department of Physics, University of California, Berkeley, 94720-7300, USA G.; Lin, M.;School of Physical Electronics, University of Electronic Science and Technology of China , ChengDu 610065, China Yiqin, S. Electromagnetic field optimisation procedure for the microwave oven. International Journal of Electronics 2010, Volume 97, pp. 339-347.

[9] Pedreño-Molina, J.L.; Monzó-Cabrera, J.; Catalá-Civera, J.M. Sample movement optimization for uniform heating in microwave heating ovens. Int. Journal of RF \& Microwave Computer-Aided Engineering 2007,Volume 17 (2), pp. 142-152.

[10] Plaza-Gonzalez, P.; Monzó-Cabrera, J.; Catalá-Civera, J.M.; Sánchez-Hernández, D. Effect of mode-stirrer configurations on dielectric heating performance in multimode microwave applicators. IEEE Trans. Microwave Theory Technique 2005, Volume 53 (5), pp. 1699-1706.

[11] Resurreccion, F.P.; Luan, D.; Tang, J.; Liu, F.; Tang, Z.; Pedrow, P.D.; Cavalieri, R. Effect of changes in microwave frequency on heating patterns of foods in a microwave 
assisted thermal sterilization system. Journal of Food Engineering 2015, Volume 150, pp. $99-105$.

[12] Steed, L.E.; Troung, V.D.; Simunovic, J.; Sandeep, K.P.; Kumar, P.; Cartwright, G.D.; Swartzel, K.R. Continuous Flow Microwave-Assisted Processing and Aseptic Packaging of Purple-Fleshed Sweet potato Purees. Journal of Food Science 2008, Volume 73 (9), pp.455-462.

[13] Zuijlen, A.V.; Periago, P.M.; Amézquita, A,; Palop, A.; Brul, S.; Fernández, P.S. Characterization of Bacillus sporothermodurans IC4 spores; putative indicator microorganism for optimisation of thermal processes in food sterilization. Food Research International 2010, Volume 43, pp. 1895-1901.

[14] Ocio, M.J.; Fernández, P.S.; Rodrigo, M.; Periago, P.M.; Martínez, A. A time temperature integrator for particulated foods: thermal process evaluation. Z. Lebensmittel Untersuchung und Forschung 1997, Volume 205, pp. 325-328.

[15] Álvarez, A.; Fayos-Fernández, J.; Monzó-Cabrera, J.; Cocero, M.J.; Mato, R.B. Measurement and correlation of the dielectric properties of a grape pomace extraction media. Effect of temperature and composition. Journal of Food Engineering, 197, 98-106. 2017

[16] Chen, L.F.; Ong, C.K.; Neo, C.P.; Varadan, V.V.; Varadan, V.K. Microwave Electronics. Measurement and Material Characterization; John Wiley \& Sons, Ltd.: New York, USA, 2004.

[17] Datta, A. K.; Anatheswaran, R.C. A. K. Handbook of Microwave Technology for Food Applications Datta and R. C. Anatheswaran. Marcel Dekker, Ed; 2000 Inc. New York.

[18] Garre A., Fernandez P.S., Lindqvist R., Egea J.A. Bioinactivation: software for modelling dynamic microbial data. Food Research International 2017, Volume 93, pp.66-74. 
CAPÍTULO 5. DISEÑO DE UN HORNO DE TÚNEL DE MICROONDAS PARA LA ESTERILIZACIÓN Y SECADO DE SANDACH

[19] Esteban, M.D., Huertas, J.P., Fernández, P.S. y Palop, A. Effect of the medium characteristics and the heating and cooling rates on the nonisothermal heat resistance of Bacillus sporothermodurans IC4 spores in buffers and food. Food Microbiology 2013, 34: 158-163. 


\section{CAPÍTULO 6}

\section{DISEÑO DE UN HORNO DE TÚNEL DE MICROONDAS PARA LA ESTERILIZACIÓN Y SECADO DE SANDACH}

\subsection{Introducción y Objetivos}

Una vez estudiado el efecto de mortalidad de colonias de bacterias en material Sandach, con la estructura de biosensores y calentamiento a alta temperatura con equipos microondas de laboratorio, en este capítulo se recogen las principales características del diseño y metodología de ensayos para la esterilización y secado por microondas de Sandach, en horno de procesamiento en línea.

Los hornos de microondas industriales son la base de la transferencia de este tipo de tecnología al sector productivo, una vez resueltos los sistemas de filtrado a la entrada y salida del horno túnel, mediante el empleo de corrugaciones, como es el caso tratado en este trabajo de investigación. Estos hornos multimodo consisten en una cavidad alimentada por magnetrones actuando como fuentes de microondas, y pueden procesar distintos materiales en el interior de la cavidad. Dicha cavidad dispone de una entrada y una salida abierta para el paso del material, por medio de cinta transportadora, y cerrada para el paso del campo electromagnético, debido a la incorporación de dichos filtros.

Un aspecto muy importante para conseguir la máxima eficacia de los hornos de microondas industriales en los procesos de esterilización o pasteurización, es crear un alto grado de uniformidad en el calentamiento de la muestra o material. Algunas soluciones pueden basarse en la incorporación de elementos móviles en el interior de la cavidad que modifiquen las condiciones de contorno de la cavidad y provoquen la excitación de distintos modos electromagnéticos en función del tiempo.

Estas técnicas pueden sustituirse por el movimiento lineal del material en un horno industrial y, de esta forma, obtener una distribución del campo eléctrico homogéneo a 
lo largo del producto, se pretende de este modo que, en media temporal, esta distribución de campo sí se aproxime a una homogénea.

Los hornos industriales de calentamiento por microondas comienzan a ser un elemento emergente en muchas de las industrias o fábricas de transformación que precisan de una estación de calentamiento en el conjunto de la línea de producción. Esto es debido al elevado coste de la energía (gas, carburante, etc.) necesaria para alimentar los actuales hornos, además de otros factores decisivos como son su baja eficiencia energética, generación de emisiones contaminantes al medioambiente, la calidad del producto y la baja velocidad del proceso.

Además, los sistemas de calentamiento por alta frecuencia (microondas) de materiales no conductores, sólidos y líquidos, pueden mejorar la calidad final de producto ya que no resecan la superficie, el calentamiento es más rápido, los procesos de calentamiento son más selectivos y uniformes y la velocidad de producción es mucho más elevada.

Es igualmente importante destacar la implicación de estas actuaciones en la protección al medioambiente, en cuanto a la implementación de equipos de procesamiento térmico que no emiten gases a la atmósfera. Esto es debido a que la energía eléctrica es transformada en emisiones de campo electromagnético que son absorbidas por los materiales para su calentamiento o secado, lo que supone un gran salto hacia máquinas que conllevan una reducción drástica de emisiones al medioambiente.

Para el diseño del horno túnel de microondas que permita el calentamiento y esterilización de Sandach, en entorno industrial, se han acometido diferentes actuaciones hasta conseguir un modelo óptimo de trabajo para alcanzar el objetivo perseguido en este trabajo de investigación. A modo de resumen, se pueden enumerar las siguientes tareas que se han realizado:

- Análisis de los datos del proceso.

- Cálculo experimental de los parámetros dieléctricos de las muestras. 
- Ejecución de la aplicación MICRODES@ (plataforma software desarrollada por el Grupo I+D GEM-UPCT) para el cálculo de los parámetros teóricos de todo el proceso, incluyendo lo elementos preliminares de diseño.

- Generación del diseño proporcionado por la plataforma de simulación electromagnética y construcción de las cavidades, y los elementos adicionales como filtros de entrada y salida, launchers, ventiladores de refrigeración, puerta de acceso, etc.

- Ajuste del sistema de microondas para los ensayos previstos de transformación de Sandach.

\subsection{Componentes de horno industrial para secado por microondas}

Un horno de microondas funciona haciendo pasar la radiación no ionizante de microondas, generalmente alrededor de una frecuencia de $2,45 \mathrm{GHz}$, a través del material, de manera que agua, grasa y otras sustancias presentes en los materiales absorben la energía de las microondas. Muchas moléculas son dipolos eléctricos, lo que significa que tienen una carga positiva parcial en un extremo y una carga negativa parcial en el otro, y por tanto giran en su intento de alinearse con el campo eléctrico alterno de las microondas. Al rotar, las moléculas chocan con otras y las ponen en movimiento, dispersando así la energía en forma de calor.

De manera general, un sistema de calentamiento por microondas básico, consta de ciertos componentes acoplados, tal y como muestra la siguiente Figura 6.1, y cuyas funcionalidades y características se describen a continuación: 


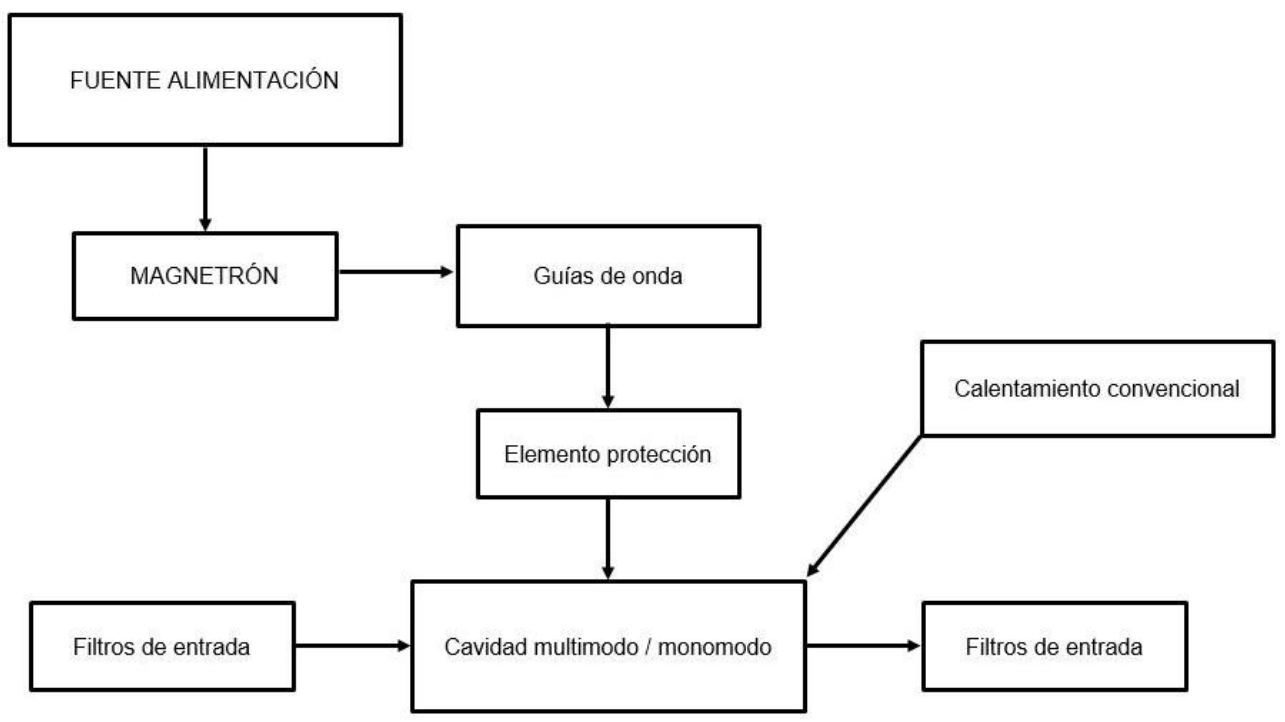

Figura 6.1. Diagrama de un sistema de calentamiento por microondas básico.

Los componentes principales del horno de calentamiento por microondas son: fuentes de alimentación, magnetrones, ventiladores, aisladores, launchers, stirrers, cavidades, cinta de transporte, controlador de fuentes, y filtros de entrada y salida [1].

- Las fuentes de alimentación de los magnetrones son los dispositivos más caros de un sistema de microondas. De hecho, dichas fuentes pueden llegar a suponer un $50-60 \%$ del coste total del equipo. La función de estos dispositivos es la de proporcionar una corriente constante para el ánodo del magnetrón, y aplicar el ciclo de trabajo correcto para la potencia a proporcionar. La fuente de alimentación es la responsable de la potencia de salida del magnetrón.
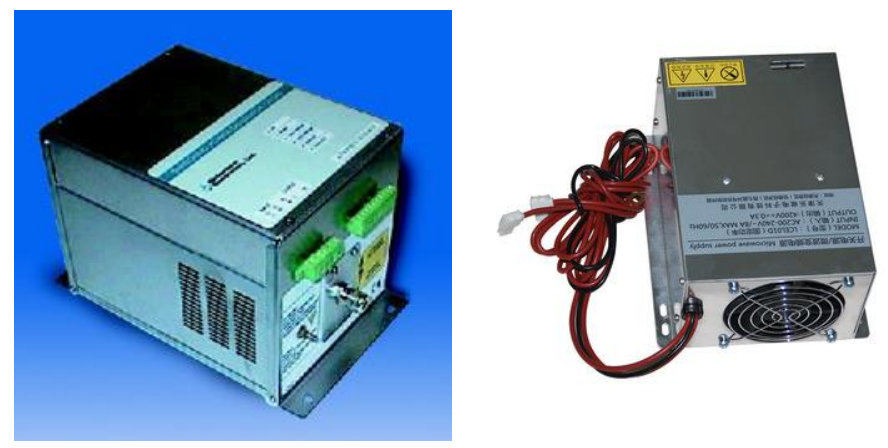

Figura 3.2. Ejemplo de fuente de alimentación programable (izquierda) y no programable (derecha) 
- El magnetrón es el elemento que utiliza la energía de baja frecuencia proporcionada por la fuente de alimentación, transformándola en energía de microondas debido a su gran estabilidad en frecuencia, una eficiencia aceptable (60-70\%), bajo coste y fiabilidad. Si bien existen otras fuentes de microondas, el magnetrón se ha convertido en la más utilizada en el sector de calentamiento por microondas principalmente por sus características anteriormente mencionadas.

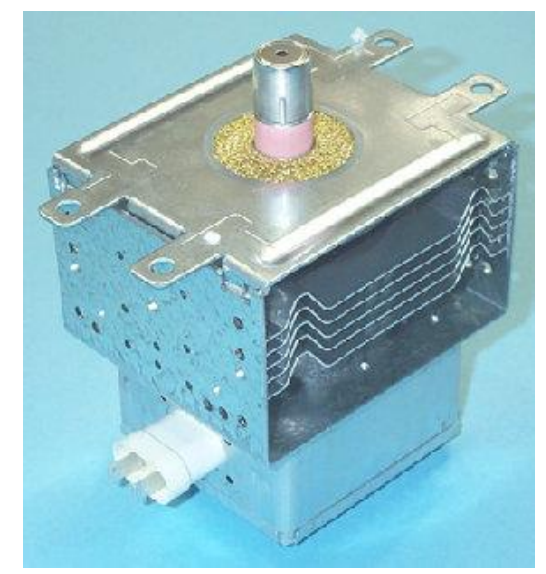

Figura 6.3. Magnetrón

Básicamente el magnetrón está compuesto por una cavidad de microondas en la cual cátodo y ánodo se encuentran a muy diferentes tensiones o voltajes, donde el cátodo es calentado por las altas corrientes que circulan por él de forma que emite electrones a la cavidad interna -figura 6.4-. El ánodo tiene una serie de cavidades que se proyectan en la dirección radial llamadas vanos, los cuales están acoplados entre sí, por lo que toda la estructura es un circuito resonante.

El cátodo se encuentra a un mayor voltaje que el ánodo y, por lo tanto, los electrones emitidos por el cátodo tienden a irse hacia el ánodo. El campo magnético generado por el imán impide una trayectoria directa para estos electrones y los hace girar en su camino desde el cátodo hasta el ánodo.

La energía cinética de los electrones debido a este giro dentro de la cavidad se acopla como energía de microondas en las cavidades. El control de voltaje de continua controla la velocidad de los electrones y por tanto la energía de 
microondas final, aunque también puede controlarse dicha velocidad mediante cambios en el campo magnético dentro de la cavidad. Finalmente, es importante reseñar que dado que manejan potencias importantes, se debe refrigerar el magnetrón cuando esté en funcionamiento ya que se calentará a una gran velocidad.

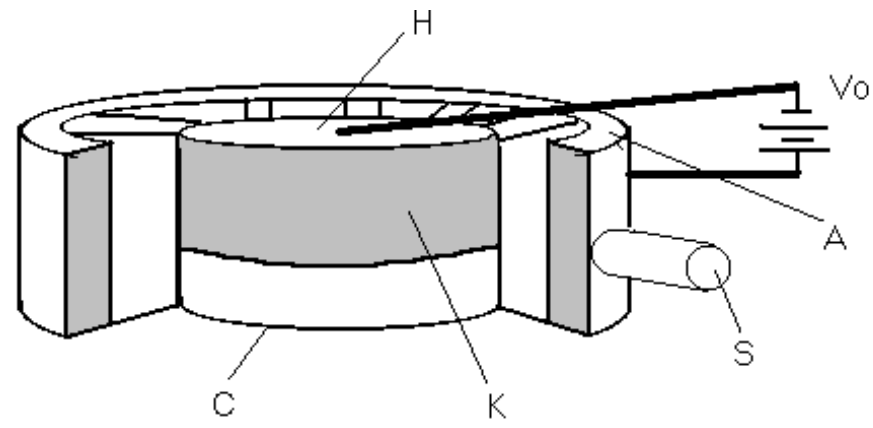
A: Ánodo
$\mathrm{K}$ : Cátodo
C: Capa del cátodo
$\mathrm{H}$ : Campo magnético
S: Salida de frecuencia
Vo: Voltaje

Figura 6.4. Diagrama de un magnetrón.

En relación con su tamaño $(10 \times 10 \times 10 \mathrm{~cm}$ para 2,45 GHz) el magnetrón maneja gran potencia (desde $1 \mathrm{kw}$ hasta $100 \mathrm{kw}$ ). Parte de esta potencia (en torno a un 20-30\%) se disipa en su pared externa (del 30 al 50\% de la energía en un horno de microondas se disipa como calor en el magnetrón) y, por ello, es necesario proporcionar refrigeración a este dispositivo, puesto que las temperaturas elevadas pueden acabar dañando su estructura interna.

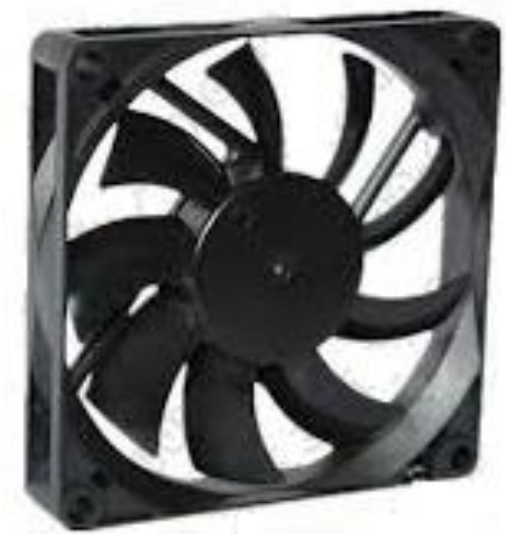

Figura 6.5 Ventilador.

- Así que se suele optar por acoplar un ventilador al magnetrón, de forma que el aire de dicho ventilador junto con las láminas exteriores del magnetrón permiten 
bajar la temperatura del mismo cuando está trabajando, ya que se calienta a una gran velocidad en su funcionamiento.

También existe la refrigeración líquida consiste en extraer el calor de los componentes de un ordenador utilizando fluidos específicos para la conducción del mismo, ya que si no es así, muchos de los componentes dejarían de funcionar porque se queman.

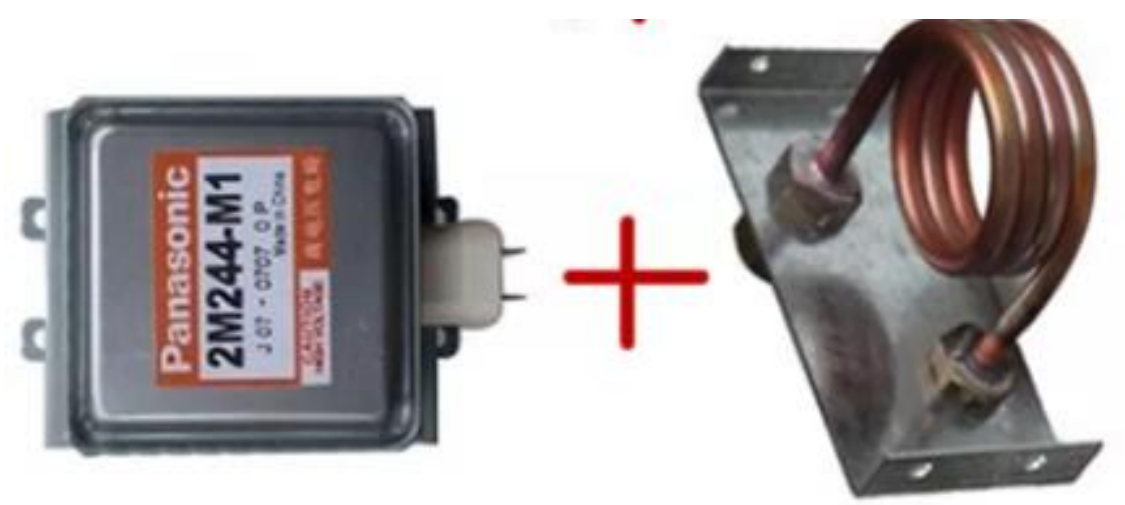

Figura 6.6 Magnetrón refrigera por agua.

- A veces, el incremento de temperatura, puede ser una causa de la rotura o mal funcionamiento del magnetrón las reflexiones de potencia. Debido a esto, se hace uso de un circuito aislador.

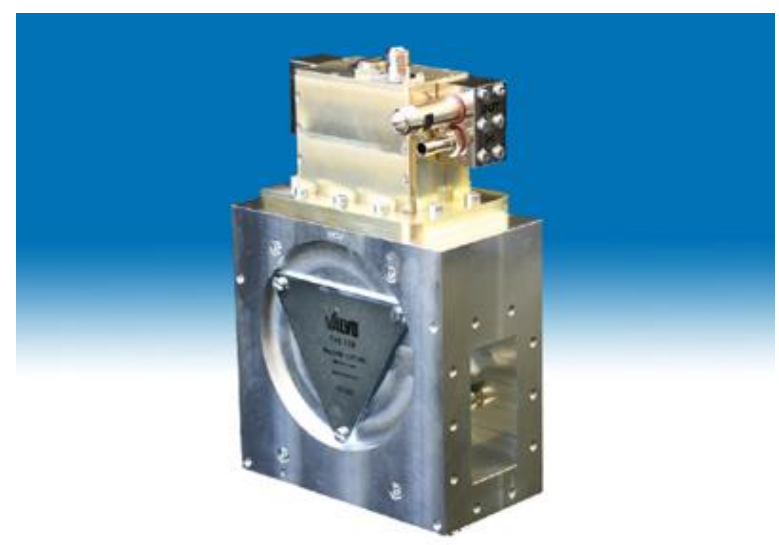

Figura 6.7 Aislador 
El aislador debe disipar esta potencia y no reflejarla, lo que permite alargar el tiempo de vida del magnetrón. Está constituido por circuladores, esto es, dispositivos de tres accesos que dirigen la señal a un puerto u otro según el puerto por el que ésta entra. Se construyen insertando ferritas polarizadas en una unión de tres líneas de transmisión. La polarización de la ferrita se realiza aplicando un campo magnético en la dirección del eje de simetría de la ferrita y pueden proporcionar valores de aislamiento de hasta $50 \mathrm{~dB}$, por lo que es aconsejable su inclusión entre el magnetrón y la cavidad de microondas. La figura 6.8 muestra el esquema típico del circulador actuando en configuración de aislador:

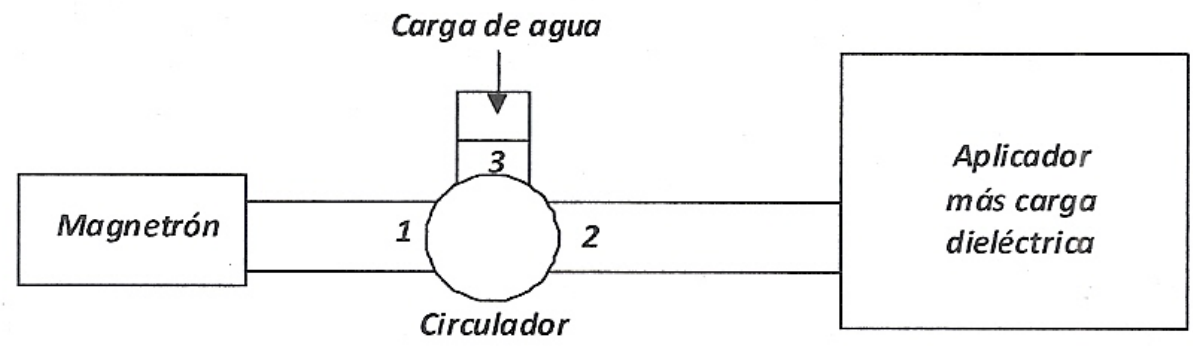

Figura 6.84. Conexión del circulador actuando como aislador del magnetrón.

- Los launchers permiten introducir la energía de microondas generada por los magnetrones en el horno de microondas. Estos launchers son guías de onda rectangulares metálicas que presentan una apertura rectangular en un extremo y en el otro una pared metálica actuando como cortocircuito.

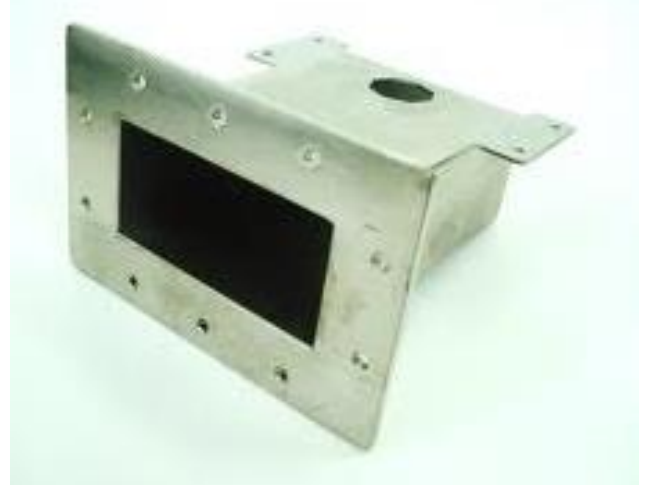

Figura 6.5 Launcher 
La Figura 6.10, muestra la configuración de los launchers o guías de onda para que sean eficientes. Puede observarse como dichos launchers son guías de onda terminadas en cortocircuito y en los que la antena de los magnetrones se introduce a una distancia determinada para que la radiación de los magnetrones sea máxima.

Esta figura también muestra las dimensiones de la guía de onda. La longitud de la misma en el eje z no será fundamental. Sin embargo sí que lo serán las dimensiones en el eje $\mathrm{x}$ e $\mathrm{y}$.

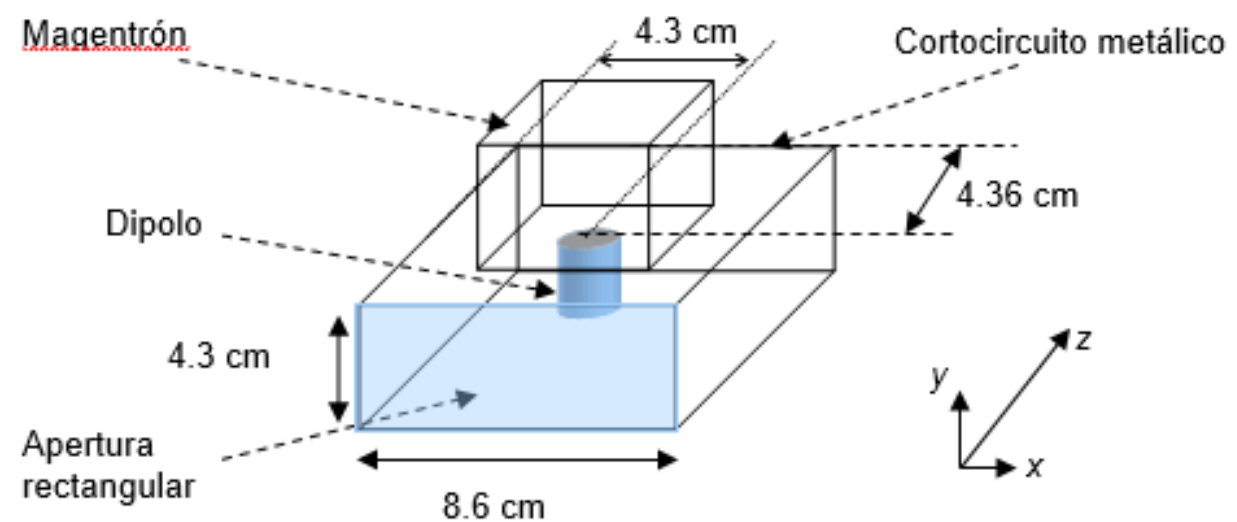

Figura 6.10. Configuración del launcher.

Como nota importante se debe remarcar que cada magnetrón llevará colocado a su lado un sistema de refrigeración, principalmente por aire frío, dadas las potencias a instalar.

El uso de hornos alimentados con múltiples fuentes mejora el calentamiento de la muestra. El posicionamiento y la orientación de las guías de entrada al horno son importantes ya que condicionan los modos que se excitan y por lo tanto la distribución de campo en el horno, de forma que pueden emplearse como parámetros de diseño. A la hora de diseñar hornos o aplicadores con múltiples fuentes de alimentación, una consideración importante es que no haya acoplo entre las fuentes. Para mejorar la uniformización del calor usando múltiples 
fuentes y a la vez disminuir el acoplo entre las mismas, éstas se deben de situar en la cavidad de forma que cada fuente excite un conjunto independiente de modos resonantes. En el diseño realizado, las guías se posicionan ortogonalmente con el fin de reducir el acoplo entre las mismas [2].

- El campo eléctrico en una cavidad multimodo, donde no existe ninguna variación geométrica, tiene patrones fijos en el espacio que implican la existencia de puntos calientes y fríos. Es decir, cuando la muestra se calienta en este tipo de hornos y no forzamos la variación del campo eléctrico, la distribución de temperatura mostrará puntos calientes ('hot spots') y puntos fríos ('cold spots'). Es importante indicar que la uniformidad de calentamiento es el aspecto principal que determina la calidad final del procesamiento por microondas.

Para mejorar dicha uniformidad (asociada a la distribución de campo) se utilizan agitadores de modos o "stirrers", que Los agitadores de modos se componen de láminas metálicas que cambian de posición a lo largo del tiempo y que generan diferentes patrones de campo cuando cambian de posición. Tal y ocmo puede apreciarse en la Figura 6.11, su efecto es cambiar el campo eléctrico en la cavidad y en la muestra para cada posición.

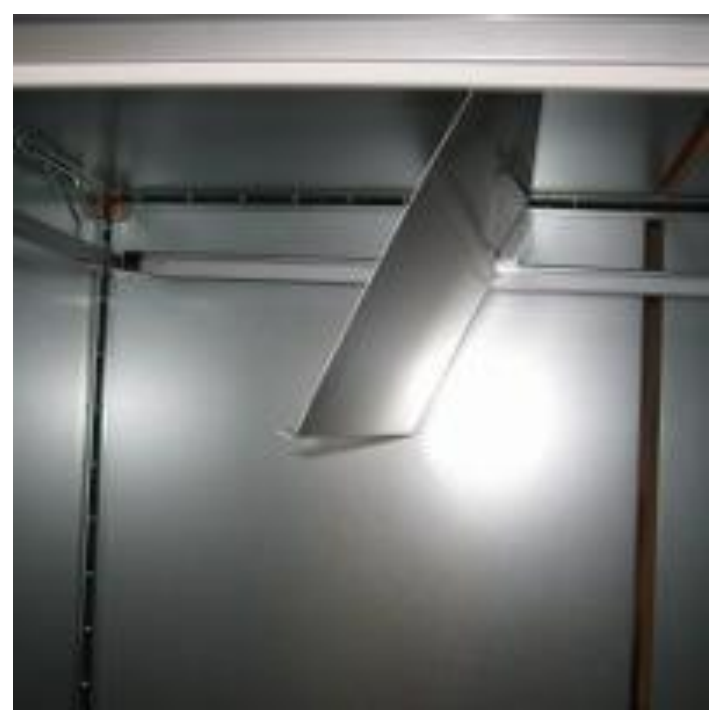

Figura 6.11. Stirrer 
- La cavidad o aplicador de microondas es aquella parte del sistema en la cual se introduce la muestra para ser calentada. La cavidad de microondas es el responsable de dos cuestiones fundamentales en el proceso de calentamiento por microondas: La eficiencia del proceso de calentamiento. La uniformidad del perfil de temperaturas del material a ser calentado.

Por lo tanto, su diseño es fundamental para conseguir un proceso de calentamiento eficiente y eficaz tanto en términos de energía como en la consecución de un producto de calidad elevada.

Así pues, se puede definir la cavidad de microondas como aquella estructura metálica que permite confinar la energía de microondas junto con el material a calentar y que es responsable de la eficiencia energética del proceso y de la uniformidad de calentamiento por microondas. Los requisitos que debe cumplir la cavidad son:

$\checkmark$ Adaptación a las dimensiones físicas y eléctricas del material.

$\checkmark$ Adaptación al tipo de aplicación (continua, por lotes,....).

$\checkmark$ Adaptación a las características térmicas del material.

$\checkmark$ Eficiencia energética para presentar la mayor eficiencia energética posible, lo que implica que optimización de las reflexiones y acoplos de las diferentes fuentes.

$\checkmark$ Máxima uniformidad posible de campo eléctrico paa que la temperatura en el cuerpo calentado sea constante.

$\checkmark$ Dimensionado de la potencia a utilizar.

$\checkmark$ Confinamiento adecuado de la energía de microondas, cumpliendo con las normativas nacionales sobre emisiones radioeléctricas [3]. Ello implica el adecuado diseño y construcción de los filtros y puertas de este tipo de hornos. 
- Para calentar el producto se coloca sobre una cinta de transporte. Su función es trasladar el material a través del horno donde se encuentran los generadores de microondas o magnetrones. Los hornos con cinta son aptos para los procesos en continuo como por ejemplo el calentamiento o el secado; como el caso que nos ocupa.

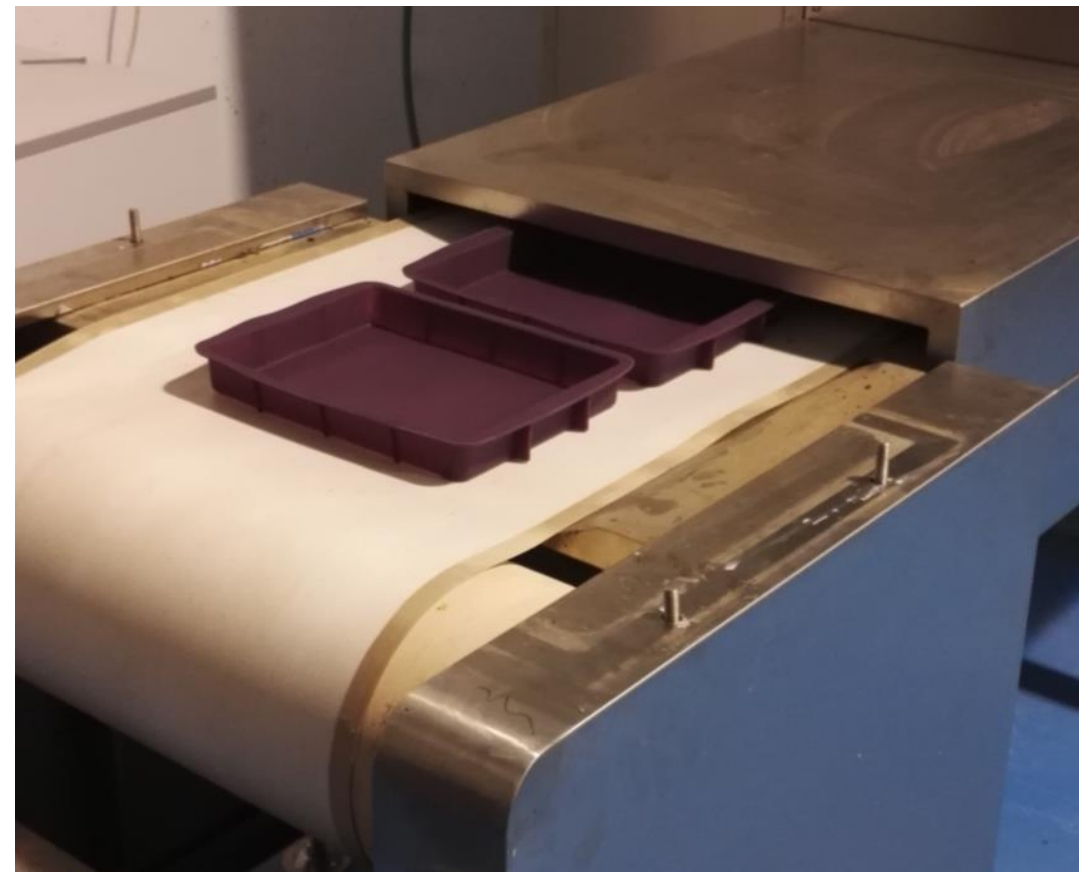

Figura 6.12. Cinta de transporte

- El controlador es utilizado para la protección de la fuente de alimentación, regulando su energía y asegurando así su buen funcionamiento. Como se ha destacado anteriormente, la fuente de alimentación es el elemento que proporciona energía al magnetrón. Dicha corriente es muy alta, por lo que requiere mucho cuidado.

- Los filtros reactivos permiten la entrada/salida de la muestra en los procesos industriales continuos sin que salga demasiada energía de microondas al exterior. Son filtros elimina banda muy selectivos que deben diseñarse con el dieléctrico en su interior para obtener un buen diseño. El modelo elegido son los filtros reactivos corrugados,cuya fabricación es sencilla, tal y como muestra la siguiente figura, a modo de ejemplo. [4-6]. 


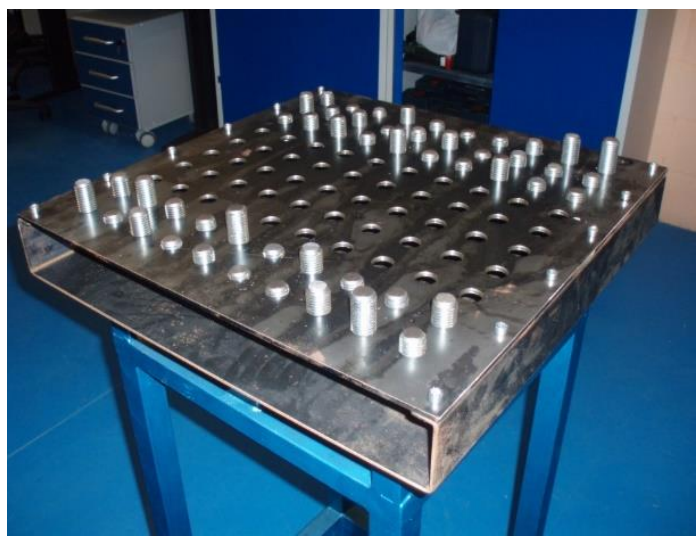

Figura 6.13. Ejemplo de fabricación de filtros reactivos para hornos microondas

- Y, por úlitmo, el sistema de extracción de vapor de agua en la parte superior del horno microondas, ayuda al proceso de secado.

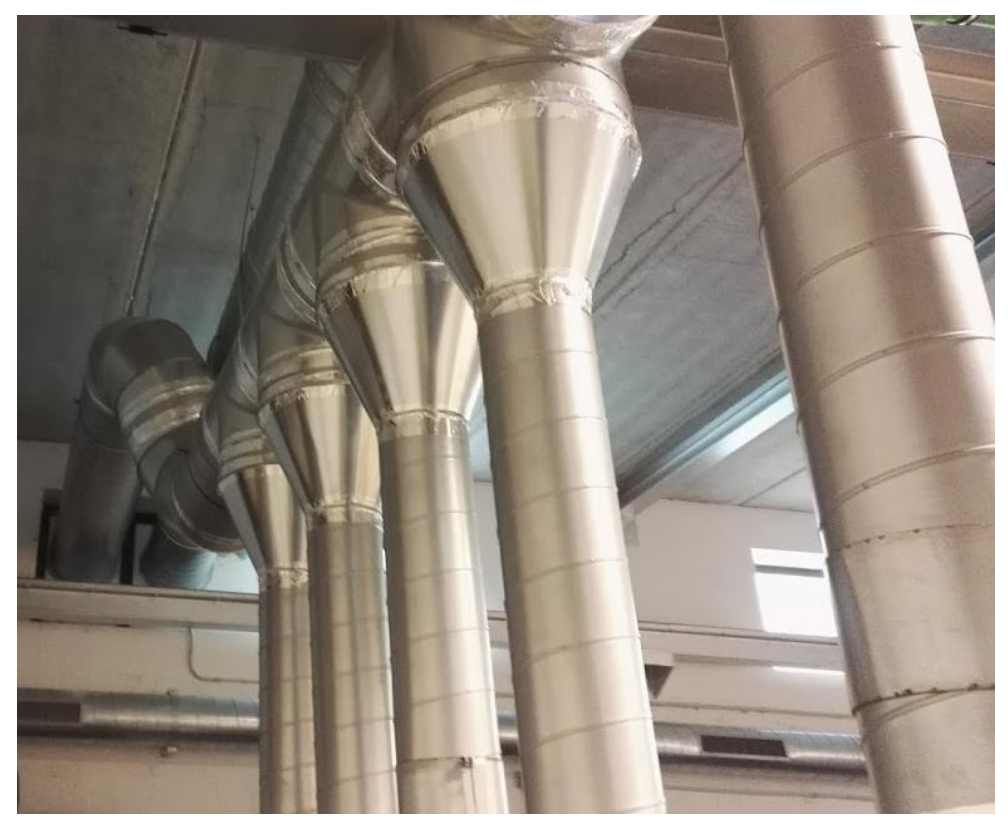

Figura 6.14. Ejemplo de sistema de extracción horno microondas semi-industrial

\subsection{Herramienta software para el desarrollo del horno industrial}

Para el diseño de los parámetros del horno túnel industrial de microondas se ha utilizado una plataforma de simulación, de desarrollo propio, que permite dimensionar el equipo y todos sus elementos para procesar las bandejas de Sandach que alimentan la cavidad. 
Se trata de la herramienta Microdes@ [74], que ha sido desarrollada por el Grupo I+D GEM-UPCT utilizando las capacidades de Microsoft Visual Studio e integrando macros de CST (Microwave Studio Computer Simulation Technology), tal y como muestra el siguiente esquema:

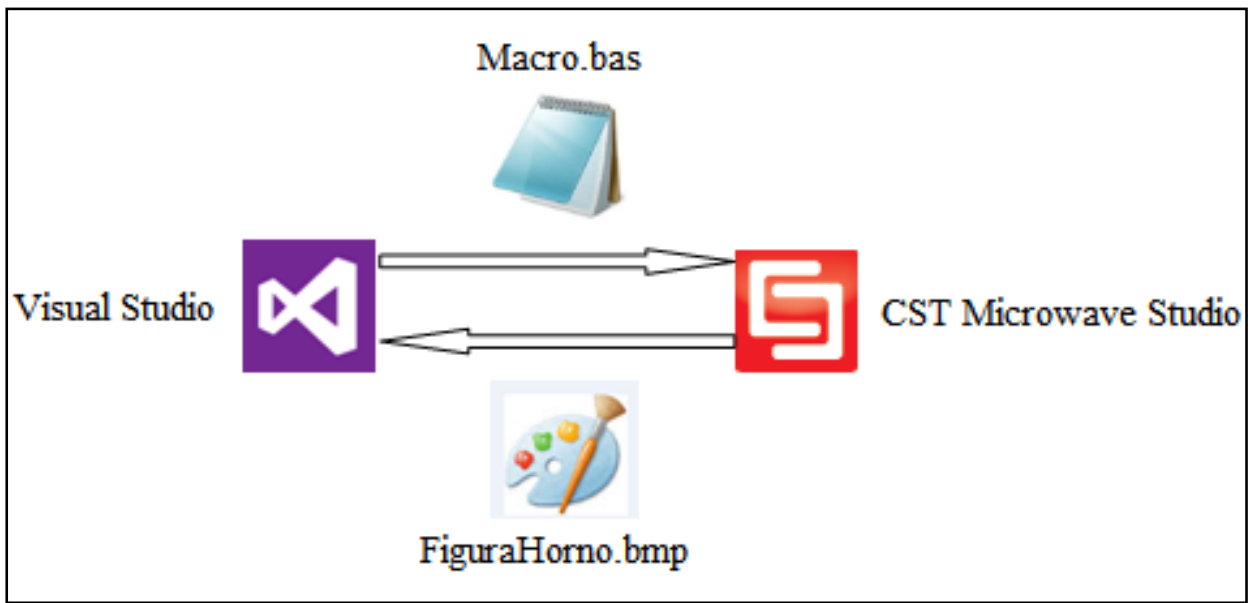

Figura 6.15. Integración de herramientas SW para el desarrollo de la aplicación Microdes

Microdes@permite realizar simulaciones de las condiciones de trabajo y, cuyo diseño y programación. Este software, es capaz de calcular las condiciones de trabajo de un horno microondas de procesamiento en línea a partir de las características físicas, dieléctricas y térmicas de las muestras a procesar bajo exigencia de producción.

Se trata de una herramienta especializada para la simulación electromagnética de componentes de alta frecuencia en tres dimensiones, obteniendo el diseño de la estructura final del horno que utiliza las ecuaciones de cálculo de potencia en procesos de calentamiento y/o secado por microondas tratadas anteriormente en el capítulo 3.

Cuando sólo se produce calentamiento, y asumiendo una eficiencia del 100\% en el horno de microondas, la potencia necesaria puede calcularse conociendo el calor específico del material $\left(C_{p}\right)$, la masa a procesar dentro del horno, el incremento de temperatura y el tiempo del proceso:

$$
P_{\text {abs calentamiento }}(W)=\operatorname{masa}(\mathrm{Kg}) \cdot C_{p}\left(\mathrm{~J} / \mathrm{Kg}^{\mathrm{o}} \mathrm{C}\right) \cdot \frac{\Delta T\left({ }^{\circ} \mathrm{C}\right)}{\Delta t(s)}
$$


siendo $\Delta T$ el incremento de temperatura, $\Delta t$ el tiempo total de uso del horno en segundos y masa $(\mathrm{Kg})$ la masa total a procesar durante este tiempo.

En el caso de secado por microondas, hay que tener en cuenta, previamente, cuánta agua hay en el producto atendiendo al contenido de humedad en base seca, y calcular la potencia necesaria para calentar tanto el material seco como el agua. Es decir, se considera el calor necesario para calentar el agua interna del material y el necesario para calentar sólo la masa sólida. Además, la potencia necesaria para evaporar el agua es:

$$
P_{\text {abs evaporacion }}(W)=\text { masa agua }(K g) \cdot \Delta H_{v}(J / K g) \cdot \frac{1}{\Delta t(s)}
$$

donde masa_agua es la cantidad de agua a evaporar, $\Delta H_{v}$ es el calor latente de evaporación y $\Delta t$ es el tiempo de uso del horno para producir esa evaporación de agua. El contenido de humedad en base seca es:

$$
X=\frac{m-m s}{m s}=\frac{m a s a \text { agua }}{m s}
$$

siendo $m$ la masa total a secar, $X$ el contenido de humedad en base seca del producto, $m_{s}$ será la masa seca del producto que se calcula a partir de estos otros dos datos y masa_agua es la masa de agua inicial en el cuerpo. Por lo tanto, cuando existe secado la potencia total se calcula como:

$$
\begin{gathered}
P_{T}=P_{\text {abs calentamiento }}(\text { solido })+P_{\text {abs calentamiento }}(\text { agua }) \\
+P_{\text {abs evaporacion }}(\text { agua })
\end{gathered}
$$

Esta herramienta permite la toma de datos del proceso para, posteriormente, calcular los parámetros con los que se debe configurar el horno real, e incluso generar la estructura CAD en CST, si fuese necesario, habilitando la posibilidad de realizar la simulación a partir del Diferencia Finitas en el Dominio del Tiempo (FDTD) para la resolución de las ecuaciones diferenciales de campo eléctrico en su interior, así como para la generación de un modelo optimizado que se adapte al proceso inicial. 

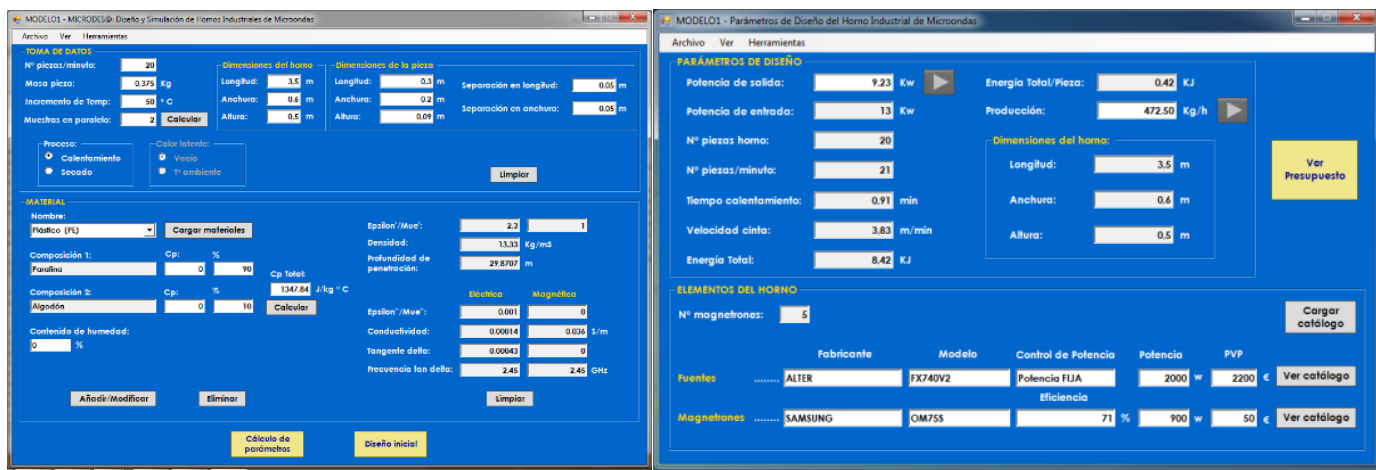

Figura 6.16. Interfaz de la herramienta MICRODES para diseño de horno microondas(1)

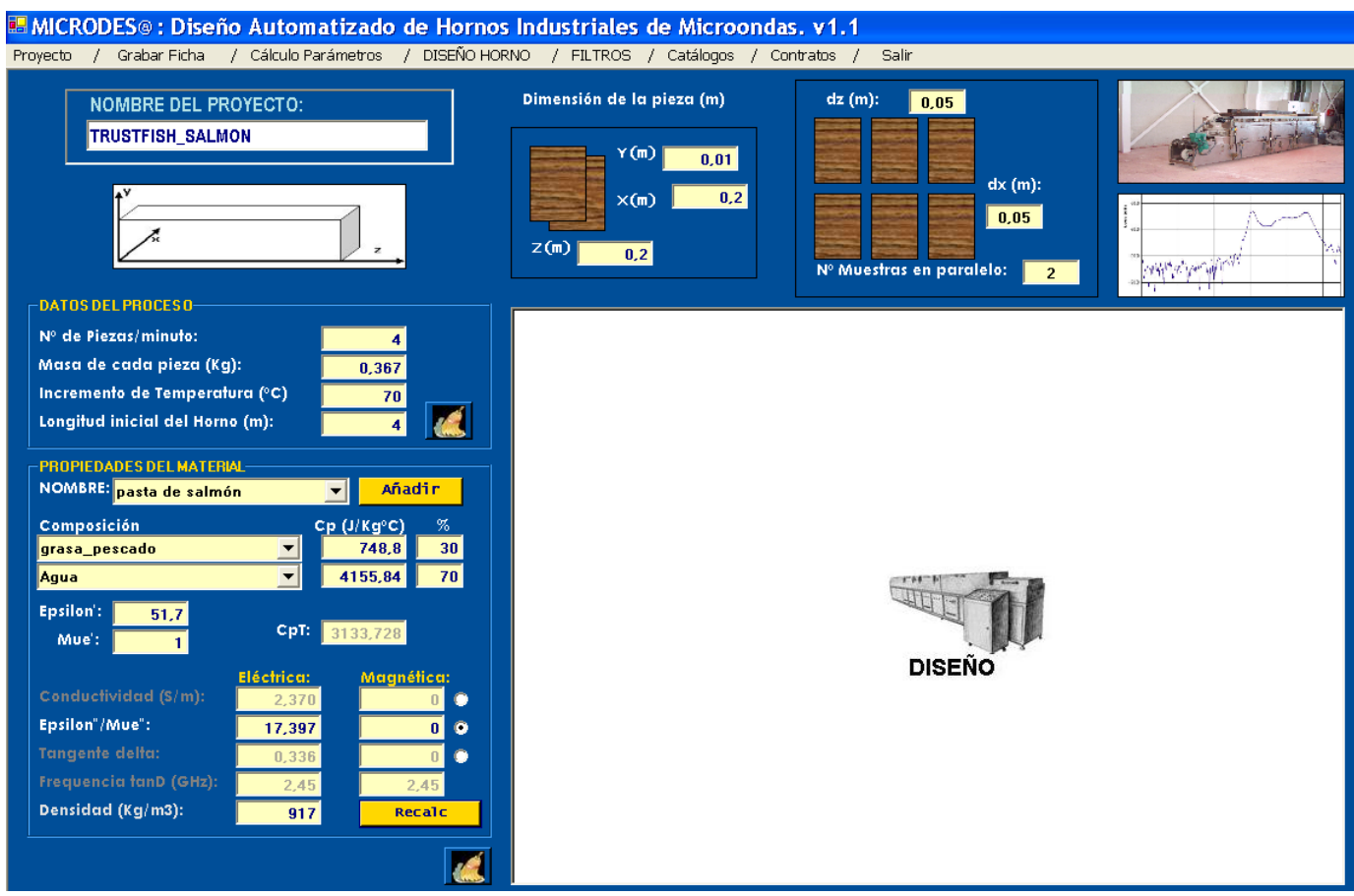

Figura 6.17. Interfaz de la herramienta MICRODES para diseño de horno microondas(2)

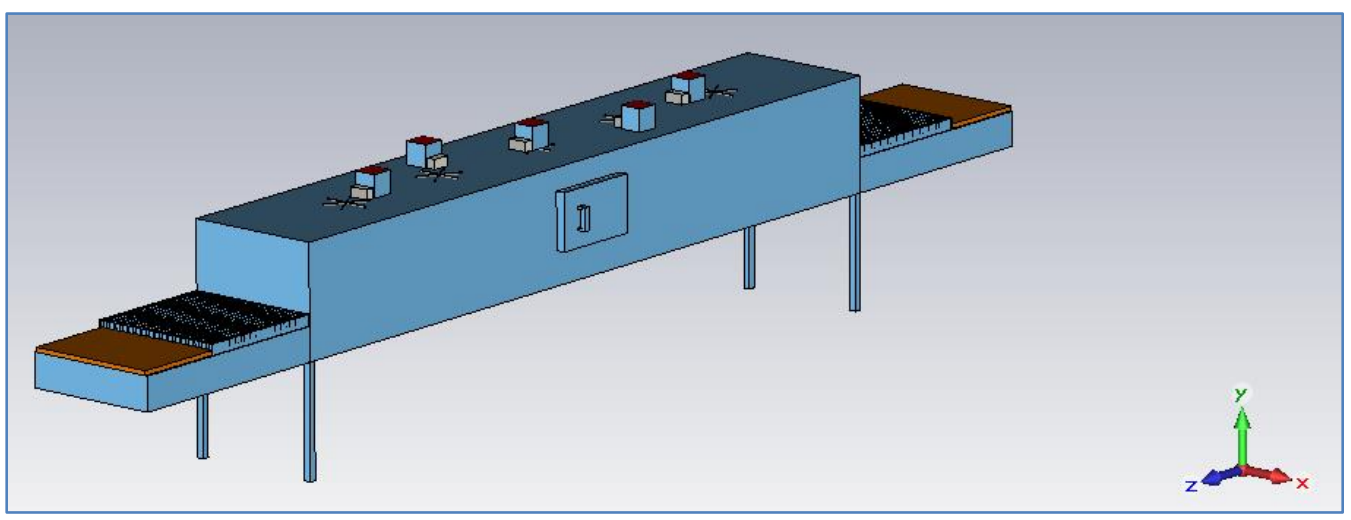

Figura 6.18. Ejemplo de equipo de horno túnel microondas generado con MICRODES@ 


\subsection{Configuración del Horno Industrial de Microondas para secado de Sandach}

En concreto, este horno industrial del Grupo I+D GEM-UPCT tiene las siguientes características y especificaciones:

- Evacuación de GASES: $1 \mathrm{Kg} / \mathrm{Kw}$ cada $1 \mathrm{~h}$ (generalmente se expresa en litros/hora o $\mathrm{m}^{3} /$ hora)

- Frecuencia de Trabajo: $2450 \pm 50 \mathrm{MHz}$

- Potencia de entrada: $16 \mathrm{Kw}$

- Potencia de salida de microondas: $12 \mathrm{Kw}$ (ajustable)

- Número de cavidades: 3

- Tipo de refrigeración de Fuentes y Magnetrones: Aire forzado.

- Velocidad de la Cinta: 0 a 2,7 m/min

- Anchura de la Cinta: $55 \mathrm{~cm}$

- Altura de los filtros de entrada y salida: $4 \mathrm{~cm}$

- Longitud del Horno: 5,2 m

Las siguientes imágenes muestran el equipo de microondas semi-industrial, los detalles del sistema de actuación sobre las fuentes de los magnetrones, cinta transportadora, etc. y su ubicación en el laboratorio GEM del Parque Tecnológico de Fuente Álamo (Murcia).

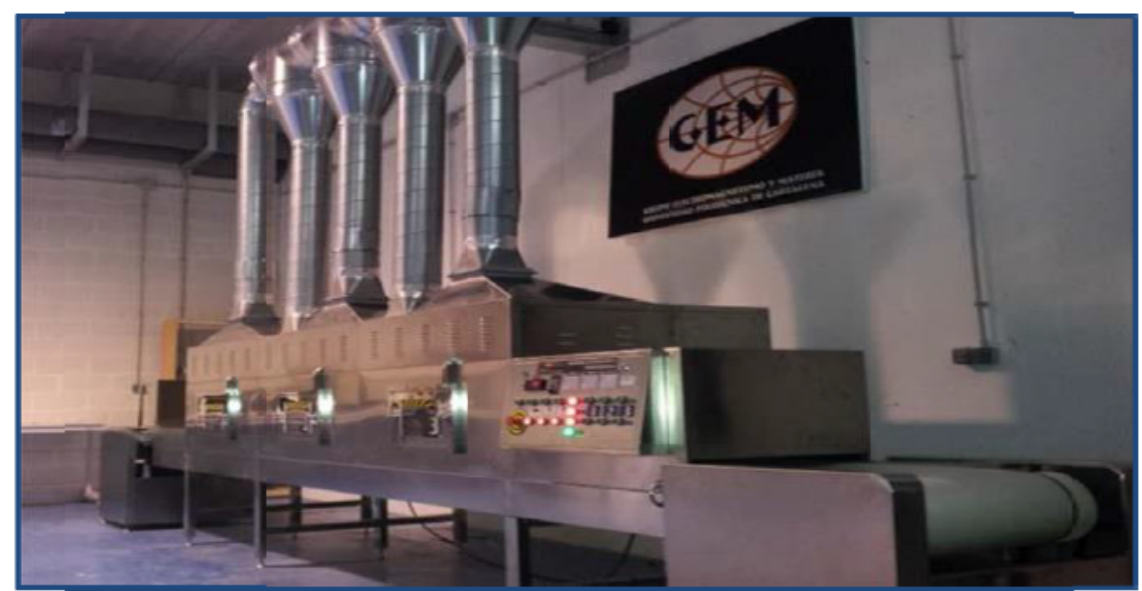

Figura 6.19. Vistas del horno semi-industrial del grupo I+D GEM-UPCT en el PTFA 
Construido íntegramente en acero inoxidable, el horno cuenta con tres zonas de calentamiento asistido por microondas. Como se puede apreciar en la figura 6.20 , la cinta transportadora integrada permite la introducción del producto (figura 6.12), pudiendo ajustar la velocidad del mismo gracias al variador electrónico de velocidad incorporado de serie.

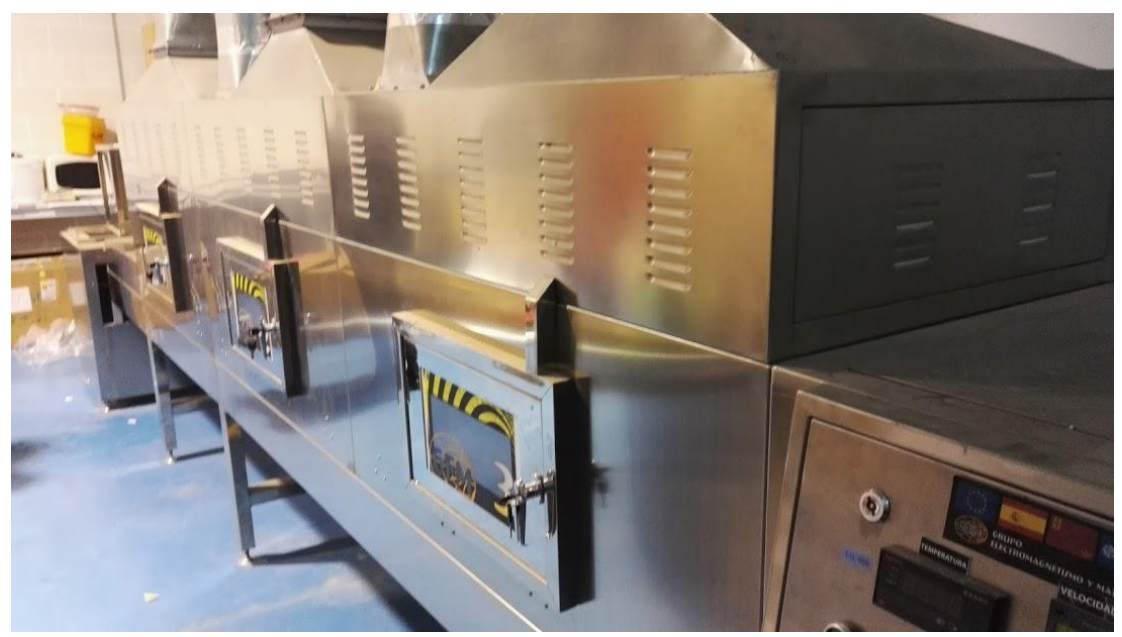

Figura 6.20. Imagen en la que se aprecian las tres zonas de esterilización.

El túnel continuo incorpora en su estructura una serie de puertas (figura 6.20) que le aportan mayor versatilidad, por un lado, ofrecen la posibilidad de limpieza del interior, si por las características del producto fuera necesario (en nuestro caso para el Sandach y la Sopa vegetal nos fue de mucha utilidad), o para el simple mantenimiento.

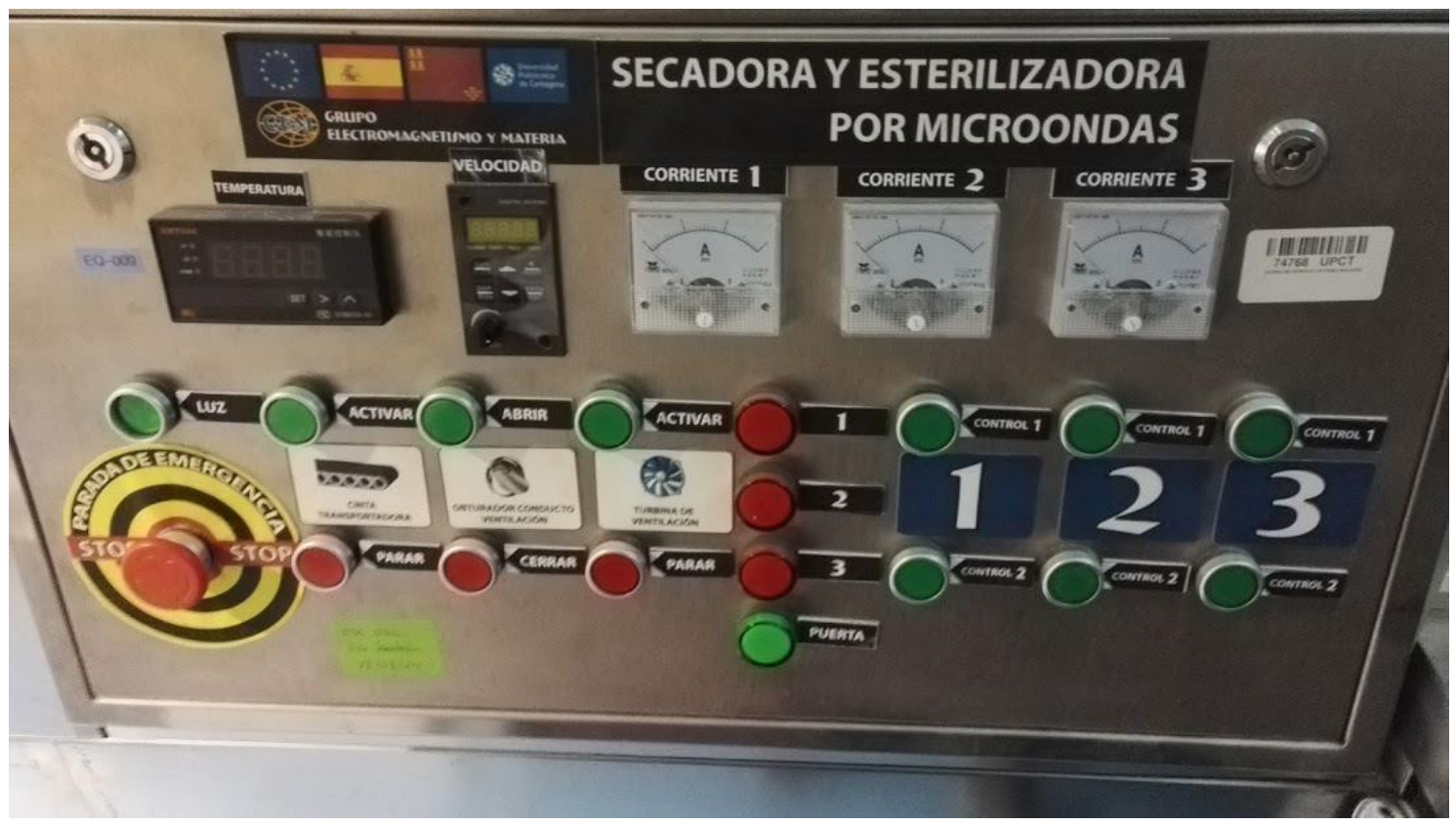

Figura 6.21. Vista del control de mandos del horno. 
En la figura 6.21, apreciamos el control de mandos que gobierna el funcionamiento del horno, en ella podemos ver los displays de temperatura y velocidad, medidores de corriente de las tres cavidades, así como los pulsadores para poder discriminar entre varias opciones entre ellas.

El horno de microondas, cuenta con un sistema integrado de extracción y refrigeración de aire para impedir sobrecalentamientos no deseados, como se puede ver en la figura 6.22, bien dentro del túnel, que pudiera producirse por acumulación de calor después de varias horas, bien de sus componentes eléctricos y/o mecánicos, evitando posibles averías, de este modo se aumenta su vida útil y se reduce su mantenimiento como se puede ver en la figura 6.22 .

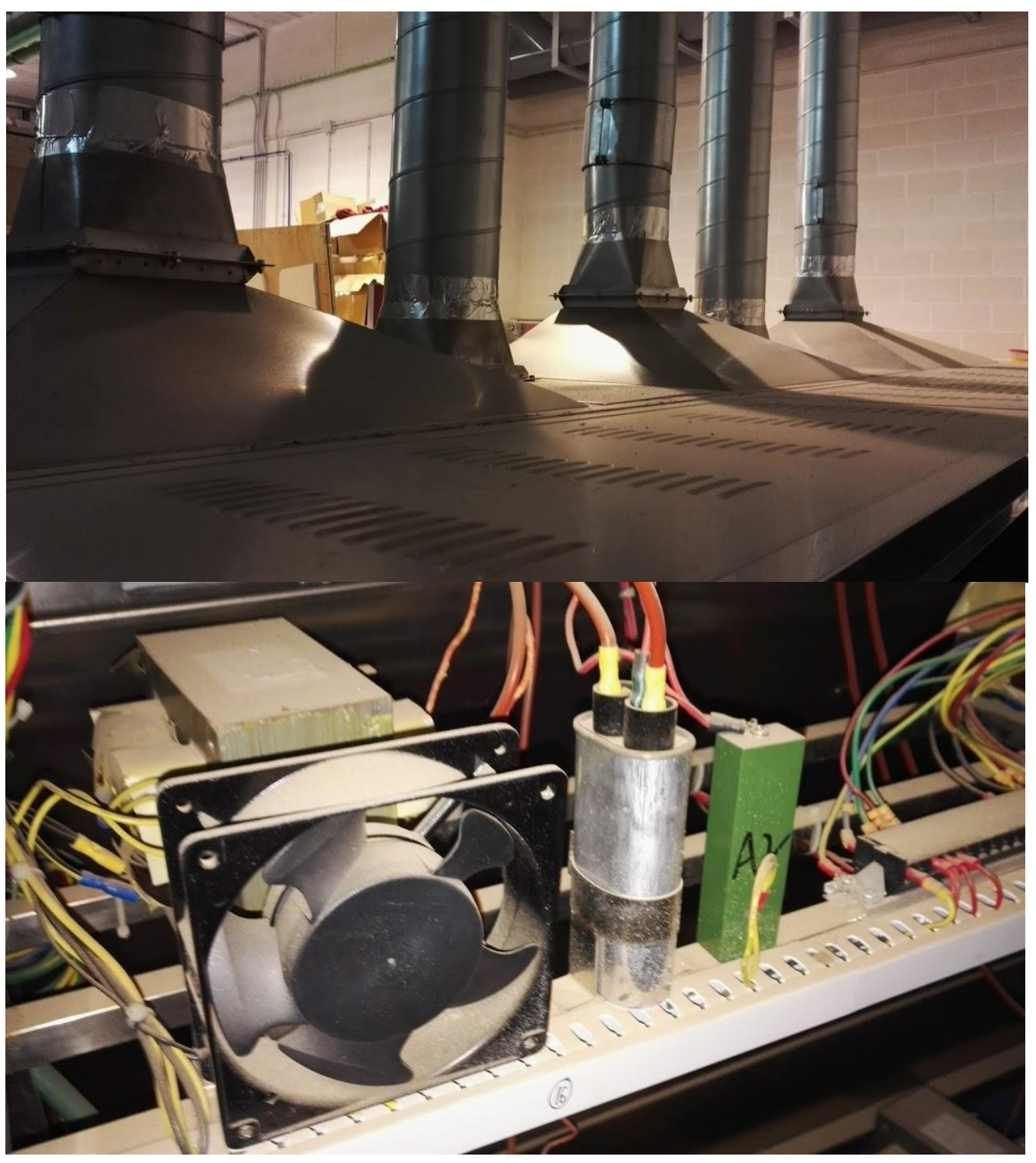

Figura 6.22. Vista del sistema de refrigeración y extracción del horno. 
En la figura 6.23 , se puede observar la disposición de los ventiladores junto a la fuente de la alimentación y la de los magnetrones unidos al launcher.

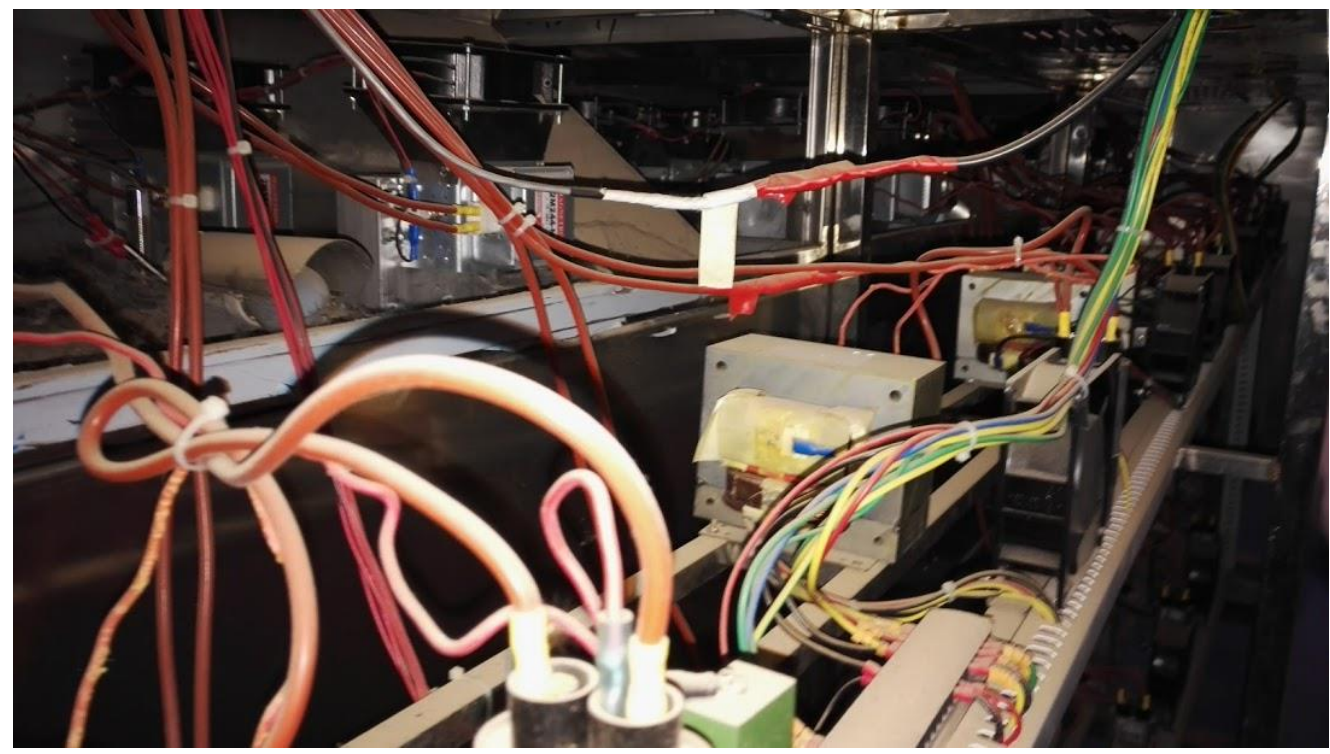

Figura 6.23. Vista del sistema de refrigeración y extracción del horno.

\subsection{Normativa que regula el tratamiento industrial por microondas}

A la misma vez que se ha producido un desarrollo de la industria de microondas, se ha incrementado la importancia de la seguridad en todo tipo de procesos industriales, implantándose este requisito en todos sus niveles. Las actuales normativas que limitan las radiaciones que se emiten hacia el exterior en dispositivos que emplean campos electromagnéticos a frecuencias industriales científicas y médicas (ICM) garantizan la seguridad del personal expuesto a tales radiaciones. Este hecho es aplicable al entorno de los procesos industriales de calentamiento que puedan utilizar hornos de microondas con fugas naturales (debidas a las aperturas de los puertos de entrada y salida) o escapes no deseados (debidos a fisuras o defectos de fabricación del horno) del campo electromagnético hacia el exterior [UNE-EN 55011:2016/A1:2017]. Equipos industriales (clase A), científicos y médicos (clase B). Características de las perturbaciones radioeléctricas. Límites y métodos de medición. (Ratificada por la Asociación Española de Normalización en junio de 2017. 
Esta norma cubre los requisitos de emisión relacionados con las perturbaciones de radiofrecuencia (RF) en el rango de frecuencia de $9 \mathrm{kHz}$ a $400 \mathrm{GHz}$.

Hasta hoy, no se han publicado nuevos estudios que justifiquen una modificación de los límites de la OMS y la UE, por lo que cabe considerar que los niveles actuales de emisión se consideran seguros para garantizar la protección de la salud de la población.

\begin{tabular}{|c|c|c|c|}
\hline & \multicolumn{3}{|c|}{ Límites RD 1066/2001 } \\
\hline Frecuencia & $\begin{array}{l}900 \mathrm{MHz} \\
\left(\mu \mathrm{W} / \mathrm{cm}^{2}\right)-(V / \mathrm{m})\end{array}$ & $\begin{array}{l}1800 \mathrm{MHz} \\
\left(\mu \mathrm{W} / \mathrm{cm}^{2}\right) \\
(\mathrm{V} / \mathrm{m})\end{array}$ & $\begin{array}{l}2 \mathrm{GHz} \\
\left(\mu \mathrm{W} / \mathrm{cm}^{2}\right)\end{array}$ \\
\hline 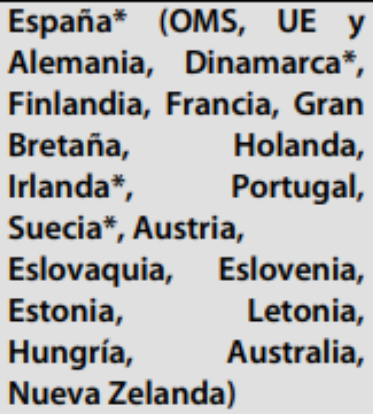 & $\begin{array}{l}450 \mu \mathrm{W} / \mathrm{cm}^{2} \\
\text { ó } 41 \mathrm{~V} / \mathrm{m}\end{array}$ & $\begin{array}{l}900 \mu \mathrm{W} / \mathrm{cm}^{2} \\
\text { ó } 58 \mathrm{~V} / \mathrm{m}\end{array}$ & $\begin{array}{l}1000 \\
\mu \mathrm{W} / \mathrm{cm}^{2}\end{array}$ \\
\hline
\end{tabular}

Tabla 6.1. Límites exposiciones radioeléctricas RD 1066/2001

\subsection{Conclusiones}

Este capítulo tenía como objetivo la presentación de una herramienta de simulación para el diseño de un horno industrial de microondas y su construcción, debiendo satisfacer las necesidades del tratamiento en cuanto a dimensiones de la muestra y del horno, coste, requerimientos del proceso, potencia o producción.

Por otra parte, el calentamiento por microondas depende de las propiedades del material que sea introducido y del tipo de proceso seleccionado: calentamiento o secado, circunstancia que resuelve la herramienta MICRODES@, aportando una solución óptima y automática para cada caso.

Para realizar el diseño del horno, se recogen las propiedades del material que va a ser 
procesado en la pantalla de toma de datos de la aplicación, además de las dimensiones del horno o los datos del proceso.

Dependiendo de estos datos de entrada, se calculan los parámetros de diseño necesarios, tales como la velocidad de la cinta, la potencia a emitir, la producción o el tiempo de calentamiento, requeridos para poder diseñar y simular el horno.

Al mismo tiempo, se debe verificar unos parámetros de seguridad para evitar radiaciones de ondas microondas al exterior, mediante el cumplimiento de la norma UNE-EN-55011, que regula en España los límites y métodos de medida de las perturbaciones radioeléctricas producidas por aparatos industriales.

\subsection{Referencias}

[1] Alejandro Díaz Morcillo, Juan Monzó Cabrera, "Líneas de Transmisión, Guías de Onda y Cavidades Resonantes", ETSIT UPCT, 2007.

[2] J.L. Pedreño-Molina, J. Monzó-Cabrera, A. Díaz-Morcillo, A. Lozano-Guerrero y F. Clemente.MICRODES@: una herramienta software para el diseño automatizado de hornos industriales de microondas. Revista Espacio Teleco, Vol. 1. ISSN 2171-2042, depósito legal MU-27-2009, Editorial Áglaya, pp: 117-122. Marzo 2010.

[3] REAL DECRETO 1066/2001, de 28 de septiembre,

[4] J. Monzó-Cabrera, J.L. Pedreño-Molina, A. Lozano-Guerrero, F.J. ClementeFernández and A. Díaz-Morcillo, "Analysis of reactive and resistive open waveguide filters for use in microwave-heating applicators", The international journal for computation and mathematics in electrical and electronic engineering. Vol. 30, No. 5, 1606-1615 (March 2011).

[5] F.J. Clemente-Fernández, J. Monzó-Cabrera, J.L. Pedreño-Molina, A.J. LozanoGuerrero, J. Fayos-Fernández and A. Díaz-Morcillo, "A new sensor-based self- 
CAPÍTULO 6. DISEÑO DE UN HORNO DE TÚNEL DE MICROONDAS PARA LA ESTERILIZACIÓN Y SECADO DE SANDACH

configurable bandstop filter for reducing the energy leakage in industrial microwave ovens", Measurement, Vol. 23065101

[6] F. J. Clemente-Fernández, J. Monzó-Cabrera, J. M. Catalá-Civera, J. L. PedreñoMolina, A. J. Lozano-Guerrero and A. Díaz-Morcillo "Waveguide bandstop filter based on irises and double corrugations for use in industrial microwave ovens", Electronics Letters, Volume 48, issue 13, 21 pp. $772-774$ (June 2012). 


\section{CAPÍTULO 7}

\section{RESULTADOS PARA LA VALIDACIÓN DEL PROCESADO DE SANDACH EN EQUIPO INDUSTRIAL DE MICROONDAS}

\subsection{Introducción y Objetivo}

Una vez identificados los regímenes óptimos de aplicación de microondas y temperaturas en los diferentes materiales en una cavidad monomodo, en este capítulo se ha desarrollado el escalado a mayores tamaños de muestra, donde los alimentos y el Sandach se han distribuido en bandejas que han sido sometidas a radiación de microondas en un proceso en línea mediante el horno de túnel descrito en el capítulo anterior. El problema en este escalado radica en la dificultad en conseguir un calentamiento homogéneo en todo el producto, teniendo en cuenta, además que en equipos microondas de dimensiones semi-industriales es extremadamente costoso trabajar en condiciones de presión para evitar la evaporación del alimento, por lo que el proceso de esterilización se ha sustituido por un proceso de calentamiento/secado por microondas a temperaturas medias inferiores a $100^{\circ} \mathrm{C}$ en el conjunto de la muestra. Lo importante de esta fase es que ya se dispone de la caracterización de los biosensores, pudiendo ser utilizados para una correlación de inactivación microbiológica de bastante precisión en el proceso de deshidratación del Sandach.

Para alcanzar el objetivo propuesto en este trabajo de investigación, se han realizado las tareas conducentes a detallar los procedimientos, metodologías y resultados de este proyecto de transferencia industrial. Los resultados han sido divididos en dos partes: PRUEBAS DE DESHIDRATACIÓN y PRUEBAS MICROBIOLÓGICAS.

\subsection{Metodología de experimentación con Sandach}

\subsubsection{Pruebas de deshidratación}

En estas pruebas experimentales, se ha estudiado la capacidad del sistema para deshidratar 
las muestras, así como los parámetros de funcionamiento necesarios para ello. Debido a la problemática en la gestión y manipulación del Sandach, se ha realizado una batería de pruebas iniciales con otros materiales más asequibles y de propiedades similares, como la crema de patata con nuez moscada. Una vez controlado el sistema, se han realizado los experimentos correspondientes con Sandach, siguiendo un procedimiento basado en las siguientes actuaciones:

- Medida de las propiedades dieléctricas del alimento. Las propiedades dieléctricas son imprescindibles para conocer el comportamiento del material en presencia de las microondas. Es un indicador básico para el cálculo de los parámetros del proceso.

- Medida de la densidad, masa, temperatura inicial y volumen de la muestra. Al igual que las propiedades dieléctricas, la cantidad de energía de microondas absorbida dependerá de la densidad, la masa y el volumen de la muestra, entre otros. Son parámetros necesarios también para el cálculo de la velocidad de procesado.

- Cálculo de la velocidad del proceso de calentamiento. Una vez conocidos los parámetros básicos de la muestra que vamos a tratar, se hace uso del programa Microdes@ para calcular la potencia y la velocidad de la cinta del horno necesaria para alcanzar la temperatura deseada en la muestra.

- Calentamiento con extracción de humedad. Con los parámetros obtenidos anteriormente, se configura el horno y se realiza el tratamiento térmico.

- Medición y registro de la temperatura final de la muestra. A partir de estas mediciones se ha calculado el grado de cumplimiento de la temperatura objetivo en la muestra.

- Pesado y cálculo de la pérdida de humedad. Conociendo la relación entre el peso inicial y el final es posible determinar la pérdida de humedad. 


\subsubsection{Análisis Microbiológico}

En esta segunda etapa se ha introducido una red de biosensores en la muestra y se han realizado diferentes tratamientos térmicos para analizar la mortalidad al final del proceso, según el siguiente procedimiento:

- Configuración de la matriz de biosensores. Se ha dividido la muestra en diferentes zonas donde se colocan los biosensores, pudiendo, de esta forma, analizar la eficiencia del tratamiento en toda la muestra.

- Medida del \% de mortalidad al final del proceso. Tras los tratamientos realizados, se ha analizado la mortalidad de cada una de estas colonias de biosensores, midiendo la correlación con la temperatura de la muestra en cada una de estas zonas. Para la realización de estos Tests se ha realizado previamente el siguiente proceso:

- Adquisición de materiales de laboratorio, incluidas bandejas aptas para los tratamientos a realizar.

- Comprobación del funcionamiento y elaboración de manual del horno de microondas.

- Medición del apantallamiento electromagnético, prestando especial atención a las zonas de entrada y salida de las muestras, así como en las puertas del horno.

\subsection{Apantallamiento Electromagnético}

Según Real Decreto 1066/2001, de 28 de septiembre, por el que se aprueba el Reglamento que establece condiciones de protección del dominio público radioeléctrico, restricciones a las emisiones radioeléctricas y medidas de protección sanitaria frente a emisiones radioeléctricas". BOE núm. 234, de 29 de septiembre de 2001, BOE núm. 257, de 26 de octubre de 2001 y BOE núm. 93, de 18 de abril de 2002, los niveles de referencia 
de la exposición sirven para ser comparados con los valores de las cantidades medidas. El respeto de todos los niveles de referencia recomendados asegurará el respeto de las restricciones básicas.

\begin{tabular}{|c|c|c|c|c|}
\hline $\begin{array}{c}\text { Gama } \\
\text { de frecuencia }\end{array}$ & $\begin{array}{c}\text { Intensidad de campo } E \\
\qquad(\mathrm{~V} / \mathrm{m})\end{array}$ & $\begin{array}{c}\text { Intensidad de campo } \mathrm{H} \\
(\mathrm{A} / \mathrm{m})\end{array}$ & $\begin{array}{c}\text { Campo B } \\
(\mu \mathrm{T})\end{array}$ & $\begin{array}{c}\text { Densidad } \\
\text { de potencia } \\
\text { equivalente } \\
\text { de onda plana } \\
\left(\mathrm{W} / \mathrm{m}^{2}\right)\end{array}$ \\
\hline $0-1 \mathrm{~Hz}$ & & $3,2 \times 10^{4}$ & $4 \times 10^{4}$ & \\
\hline $1-8 \mathrm{~Hz}$ & 10.000 & $3,2 \times 10^{4} / f^{2}$ & $4 \times 10^{4} / f^{2}$ & \\
\hline $8-25 \mathrm{~Hz}$ & 10.000 & $4.000 / f$ & $5.000 / f$ & \\
\hline $0,025-0,8 \mathrm{kHz}$ & $250 / f$ & $4 / f$ & $5 / f$ & \\
\hline $0,8-3 \mathrm{kHz}$ & $250 / f$ & 5 & 6,25 & \\
\hline $3-150 \mathrm{kHz}$ & 87 & 5 & 6,25 & \\
\hline $0,15-1 \mathrm{MHz}$ & 87 & $0,73 / f$ & $0,92 / f$ & \\
\hline $1-10 \mathrm{MHz}$ & $87 / f^{1 / 2}$ & $0,73 / f$ & $0,92 / f$ & \\
\hline $10-400 \mathrm{MHz}$ & 28 & 0,073 & 0,092 & 2 \\
\hline $400-2.000 \mathrm{MHz}$ & $1,375 f^{1 / 2}$ & $0,0037 f^{1 / 2}$ & $0,0046 f^{1 / 2}$ & $f / 200$ \\
\hline $2-300 \mathrm{GHz}$ & 61 & 0,16 & 0,20 & 10 \\
\hline
\end{tabular}

Tabla 7.1. Niveles de referencia recomendados según RD 1066/2001.

Las medidas se han realizado con el medidor de campo Narda NBM 550, y la sonda NBM E-Field-Probe EF 0392, tal y como se aprecia en la figura 7.1. Para ello, se ha llenado el horno con bandejas con agua y se ha alimentado el módulo 1, tanto a media como a máxima potencia para medir el campo radiado tanto por las puertas como por el filtro de entrada. A continuación, se ha realizado la misma operación con el módulo 3 y el filtro de salida. Los resultados se encuentran resumidos en la tabla siguientes.

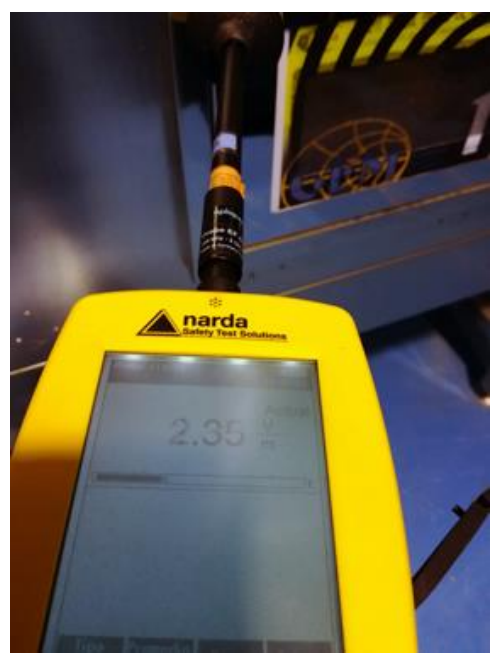

Figura 7.1. Vista medidor de campo Narda NBM 550, y la sonda NBM E-Field-Probe EF 0392 durante la medición. 
Dando como resultados, las medidas que aparecen en la siguiente tabla:

\begin{tabular}{|l|c|c|c|l|l|}
\hline Zona/ Campo E [V/m] & $\begin{array}{l}\text { Sin } \\
\text { potencia }\end{array}$ & $\begin{array}{l}\text { 3KW } \\
\text { Módulo 1 }\end{array}$ & $\begin{array}{l}\text { 6KW } \\
\text { Módulo 1 }\end{array}$ & $\begin{array}{l}\text { 3KW } \\
\text { Módulo 3 }\end{array}$ & $\begin{array}{l}\text { 4KW } \\
\text { Módulo 3 }\end{array}$ \\
\hline Entrada & 1,17 & 4,35 & 8,26 & & \\
\hline Puertas & 2,35 & 4,24 & 15,28 & 6 & 6,84 \\
\hline Salida & 2,32 & & & 18,01 & 24,12 \\
\hline
\end{tabular}

Tabla 7.2. Resultados de las primeras medidas de campo electromagnético a entrada y salida del horno.

Con estos valores comprobamos que estamos por debajo de los valores indicados por la legislación vigente.

\subsection{Caracterización de los materiales}

Tal y como indicamos anteriormente, es imprescindible conocer las propiedades dieléctricas de los materiales que vamos a introducir en el horno para poder predecir de forma aproximada su comportamiento y así ajustar los parámetros de funcionamiento del horno según el tipo de procesado que deseemos realizar. En este caso necesitamos saber las propiedades de las bandejas y los materiales en estudio.

\subsubsection{Características del soporte de material}

Las bandejas utilizadas son de Pyrex, capaces de soportar desde $-40^{\circ} \mathrm{C}$ a $260^{\circ} \mathrm{C}$, y son aptas para microondas, con una constante dieléctrica y factor de pérdidas típicos dados por el fabricante de $\varepsilon_{r}=4,3$ y $\tan \delta=0,0047$ respectivamente, siendo las dimensiones: $24,7 \mathrm{~cm} \times 16 \mathrm{~cm} \times 4 \mathrm{~cm}$. 


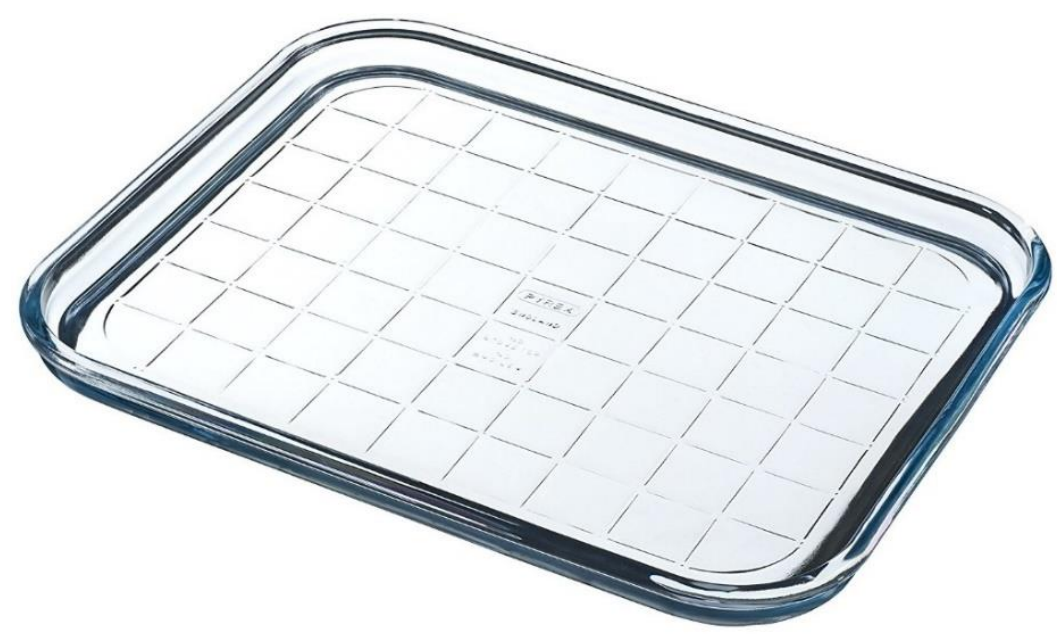

Figura 7.2. Bandeja de Pirex para depósito de material.

\subsubsection{Puré de patata y nuez moscada}

En este caso hemos realizado un trabajo de caracterización dieléctrica en función de la frecuencia $[2,40-2,50] \mathrm{GHz}$ y la temperatura $[25,0-60,0]{ }^{\circ} \mathrm{C}$

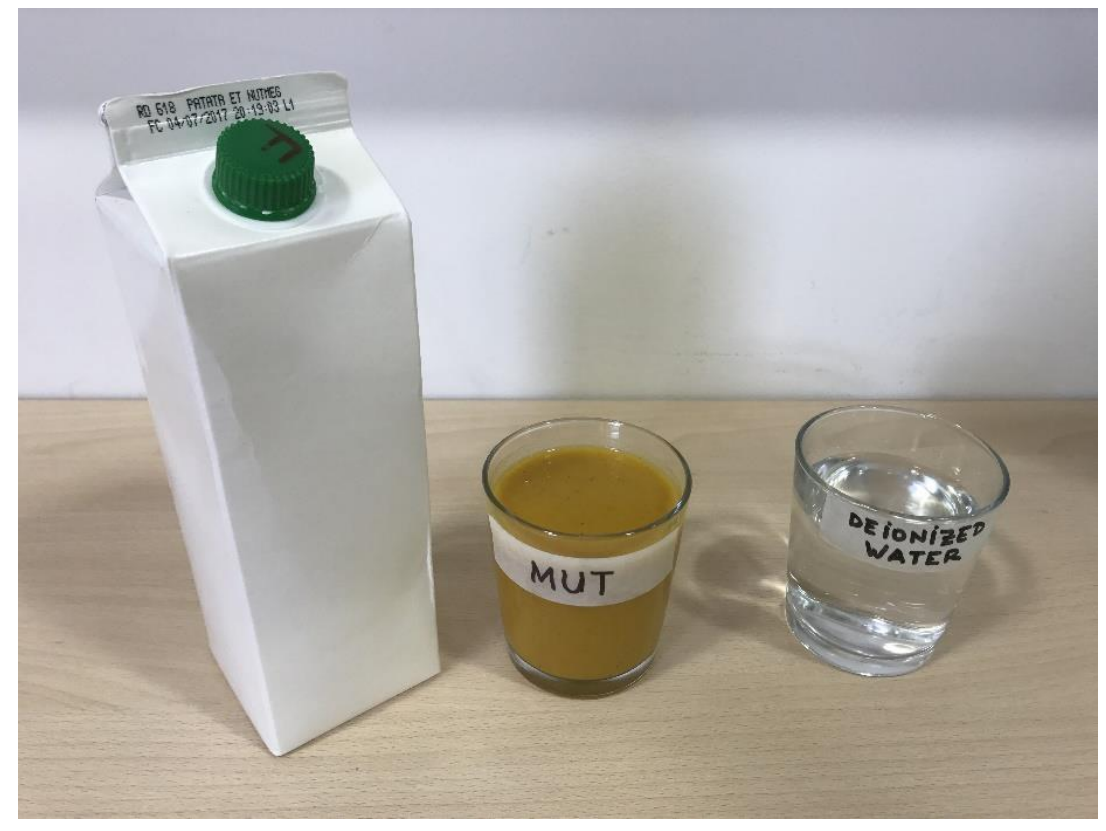

Figura 7.3. Imagen del producto medido (MUT) junto con el agua desionizada empleada para la calibración del sistema de medida 
En la figura 7.3, puede observarse un recipiente con la crema de patata y nuez moscada, junto con otro de agua desionizada que necesitábamos para calibrar el sistema de medida; pudiendo medir, tal y como apreciamos en la figura 7.4, las propiedades dieléctricas en función de la frecuencia y temperatura.

Idealmente, el comportamiento de la carga de calibración debería ser similar al del material objetivo, es decir, con una respuesta plana para el rango de frecuencia deseado.

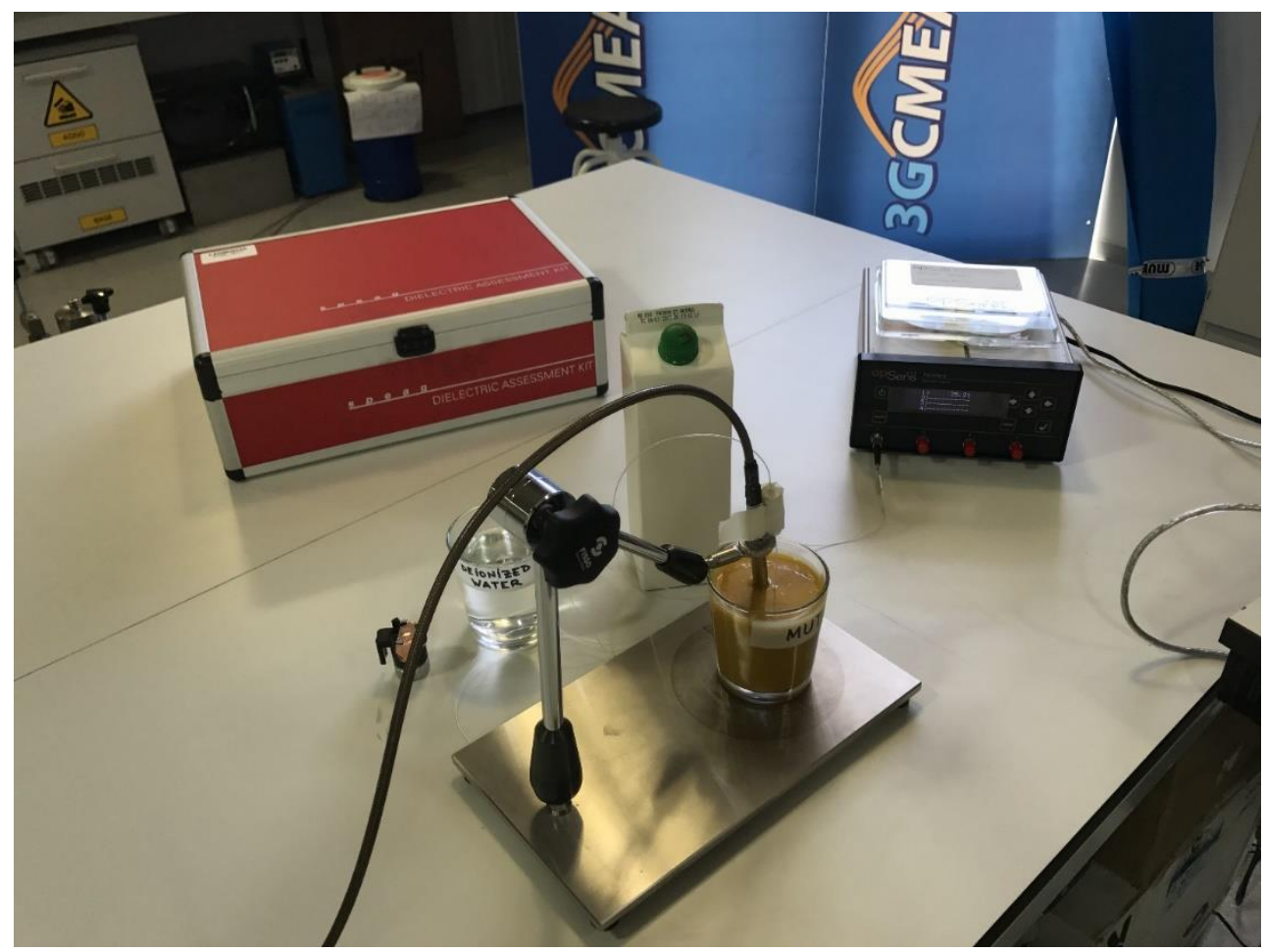

Figura 7.4. Imagen del montaje para la medida de las propiedades dieléctricas en función de la frecuencia y temperatura.

Las siguientes figuras nos muestran los resultados relativos a la constante dieléctrica $\varepsilon^{\prime}$ (que define el grado de polarización del material a ser sometido a un campo eléctrico) y $\varepsilon^{\prime \prime}$, el factor de pérdidas (que indica la capacidad de disipación de la energía eléctrica dentro del material, en forma de calor. 

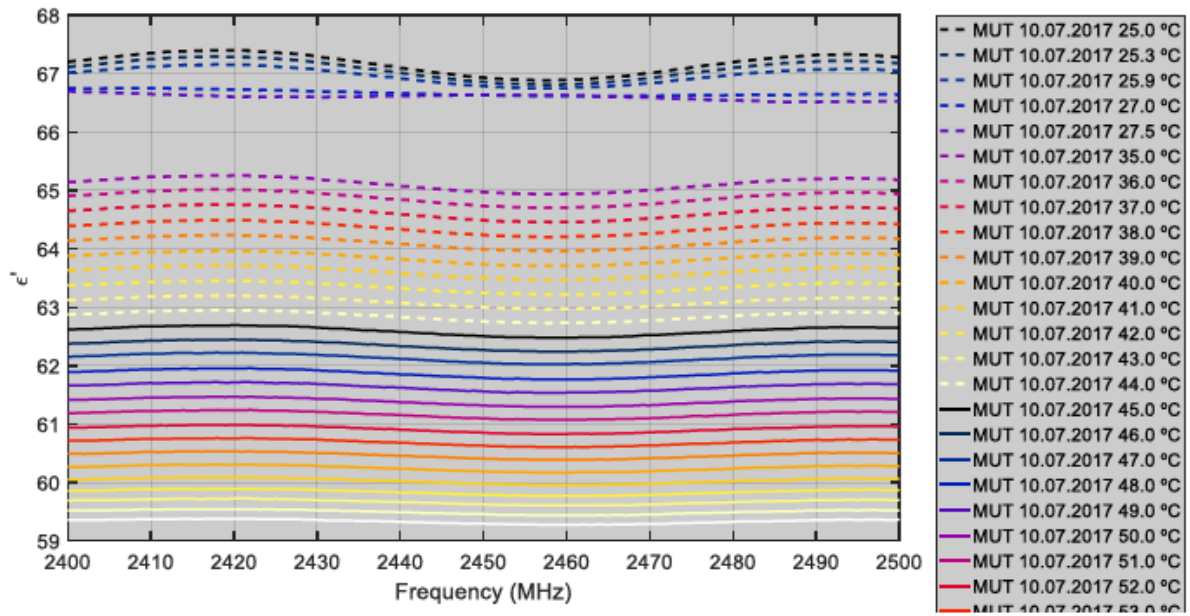

Figura 7.5. Valores de la constante dieléctrica del producto en el rango $[2.4,2.5] \mathrm{GHz}(\Delta f=1$

$\mathrm{MHz} ; 101$ puntos) y para el rango de temperaturas desde los $27^{\circ} \mathrm{C}$ hasta los $60^{\circ} \mathrm{C}$.
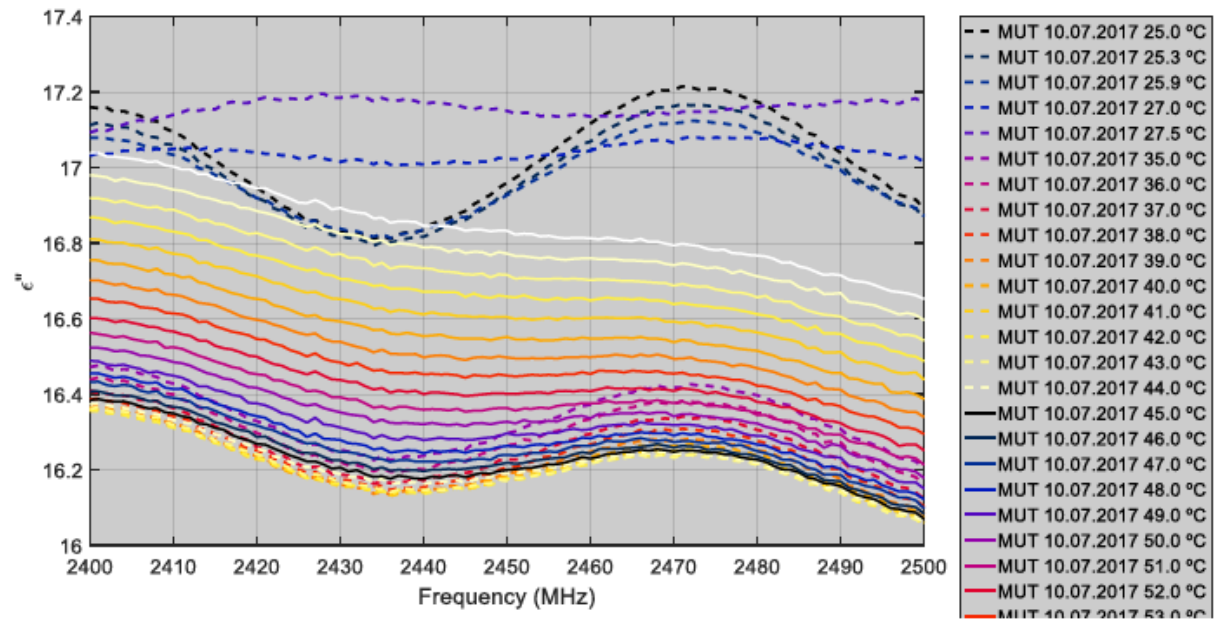

Figura 7.6. Valores del factor de pérdidas del producto en el rango [2.4, 2.5] $\mathrm{GHz}(\Delta f=1 \mathrm{MHz}$; 101 puntos) y para el rango de temperaturas desde los $27^{\circ} \mathrm{C}$ hasta los $60^{\circ} \mathrm{C}$.

La capacidad de un dieléctrico para almacenar carga está ligada a la polarización que sufre en su interior, en contra del campo eléctrico exterior que aparece como consecuencia de la acumulación de la carga en las armaduras del condensador. La constante dieléctrica nos permite obtener y comparar entre materiales la facilidad con que se polarizan. A mayor constante dieléctrica, mayor polarización en el interior del material. 


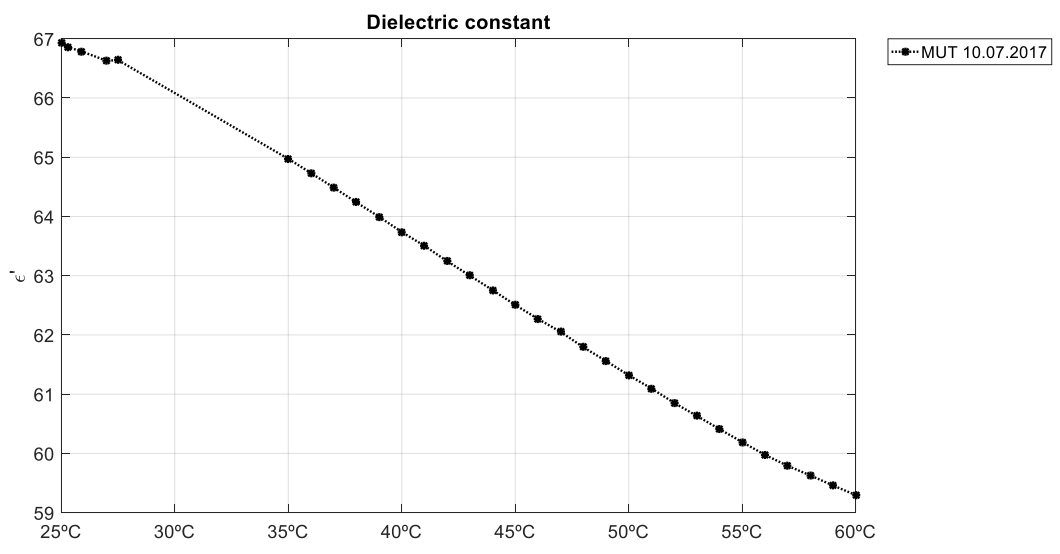

Figura 7.7. Valores de la constante dieléctrica del producto a la frecuencia de $2.45 \mathrm{GHz}$ y para el rango de temperaturas desde los $27^{\circ} \mathrm{C}$ hasta los $60^{\circ} \mathrm{C}$.

La figura anterior nos muestra que la constante dieléctrica decae conforme se aumenta la temperatura, por tanto, la acumulación de carga en el material, en este caso el puré decae.

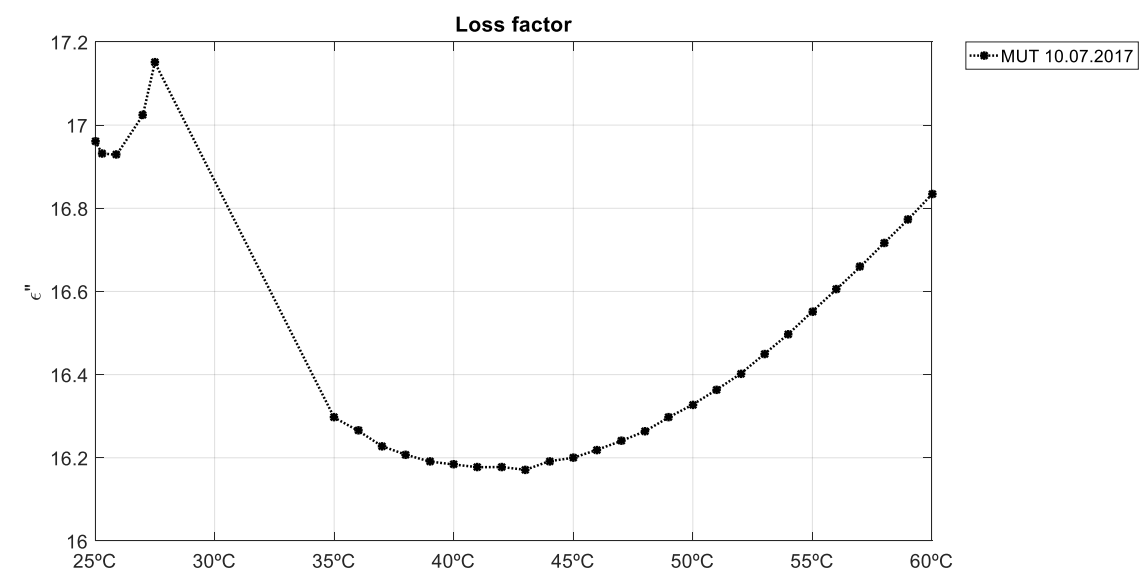

Figura 7.8. Valores del factor de pérdidas del producto a la frecuencia de $2.45 \mathrm{GHz}$ y para el rango de temperaturas desde los $27^{\circ} \mathrm{C}$ hasta los $60^{\circ} \mathrm{C}$.

La figura anterior muestra una fluctuación en el factor de pérdidas conforme aumenta la temperatura, recuperando los márgenes al llegar a la temperatura objetivo. 


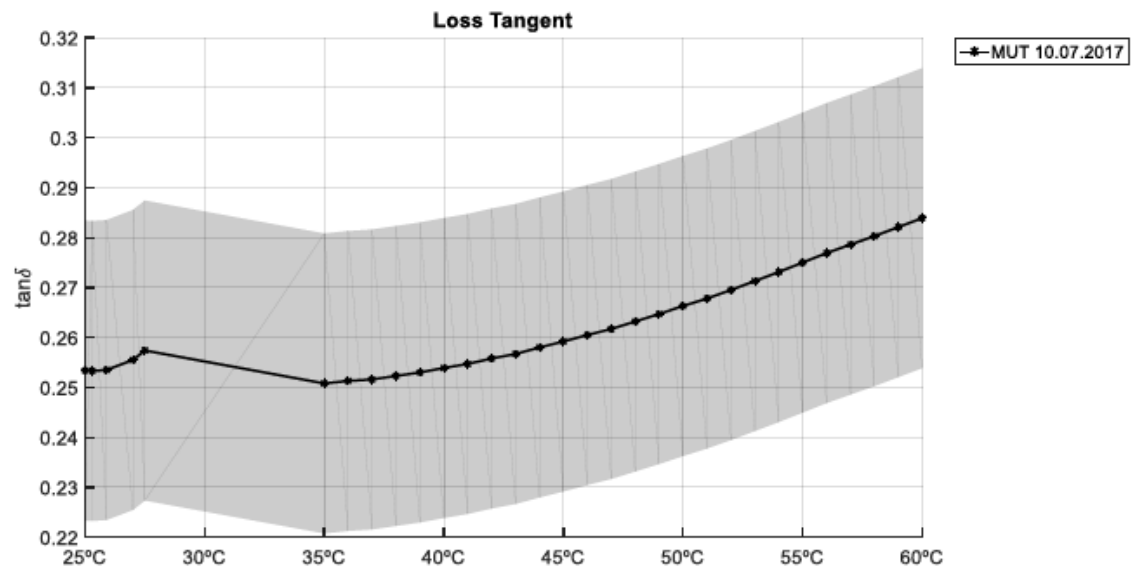

Figura 7.9. Valores de la tangente de pérdidas del producto a la frecuencia de $2.45 \mathrm{GHz}$ y para el rango de temperaturas desde los $27^{\circ} \mathrm{C}$ hasta los $60^{\circ} \mathrm{C}$.

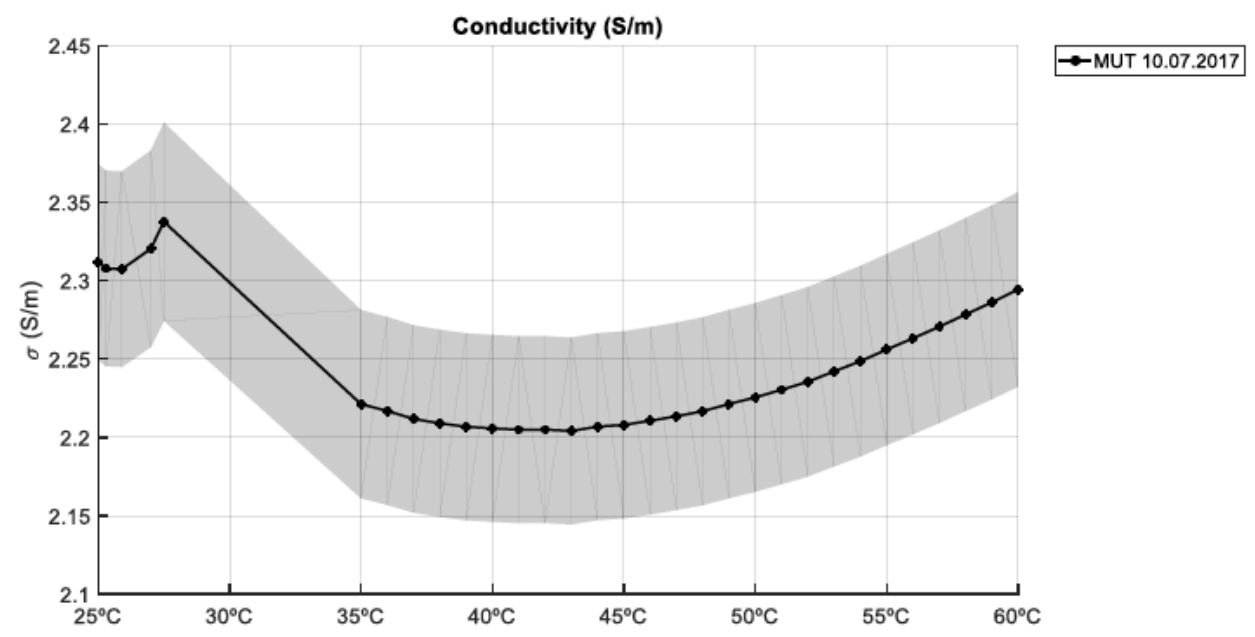

Figura 7.10. Valores de la conductividad del producto a la frecuencia de $2.45 \mathrm{GHz}$ y para el rango de temperaturas desde los $27^{\circ} \mathrm{C}$ hasta los $60^{\circ} \mathrm{C}$.

Como se aprecia en la gráfica anterior, la conductividad que presenta está comprendida, en el target de los líquidos, ya que la carga de agua de la composición es elevada. Y las zonas sombreadas muestran el margen de incertidumbre.

\subsubsection{Caracterización de Sandach}

A partir de diferentes muestras y utilizando el resonador del Laboratorio del Grupo I+D GEM -Figura 7.11-, para la medida de las propiedades dieléctricas, se han obtenido y estudiado las respuestas a la exposición electromagnética de este, material (Las medidas 
dieléctricas del sandach se realizaron a partir de lubina triturada con agua) para su caracterización dieléctrica en función de la temperatura y a la frecuencia típica de emisión de un magnetrón de microondas de $2,45 \mathrm{GHz}$.

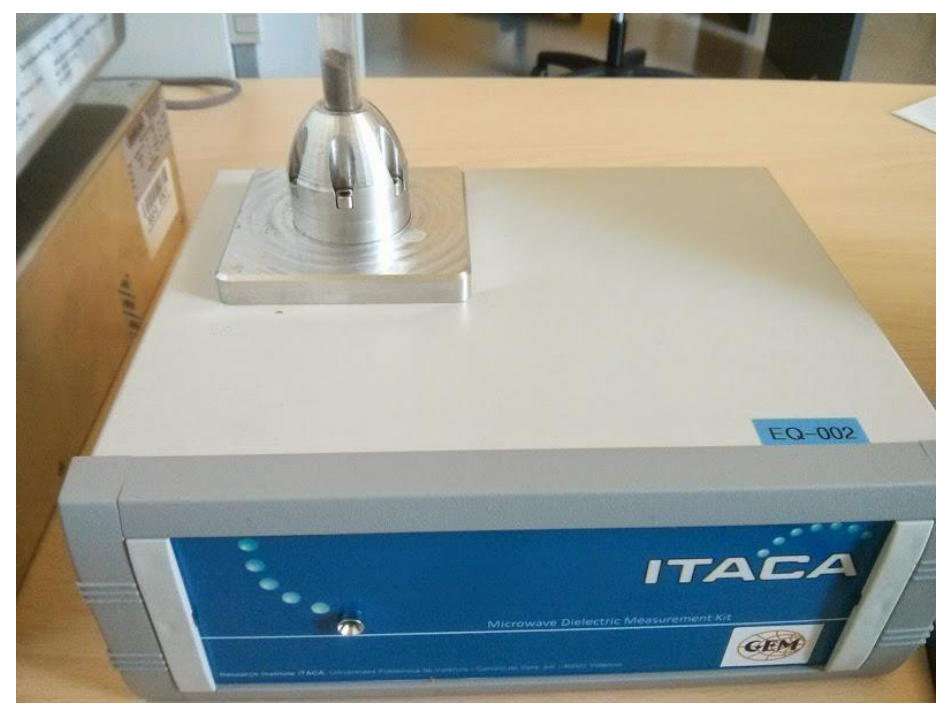

Figura 7.11. Muestra introducida en el dielectrómetro.

El Kit dieléctrico para viales es instrumento desarrollado por la División de Microondas del instituto ITACA para determinar la permitividad compleja (constante dieléctrica y factor de pérdida) de materiales líquidos, granulares o en polvo alrededor de la frecuencia ISM de $2,45 \mathrm{GHz}$.

Una vez introducida la muestra en el dielectrómetro a la temperatura deseada, la respuesta de la sonda (frecuencia de resonancia y factor de calidad) se desplaza dependiendo de las propiedades dieléctricas de la misma. A partir de la medida de la nueva respuesta, se calcula la permitividad compleja de la muestra utilizando el modelo electromagnético de la estructura por un procedimiento numérico.

Esta medida se basa en un método resonante que obtiene el valor de la permitividad eléctrica desde el cambio de la frecuencia de resonancia y la variación del factor de calidad cuando un material dieléctrico material se coloca en el interior de la cavidad [1]. El equipo permite la introducción de un frasco estándar de polipropileno de $8 \mathrm{ml}(12 \mathrm{~mm}$ 
de diámetro y $75 \mathrm{~mm}$ de longitud). Los métodos resonantes se describen en detalle en [2].

Los resultados obtenidos pueden observarse en la siguiente imagen:

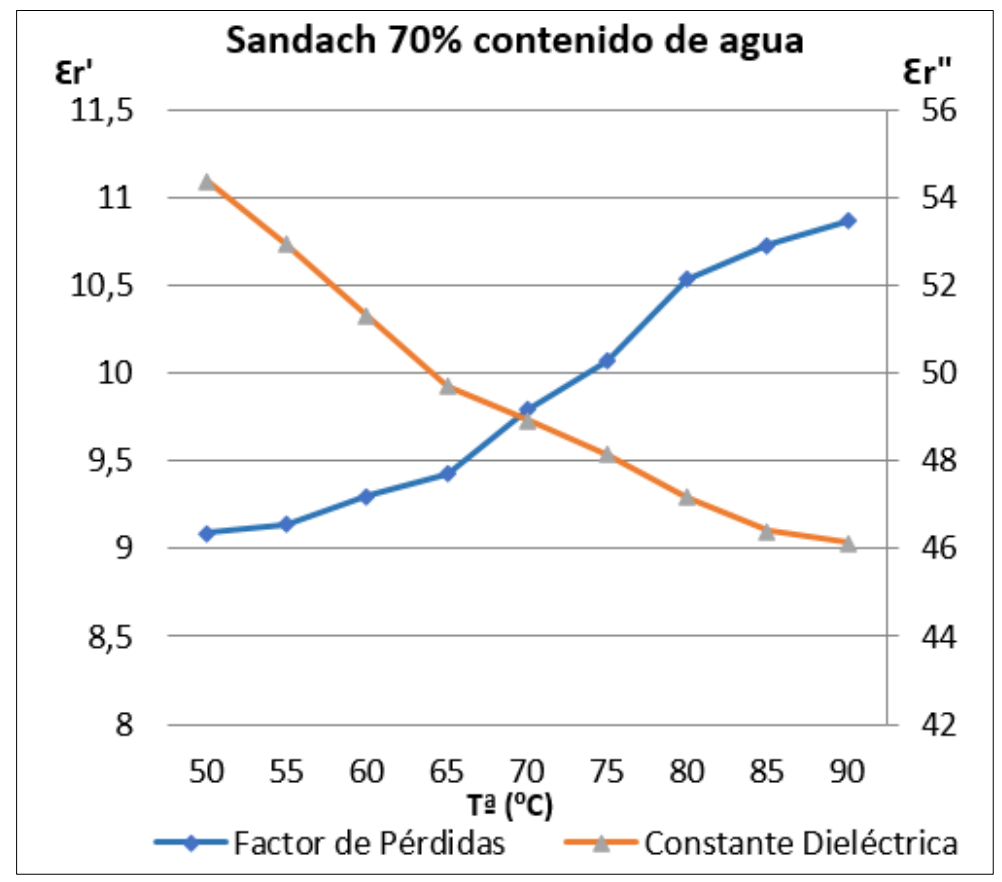

Figura 7.12. Permitividad de la muestra. $70 \%$ contenido en agua.

Como podemos ver en la imagen, con un contenido húmedo del $70 \%$, la muestra de puré presenta un descenso en la constante dieléctrica y un aumento en el factor de pérdidas conforme aumenta la temperatura, en torno a los $90^{\circ} \mathrm{C}$.

\subsection{Cálculo de la curva de temperatura durante el proceso de secado}

La curva de temperatura del proceso se divide idealmente en tres fases distintas:

- Fase de calentamiento inicial: En esta fase la muestra aumenta su temperatura de forma aproximadamente lineal en función de la potencia de microondas absorbida hasta alcanzar la potencia de estabilización. La ecuación que describe este aumento de temperatura es: 


$$
P_{a b s}=m \cdot c_{p} \cdot \frac{d T}{d t}
$$

- Fase de mantenimiento: En esta fase, la muestra va modificando su temperatura a la vez que las propiedades dieléctricas de la muestra cambian por el efecto de la pérdida de humedad y del propio incremento de la temperatura. La evaporación de agua también contribuye al mantenimiento de una temperatura constante en el material.

- Fase de enfriamiento: En esta fase, no hay alimentación de microondas y la temperatura de la muestra desciende lentamente hasta alcanzar la temperatura ambiente.

Para caracterizar la curva completa, se debe estimar el comportamiento en las dos fases iniciales a partir de la fase final. Es decir, se puede caracterizar la fase de enfriamiento mediante datos experimentales. A partir de aquí, obtener la temperatura alcanzada dentro del horno para la fase de mantenimiento $y$, estimando la potencia de microondas absorbida por el material, obtener la curva de la fase de calentamiento inicial.

El cálculo de la curva de enfriamiento se puede realizar a partir de los valores obtenidos por la cámara termográfica. Conociendo el tiempo que ha pasado desde que la muestra dejó de ser tratada con microondas, puede estimarse la temperatura alcanzada antes de salir del horno, entendiendo que ésta es la potencia de la fase de mantenimiento.

Se puede apreciar en la figura 7.13, que la curva de enfriamiento responde a las expectativas, ya que llegado al pico de temperatura máximo, las muestras presentan una disminución notable de la temperatura con el tiempo. 


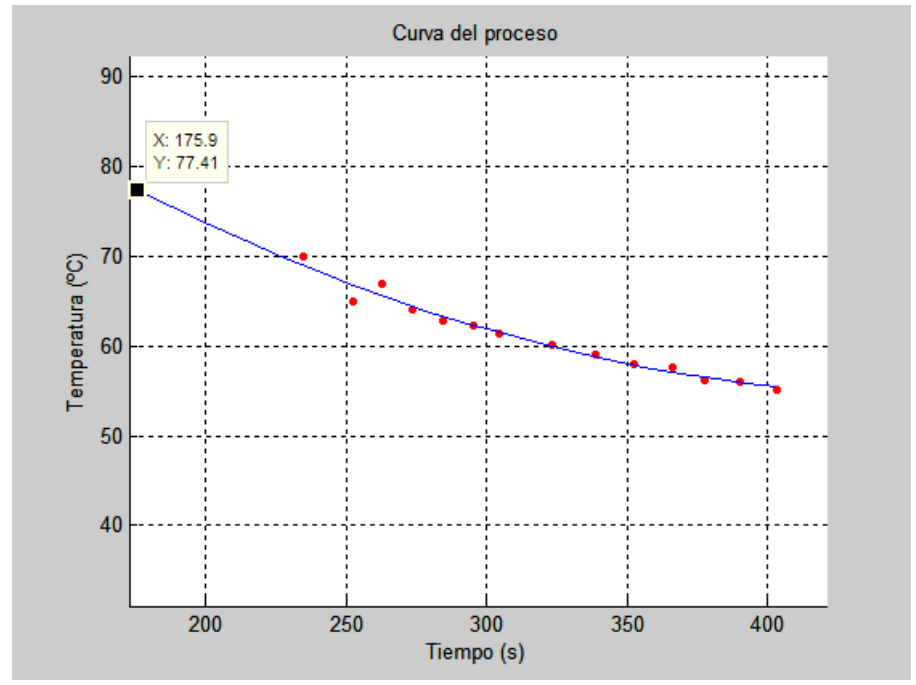

Figura 7.13. Curva de enfriamiento ( $T^{a} /$ Tiempo).

A partir de aquí, sabiendo la potencia absorbida, la masa de la muestra y el calor específico, se obtiene la pendiente de la recta de calentamiento de la fase de calentamiento inicial. El tiempo de esta fase vendrá dado por el corte de esta recta con la recta de valor temperatura de mantenimiento, obteniendo la siguiente curva característica del proceso:

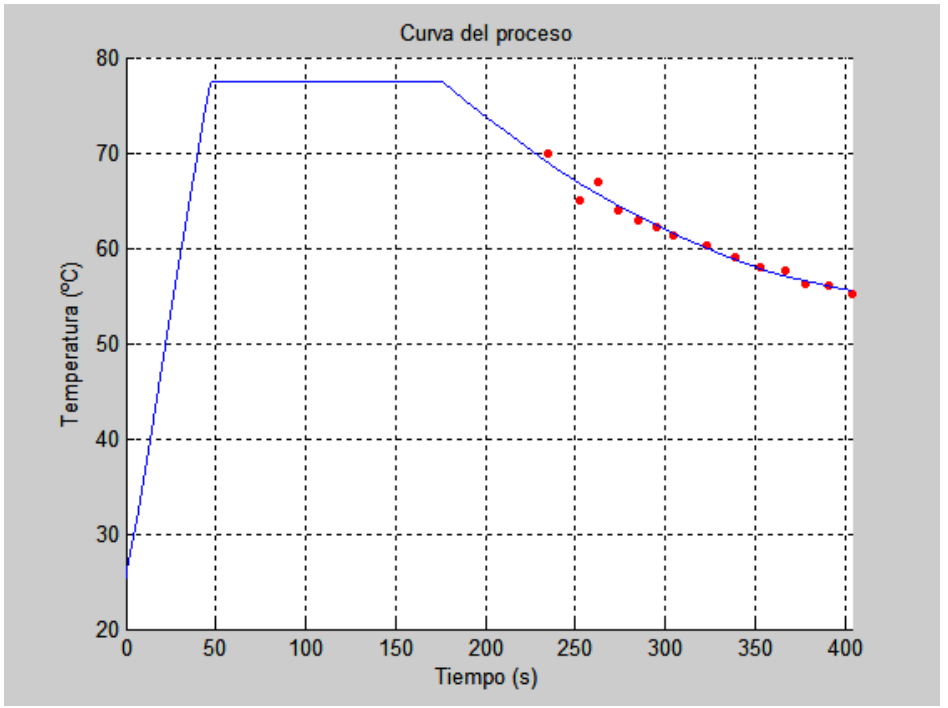

Figura 7.14. Ejemplo de Curva característica de recta de calentamiento y enfriado en sopa vegetal. ( $T^{a} /$ Tiempo). 
Como puede observarse en la anterior curva, el proceso tiene tres etapas bien caracterizadas, una primera recta de incremento de temperatura rápido con el tiempo, una segunda después de alcanzar la temperatura objetivo, donde al paso del tiempo, se aprecia una estabilización de la misma, hasta la tercera etapa en la que se produce una curva de enfriado al paso del tiempo.

\subsection{Disposición y configuración de los Biosensores}

Para realizar los test microbiológicos se han introducido biosensores en la muestra y se ha estudiado la inactivación de los microorganismos inoculados después del tratamiento térmico. Para producir los biosensores se ha utilizado la técnica de esferificación, consistente en mezclar el medio de cultivo con una solución de alginato que se introduce en un baño con cloruro cálcico, produciendo pequeñas esferas. Estas esferas de medio de cultivo son inoculadas posteriormente con el microorganismo a analizar.

Para estudiar el proceso de inactivación microbiológica en el horno túnel de microondas, se ha diseñado una metodología de distribución de los biosensores en cada bandeja, consistente en una matriz rígida que permite depositar los biosensores de forma regular para, posteriormente, extraerlos y medir su grado de mortalidad en las condiciones de experimentación, generando una matriz de 20 biosensores $(4 \times 5)$. La altura de cada muestra en el interior de la bandeja es de $0,5 \mathrm{~cm}$, de manera que puedan considerarse laminares a efectos del tratamiento con microondas, como muestra la siguiente figura:

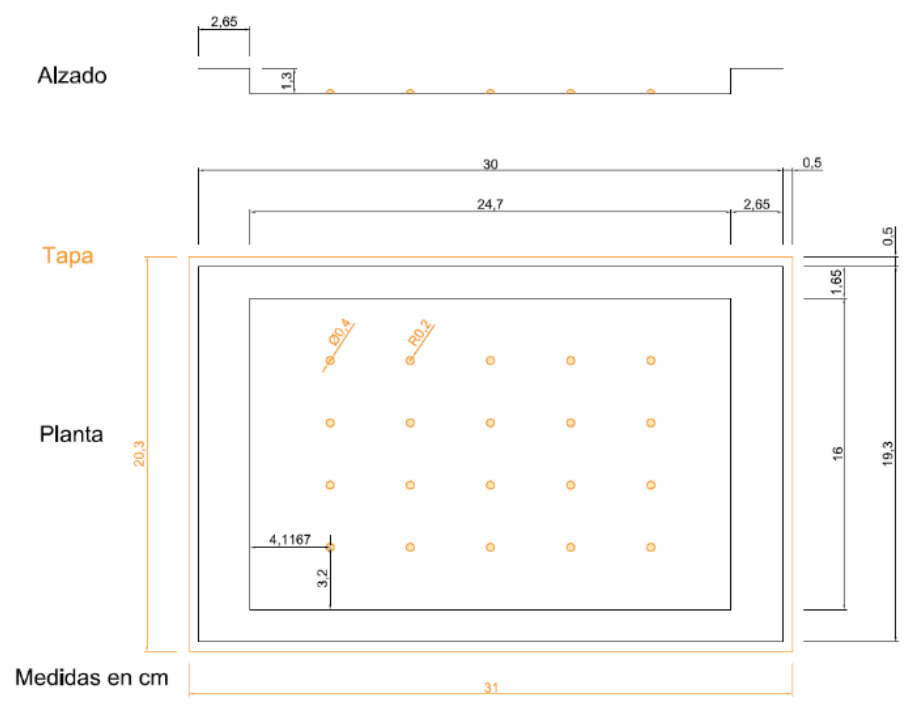

Figura 7.15. Medidas y disposición del sistema de distribución uniforme de biosensores en cada bandeja. 


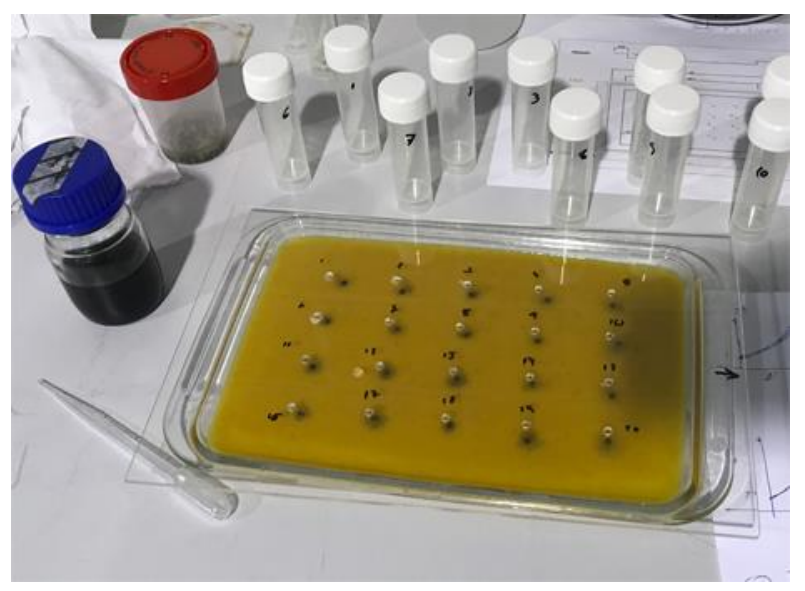

Figura 7.16. Sistema de distribución uniforme de biosensores en cada bandeja.

Para asegurar que los biosensores se encuentran en la cuadrícula correspondiente se utiliza una tapa de metacrilato con orificios por donde se introduce el biosensor.

\subsection{Pruebas experimentales del proceso en el horno industrial de microondas de túnel}

En este apartado mostraremos los datos medidos en las diferentes pruebas, tanto de esterilización como de secado para la experimentación en el horno industrial. Se han seleccionado las siguinetes muestras: medio de uso general adecuado para el cultivo de una amplia variedad de tipos de organismos, denominado Brain Heart Infusion (BHI), subproductos animales a base de pescado o Sandach (F-ABP), y sopa de verduras (consistente en un 30\% de vegetales, donde los ingredientes principales son zanahorias, patata, apio, cebolla, tomate, nabo, calabaza, almidón de maíz y leche deshidratada).

Pruebas de calentamiento con microondas a escala pre-industrial. A partir de los regímenes de potencia-tiempo, identificados anteriormente para cada tipo de muestra, se han llevado a a cabo diferentes pruebas de calentamiento por microondas en varias tipologías de muestras, así como el posterior análisis microbiológico para el testeo de la tecnología desarrollada. En esta validación, mediante la metodología de evaluación de riesgos (EFSA), se ha podido establecer el grado de seguridad alimentaria exigida para el tratamiento de este tipo de productos. 
Evaluación de uniformidad de muestras en horno industrial. Aunque, mediante simulaciones electromagnéticas en base al número y posiciones relativas de las bandejas en el interior de la cavidad, se han analizado distintas técnicas de uniformización de campo eléctrico en el horno túnel, en esta fase se han utilizado cámaras termográficas para medir el grado de homogeneidad en calentamiento en presencia/ausencia de los biosensores y para diferentes tipos de muestras.

Análisis de resultados. Durante todo el desarrollo de las actividades conducentes a la elaboración de este trabajo de investigación, se han ido analizando los resultados parciales en cada fase, con el fin de obtener las conclusiones más relevantes y, más importante, las líneas futuras para avanzar en esta línea de investigación y su correspondiente transferencia tecnológica al sector productivo.

En la siguiente imagen podemos observar la preparación de las bandejas con $\mathrm{BHI}$, para ser introducidas en la cinta transportadora y poder estudiar la disminución de contenido en agua del material.

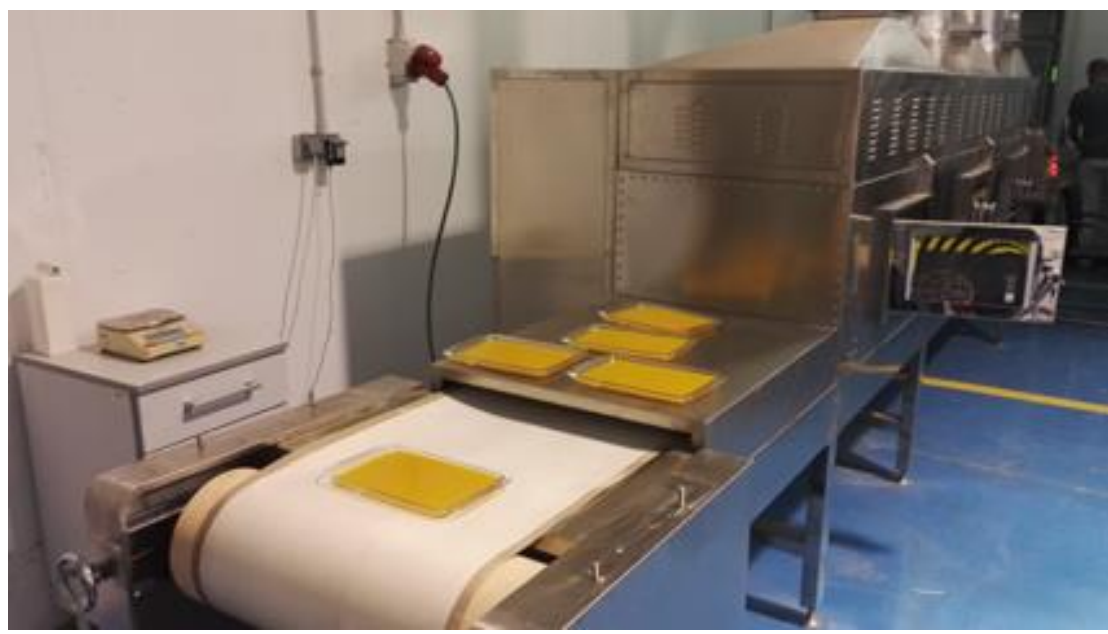

Figura 7.17. Imagen del proceso de alimentación de muestras en el horno microondas .

Una vez configurado el sistema de microondas con las muestras caracterizadas, se han realizado las pruebas experimentales más significativas para validar el diseño e implementación de este trabajo de investigación, tal y como se muestra en los siguientes apartados. 


\subsubsection{Medida de deshidratación sin empleo de Biosensores}

En esta fase se han desarrollado los cálculos conducentes a la configuración óptima del horno túnel de microondas para diferentes objetivos de temperatura en dos tipos de muestras de Sopa vegetal (con contenido en Puré de Patata y con Nuez Moscada), y posteriormente con Sandach sin la inclusión de los biosensores. Todas las pruebas/test experimentales han seguido el mismo proceso descrito en los apartados anteriores, generando los siguientes resultados.

\section{Cálculo de parámetros del horno.}

Antes de disponer la bandeja con el material en el comienzo de la cinta transportadora para entrar al horno, se procedía a realizar la medida termográfica de la distribución incial de temperatura en cada una de ellas.

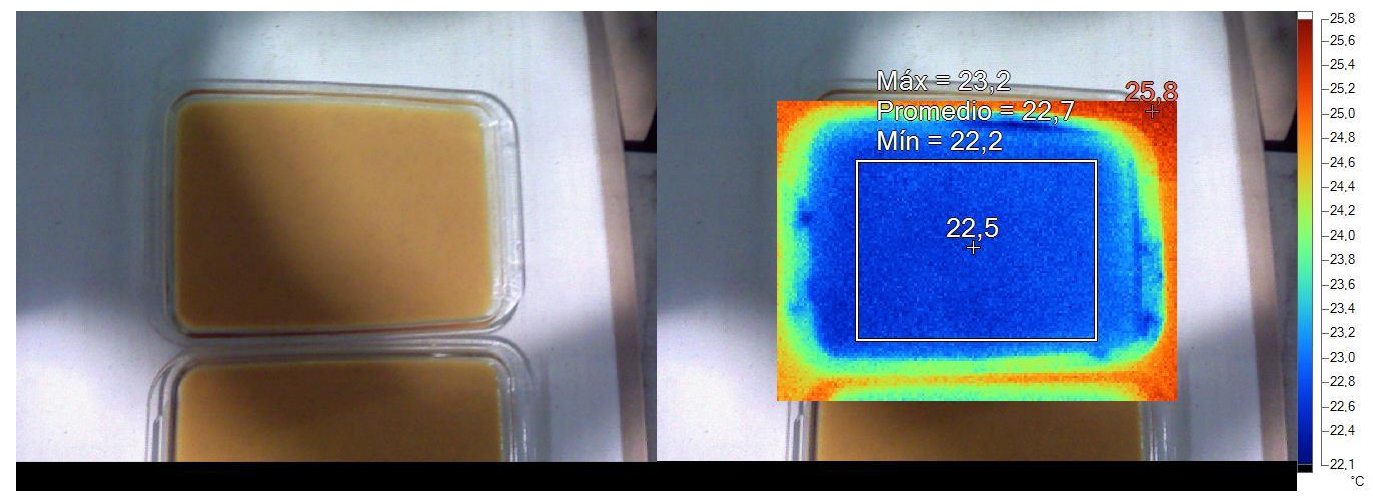

Figura 7.18. Cálculo de la temperatura inicial de la muestra. Test1

Y como también se ha hecho para muestras pequeñas del material, se dispuso a realizar las medidas de las propiedades dieléctricas y físicas de cada tipo de producto, con el objetivo de proporcionar los datos de cálculo de parámetros del horno a la aplicación MICRODES.

Para esta muestra de patata con nuez moscada los datos de las propiedades de la misma son los siguientes: 


\begin{tabular}{|c|c|c|c|}
\hline Permitividad & Factor de pérdidas & $\varepsilon^{\prime}=61,2$ & $\varepsilon^{\prime \prime}=16,3$ \\
\hline \multicolumn{2}{|c|}{ Calor específico (J/Kg으) } & \multicolumn{2}{|c|}{3643} \\
\hline \multicolumn{2}{|c|}{ Densidad (kg/l) } & \multicolumn{2}{|c|}{1,0121} \\
\hline \multicolumn{2}{|l|}{ Masa (Kg) } & \multicolumn{2}{|c|}{0,2} \\
\hline \multicolumn{2}{|c|}{ Volumen (litros) } & \multicolumn{2}{|c|}{0,1976} \\
\hline \multicolumn{2}{|c|}{ Temperatura Inicial muestra (으) } & \multicolumn{2}{|c|}{$21-22$} \\
\hline \multicolumn{2}{|c|}{ Temperatura Inicial bandeja (으) } & \multicolumn{2}{|c|}{$21-22$} \\
\hline
\end{tabular}

Tabla 7.3. Datos calculados de las características de la muestra 1. Test1

Una vez caracterizada la muestra, para el cálculo de los parámetros de funcionamiento del horno microondas se ha utilizado la herramienta Microdes@ para obtener los cálculos que van a permitir ajustar el horno a cada proceso, optimizar su rendimiento y conocer su consumo energético.

Calculamos la velocidad de la cinta para alcanzar la temperatura deseada en el primer módulo, manteniéndola durante todo el proceso a través del resto de módulos, evaporando el contenido de agua.

En la siguiente imagen se muestra una captura de la herramienta, ya comentada, con la que se procedió en cada prueba, al ajuste del horno para las características del material a procesar.

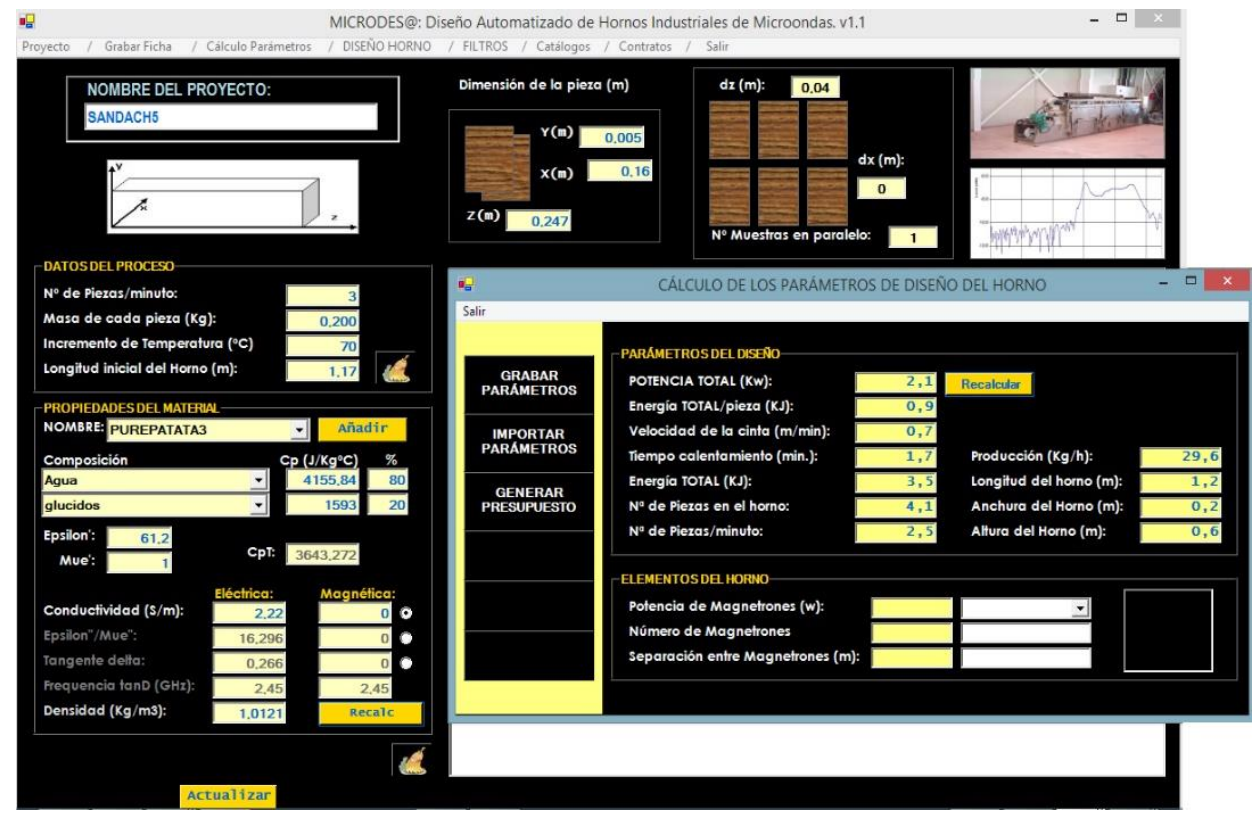

Figura 7.19. Herramienta SW Microdes@ para el ajuste del horno de microondas. Test1. 
En el caso de la primera muestra tratada, los parámetros del horno necesarios fueron los siguientes:

\begin{tabular}{|l|c|}
\hline Velocidad de la Cinta (m/min) & 0,7 \\
\hline Potencia Total (M1,M2,M3) (kW) & 2,$1 ; 2,1 ; 2,1$ \\
\hline Energía Total pieza (M1, M2, M3) (KJ) & 0,$9 ; 0,9 ; 0,9$ \\
\hline Energía Total (KJ) & 3,$5 ; 3,5 ; 3,5$ \\
\hline Tiempo total de proceso/bandeja (s) & 300 \\
\hline $\begin{array}{l}\text { Número de bandejas simultaneas en } \\
\text { interior horno }\end{array}$ & 5 \\
\hline No Piezas/minuto & 2,5 \\
\hline
\end{tabular}

Tabla 7.4. Datos de las pruebas realizadas en horno túnel de microondas. Test1

Concluido el proceso de calentamiento por microondas para cada prueba, se han generado los resultados de deshidratación, sin considerar aspectos microbiológicos, tal y como refleja la siguiente tabla:

\begin{tabular}{|l|c|}
\hline Temperatura Final de la muestra $\left({ }^{\circ} \mathbf{C}\right)$ & $88,75 \pm 1,9$ \\
\hline Masa final (Kg) & 0,0713 \\
\hline Evaporación en base seca (\%) & 64,97 \\
\hline
\end{tabular}

Tabla 7.5. Resultados de temperatura alcanzada, pérdida de masa y \% de evaporación (secado). Test1.

En la siguiente gráfica se pueden observar las temperaturas máximas, medias y mínimas alcanzadas durante el proceso. Se observa que se superan los $100^{\circ} \mathrm{C}$ en diferentes partes del desarrollo del test. 


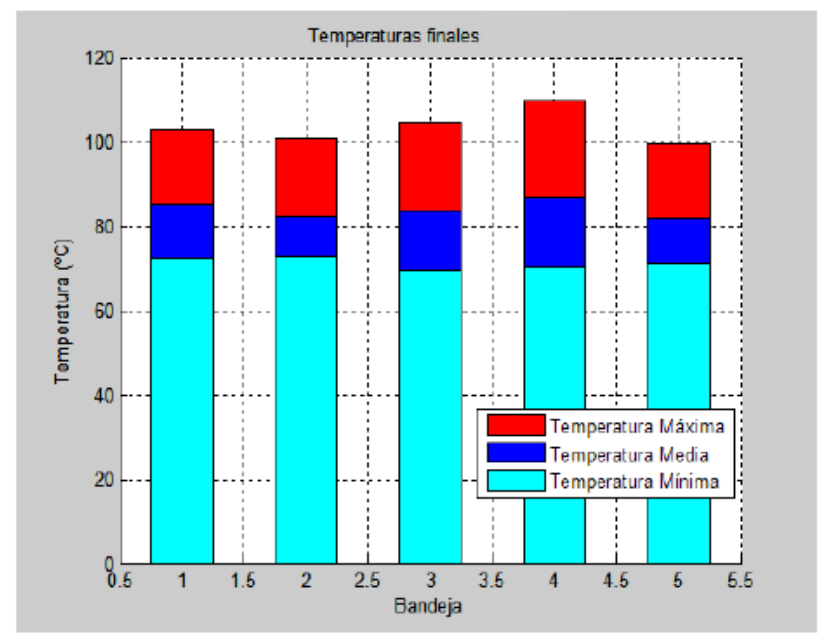

Figura 7.20. Resultados de temperatura alcanzada. Test1

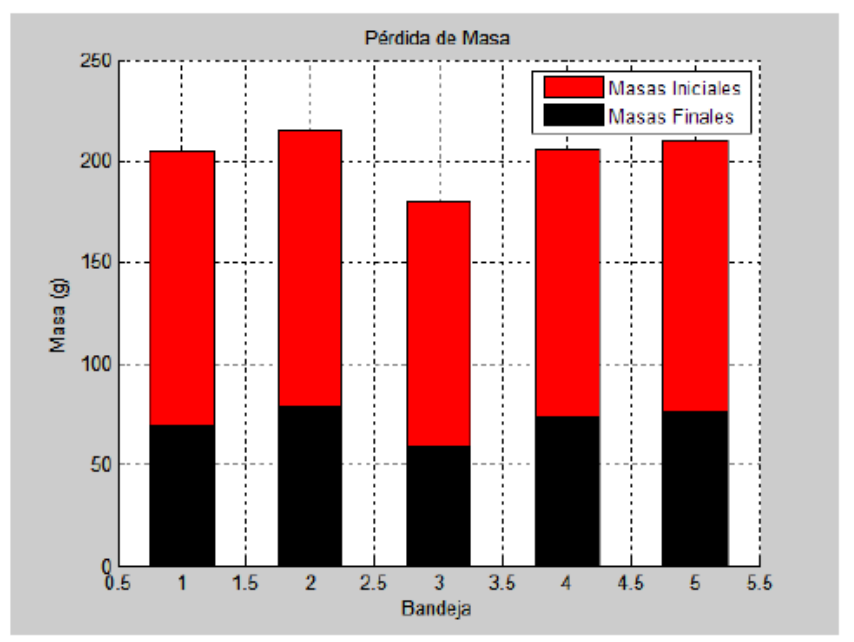

Figura 7.21. Resultados de pérdida de masa. Test1

La figura 7.21 arroja unos datos que serán reveladores para el propósito que se busca. Se puede observar como la disminución de masa después al finalizar el test es muy significativa, llegando a reducirse en dos tercios de su masa inicial.

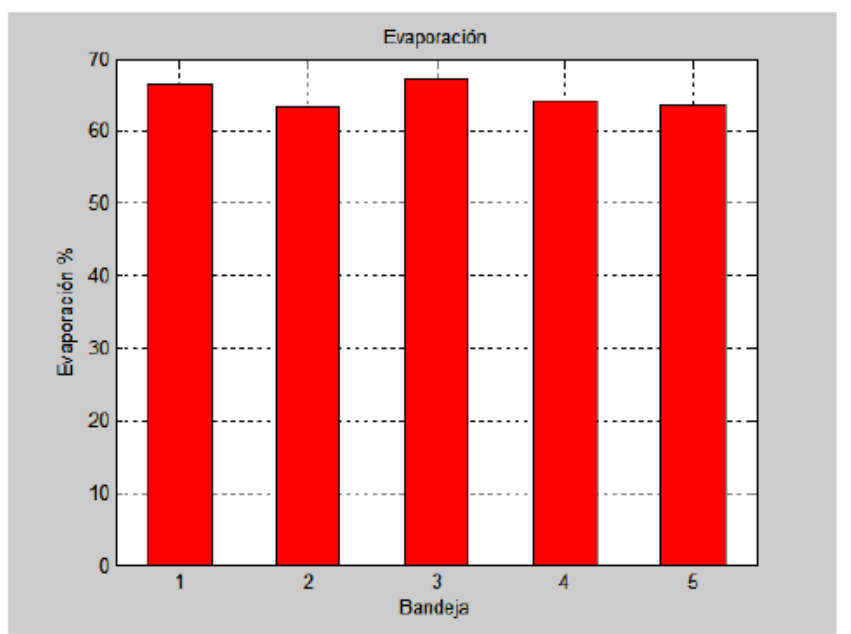

Figura 7.22. Resultados de \% de evaporación (secado). Test1 
Los datos que ser aprecian en la figura 7.22, también son importantes ya que demuestran el alto porcentaje de evaporación de agua que se produce, llegando casi al $70 \%$ del contenido húmedo del material; acercándonos así al cometido final, tal y como podemos ver en la siguiente imagen.
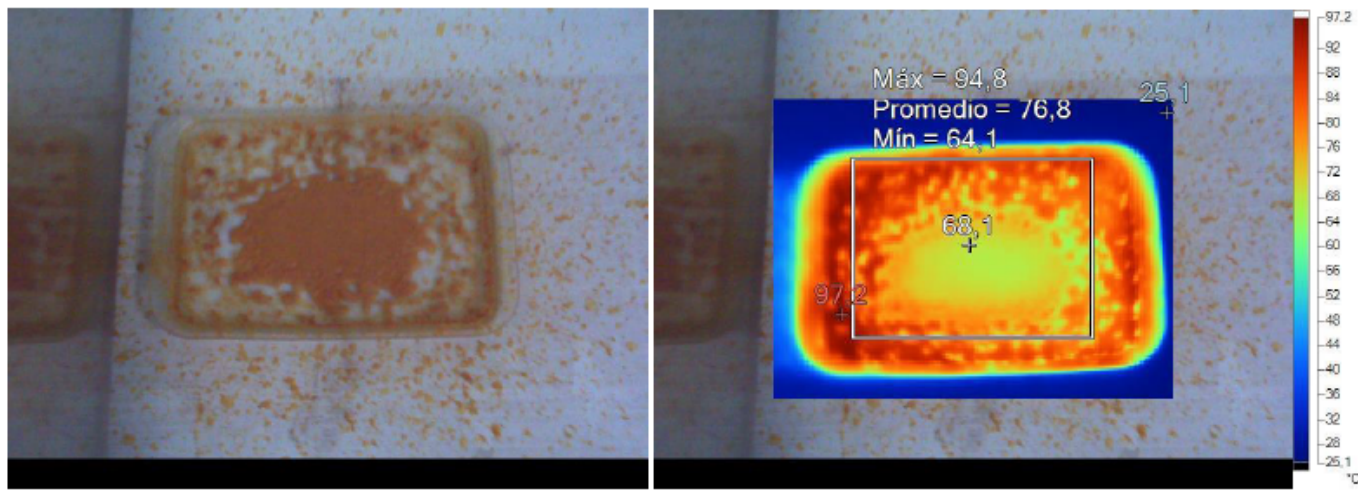

Figura 7.23. Imágenes de las muestras durante el proceso de deshidratación. Test1

Para el cálculo de la curva térmica se han tenido en cuenta los siguientes datos:

\begin{tabular}{|l|c|}
\hline Temperatura media a la salida del filtro $\left({ }^{\circ} \mathrm{C}\right)$ & 75,72 \\
\hline Velocidad (m/s) & 0,7 \\
\hline $\begin{array}{l}\text { Tiempo sin alimentación hasta la } \\
\text { termografía (s) }\end{array}$ & 94 \\
\hline Potencia absorbida/modulo (KW) & 2,1 \\
\hline
\end{tabular}

Tabla 7.6. Datos para el cálculo de la curva térmica. Test1

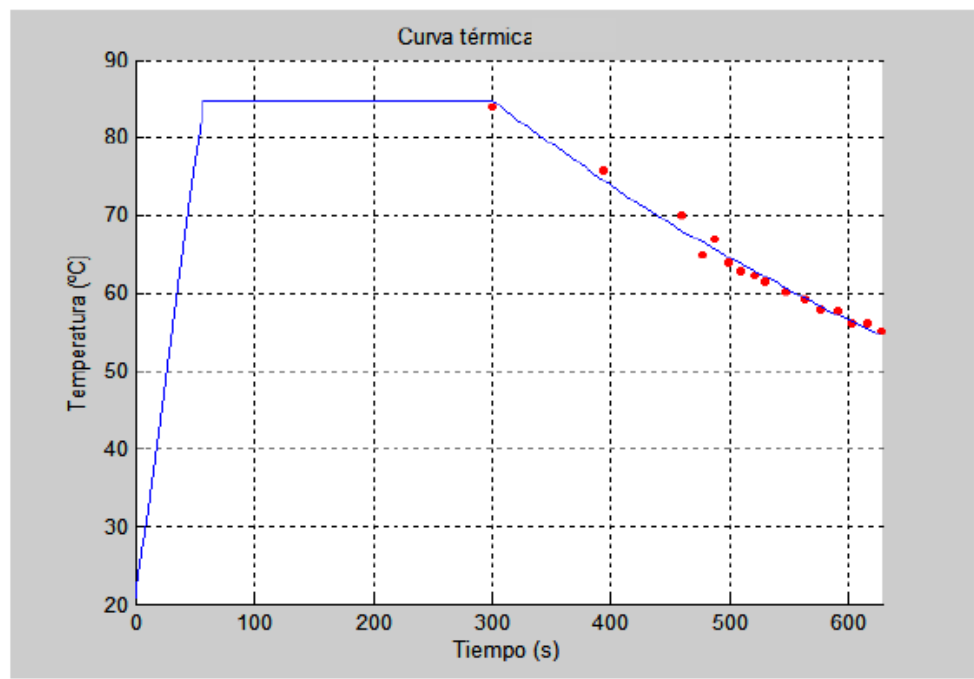

Figura 7.24. Curva Térmica. Test1 
La curva de la figura 7.24 muestra claramente como la muestra pasa por las tres fases de temperatura, siendo los tiempos de las mismas los que aparecen en la siguiente tabla

\begin{tabular}{|l|c|}
\hline Fase calentamiento inicial (s) & 57,33 \\
\hline Fase de mantenimiento (s) & 242,67 \\
\hline Tiempo de procesado (s) & 300 \\
\hline
\end{tabular}

Tabla 7.7. Tiempos de fase en el calentamiento. Test1.

A continuación, se han realizado pruebas para comprobar la validez con un incremento de temperatura en la muestra.

Como se hizo con la primera muestra, se midió la temperatura inicial de esta segunda muestra para ver el valor de partida, tanto de la muestra como de la bandeja

Para esta muestra, el segundo test que se presenta, siguiendo con puré de patata y nuez moscada los datos de las características de la misma son los siguientes:

\begin{tabular}{|c|c|}
\hline Permitividad & \begin{tabular}{l|l}
$\varepsilon^{\prime}=61,2$ & $\varepsilon^{\prime \prime}=16,3$ \\
\end{tabular} \\
\hline Calor específico $\left(\mathrm{J} / \mathrm{Kg}^{\circ} \mathrm{C}\right)$ & 3643 \\
\hline Densidad (kg/l) & 1,0121 \\
\hline Masa $(K g)$ & 0,2 \\
\hline Volumen (litros) & 0,1976 \\
\hline Temperatura Inicial muestra $\left({ }^{\circ} \mathrm{C}\right)$ & $25,8-23,7$ \\
\hline Temperatura Inicial bandeja $\left({ }^{\circ} \mathrm{C}\right)$ & $25,8-23,7$ \\
\hline
\end{tabular}

Tabla 7.8. Datos calculados de las características de la muestra. Test 2.

Los parámetros del horno que se introdujeron en el software para esta segunda prueba fueron los siguientes: 


\begin{tabular}{|l|c|}
\hline Velocidad de la Cinta (m/min) & 0,7 \\
\hline Potencia Total (M1,M2,M3) (kW) & $\begin{array}{l}2,1 ; 2,1 ; 2,1 \text { (limitado } \\
\text { a } 80^{\circ} \mathrm{C} \text { el módulo 3) }\end{array}$ \\
\hline Energía Total pieza (M1, M2, M3) (KJ) & 0,$9 ; 0,9 ; 0,9$ \\
\hline Energía Total (KJ) & 3,$5 ; 3,5 ; 3,5$ \\
\hline Tiempo total de proceso/bandeja (s) & 300 \\
\hline $\begin{array}{l}\text { Número de bandejas simultaneas en } \\
\text { interior horno }\end{array}$ & 5 \\
\hline $\mathbf{N}^{\circ}$ Piezas/minuto & 2,5 \\
\hline
\end{tabular}

Tabla 7.9. Datos de las pruebas realizadas en horno túnel de microondas. Test2.

Los resultados de deshidratación fueron, sin considerar aspectos microbiológicos, tal y como refleja la siguiente tabla:

\begin{tabular}{|l|c|}
\hline Temperatura Final de la muestra $\left({ }^{\circ} \mathbf{C}\right)$ & $81,61+-3,2$ \\
\hline Masa final $(\mathbf{K g})$ & 0,084 \\
\hline Evaporación (\%) & 60,47 \\
\hline
\end{tabular}

Tabla 7.10. Resultados de temperatura alcanzada, pérdida de masa y \% de evaporación (secado). Test2.

Como se observa en los resultados respecto de la primera prueba, la evaporación de agua en esta segunda ha sido inferior; esto ocurre porque la temperatura media y final de la muestra ha sido inferior.

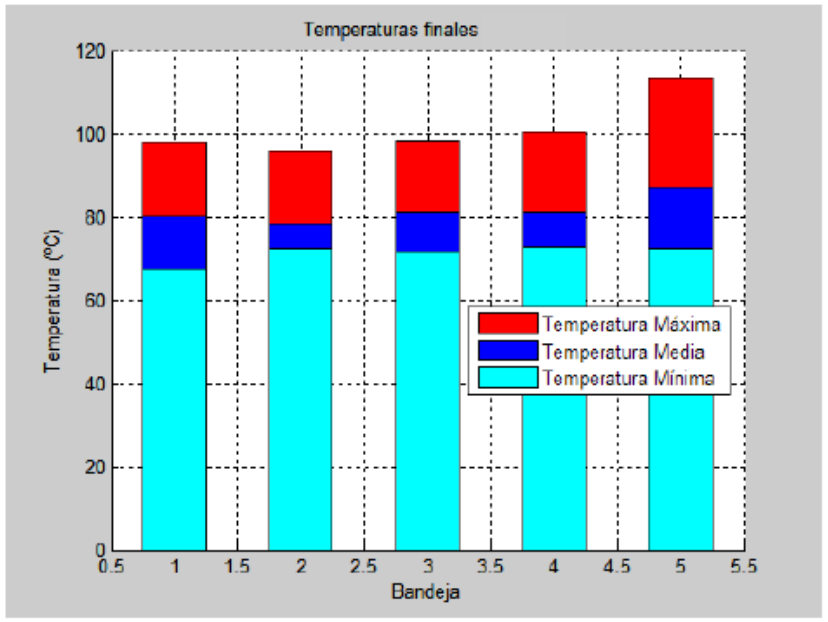

Figura 7.25. Resultados de temperatura alcanzada, pérdida de masa y \% de evaporación (secado). Test2. 
Como se puede apreciar en la figura anterior, la temperatura en ninguna de las cuatro primeras bandejas introducidas llega a superar los $100^{\circ} \mathrm{C}$, sólo en la última alcanza esa cifra y esto hace que la media sea menor que en la prueba anterior y por ende su deshidratación como muestra las siguientes figuras.
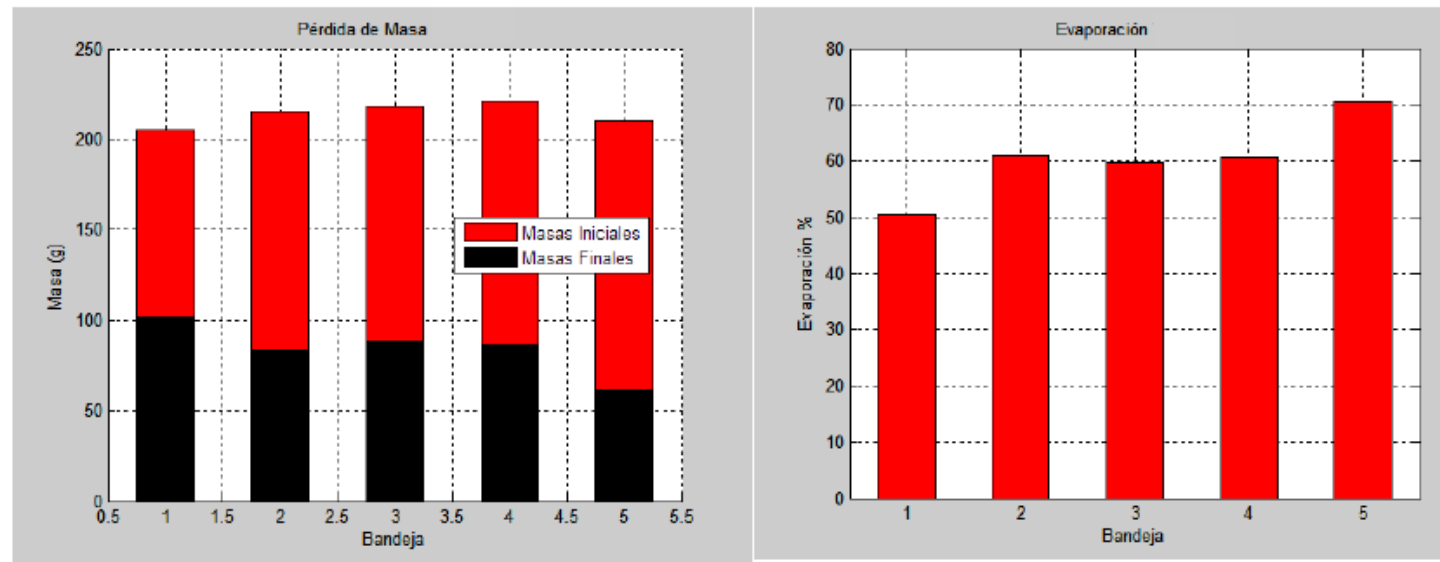

Figura 7.26. Resultados de, pérdida de masa y \% de evaporación (secado). Test2.

La curva térmica obtenida para este test es prácticamente la misma que para el anterior.

En el tercer test (puré de patata y nuez moscada) que se presenta se aumentó la temperatura $10^{\circ} \mathrm{C}$ más, para observar el incremento de evaporación; siendo los parámetros calculados, según las características de la muestra los siguientes:

\begin{tabular}{|l|c|c|}
\hline Permitividad & $\varepsilon^{\prime}=61,2$ & $\varepsilon^{\prime \prime}=16,3$ \\
\hline Calor especifico $\left(\mathbf{J} / \mathbf{K g}^{\circ} \mathbf{C}\right)$ & 3643 \\
\hline Densidad $\mathbf{( k g / l )}$ & 1,0121 \\
\hline Masa (Kg) & 0,2 \\
\hline Volumen (litros) & 0,1976 \\
\hline Temperatura Inicial muestra $\left(^{\circ} \mathbf{C}\right)$ & $25,3-28,6$ \\
\hline Temperatura Inicial bandeja $\left(^{\circ} \mathbf{C}\right)$ & $25,3-28,6$ \\
\hline
\end{tabular}

Tabla 7.11. Datos calculados de las características de la muestra. Test 3.

Para ello se recalcularon los parámetros del horno con MICRODES, como para cada prueba.

Obteniendo la siguiente configuración de parámetros del horno, según muestra la tabla 7.12 


\begin{tabular}{|l|c|}
\hline Velocidad de la Cinta (m/min) & 0,525 \\
\hline Potencia Total (M1,M2,M3) & 2,$1 ; 2,1 ; 2,1$ \\
\hline Energía Total pieza (M1, M2, M3) (KJ) & $1,1,1$ \\
\hline Energía Total (KJ) & $4,4,4$ \\
\hline Tiempo total de proceso/bandeja (s) & 394,28 \\
\hline $\begin{array}{l}\text { Número de bandejas simultaneas en } \\
\text { interior horno }\end{array}$ & 5 \\
\hline $\mathbf{N}^{\circ}$ Piezas/minuto & 2,1 \\
\hline
\end{tabular}

Tabla 7.12. Datos de las pruebas realizadas en horno túnel de microondas. Test3.

Como se puede apreciar en la siguiente tabla, se consiguió un porcentaje de evaporación del $83,35 \%$

\begin{tabular}{|l|c|}
\hline Temperatura Final de la muestra $\left({ }^{\circ} \mathbf{C}\right)$ & 95,06 \\
\hline Masa final (Kg) & 33,22 \\
\hline Evaporación (\%) & 83,35 \\
\hline
\end{tabular}

Tabla 7.13. Resultados de temperatura alcanzada, pérdida de masa y \% de evaporación (secado). Test3.

En la siguiente figura, 7,27, podemos ver el incremento de temperatura que se propuso, respecto de las pruebas anteriores; podemos ver como la bandeja 5 alcanzo una temperatura cercana a los $150^{\circ}$. Este incremento supuso, como se ha comentado un porcentaje de evaporación mayor y una pérdida de masa en la muestra acorde con ese incremento, como se aprecia en las figuras 7.28 y 7.29 .

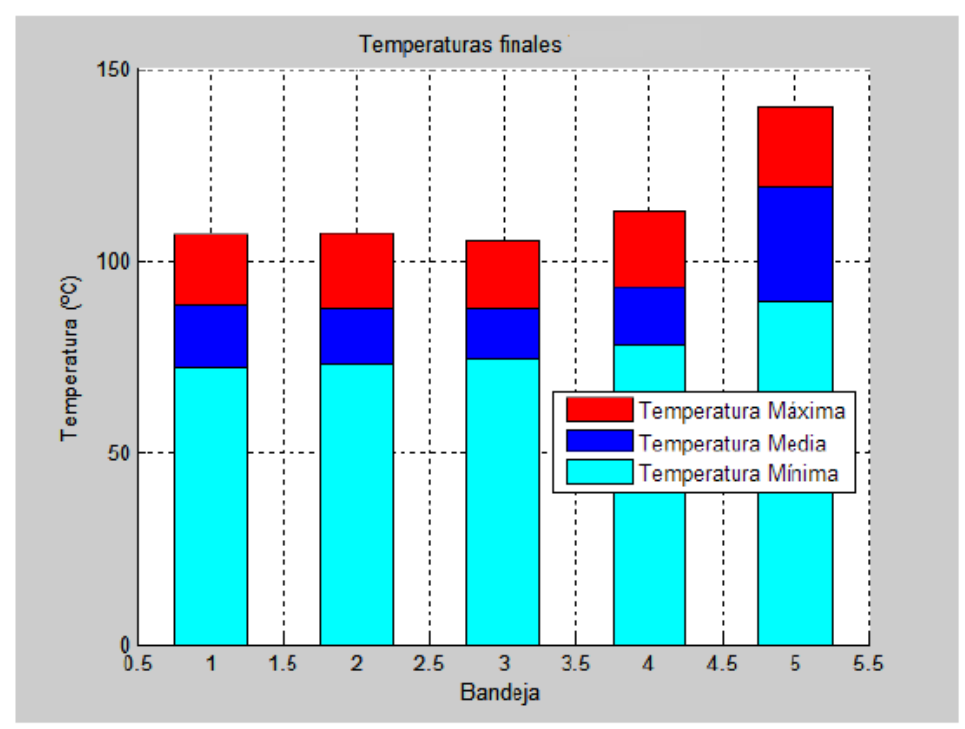

Figura 7.27. Resultados de temperatura alcanzada. Test3. 


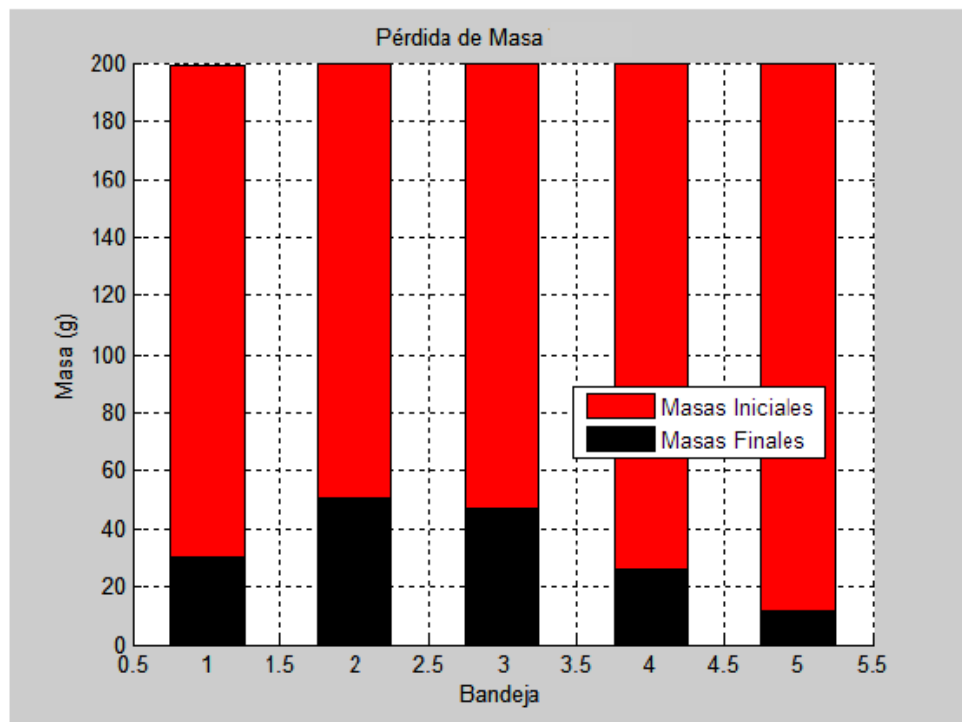

Figura 7.28. Resultados de pérdida de masa. Test3.

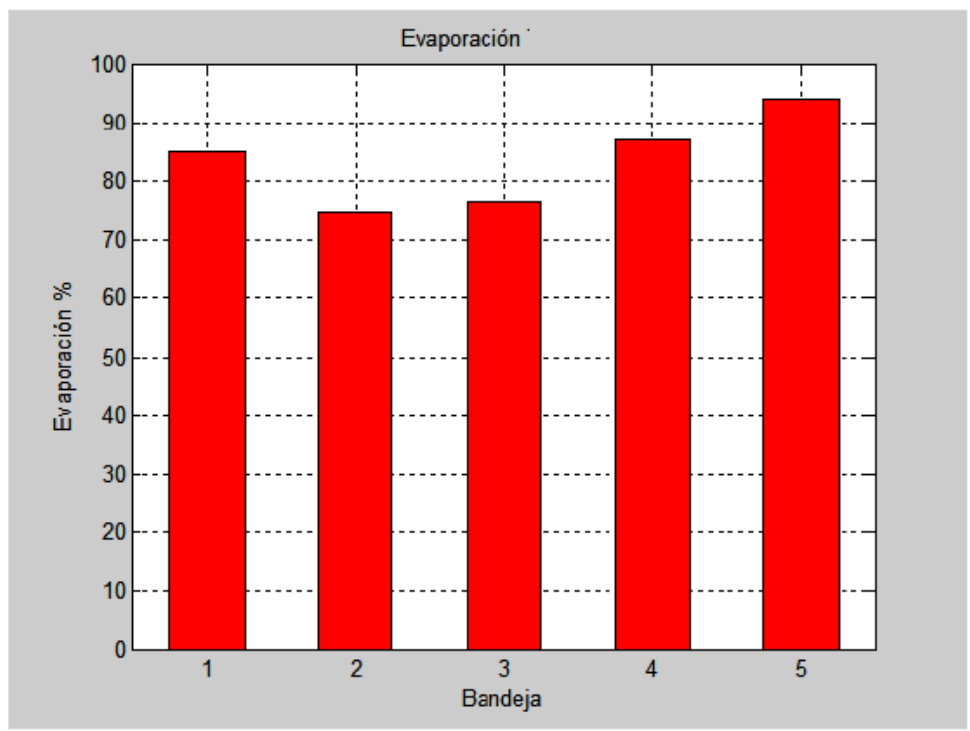

Figura 7.29. Resultados \% de evaporación (secado). Test3.

En la siguiente figura 7.30, podemos apreciar la deshidratación más pronunciada en la muestra que nos ocupa, a diferencia de los anteriores test comentados.

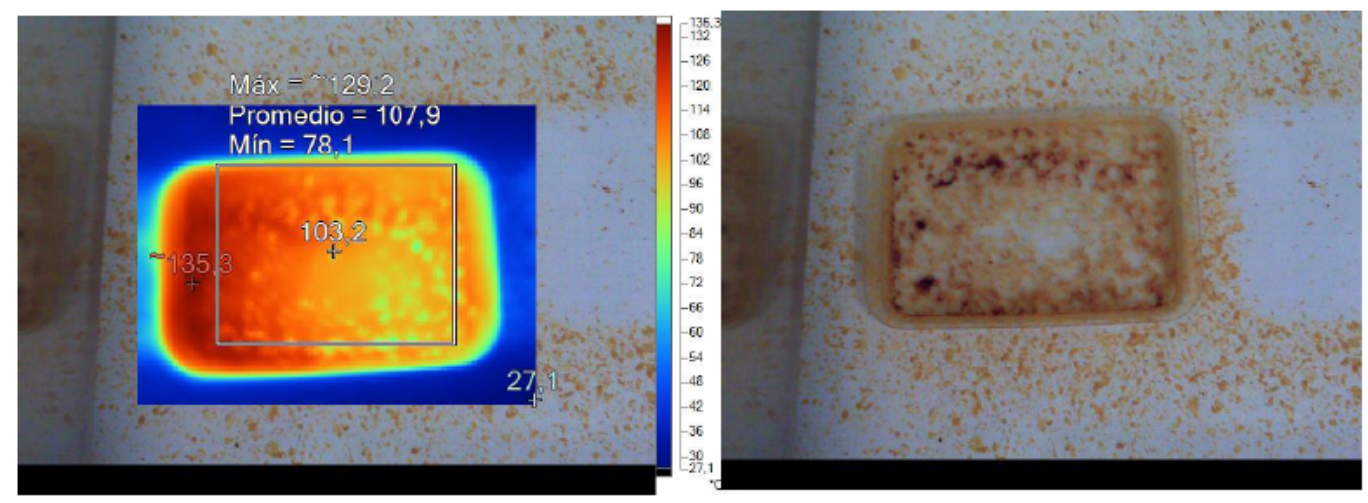

Figura 7.30. Imágenes de las muestras durante el proceso de deshidratación. Test3. 
Para el cálculo de la curva térmica se han tenido en cuenta los siguientes datos:

\begin{tabular}{|l|c|}
\hline Temperatura media a la salida del filtro $\left(^{\circ} \mathbf{C}\right)$ & 84,08 \\
\hline Distancia recorrida desde el horno hasta la termografía (m) & 1,097 \\
\hline Velocidad $(\mathbf{m} / \mathbf{s})$ & 0,525 \\
\hline Tiempo sin alimentación hasta la termografía (s) & 124,57 \\
\hline Potencia absorbida/modulo $(\mathbf{K W})$ & 2,1 \\
\hline
\end{tabular}

Tabla 7.14. Datos para el cálculo de la curva térmica. Test3.

Quedando una curva térmica como la que muestra la siguiente figura.

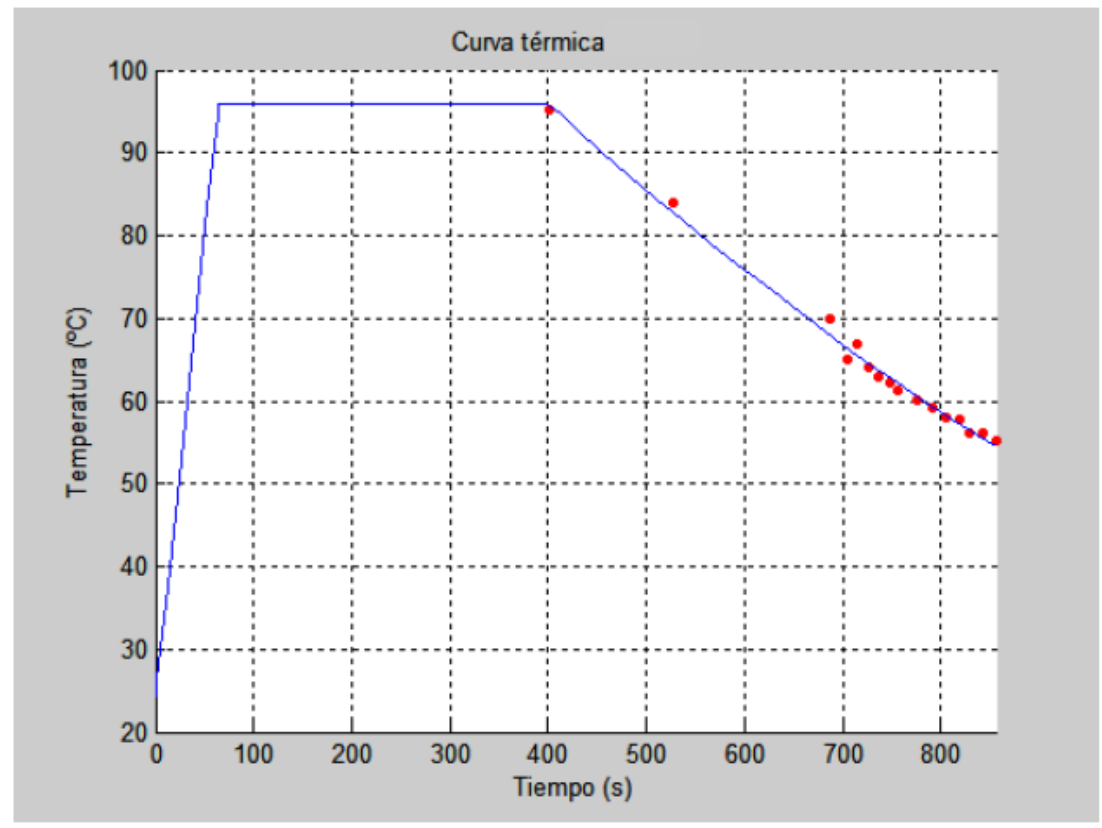

Figura 7.31. Curva Térmica del Test3.

Los tiempos de las diferentes fases obtenidos fueron; en los que se puede apreciar un incremento de estos en cada fase:

\begin{tabular}{|l|c|}
\hline Fase calentamiento inicial (s) & 64,36 \\
\hline Fase de mantenimiento (s) & 329,92 \\
\hline Tiempo de procesado (s) & 394,28 \\
\hline
\end{tabular}

Tabla 7.15. Tiempos de fase en el calentamiento. Test3. 


\subsubsection{Análisis microbiológico}

En esta fase final de la investigación se han realizado las pruebas conducentes al estudio de la eliminación de patógenos de forma uniforme en las muestras de Sopa Vegetal y Sandach, en función de la temperatura alcanzada y de la distribución en cada una de las bandejas. En estos ensayos, tomado el valor inicial de 8,26 CFU (medida referencia de control), se ha podido deducir el porcentaje de reducción de la actividad microbiana en cada uno de los 20 puntos uniformemente distribuidos.

\section{Estudios de distribución de biosensores en las muestras.}

Para estudiar el proceso de inactivación microbiológica en el horno túnel de microondas, se ha diseñado una metodología de distribución de los biosensores en cada bandeja, consistente en una matriz rígida que permite depositar los biosensores de forma regular para, posteriormente, extraerlos y medir su grado de mortalidad en las condiciones de experimentación, generando una matriz de 20 biosensores (4×5). La altura de cada muestra en el interior de la bandeja es de $0,5 \mathrm{~cm}$, de manera que puedan considerarse laminares a efectos del tratamiento con microondas.

Para conocer con exactitud la variabilidad del calentamiento por microondas ha sido necesario establecer la inactivación que alcanzan los biosensores en función de la posición en la muestra dentro del horno. Se ha diseñado una metodología de distribución espacial de los biosensores, como ya se ha comentado, para modelar la temperatura en la masa de material biológico, evaluando la efectividad de la respuesta a un indicador colorimétrico para la determinación rápida del grado de alcance del nivel de inactivación adecuado. En base a los resultados, se ha obtenido el mapa de distribución bidimensional de la intensidad de calentamiento y su variabilidad dentro del horno microondas, considerando las muestras como laminares.

\section{Pruebas con Sopa Vegetal}

Con el fin de evaluar el comportamiento de los biosensores cuando son sometidos a 
radiación de microondas de $2,45 \mathrm{GHz}$ de alta potencia y comprobar la capacidad de resistencia para poder ser recuperados, al término del proceso de calentamiento, se han realizado varias pruebas preliminares con valores finales de temperatura progresivos $\left(60^{\circ} \mathrm{C}, 70^{\circ} \mathrm{C}\right.$ y $\left.80^{\circ} \mathrm{C}\right)$, mismo volumen de muestra e idéntica distribución de sensores. Los parámetros del horno han sido ajustados para alcanzar la temperatura prevista, utilizando las medidas de constante dieléctrica y factor de pérdidas, realizadas y mostradas en la siguiente figura.
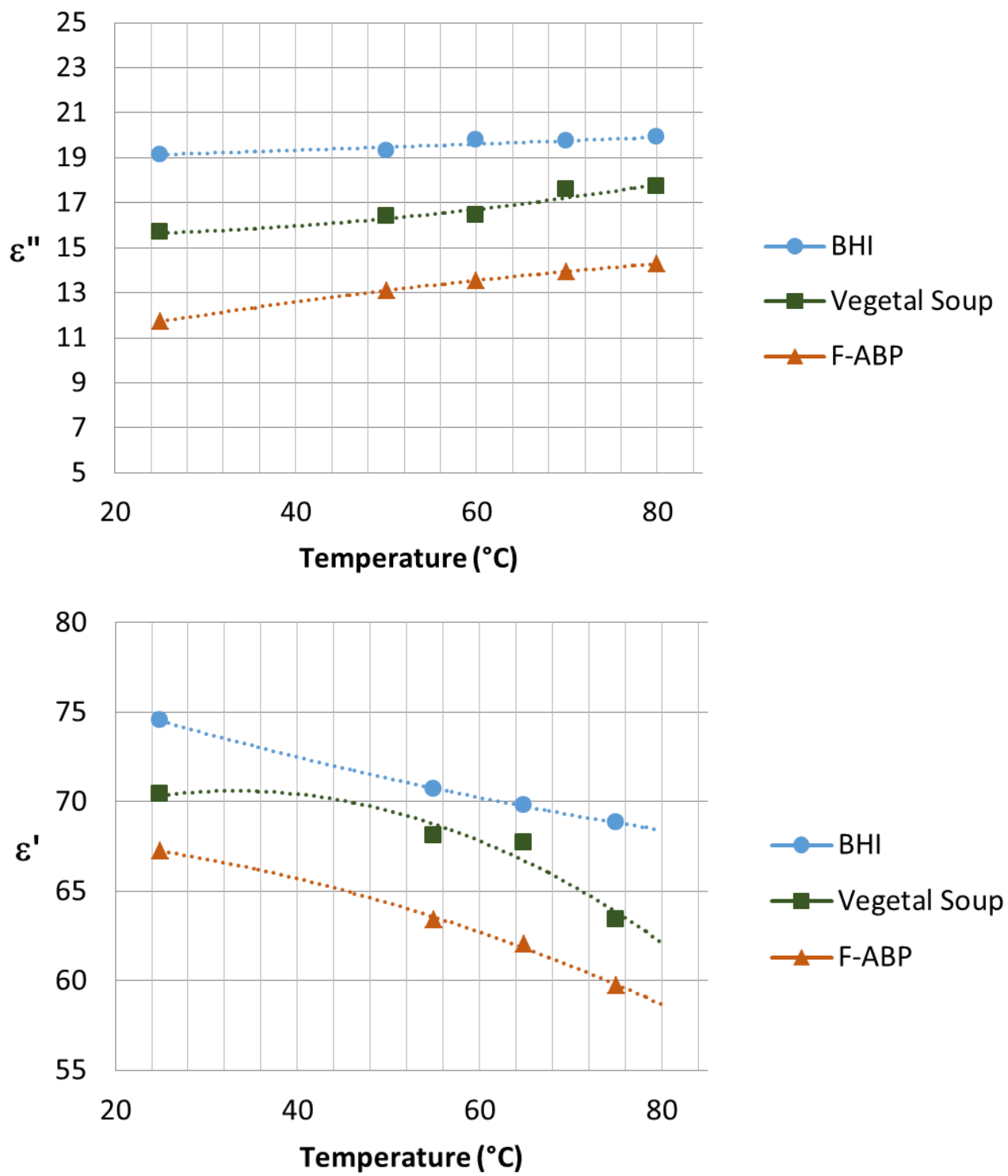

Figura 7.32. Caracterización dieléctrica de los materiales BHI, Sandach y Sopa Vegetal

Para la estimación del grado de inactivación microbiológica, se ha de considerar la relación existente entre la medida de log(CFU) y el porcentaje de mortalidad, cuyo 
modelo gráfico se representa en la siguiente figura.

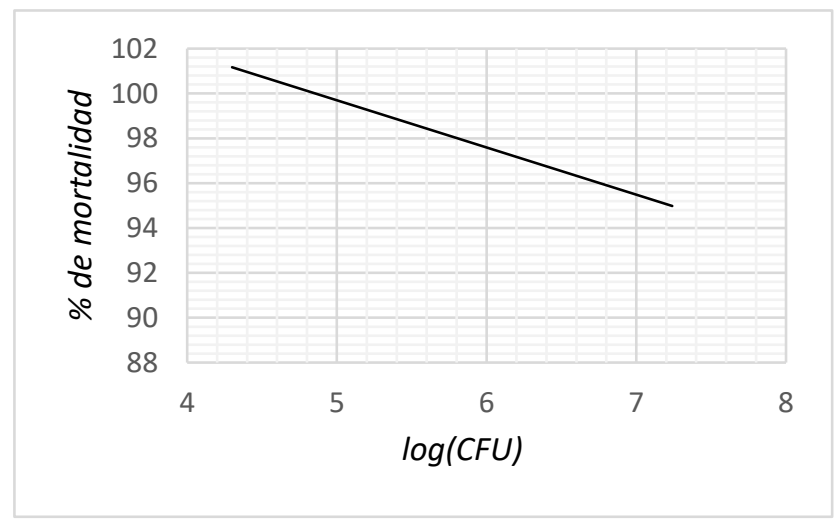

Figura 7.33. Relación entre $\log (\mathrm{CFU})$ y \% de mortalidad microbiológica

Una vez que los biosensores han sido extraídos del material, tras el proceso de calentamiento por microondas y diferentes objetivos de temperatura, se ha realizado el recuento de colonias supervivientes y su transposición al valor de mortalidad en \% sobre el nivel inicial, en función de la curva de la figura 7.33.

Para los todos los tests, se ha obtenido la matriz de recuento de colonias y la varianza con un factor (ANOVA). Las siguientes figuras mostrarán estos valores y el \% de mortalidad microbiológica en cada posición del biosensor.

Como se hizo con las muestras antes de introducir biosensores, en esta nueva prueba que se presenta como Test4 (puré de patata y nuez moscada), medimos la temperatura inicial de la misma. En esta muestra se introdujeron 3 biosensores en la bandeja 2 y se aumentó hasta una temperatura de aprox. $60^{\circ} \mathrm{C}$.
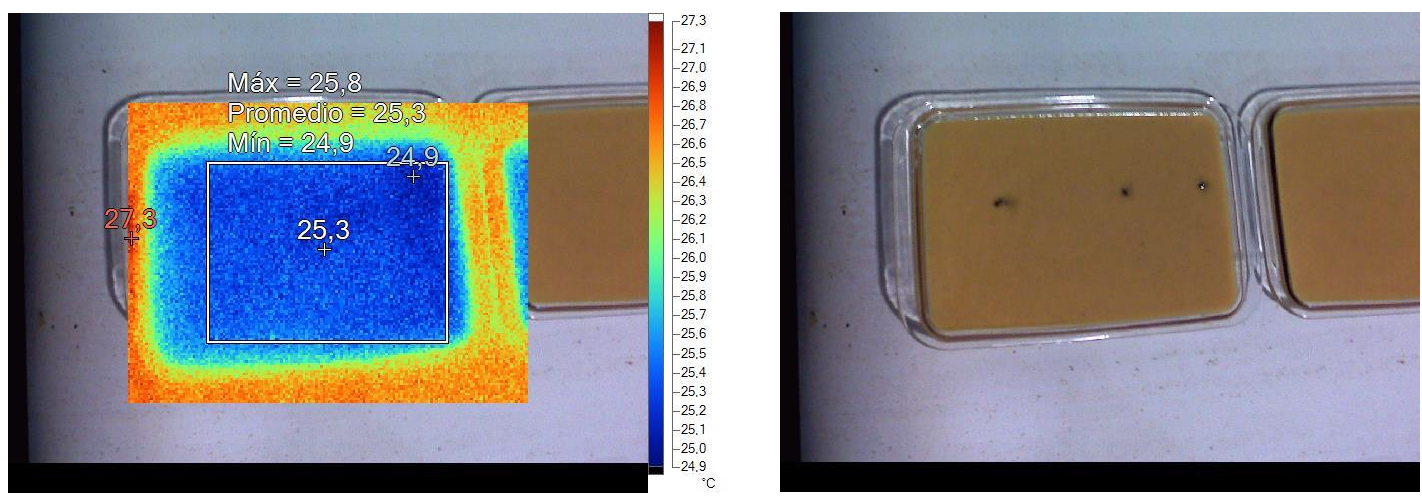

Figura 7.34. Cálculo de la temperatura inicial de la muestra. Test4. 
Los datos calculados para esta muestra fueron los siguientes:

\begin{tabular}{|c|c|}
\hline Permitividad & \begin{tabular}{l|l}
$\varepsilon^{\prime}=61,2$ & $\varepsilon^{\prime \prime}=16,3$ \\
\end{tabular} \\
\hline Calor específico $\left(\mathrm{J} / \mathrm{Kg}^{\circ} \mathrm{C}\right)$ & 3643 \\
\hline Densidad (kg/l) & 1,0121 \\
\hline Masa (Kg) & 0,2 \\
\hline Volumen (litros) & 0,1976 \\
\hline Temperatura Inicial muestra $\left({ }^{\circ} \mathrm{C}\right)$ & $23,7-26,1$ \\
\hline Temperatura Inicial bandeja $\left({ }^{\circ} \mathrm{C}\right)$ & $23,7-26,1$ \\
\hline
\end{tabular}

Tabla 7.16. Datos calculados de las características de la muestra. Test 4.

Para esta prueba se han alimentado los módulos a media potencia y se aumenta la velocidad de la cinta al máximo para comprobar si los biosensores aguantan el proceso con microondas.

Los parámetros del horno para esta muestra serán:

\begin{tabular}{|l|c|}
\hline Velocidad de la Cinta (m/min) & 2,56 \\
\hline Potencia Total (M1,M2,M3) (kW) & 2,$1 ; 2,1 ; 2,1 ;$ \\
\hline Energía Total pieza (M1, M2, M3) (KJ) & 0,$2 ; 0,2 ; 0,2$ \\
\hline Energía Total (KJ) & $1,1,1$ \\
\hline $\begin{array}{l}\text { Número de bandejas simultaneas en } \\
\text { interior horno }\end{array}$ & 5 \\
\hline $\boldsymbol{N}^{\circ}$ Piezas/minuto & 10,4 \\
\hline
\end{tabular}

Tabla 7.17. Datos de las pruebas realizadas en horno túnel de microondas. Test4.

Las siguientes imágenes muestran la evolución de la muestra con los biosensores durante el proceso de calentamiento.
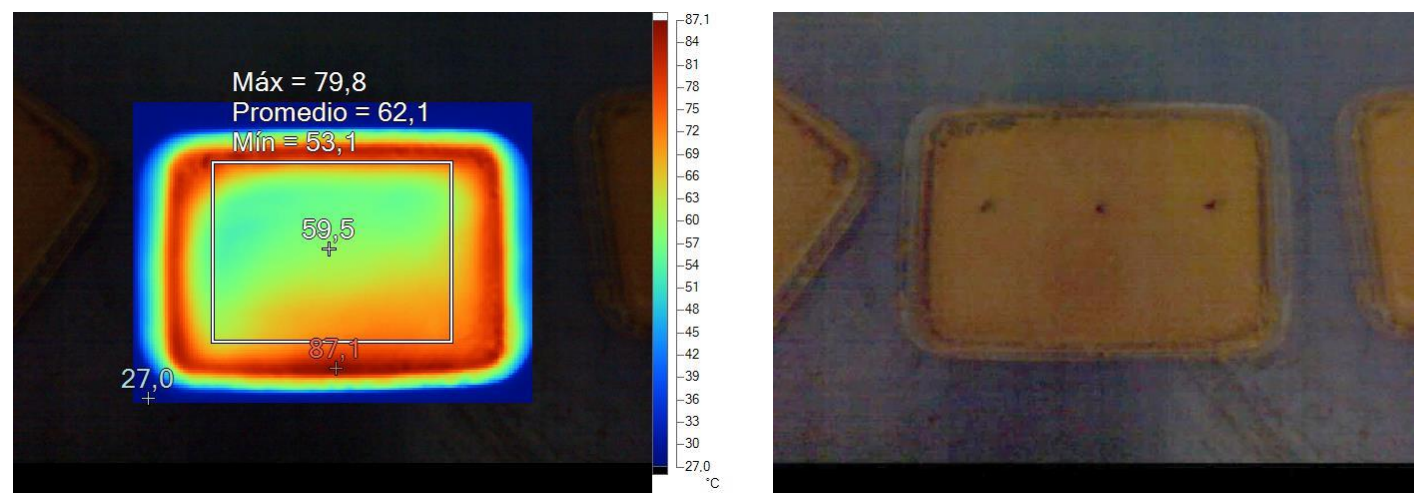

Figura 7.35. Imágenes de las muestras durante el proceso de deshidratación. Test4. 
Repetimos la prueba, esta vez aumentando la temperatura gradualmente hasta llegar a los $80^{\circ} \mathrm{C}$, Test5 (puré de patata y nuez moscada), para exponer a los biosensores a temperaturas más altas y esperar su reacción.

En esta ocasión hemos introducido 20 biosensores en una única bandeja, tal y como muestra la figura 7.36 .
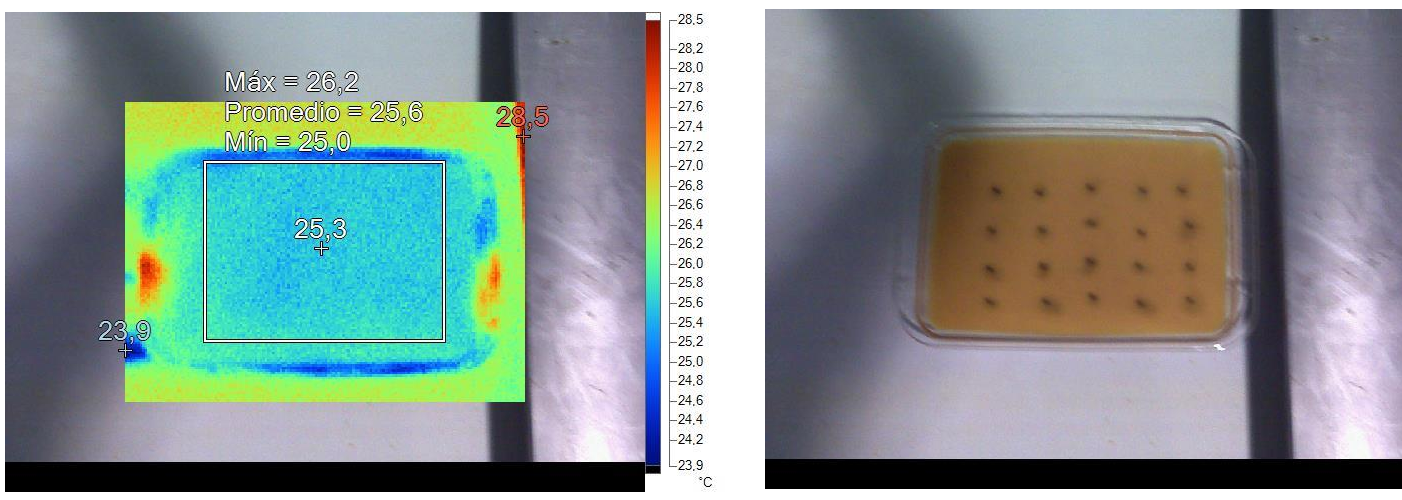

Figura 7.36. Cálculo de la temperatura inicial de la muestra. Test5.

Las propiedades de la muestra en esta prueba fueron:

\begin{tabular}{|c|c|}
\hline Permitividad & $\varepsilon^{\prime}=61,2 \quad \varepsilon^{\prime \prime}=16,3$ \\
\hline Calor específico $\left(\mathrm{J} / \mathrm{Kg}^{\circ} \mathrm{C}\right)$ & 3643 \\
\hline Densidad (kg/l) & 1,0121 \\
\hline Masa $(K g)$ & 0,2 \\
\hline Volumen (litros) & 0,1976 \\
\hline Temperatura Inicial muestra $\left({ }^{\circ} \mathrm{C}\right)$ & $26,2-25$ \\
\hline Temperatura Inicial bandeja $\left({ }^{\circ} \mathrm{C}\right)$ & $26,2-25$ \\
\hline
\end{tabular}

Tabla 7.18. Datos calculados de las características de la muestra. Test 5.

Calculamos la velocidad de la cinta para alcanzar la temperatura deseada en el primer módulo, manteniéndola durante todo el proceso a través del resto de módulos, evaporando el contenido de agua.

Los parámetros del horno para esta muestra serán: 


\begin{tabular}{|l|c|}
\hline Velocidad de la Cinta (m/min) & 1,2 \\
\hline Potencia Total (M1,M2,M3) (kW) & 2,$1 ; 2,1 ; 2,1$ \\
\hline Energía Total pieza (M1, M2, M3) (KJ) & 0,$5 ; 0,5 ; 0,5$ \\
\hline Energía Total (KJ) & 0,$5 ; 0,5 ; 0,5$ \\
\hline Tiempo total de proceso/bandeja (s) & 175,50 \\
\hline $\begin{array}{l}\text { Número de bandejas simultaneas en } \\
\text { interior horno }\end{array}$ & 1 \\
\hline$N^{\circ}$ Piezas/minuto & 5 \\
\hline
\end{tabular}

Tabla 7.19. Datos de las pruebas realizadas en horno túnel de microondas. Test5.

Las medidas más significativas tras el proceso de calentamiento son las expresadas en la siguiente tabla:

\begin{tabular}{|l|c|}
\hline Temperatura Final de la muestra $\left(^{\circ} \mathbf{C}\right)$ & $88,75 \pm 1,9$ \\
\hline Masa final $(\mathbf{K g})$ & 0,0713 \\
\hline Evaporación (\%) & 64,97 \\
\hline
\end{tabular}

Tabla 7.20. Resultados de temperatura alcanzada, pérdida de masa y \% de evaporación (secado). Test5.

A continuación, podemos ver las imágenes de la muestra en su proceso de calentamiento en el interior del horno microondas.
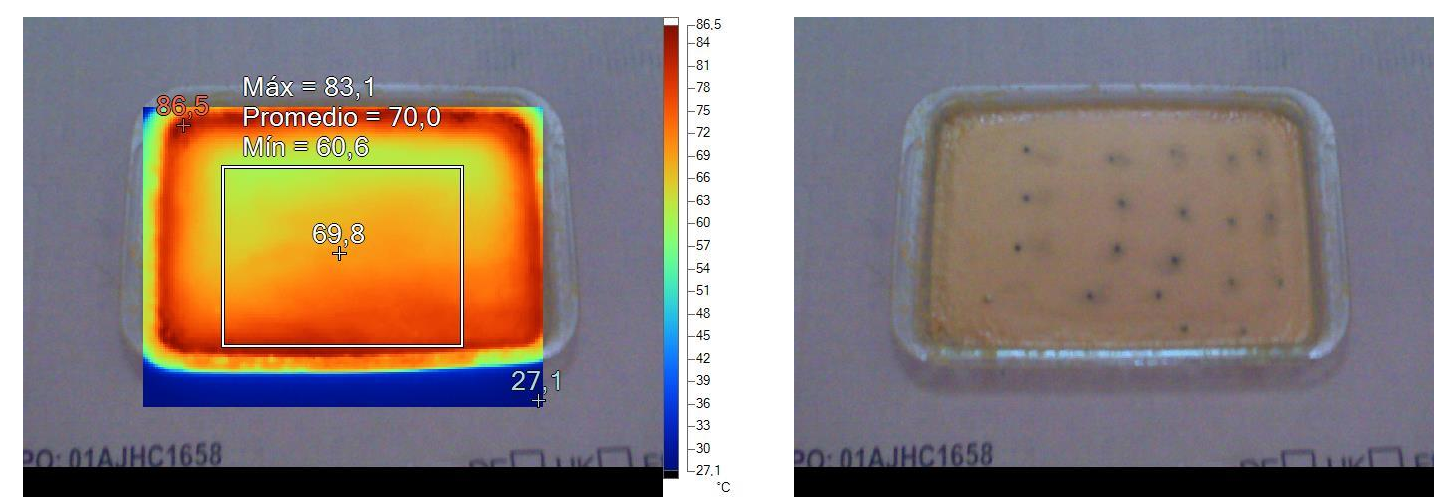

Figura 7.37. Resultados de temperatura alcanzada, pérdida de masa y \% de evaporación (secado). Test5

Para los tests, se ha obtenido la matriz de recuento de colonias y la varianza con un factor (ANOVA). Las siguientes figuras muestran este valor y el \% de mortalidad microbiológica en cada posición del biosensor. 

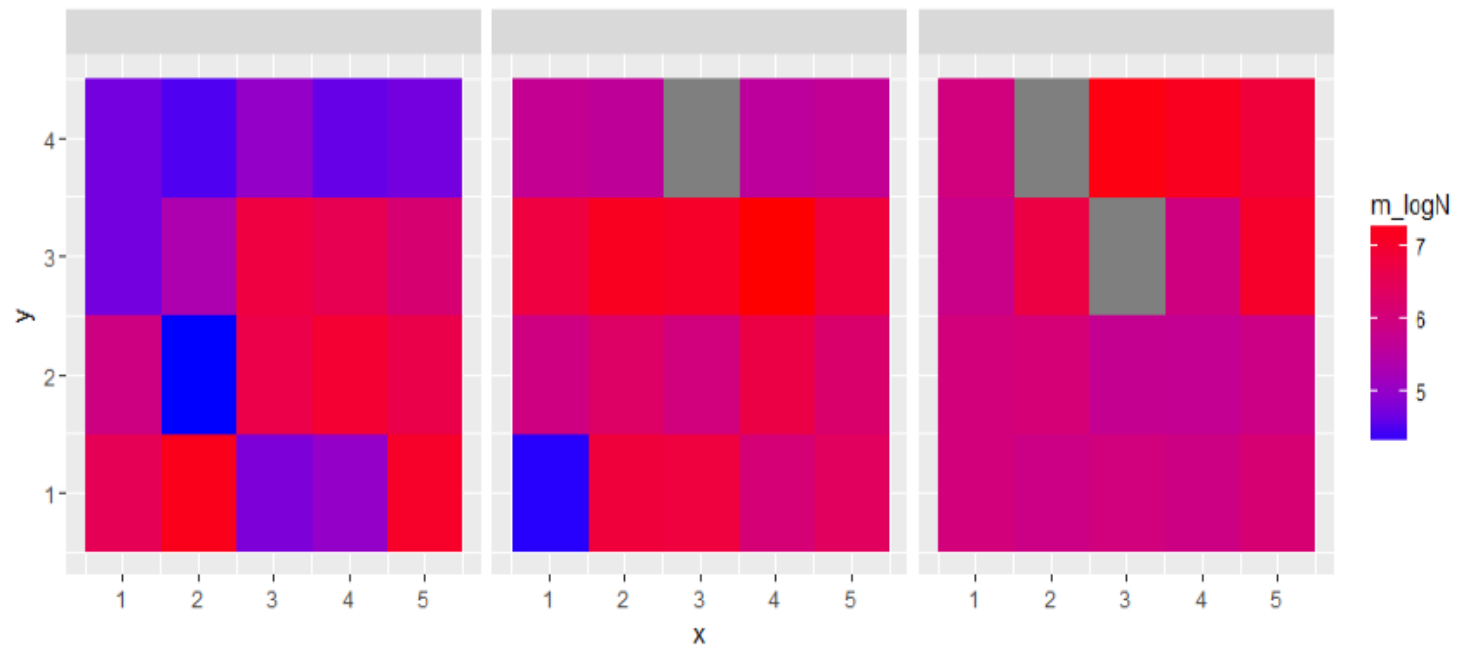

Figura 7.38 Análisis ANOVA de la varianza de recuento de CFUs (Tests $60^{\circ} \mathrm{C}, 70^{\circ} \mathrm{C}, 80^{\circ} \mathrm{C}$, de izquierda a derecha respectivamente)

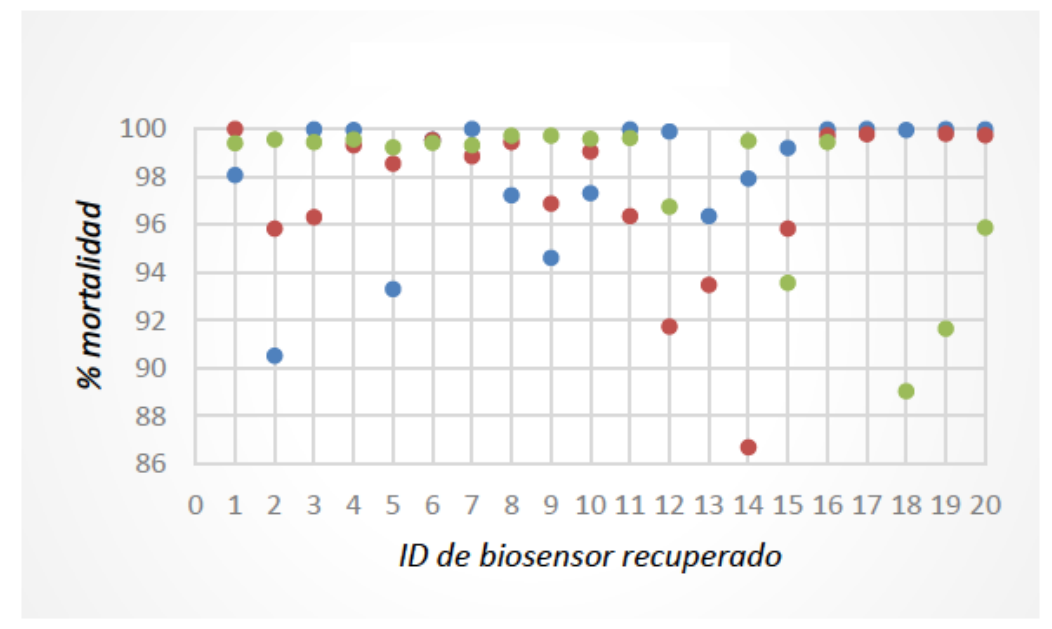

Figura 7.39. \% de mortalidad en cada posición de biosensores sobre el material, correspondientes a los Tests $60^{\circ} \mathrm{C}(a z u l), 70^{\circ} \mathrm{C}$ (verde), $80^{\circ} \mathrm{C}$ (rojo).

Tras comprobar que es posible recuperar y medir las colonias de bacterias hasta temperaturas de $80^{\circ} \mathrm{C}$, se ha realizado la prueba de deshidratación a una temperatura de $90^{\circ} \mathrm{C}$ con la misma sopa vegetal, para poder aplicarlo luego a una muestra de Sandach bajo las mismas condiciones del proceso de calentamiento por microondas, siendo en este caso una potencia irradiada de $3 \mathrm{Kw}$ (2,1 Kw efectivos) durante 300 segundos, con una velocidad de cinta de $0,7 \mathrm{~m} / \mathrm{min}$. El resultado se muestra en la siguiente figura: 

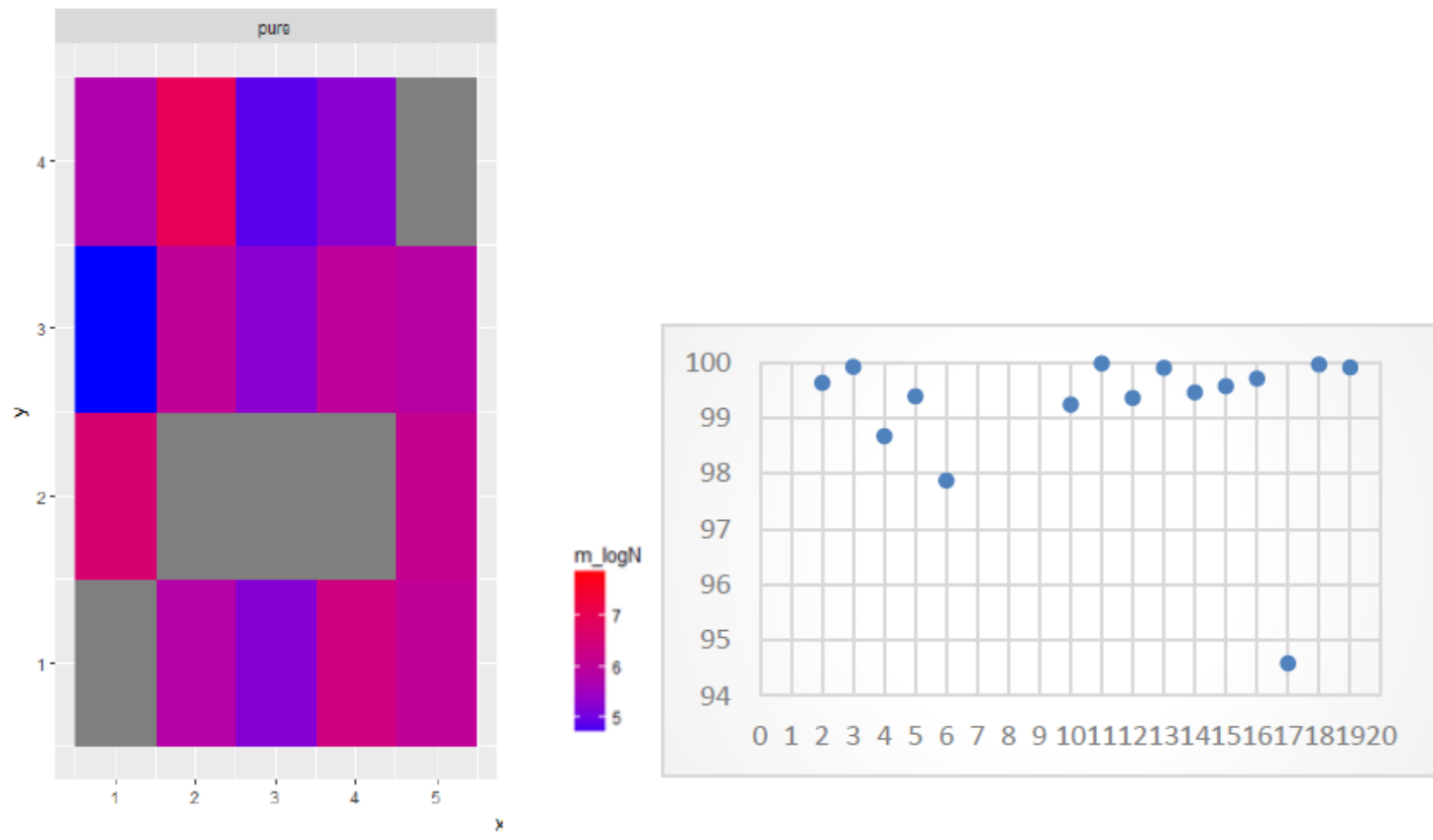

Figura 7.40 Análisis ANOVA de CFUs (Tests $90^{\circ} \mathrm{C}$ ) y \% de mortalidad.

\section{Pruebas con Sandach}

En el Test 6, la composición del material se realizó a partir de lubina triturada con un porcentaje de $70 \%$ de agua, como ya se ha explicado con anterioridad. Las condiciones de diseño el horno fueron las mismas que en la prueba con sopa vegetal a $90^{\circ} \mathrm{C}$.

En la siguiente imagen que se muestra podemos ver la muestra de sandach, en la que se introdujeron 20 biosensores, en una sola bandeja, entrando en la cinta transportadora, habiendo medido su temperatura inicial de manera previa.
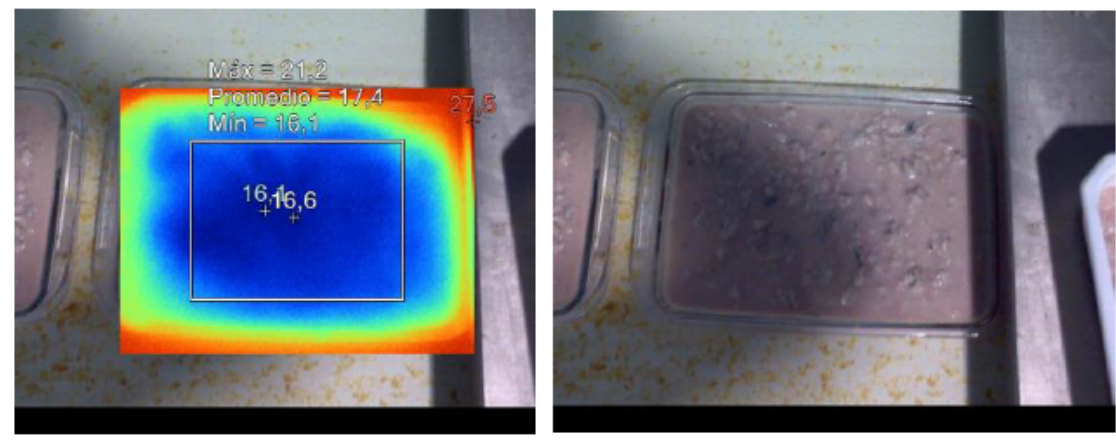

Figura 7.41. Cálculo de la temperatura inicial de la muestra. Test6. 
Habiendo medido los parámetros de la muestra, estos los podemos observar en la siguiente tabla:

\begin{tabular}{|c|c|c|}
\hline \begin{tabular}{|l|l} 
Permitividad & \\
\end{tabular} & $\varepsilon^{\prime}=54,39$ & $\varepsilon^{\prime \prime}=9,1$ \\
\hline Calor específico $\left(\mathrm{J} / \mathrm{Kg}^{\circ} \mathrm{C}\right)$ & \multicolumn{2}{|c|}{5155} \\
\hline Densidad (kg/l) & \multicolumn{2}{|c|}{0,917} \\
\hline Masa $(K g)$ & \multicolumn{2}{|c|}{0,2} \\
\hline Volumen (litros) & \multicolumn{2}{|c|}{0,218} \\
\hline Temperatura Inicial muestra $\left({ }^{\circ} \mathrm{C}\right)$ & \multicolumn{2}{|c|}{$19,6-16,1$} \\
\hline Temperatura Inicial bandeja $\left({ }^{\circ} \mathrm{C}\right)$ & \multicolumn{2}{|c|}{$19,6-16,1$} \\
\hline
\end{tabular}

Tabla 7.21. Datos calculados de las características de la muestra. Test 6.

Los parámetros del horno para esta prueba obtenidos, a través de MICRODES, fueron:

\begin{tabular}{|l|c|}
\hline Velocidad de la Cinta (m/min) & 0,5 \\
\hline Potencia Total (M1,M2,M3) (kW) & 2,$1 ; 2,1 ; 2,1$ \\
\hline Energía Total pieza (M1, M2, M3) (KJ) & 1,$2 ; 1,2 ; 1,2$ \\
\hline Energía Total (KJ) & 4,$9 ; 4,9 ; 4,9$ \\
\hline Tiempo total de proceso/bandeja (s) & 414 \\
\hline $\begin{array}{l}\text { Número de bandejas simultaneas en } \\
\text { interior horno }\end{array}$ & 4 \\
\hline$N^{\circ}$ Piezas/minuto & 2 \\
\hline
\end{tabular}

Tabla 7.22. Datos de las pruebas realizadas en horno túnel de microondas. Test6.

Los resultados que se obtienen en esta muestra aparecen en la siguiente tabla:

\begin{tabular}{|l|c|}
\hline Temperatura Final de la muestra $\left({ }^{\circ} \mathbf{C}\right)$ & $80,68 \pm 4,37$ \\
\hline Masa final $(\mathbf{K g})$ & 0,61 \\
\hline Evaporación (\%) & 74,97 \\
\hline
\end{tabular}

Tabla 7.23. Resultados de temperatura alcanzada, pérdida de masa y \% de evaporación (secado). Test6.

Las condiciones iniciales y finales de la muestra, tras el proceso de calentamiento con microondas, permitieron de nuevo recuperar un elevado porcentaje de biosensores para su análisis por zonas. 

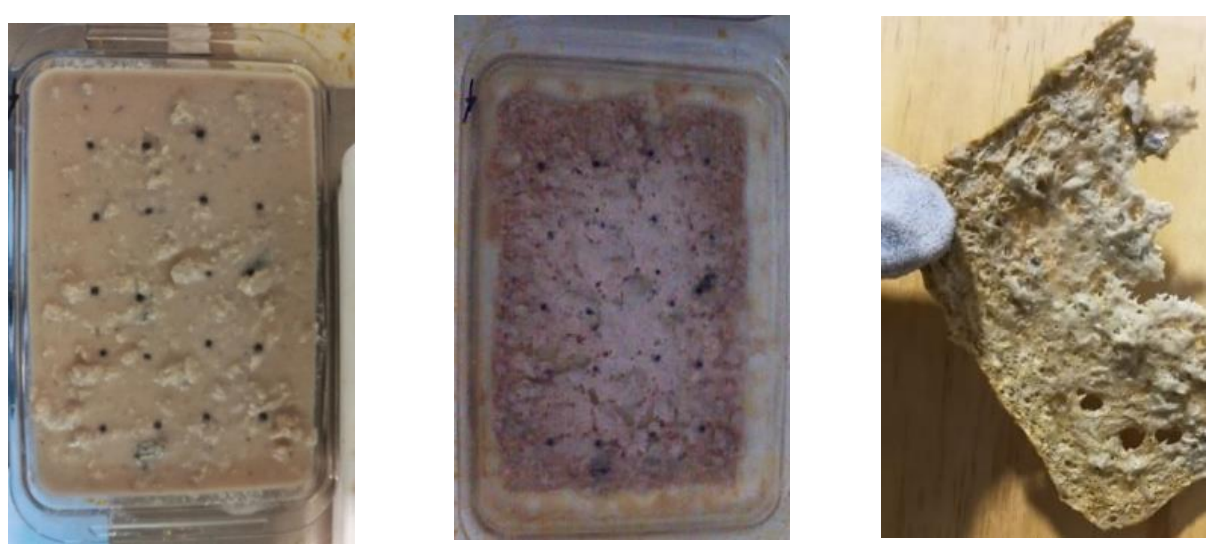

Figura 7.42. Resultado de la muestra Sandach, antes y después del procesado $\left(T^{a}=90^{\circ} \mathrm{C}\right)$.

Como resultado final, se muestran los valores obtenidos de pérdida de humedad en 5 bandejas de Sandach durante el mismo proceso de deshidratación, así como el resultado de la inactivación microbiológica en una de ellas.
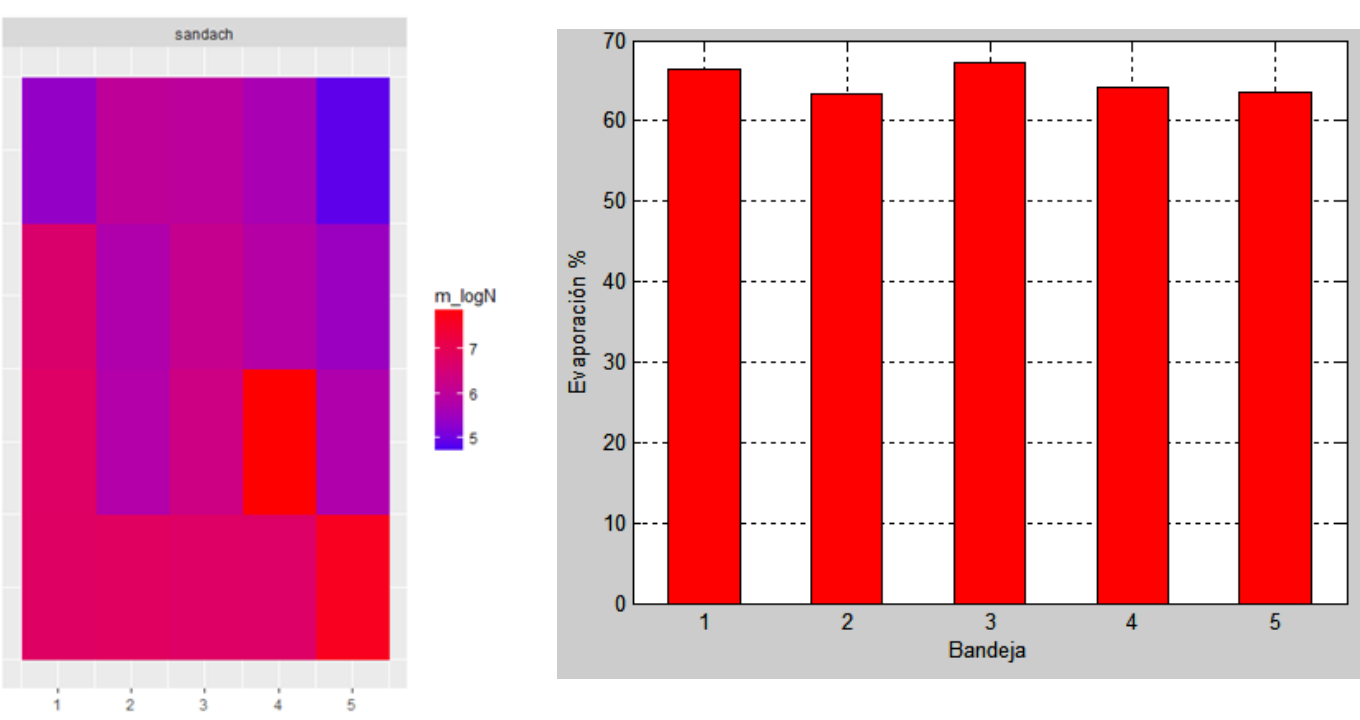

Figura 7.43. Resultados microbiológicos y de deshidratación en Sandach. 


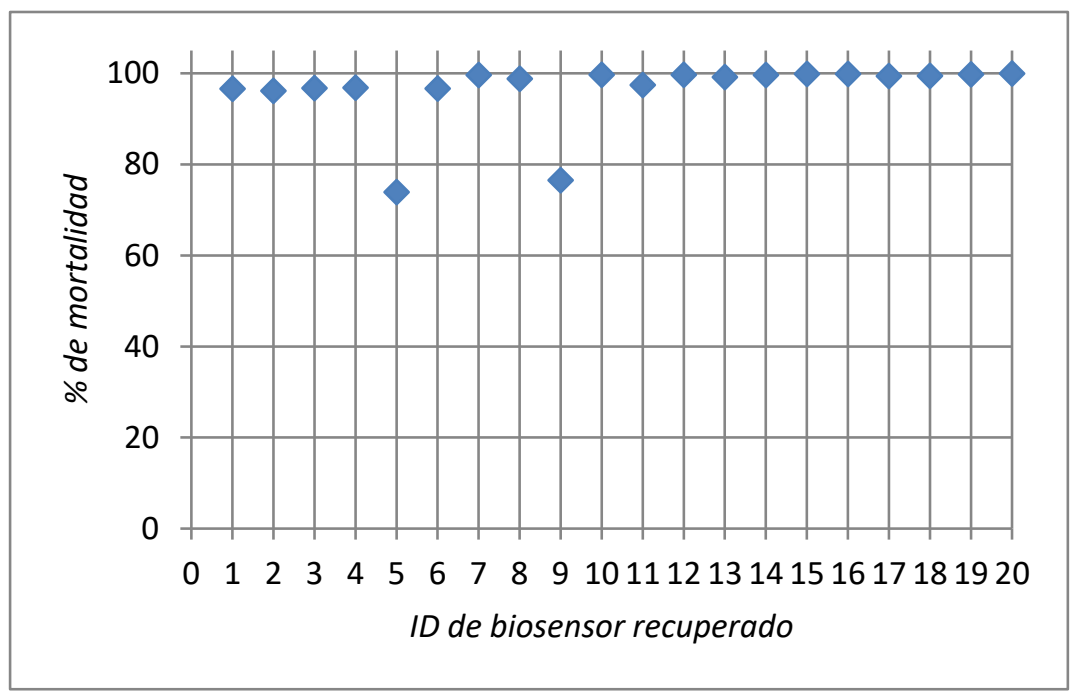

Figura 7.44. Cálculo de \% de mortalidad para cada punto biosensor.

Podemos concluir a la vista de esta última figura que la media en porcentaje de la mortandad microbiana de los 20 inactivadores, está en torno al 98\%.

\subsection{Conclusiones}

Tras los resultados obtenidos, se han considerado diferentes conclusiones en relación con el procesado de Sandach para su adecuación al secado con microondas y eliminación de bacterias y microorganismos:

- Podemos apreciar una leve desigualdad en la mortalidad dependiendo de la zona en las bandejas.

- Hay un claro aumento de la mortalidad al aumentar la temperatura.

- Se puede prever una necesidad de reducir la evaporación, por ejemplo, tapando los recipientes en los que se alojen las muestras.

- Se podría estudiar la mejora de la uniformidad con el movimiento del alimento, a través del transporte en la cinta del mismo. 
- Con una temperatura objetivo de $90^{\circ} \mathrm{C}$, se produce una reducción de microorganismos por encima del $98 \%$ en toda la muestra.

- A temperaturas más altas, se produce la evaporación-pérdida de algunos biosensores en sopa vegetal y una menor pérdida en Sandach, debido al efecto de estar en un medio de lípidos que es más afín al contenido del algilato.

- Los biosensores desarrollados no interaccionan con las microondas de forma muy diferente a como lo hace el material, aún a altas temperaturas.

- La pérdida de humedad en el proceso de secado cumple con los requisitos de reducción de entre 60-70\% de contendio líquido de las muestras de Sandach.

- El formato físico deshidratado de las muestras de Sandach (con eliminación de los microorganismos más comunes) se presenta como apto para:

$\checkmark$ Ahorro en el transporte para su posterior eliminación.

$\checkmark$ Transformación, con poca energía adicional, en otro tipo de subproducto (como harinas de pescado, pe.).

$\checkmark$ Cumplir con el Real Decreto 1528/2012.

\subsection{Referencias}

[1] Álvarez, A.; Fayos-Fernández, J.; Monzó-Cabrera, J.; Cocero, M.J.; Mato, R.B. Measurement and correlation of the dielectric properties of a grape pomace extraction media. Effect of temperature and composition. Journal of Food Engineering, 197, 98-106. 2017

[2] Chen, L.F.; Ong, C.K.; Neo, C.P.; Varadan, V.V.; Varadan, V.K. Microwave Electronics. Measurement and Material Characterization; John Wiley \& Sons, Ltd.: New York, USA, 2004.

[3] Real Decreto 1528/2012., 8 de Noviembre. 


\section{CAPÍTULO 8 \\ CONCLUSIONES Y LÍNEAS FUTURAS}

\subsection{Conclusiones}

Las altas frecuencias, microondas y radiofrecuencia, se han posicionado como unas tecnologías alternativas a los métodos convencionales de conservación y procesado de productos.

En este trabajo de investigación se ha diseñado un sistema de microondas con ventana de presión y cavidad cilíndrica monomodo, junto con un sistema de alimentación autoregulado, que ha permitido lograr una temperatura prefijada para el material, con el fin de estudiar la esterilización de diferentes muestras en términos de inactivación microbiológica para, posteriormente, poder extrapolar el proceso a deshidratado de Sandach en entornos semi-industriales. Se ha elegido este tipo de subproducto puesto que en España y en los países líderes en esta área, se genera en gran cantidad en las industrias acuícolas.

Además, su eliminación o transformación está sometida a procesos muy restrictivos en la normativa española y europea, en la que el procesado por microondas no se contempla explícitamente. Las enormes ventajas que supone el uso de tecnología de microondas frente a las convencionales van a permitir, ayudado por los resultados de este trabajo de investigación, una mejora en la eficiencia energética y un mayor rendimiento en el sector productivo de transformación de Sandach de piscifactorías. Como es obvio, el trabajo aquí desarrollado puede ser extrapolable a otros productos derivados de sectores diferentes, como por ejemplo el ganadero (purines).

Para ello, previamente se ha validado el correcto funcionamiento de la cavidad diseñada y del sistema dinámico de control, midiendo las características dieléctricas de las muestras, en función de la temperatura. El control de la uniformidad del sistema, de gran importancia para los temas de inactivación microbiológica, ha permitido un estudio sistemático de la evolución de los recuentos microbianos de tres materiales diferentes a 
esterilizar (BHI, sopa Vegetal y Sandach de lubina). Como paso previo, este sistema puede garantizar efectivamente una inactivación microbiana en los alimentos en el proceso de esterilización (con presión añadida) a temperaturas superiores a $100^{\circ} \mathrm{C}$.

En la primera fase, se ha medido la inactivación mediante calentamiento por microondas en diferentes sustratos (medios de laboratorio y alimentos) utilizando una bacteria patógena transmitida por los alimentos, Bacillus cereus, como sensor, mostrando un loglineal en todas las condiciones ensayadas (temperaturas entre $95^{\circ} \mathrm{C}$ y $105^{\circ} \mathrm{C}$ ) y una inactivación similar a un calentamiento convencional, indicando un perfil de temperatura homogéneo.

Una vez caracterizado el proceso de esterilización de muestras en el equipo de laboratorio, diseñado y desarrollado durante este trabajo de investigación, se han generado las condiciones de trabajo de un horno túnel de microondas de $16 \mathrm{Kw}$ para procesado de alimentos, que permita asegurar la deshidratación del Sandach y la eliminación de patógenos.

Para ello, se ha utilizado la herramienta Microdes@ (desarrollo propio Grupo I+D GEM) y se ha sintetizado una serie de biosensores que permiten ser introducidos en las muestras (ubicadas en bandejas a modo de material laminar) creando una distribución de uniformidad válida en su interior y midiendo el grado de inactivación en los procesos de secado del producto. Los resultados obtenidos han permitido conocer el comportamiento del proceso de deshidratación de Sandach con eliminación de patógenos, mediante pasteurización, para poder ser transformado en otro producto (p.e., harinas de pescado para pienso) asegurando el cumplimiento de la normativa europea (en España según Real Decreto 1528/2012).

La deshidratación de Sandach en los hornos microondas, respecto a otros medios tradicionales, es mejor por su limpieza, ahorro de energía, control preciso del proceso y la reducción de os ciclos de tiempo utilizados en el procesamiento. Al utilizar las microondas como medio de destrucción de microorganismos, se ha comprobado la reducción de la carga microbiana, existiendo una relación directa entre el tiempo de 
exposición y la letalidad de los microorganismos.

Así mismo, ras los resultados obtenidos, se comprueba que la exposición directa a ondas electromagnéticas de frecuencia de microondas durante 30s a 1000 watts de potencia, muestra una efectividad del 100\% en la esterilización de alimentos.

La aplicación de estas tecnologías ha alcanzado, en la última década, un nivel de madurez considerable. Hoy en día estos procesos industriales son capaces de garantizar la seguridad de los alimentos y minimizar el impacto de los procesos térmicos sobre sus características nutricionales y propiedades sensoriales. El hecho de que en Europa existan varios proveedores de esta clase de equipos demuestra la importancia que estas tecnologías están cobrando cada vez más en el sector agroalimentario. En cambio, en EE.UU. esta tecnología ya está plenamente aceptada.

En los últimos años, las microondas han experimentado un gran avance en el ámbito industrial. Además de representar un proceso continuo, un equipo de microondas destaca sobre todo por la rapidez del tratamiento, el tipo de procesado térmico "suave" y una mejor calidad sensorial y nutricional respecto, por ejemplo, a un producto pasteurizado mediante métodos convencionales. Estas calidades demuestran que esta tecnología está lista para su implementación en la industria alimentaria, y en particular para aumentar la competitividad de las empresas.

En el caso concreto de los productos pesqueros, la naturaleza del producto transformado influye de forma considerable en el resultado final y los hace aptos para ser tratados por microondas.

\subsection{Líneas futuras}

Tras el conocimiento científico-técnico adquirido para este trabajo de investigación y una vez realizadas las pruebas y desarrollos de experimentación durante los años de duración de este trabajo de doctorado, a la vista de los resultados obtenidos se pueden considerar los siguientes aspectos como líneas futuras de mejora de las metodologías utilizadas: 
- Mejorar las propiedades químicas de los biosensores desarrollados para evitar la dispersión de los mismos a altas temperaturas en base a nuevos compuestos que no interaccionen con el material pero que, a la vez, tenga propiedades dieléctricas y conductoras similares.

- Necesidad de movimiento del alimento con otras configuraciones: por ejemplo tubos de PTFE por los que el material viaja en el horno de microondas. Esto permite el uso de dimensiones menores y una temperatura mucho más uniforme para todo el producto. Son necesarias bombas que impulsen el material en el tubo. Esto hace que se puedan usar mayores presiones y temperatura y por lo tanto el aumento de la mortalidad sin propiciar la evaporación.

- Incorporar mecanismos habituales (stirrers) y novedosos (dispositivos de estado sólido) de mejora de uniformidad en horno multimodo de microondas para homogeneizar el campo eléctrico en toda la dimensión de la muestra.

- Implementar un sistema de control de la potencia suministrada al horno para reducir la intensidad de campo eléctrico en la última etapa de la fase de secado, dadas las posibilidades del horno túnel de microondas utilizado en las pruebas experimentales este trabajo investigador.

- Proponer a las autoridades pertinentes la redacción oportuna en la Normativa de transformación de Sandach por Microondas, que mencione la idoneidad demostrada en este trabajo, para el tratamiento de subproducto animal no destinado a consumo humano. 